\title{
A molecular basis for the loss of muscle oxidative phenotype: Implications for COPD
}

Citation for published version (APA):

Remels, A. H. V. (2009). A molecular basis for the loss of muscle oxidative phenotype: Implications for COPD. [Doctoral Thesis, Maastricht University]. Maastricht University.

https://doi.org/10.26481/dis.20091211ar

Document status and date:

Published: 01/01/2009

DOI:

10.26481/dis.20091211ar

Document Version:

Publisher's PDF, also known as Version of record

\section{Please check the document version of this publication:}

- A submitted manuscript is the version of the article upon submission and before peer-review. There can be important differences between the submitted version and the official published version of record.

People interested in the research are advised to contact the author for the final version of the publication, or visit the DOI to the publisher's website.

- The final author version and the galley proof are versions of the publication after peer review.

- The final published version features the final layout of the paper including the volume, issue and page numbers.

Link to publication

\footnotetext{
General rights rights.

- You may freely distribute the URL identifying the publication in the public portal. please follow below link for the End User Agreement:

www.umlib.nl/taverne-license

Take down policy

If you believe that this document breaches copyright please contact us at:

repository@maastrichtuniversity.nl

providing details and we will investigate your claim.
}

Copyright and moral rights for the publications made accessible in the public portal are retained by the authors and/or other copyright owners and it is a condition of accessing publications that users recognise and abide by the legal requirements associated with these

- Users may download and print one copy of any publication from the public portal for the purpose of private study or research.

- You may not further distribute the material or use it for any profit-making activity or commercial gain

If the publication is distributed under the terms of Article $25 \mathrm{fa}$ of the Dutch Copyright Act, indicated by the "Taverne" license above, 
A molecular basis for the loss of muscle oxidative phenotype: implications for COPD 
(C) Alexander Remels, Maastricht, the Netherlands 2009

ISBN: 978-90-9024792-2

Cover design: Eef Brandsma

Layout: Tiny Wouters

Production: Datawyse | Universitaire Pers Maastricht

All rights reserved. No part of this book may be reproduced or transmitted, in any form or by any means, without written permission from the author
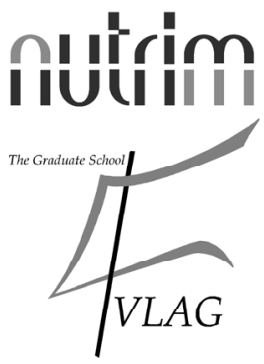

The studies presented in this thesis were performed at the Nutrition and Toxicology Research Institute Maastricht (NUTRIM), which participates in the Graduate School VLAG (Food Technology, Agrobiotechnology,Nutrion, and Health Sciences), accredited by the Royal Netherlands Academy of Arts and Sciences (KNAW) 


\title{
A molecular basis for the loss of muscle oxidative phenotype: implications for COPD
}

\author{
PROEFSCHRIFT
}

ter verkrijging van de graad van doctor aan de Universiteit Maastricht, op gezag van de Rector Magnificus, Prof. mr. G.P.M.F. Mols, volgens het besluit van het College van Decanen, in het openbaar te verdedigen op vrijdag 11 december 2009 om 14.00 uur

door

\section{Alexander Remels}




\section{Promotor}

Prof. dr. ir. A.M.W.J. Schols

\section{Copromotoren}

Dr. H.R. Gosker

Dr. R.C. Langen

Dr. P. Schrauwen

\section{Beoordelingscommissie}

Prof. dr. W.A. Buurman (voorzitter)

Prof. dr. M.J.A.P. Daemen

Dr. M.P. De Winther

Prof. dr. J. Gea (Servicio de Neumología, Hospital del Mar, Barcelona, Spanje) Prof. dr. B. Staels (Department of Atherosclerosis, Institut Pasteur de Lille, Lille, Frankrijk)

The publication of this thesis is financially supported by: Nutricia Advanced Medical Nutrition, Danone Research-Centre for Specialised Nutrition, Stichting Pulmonologie, AstraZeneca, Boehringer Ingelheim BV, CIRO-Horn, GlaxoSmithKline, Novartis Pharma B.V. and Pfizer. 


\section{Table of Contents}

$\begin{array}{lll}\text { Chapter } 1 & \text { General Introduction } & 7\end{array}$

Chapter 2 Peroxisome proliferator-activated receptors: a therapeutic 13 target in COPD?

Chapter 3 Regulation of mitochondrial biogenesis during myogenesis 29

Chapter $4 \quad$ Expression and content of PPARs is reduced in skeletal 51 muscle of COPD patients

Chapter 5 TNF- $\alpha$ impairs regulation of muscle oxidative phenotype: $\quad 69$ Implications for cachexia in COPD?

Chapter $6 \quad$ PPAR- $\gamma$ inhibits NF-KB-dependent transcriptional 101 activation in skeletal muscle

$\begin{array}{lll}\text { Chapter } 7 & \text { General discussion and future directions } & 125\end{array}$

$\begin{array}{ll}\text { Summary } & 147\end{array}$

$\begin{array}{ll}\text { Samenvatting } & 153\end{array}$

Dankwoord 159

$\begin{array}{ll}\text { List of publications } & 163\end{array}$

$\begin{array}{ll}\text { Curriculum Vitae } & 169\end{array}$ 

Chapter 1

General Introduction 
Chapter 1

8 


\section{Background}

As defined by the World Health Organisation (WHO), disease burden of chronic disorders is not solely confined to primary organ failure ${ }^{1}$. Several chronic disorders as chronic obstructive pulmonary disease (COPD) and chronic heart failure (CHF) are characterised by clinically relevant systemic complications that contribute to increased morbidity and decreased exercise capacity independent of primary organ dysfunction. These include increased circulatory levels of pro-inflammatory cytokines e.g. tumour necrosis factor alpha (TNF- $\alpha$ ) and peripheral skeletal muscle abnormalities ${ }^{2}$. Both muscle wasting and impaired functioning of the remaining muscle contribute to reduced muscle strength and endurance in chronic inflammatory diseases and lead to progressive disability and poor health status ${ }^{2,3}$. Besides the presence of muscle atrophy, it is well established that peripheral skeletal muscle oxidative phenotype is disturbed in these disorders. This includes a fiber type shift towards a more glycolytic phenotype, impaired mitochondrial functioning and reduced activity levels of enzymes involved in substrate oxidation ${ }^{2,4-8}$. Traditionally, research addressing the impact of inflammatory events on skeletal muscle tissue has mainly focused on the process of skeletal muscle atrophy. Several experimental models have clearly shown that there is a causal relation between inflammatory events and loss of muscle mass ${ }^{9,10}$. The nature of the relationship between inflammation and muscle atrophy in human subjects however remains to be determined. In addition, the etiology of impaired muscle oxidative phenotype in chronic inflammatory disorders is still unclear. In the last decade, the PGC-1a/PPAR pathway has emerged as one of the major signalling cascades regulating skeletal muscle oxidative phenotype. Activation of this pathway potently up-regulates skeletal muscle oxidative capabilities and induces a phenotype reminiscent of that induced by exercise training ${ }^{11,12}$. Whether or not this pathway is impaired in skeletal muscle of COPD patients is unknown. Since an increased inflammatory status is a common denominator of several chronic disorders, which are characterised by impaired skeletal muscle oxidative phenotype, a role for inflammatory mediators in impaired functioning of muscle in these disorders might be postulated. In support of this, in COPD, it has been shown that exercise capacity is inversely associated with plasma inflammatory markers ${ }^{13}$. Yet, whether inflammation affects skeletal muscle oxidative phenotype and, if so, which signalling pathways are involved remains to be fully elucidated. 


\section{Aims and outline of the thesis}

The overall aim of the work presented in this thesis was to investigate the molecular basis for loss of muscle oxidative phenotype in COPD by adopting a molecular biology approach and subsequent translation of experimental findings to the patient. Three specific aims are addressed in this thesis:

1. To evaluate whether the PGC-1a/PPAR signalling pathway is impaired in skeletal muscle of COPD patients and if this is associated with the loss of muscle oxidative phenotype and inflammation.

2. To elucidate the role of inflammatory mediators and subsequent inflammatory signalling on the regulation of skeletal muscle oxidative phenotype.

3. To investigate potential bi-directional interplay between inflammatory signalling pathways and the PGC-1a/PPAR pathway.

Chapter 2 elaborates on the concept of skeletal muscle pathology, inflammation and implication of the PGC-1a/PPAR pathway in COPD systemic pathology. An extensive overview of the current literature on COPD systemic pathology is provided and the therapeutic potential of modulation of the PGC1a/PPAR pathway in targeting distinct aspects of systemic complications of the disease including alleviation of inflammatory status and skeletal muscle dysfunction is discussed. The role of the PGC-1a/PPAR pathway in development of skeletal muscle oxidative phenotype during myogenic differentiation is unclear. Therefore, in chapter 3, a model of cultured skeletal muscle cells was used to investigate these markers in relation to the development of skeletal muscle oxidative phenotype during myogenesis. Since PGC-1 $\alpha$ and PPARs are implicated in the regulation of skeletal muscle oxidative phenotype ${ }^{11,12}$, content and expression levels of constituents and targets of the PGC-1a/PPAR pathway in skeletal muscle of COPD patients and their relation with the presence of systemic inflammatory mediators was investigated in chapter 4. Associations between the presence of a systemic inflammatory response and impairment of exercise capacity have been demonstrated in $\mathrm{COPD}^{13}$. Since the direct impact of inflammation on muscle oxidative phenotype is unknown, chapter 5 was aimed at investigating the direct effects of inflammatory mediators on regulation of skeletal muscle oxidative phenotype. TNF- $\alpha$ was chosen as a model inflammatory mediator, as it has been shown that not only circulatory levels, but also muscular protein content of this cytokine is elevated in COPD patients ${ }^{14,15}$. The transcription factor nuclear factor kappa B (NF-kB) which is activated in the musculature of severe COPD patients ${ }^{16}$, is a key intra-cellular pathway relaying inflammatory signals $^{17}$. Parameters of oxidative phenotype, involvement of the NF-KB 
pathway and impact of the NF-KB cascade on the PGC-1a/PPAR pathway were investigated upon chronic stimulation of muscle cells with TNF- $\alpha$. To address the bi-directional nature of the interaction between the NF-KB and PGC-1a/PPAR pathway in skeletal muscle, chapter 6 investigated the ability of different PPAR isoforms to interfere with pro-inflammatory cytokine-induced NF-KB activation. In chapter 7 the implications of the experimental findings of the different studies described in this thesis are discussed. 


\section{References}

1. Wood $\mathrm{PH}$. Appreciating the consequences of disease: the international classification of impairments, disabilities, and handicaps. WHO Chron 1980;34:376-80.

2. Gosker HR, Wouters EF, van der Vusse GJ and Schols AM. Skeletal muscle dysfunction in chronic obstructive pulmonary disease and chronic heart failure: underlying mechanisms and therapy perspectives. Am J Clin Nutr 2000;71:1033-47.

3. Satta A, Migliori GB, Spanevello A, Neri M, Bottinelli R, Canepari M, Pellegrino MA and Reggiani C. Fibre types in skeletal muscles of chronic obstructive pulmonary disease patients related to respiratory function and exercise tolerance. Eur Respir J 1997;10:2853-60.

4. Gosker HR, Engelen MP, van Mameren H, van Dijk PJ, van der Vusse GJ, Wouters EF and Schols AM. Muscle fiber type IIX atrophy is involved in the loss of fat-free mass in chronic obstructive pulmonary disease. Am J Clin Nutr 2002;76:113-9.

5. Miyagi K, Asanoi H, Ishizaka S, Kameyama T, Wada O, Seto H and Sasayama S. Importance of total leg muscle mass for exercise intolerance in chronic heart failure. Jpn Heart J 1994;35:15-26.

6. Gosker HR, Kubat B, Schaart G, van der Vusse GJ, Wouters EF and Schols AM. Myopathological features in skeletal muscle of patients with chronic obstructive pulmonary disease. Eur Respir J 2003;22:280-5.

7. Gosker H, Zeegers M, Wouters E and Schols AM. Muscle fibre type shifting in the vastus lateralis of patients with COPD is associated with disease severity: a systematic review and meta-analysis. Thorax 2007;62:944-9.

8. Gosker HR, Hesselink MK, Duimel H, Ward KA and Schols AM. Reduced mitochondrial density in the vastus lateralis muscle of patients with COPD. Eur Respir J 2007;30:73-9.

9. Cai D, Frantz JD, Tawa NE, Jr., Melendez PA, Oh BC, Lidov HG, Hasselgren PO, Frontera WR, Lee J, Glass DJ and Shoelson SE. IKKbeta/NF-kappaB activation causes severe muscle wasting in mice. Cell 2004;119:285-98.

10. Ladner KJ, Caligiuri MA and Guttridge DC. Tumor necrosis factor-regulated biphasic activation of NF-kappa B is required for cytokine-induced loss of skeletal muscle gene products. J Biol Chem 2003;278:2294-303.

11. Luquet S, Lopez-Soriano J, Holst D, Fredenrich A, Melki J, Rassoulzadegan M and Grimaldi PA. Peroxisome proliferator-activated receptor delta controls muscle development and oxidative capability. Faseb J 2003;17:2299-301.

12. Lin J, Wu H, Tarr PT, Zhang CY, Wu Z, Boss O, Michael LF, Puigserver P, Isotani E, Olson EN, Lowell BB, Bassel-Duby R and Spiegelman BM. Transcriptional co-activator PGC-1 alpha drives the formation of slow-twitch muscle fibres. Nature 2002;418:797-801.

13. Broekhuizen R, Wouters EF, Creutzberg EC and Schols AM. Raised CRP levels mark metabolic and functional impairment in advanced COPD. Thorax 2006;61:17-22.

14. Joppa P, Petrasova D, Stancak B and Tkacova R. Systemic inflammation in patients with COPD and pulmonary hypertension. Chest 2006;130:326-33.

15. Montes de Oca M, Torres SH, De Sanctis J, Mata A, Hernandez N and Talamo C. Skeletal muscle inflammation and nitric oxide in patients with COPD. Eur Respir J 2005;26:390-7.

16. Agusti A, Morla M, Sauleda J, Saus C and Busquets X. NF-kappaB activation and iNOS upregulation in skeletal muscle of patients with COPD and low body weight. Thorax 2004; 59:483-7.

17. Pahl HL. Activators and target genes of Rel/NF-kappaB transcription factors. Oncogene 1999;18:6853-66. 


\section{Chapter 2}

\section{Peroxisome proliferator-activated receptors: a therapeutic target in COPD?}

Alexander H Remels, Harry R Gosker, Patrick Schrauwen, Ramon C Langen, Annemie M Schols. Systemic inflammation and skeletal muscle dysfunction in chronic obstructive pulmonary disease: state of the art and novel insights in regulation of muscle plasticity.

Clin Chest Med 2007;28:537-52 


\section{Abstract}

Extra-pulmonary pathology significantly impairs clinical outcome in COPD. The peroxisome proliferator-activated receptors (PPARs) are implicated in the regulation of several hallmarks of systemic COPD pathology, including cachexia, decreased oxidative muscle metabolism, oxidative stress and systemic inflammation. Recently, expression of PPARs and related co-factors was shown to be reduced in peripheral skeletal muscle of patients with moderate to severe COPD and muscle weakness. We hypothesise that impaired PPAR signalling may underlie some of the muscular disturbances in COPD. Proposed mechanisms as well as the therapeutic potential of PPAR modulation in treatment of skeletal muscle dysfunction will be outlined in this perspective. 


\section{Introduction}

Chronic obstructive pulmonary disease (COPD) is a lung disease characterised by irreversible airway obstruction and an abnormal chronic inflammatory response of the airways. Dominant symptoms are dyspnoea and impaired exercise capacity. These symptoms lead to progressive disability and poor health status but poorly correlate with severity of local impairment in the lungs. Surprisingly, even in the most recent international guidelines for diagnosis of COPD, staging is still based on severity of airway obstruction only ${ }^{1}$. However, there is increasing evidence in the literature that COPD should not be considered as a localised pulmonary disorder but as a systemic disease involving pathology in several extra-pulmonary tissues. Well characterised systemic features are a chronic low grade systemic inflammation and altered protein metabolism which, in a subgroup of severe COPD patients, results initially in muscle atrophy only (commonly referred to as sarcopenia) and in later stages also in cachexia ${ }^{2,3}$. Muscle atrophy is associated with increased mortality risk independent of disease staging ${ }^{4}$. Besides muscle atrophy, it is well established that intrinsic abnormalities in structure and metabolism are present in the remaining muscle in moderate to severe COPD. Muscle atrophy and muscle dysfunction contribute to reduced strength and endurance of the muscle which in turn limits exercise capacity. A recent meta-analysis showed that skeletal muscle in patients with moderate to severe COPD shows a fiber type shift from type I oxidative fibers to type II glycolytic fibers ${ }^{5}$. In addition, skeletal muscle in patients is characterised by a reduced oxidative capacity and recently in vitro impaired mitochondrial respiration was even shown in underweight patients with severe $\mathrm{COPD}^{6}$. It is still unclear whether the molecular mechanisms of muscular impairment in COPD are governed by disease-specific factors or common denominators of chronic wasting disease. The elucidation of these mechanisms is a crucial step towards developing specific therapies aimed at improving functionality and health status of these patients. Intriguingly, oxidative capacity and fiber type composition of skeletal muscle are controlled or affected by signalling through the nuclear receptor family of peroxisome proliferator-activated receptors (PPARs) ${ }^{7}$. Moreover, PPARs have also been shown to possess important anti-inflammatory properties by modulation of inflammatory signalling through the nuclear factor kappa B (NF-KB) pathway ${ }^{8}$. These combined actions could make PPARs an attractive target for therapeutic intervention aimed at alleviating skeletal muscle weakness in COPD as will be highlighted in this perspective. 


\section{Peroxisome proliferator-activated receptors (PPARs) and COPD}

Three PPAR isoforms can be distinguished: $\alpha, \beta / \delta$ and $\gamma$. All three exhibit tissue-specific expression, ligand-specific activation and the ability to heterodimerise with retinoid $X$ receptors (RXR) resulting in the transcription of target genes. During the past decade, PPARs have been implicated in several physiological processes such as the regulation of lipoprotein and lipid metabolism, glucose homeostasis, the inflammatory response and cellular differentiation ${ }^{9}$.

PPAR- $\alpha$ is expressed in many oxidative tissues, including skeletal muscle. The primary role of PPAR- $\alpha$ in skeletal muscle is regulation of fatty acid homeostasis and transcriptional control of lipid regulatory genes ${ }^{10}$. Additionally, PPAR- $\alpha$ is involved in the regulation of amino acid metabolism by downregulating blood- and tissue branched chain amino acid (BCAA) levels ${ }^{11}$. Other effects of PPAR- $\alpha$ activation include attenuation of inflammatory responses through inhibition of NF-KB-driven gene transcription ${ }^{12}$. Interestingly, secretion of inflammatory mediators in the lung decreased upon PPAR- $\alpha$ activation in a mouse model of chronic lung inflammation ${ }^{13}$. PPAR- $\alpha$ is activated by a number of naturally occurring, lipid-derived molecules including long-chain fatty acids, eicosanoids and leukotriene B4, while the fibrate class of hypolipidemic drugs, including fenofibrate and gemfibrozil, serves as synthetic PPAR- $\alpha$ ligands.

Although most abundant in adipose tissue, PPAR- $\gamma$ is expressed at low levels in skeletal muscle. Interestingly from a pulmonary perspective, PPAR-y is also expressed in the human lung. PPAR- $y$ regulates the storage of fat in adipose tissue and reduces plasma glucose, lipid and insulin levels in animal models of type 2 diabetes mellitus, as well as in humans ${ }^{14}$. Like PPAR- $\alpha$, PPAR-y is involved in attenuation of the inflammatory response by reducing NF-KB DNAbinding and repression of NF-KB activation through inhibition of the IKB kinase complex activity ${ }^{12,15}$. Anti-inflammatory effects of PPAR-y activation in the lung have been shown consistently in experimental models of asthma and other airway diseases, such as COPD ${ }^{16}$. PPAR-y is the main target of the thiazolidinedione (TZD) class of insulin-sensitizing drugs, which are currently a mainstay of therapy for type 2 diabetes mellitus. Besides these synthetic ligands, PPAR-y is activated by several naturally occurring compounds, such as prostaglandin $\mathrm{J} 2$ derivates and polyunsaturated fatty acids (PUFAs) ${ }^{17}$.

PPAR- $\delta$ is a powerful regulator of fatty acid utilization and energy homeostasis in several tissues including the heart and skeletal muscle ${ }^{7}$. Consistent with such a role, PPAR- $\delta$ protein content is increased during physiological 
conditions characterised by elevated fatty acid utilization, such as physical exercise or fasting. However, as PPARs are transcriptional regulators, their functionality is not only determined by abundance, but also by their activity. This may explain apparently contradictory reports showing increased PPAR- $\delta$ expression in skeletal muscle following short term fasting versus decreased PPAR- $\delta$ expression after longer periods of fasting ${ }^{18,19}$. Therefore, selection of different time points, as well as PPAR abundance and activity measurements are necessary to clarify the actual sequence of events in skeletal muscle during metabolic adaptation. Over-expression of PPAR- $\delta$ or its activation by synthetic agonists strongly increases the lipid catabolic activities of skeletal muscle, not only by up-regulating genes involved in this metabolic pathway, but also by inducing mitochondrial biogenesis and by promoting an increment of oxidative fibers $^{20}$. PPAR- $\delta$ is characterised by the large size of its ligand-binding pocket which allows interaction with a greater variety of activators when compared with other nuclear hormone receptors. PPAR- $\delta$ is activated by PUFAs, prostacyclin and synthetic molecules like phenoxyacetic acid derivates (e.g. GW 501516 and GW 0742) ${ }^{17}$.

We recently showed that PPAR- $\delta$ protein content is reduced in skeletal muscle of COPD patients compared to healthy control subjects. In addition, mRNA levels of the PPAR co-activator 1a (PGC-1a), which is a PPAR co-activator and a master regulator of mitochondrial biogenesis, were lower in muscle of COPD patients compared to controls while mRNA levels of PPAR- $\alpha$ were significantly lower in cachectic patients compared to non-cachectic patients ${ }^{21}$. Muscle oxidative phenotype, which is positively influenced by PPAR- $\delta, P G C-1 \alpha$ and PPAR- $\alpha$, is reduced in COPD ${ }^{6}$. This suggests that a reduced PPAR- $\delta$ and/or PPAR- $\alpha$ content or function in this disease may be involved in the observed reduction in muscular oxidative capacity that may even lead to mitochondrial dysfunction. Many pathological hallmarks of COPD have been shown to exert a negative effect on PPAR expression and activity. Hypoxia and inflammation could be responsible for lower PPAR expression levels or protein content as there are several reports that suggest a negative influence of these parameters on PPAR levels ${ }^{22-24}$. Furthermore, a sedentary lifestyle which is often adopted by COPD patients due to disease-specific limitations can also underlie reduced levels of PPAR and PGC-1a in skeletal muscle as it has been shown that physical activity level is an important factor regulating these factors ${ }^{25,26}$. Intriguingly, in other disease models, as congestive heart failure (CHF) and diabetes mellitus (DM), both characterised by systemic inflammation and physical inactivity, a decreased oxidative capacity of skeletal muscle is also associated with a decreased expression of PGC-1 $\alpha$, PPAR- $\alpha$ and PPAR- $\delta$ mRNA suggesting a prominent role for inflammation and physical activity level in controlling PPAR and PGC-1a levels ${ }^{27-29}$. Furthermore, it would be 
interesting to investigate PPAR and PGC-1 $\alpha$ expression levels at different stages of COPD to increase insight in the etiology and pathological mechanisms governing the observed decrease in skeletal muscle oxidative capacity in these patients.

\section{PPARs and regulation of skeletal muscle function}

\section{Inflammation}

Systemic inflammation is an important factor in the pathogenesis of weight loss and muscle wasting ${ }^{30-32}$. Many inflammatory responses are mediated by signalling through NF-KB. In its inactive form, NF-KB is bound to its inhibitor I kappa $\mathrm{B}$ alpha $(\mathrm{I} \mathrm{KB} \alpha)$ and is located in the cytosol. After activation, NF-KB is released and translocates to the nucleus where it initiates the transcription of its target genes, including those encoding inflammatory mediators ${ }^{33}$. NF-KB activation per se is sufficient for the induction of muscle atrophy ${ }^{34}$. Conversely, inhibition of NF-KB restored muscle mass in a number of experimental atrophy models including denervation and cancer cachexia ${ }^{34}$. Interestingly, NF-KB activation has been shown in skeletal muscle of severely underweight COPD patients by decreased content of the inhibitory protein of NF-KB (IKBa) and increased DNA binding of NF-KB ${ }^{35}$. Data regarding expression of inflammatory genes in relation to NF-kB activation are however lacking. Furthermore, some studies reported increased levels of inflammatory markers, including TNF- $\alpha$ protein, in skeletal muscle of COPD patients ${ }^{36,37}$, while others did not ${ }^{38}$. This discrepancy may be related to differences in COPD phenotypes and muscle studied. Additional studies measuring inflammatory mediators in skeletal muscle of different COPD phenotypes (cachectic vs non-cachectic) are needed to elucidate the exact implication of inflammatory signalling in the process of skeletal muscle wasting and cachexia in COPD.

Potent anti-inflammatory properties have been described for different PPAR isoforms. It was shown that specific PPAR- $\alpha$ activators effectively reduced NF-KB activation and re-established control over pro-inflammatory cytokine production, such as interleukin 6 (IL-6) and tumour necrosis factor alpha (TNF- $\alpha$ ), in various mouse tissues ${ }^{39}$. In addition, PPAR- $\alpha$ activators were found to induce expression of the NF-KB inhibitory factor $\mathrm{I} B \mathrm{Ba}$ in primary smooth muscle cells ${ }^{40}$. PPAR-y may also play an important role in the regulation of inflammation. Several PPAR-y ligands have been shown to possess antiinflammatory properties. For example, $15 \mathrm{~d}-\mathrm{PGJ}_{2}$ was shown to inhibit matrix metalloproteinase-9, IL-1 $\beta, \quad$ IL- 6 and TNF- $\alpha$ production by human monocytes/macrophages ${ }^{41,42}$. The TZD troglitazone decreased plasma levels of 
TNF- $\alpha$ in obese human subjects and effectively reduced nuclear localisation of $\mathrm{NF}-\mathrm{KB}$ in mononuclear cells, suggesting a reduction in NF-KB-mediated transcription ${ }^{43}$. Besides inhibition of nuclear translocation, PPAR-y activation can also interfere with NF-KB signalling by a mechanism involving competition for transcriptional co-factors ${ }^{44}$. Furthermore, PPAR- $y$ activation can repress NF-KB activity by reducing NF-KB DNA-binding activity and preventing IKBa degradation ${ }^{45}$. Reports on anti-inflammatory effects of PPAR- $\delta$ are scarce. However, a recent study showed that PPAR- $\delta$ activation in $\mathrm{C} 2 \mathrm{C} 12$ mouse skeletal muscle cells displayed anti-inflammatory properties ${ }^{46}$.

In summary, convincing data implicate inflammation as a trigger of cachexia, which may be modulated by systemic delivery of PPAR agonists by suppressing inflammatory- and subsequent atrophy signalling in skeletal muscle.

\section{Oxidative stress}

Development and progression of skeletal muscle atrophy in COPD has also been associated with an imbalance between reactive oxygen species (ROS) production and antioxidant capacity ${ }^{47,48}$. Oxidative stress is present systemically as well as locally in skeletal muscle of COPD patients ${ }^{49}$. Experimental studies have shown that ROS can increase muscle proteolysis, inhibit muscle-specific protein expression, and increase muscle cell apoptosis $^{50-52}$. Moreover, several studies demonstrated that markers of nitrosative stress are also enhanced in skeletal muscle of COPD patients. Inducible nitric oxide synthase (iNOS) expression and/or nitrotyrosine formation were found to be enhanced in skeletal muscle of COPD patients in several independent studies suggesting that, in addition to oxidative stress, skeletal muscle is also exposed to nitrosative stress, which may contribute to the process of protein degradation as well ${ }^{35,37,53}$. In contrast, it has been shown that nitric oxide (NO), at modest concentrations (i.e. when it appears to act as a signalling molecule causing reversible post-translational modifications) stimulates the formation of metabolically active new mitochondria through activation of the AMPK/SIRT1/PGC-1 $\alpha / P P A R-\delta$ signalling pathway ${ }^{54,55}$. Based on the latter, it can not be excluded that NO may serve to counteract mitochondrial dysfunction in conditions characterised by muscle degeneration, such as COPD and further studies are necessary to properly address this issue.

A bulk of evidence points towards an inhibitory and attenuating effect of PPAR$\alpha$ on oxidative stress. PPAR- $\alpha$ agonists can directly attenuate oxidative stress by preventing ROS generation, as it was shown that PPAR- $\alpha$ activation in mice restored impaired cellular redox balance, evidenced by a lowering of tissue lipid 
peroxidation and elimination of constitutively active NF-KB ${ }^{39}$. Furthermore, PPAR- $\alpha$ activation by fish oil feeding and fenofibrate administration to mice, down-regulated hydroxysteroid markers of ROS production in the liver ${ }^{56}$. Several studies demonstrated that activation of PPAR- $\alpha$ in vivo also causes an up-regulation in a number of antioxidant enzymes, including catalase, $\mathrm{Cu}^{2+}$ and $\mathrm{Zn}^{2+}$ superoxide dismutase (SOD) and mediators of the glutathione pathway ${ }^{57}$. More recent research confirms previous reports that PPAR- $\alpha$ activation in rats increases the antioxidant capacity and thereby modulates the oxidantantioxidant balance in favour of the latter ${ }^{58,59}$. In addition, cardiac-specific PPAR- $\alpha$ deficiency was accompanied by a decrease in cardiac manganese SOD expression and activity and a subsequent increase in oxidative/nitrosative damage ${ }^{60}$. Besides PPAR- $\alpha$ agonists, PPAR- $y$ agonists are also able to reduce ROS formation ${ }^{61,62}$. Two different PPAR-y ligands were found to increase catalase mRNA expression and activity in endothelial cells ${ }^{63}$. Furthermore, glutathione and ascorbic acid levels in the hearts of diabetic rabbits were increased after PPAR- $\gamma$ activation when compared to diabetic non-treated animals ${ }^{64}$. The exact mechanisms involved in the reduction of oxidative stress by PPAR- $\alpha$ and PPAR-y agonists remain elusive.

Oxidative stress has been demonstrated consistently in skeletal muscle of COPD patients ${ }^{53}$. As PPAR activation diminishes oxidative stress in multiple tissues, it is reasonable to expect similar effects in skeletal muscle, which may be beneficial in alleviating skeletal muscle dysfunction in COPD.

\section{Oxidative metabolism}

A decrease in the type I slow oxidative muscle fibers and a concomitant increase in type II fast twitch glycolytic fibers is reported in peripheral skeletal muscles of COPD patients, indicative of a relative shift from oxidative to glycolytic capacity ${ }^{65}$. Because type II muscle fibers have a lower resistance to fatigue, this fiber type shift may result in reduced endurance as observed in peripheral skeletal muscle of COPD patients. In concordance with this fiber type shift, analyses of enzyme activities also reveal an overall increase in glycolytic and decrease in oxidative activities in peripheral skeletal muscles of these patients affecting muscle substrate metabolism ${ }^{6,66}$. 


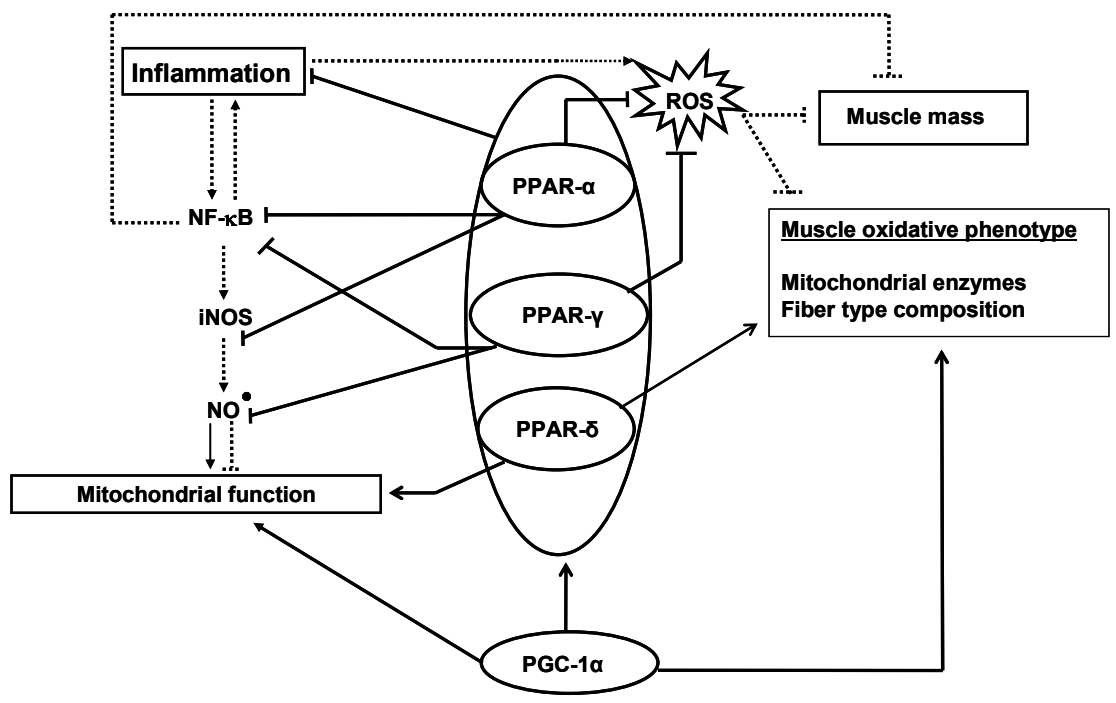

Figure 2.1 Negative effects of inflammation, oxidative- and nitrosative stress on muscle mass and oxidative phenotype and the different levels of modulation by peroxisome proliferatoractivated receptors (PPARs). Inflammation, oxidative- and nitrosative stress negatively affect muscle mass and oxidative capacity. Different PPAR subtypes inhibit inflammatory signalling and oxidative- and nitrosative stress at the indicated levels and may prevent or restore loss of muscle mass and oxidative phenotype. In addition, PPAR- $\delta$ and PPAR-y co-activator-1 $\alpha$ (PGC-1 $\alpha$ ) may positively modulate muscle mass and oxidative phenotype and may oppose the effects of inflammation and oxidativenitrosative stress. NF-KB $=$ Nuclear Factor kappa B, iNOS = inducible nitric oxide synthase, $\mathrm{NO}=$ nitric oxide, $\mathrm{ROS}=$ reactive oxygen species. Dotted lines indicate a negative effect on muscle mass and/or muscle oxidative phenotype. Full lines indicate a positive effect on muscle mass and/or muscle oxidative phenotype. Blocked arrowheads indicate an inhibitory signal and regular arrowheads represent a stimulatory signal.

Expression of muscle genes that promote selective utilisation of lipid substrates is augmented during physiological states that are associated with increased systemic delivery of free fatty acids, such as exercise. Interestingly, many of the same muscle genes are also up-regulated by in vivo administration of PPAR- $\alpha$ activators. It is observed that PPAR- $\alpha$ protein content is increased by exercise training and induced during myocyte differentiation, two conditions characterised by an increase in oxidative capacity ${ }^{67,68}$. In addition, PPAR- $\alpha$ regulates fatty acid utilisation and expression of several genes involved in fatty acid $\beta$-oxidation in primary human skeletal muscle cells ${ }^{69}$. Skeletal muscle expresses high levels of PPAR- $\delta$ and activation of the $\delta$-subtype increases fatty acid $\beta$-oxidation as well as mRNA levels of several classical PPAR- $\alpha$ target genes in both rodent and human skeletal muscle cells ${ }^{70}$. Overexpression of PPAR- $\delta$ in C2C12 myotubes, in vitro, resulted in an increment in 
fatty acid oxidation after activation by a synthetic ligand ${ }^{71,72}$. In addition, analysis of rat myotubes treated with the PPAR- $\delta$ subtype selective agonist, GW 501516, revealed that PPAR- $\delta$ controls fatty acid oxidation by regulating genes involved in fatty acid transport, $\beta$-oxidation, and mitochondrial respiration ${ }^{73,74}$. These results, showing a significant overlap in the functions of PPAR- $\alpha$ and PPAR- $\delta$, indicate that both subtypes play an important role in mediating lipid-induced regulation of oxidative pathways.

A recent study examining mice over-expressing PPAR- $\delta$ in muscle showed that the number of succinate dehydrogenase (SDH) positive fibers (as a measure for oxidative fibers) was considerably increased in various muscles. This remodelling was due to hyperplasia and/or conversion of SDH negative to SDH positive fibers, similar to what is observed upon endurance training ${ }^{71,75}$. These histological observations were confirmed by the finding that muscle-specific PPAR- $\delta$ over-expression led to an increase of other oxidative enzymes, such as citrate synthase and $\beta$-hydroxyacyl-CoA dehydrogenase. In addition, mitochondrial biogenesis was also enhanced. Conversely, activities of glycolytic enzymes remained unchanged ${ }^{75}$. Conversion of glycolytic fibers to oxidative fibers has also been reported in genetically altered animals that overexpress PGC-1a, which is a PPAR co-activator and a master regulator of mitochondrial biogenesis. Notably, putative type II muscles from PGC-1a transgenic mice also express proteins characteristic of type I fibers, such as troponin I (slow) and myoglobin, and show a greater resistance to fatigue. These data indicate that, in addition to PPAR- $\delta$, PGC-1 $\alpha$ is also a principal factor regulating muscle fiber type determination and skeletal muscle exercise capacity $^{76}$.

Given the strong involvement of the PPARs and PGC-1a in regulation of skeletal muscle oxidative phenotype, the fact that skeletal muscle oxidative phenotype is impaired in COPD and the observation of reduced PPAR expression levels in skeletal muscle of COPD patients, it is tempting to suggest a possible therapeutic role for PPAR activators in muscle metabolism in COPD.

\section{How to modulate PPAR activity in COPD?}

COPD management requires an integrated approach aimed at pulmonary and extra-pulmonary manifestations. In addition to therapies aimed at alleviating the primary lung impairment, evidence is accumulating that therapies targeting skeletal muscle dysfunction have a significant positive effect on quality of life and may even improve survival. Experimental studies have shown that PPAR- $\alpha$ and PPAR-y can exert anti-inflammatory effects in the pulmonary compartment, 
which, with additional research, may translate into an interesting therapeutic avenue in the context of COPD lung pathology ${ }^{13,66,67}$. Moreover, based on the evidence described in the present review, it is tempting to suggest that a reduced content and activity of the PPARs may underlie some of the muscular disturbances in COPD. Nutritional intervention and exercise may positively influence PPAR content and activity in skeletal muscle. Indirect support for this notion is the beneficial effect of pulmonary rehabilitation on mitochondrial (fat) oxidative capacity and hence on skeletal muscle function in skeletal muscle of COPD patients ${ }^{77}$. PUFAs are common components of fatty fish and olive oil and are known PPAR activators. Interestingly, a recent Randomised Clinical Trial showed that nutritional supplementation with PUFAs as adjunct to exercise training in COPD patients markedly enhanced exercise capacity compared to the placebo-treated group ${ }^{78}$. The time point of intervention with PPAR activators is also a point of interest. Two different aspects must be kept in mind. First, the positive influence of PPAR activators on skeletal muscle oxidative capacity and second the potent anti-inflammatory capacities of these agents. Concerning the effects on muscle oxidative capacity the rationale would be to introduce PPAR activators clinically to patients for whom daily life activities are limited by the decreased oxidative capacity of their lower limb skeletal muscles. On the other hand, PPAR activators can be used to alleviate inflammatory status of COPD patients, for example, after exacerbations or in late stage COPD to ameliorate the systemic inflammatory process. Also, it is conceivable that PPAR agonists can delay or inhibit disease-specific processes, such as inflammation, if applied at early stages of disease development.

In conclusion, single or combined PPAR agonists may represent a novel class of pharmacological agents that could be helpful in management of this disease. 


\section{References}

1. Rabe KF, Hurd S, Anzueto A, Barnes PJ, Buist SA, Calverley P, Fukuchi Y, Jenkins C, Rodriguez-Roisin R, van Weel C, Zielinski J. Global Strategy for the Diagnosis, Management, and Prevention of COPD - 2006 Update. Am J Respir Crit Care Med 2007; 176;532-55.

2. Balasubramanian VP, Varkey $B$. Chronic obstructive pulmonary disease: effects beyond the lungs. Curr Opin Pulm Med 2006;12:106-12.

3. Agusti AG. Systemic effects of chronic obstructive pulmonary disease. Proc Am Thorac Soc 2005;2:367-70; discussion 371-2.

4. Mador MJ. Muscle mass, not body weight, predicts outcome in patients with chronic obstructive pulmonary disease. Am J Respir Crit Care Med 2002;166:787-9.

5. Gosker H, Zeegers M, Wouters E, Schols AM. Muscle fiber type shifting in the vastus lateralis of patients with COPD is associated with disease severity: a systematic review and metaanalysis. Thorax 2007;62:944-9

6. Gosker HR, Kubat B, Schaart G, van der Vusse GJ, Wouters EF, Schols AM. Myopathological features in skeletal muscle of patients with chronic obstructive pulmonary disease. Eur Respir J 2003;22:280-5.

7. Luquet S, Gaudel C, Holst D, Lopez-Soriano J, Jehl-Pietri C, Fredenrich A, Grimaldi PA. Roles of PPAR delta in lipid absorption and metabolism: a new target for the treatment of type 2 diabetes. Biochim Biophys Acta 2005;1740:313-7.

8. Becker J, Delayre-Orthez C, Frossard N, Pons F. Regulation of inflammation by PPARs: a future approach to treat lung inflammatory diseases? Fundam Clin Pharmacol 2006;20: 429-47.

9. Blanquart C, Barbier O, Fruchart JC, Staels B, Glineur C. Peroxisome proliferator-activated receptors: regulation of transcriptional activities and roles in inflammation. J Steroid Biochem Mol Biol 2003;85:267-73.

10. Muoio DM, MacLean PS, Lang DB, Li S, Houmard JA, Way JM, Winegar DA, Corton JC, Dohm GL, Kraus WE. Fatty acid homeostasis and induction of lipid regulatory genes in skeletal muscles of peroxisome proliferator-activated receptor (PPAR) alpha knock-out mice. Evidence for compensatory regulation by PPAR delta. J Biol Chem 2002;277:26089-97.

11. Harris RA, Joshi M, Jeoung $\mathrm{NH}$. Mechanisms responsible for regulation of branched-chain amino acid catabolism. Biochem Biophys Res Commun 2004;313:391-6.

12. Kersten S, Desvergne B, Wahli W. Roles of PPARs in health and disease. Nature 2000;405: 421-4.

13. Delayre-Orthez C, Becker J, Guenon I, Lagente V, Auwerx J, Frossard N, Pons F. PPARalpha downregulates airway inflammation induced by lipopolysaccharide in the mouse. Respir Res 2005;6:91.

14. Rieusset J, Touri F, Michalik L, Escher P, Desvergne B, Niesor E, Wahli W. A new selective peroxisome proliferator-activated receptor gamma antagonist with antiobesity and antidiabetic activity. Mol Endocrinol 2002;16:2628-44.

15. Verges B. Clinical interest of PPARs ligands. Diabetes Metab 2004;30:7-12.

16. Spears M, McSharry C, Thomson NC. Peroxisome proliferator-activated receptor-gamma agonists as potential anti-inflammatory agents in asthma and chronic obstructive pulmonary disease. Clin Exp Allergy 2006;36:1494-504.

17. Akiyama TE, Meinke PT, Berger JP. PPAR ligands: potential therapies for metabolic syndrome. Curr Diab Rep 2005;5:45-52.

18. Luquet S, Lopez-Soriano J, Holst D, Gaudel C, Jehl-Pietri C, Fredenrich A, Grimaldi PA. Roles of peroxisome proliferator-activated receptor delta (PPARdelta) in the control of fatty acid catabolism. A new target for the treatment of metabolic syndrome. Biochimie 2004;86: 833-7.

19. de Lange $P$, Ragni $M$, Silvestri $E$, Moreno $M$, Schiavo L, Lombardi A, Farina P, Feola A, Goglia F, Lanni A. Combined CDNA array/RT-PCR analysis of gene expression profile in rat gastrocnemius muscle: relation to its adaptive function in energy metabolism during fasting. Faseb J 2004;18:350-2. 
20. Fredenrich A, Grimaldi PA. Roles of peroxisome proliferator-activated receptor delta in skeletal muscle function and adaptation. Curr Opin Clin Nutr Metab Care 2004;7:377-81.

21. Remels AH, Schrauwen P, Broekhuizen R, Willems J, Kersten S, Gosker HR, Schols AM. Expression and content of PPARs is reduced in skeletal muscle of COPD patients. Eur Respir J 2007;30:245-52.

22. Narravula S, Colgan SP. Hypoxia-inducible factor 1-mediated inhibition of peroxisome proliferator-activated receptor alpha expression during hypoxia. J Immunol 2001;166:7543-8.

23. Sung $\mathrm{CK}$, She H, Xiong S, Tsukamoto $\mathrm{H}$. Tumor necrosis factor-alpha inhibits peroxisome proliferator-activated receptor gamma activity at a posttranslational level in hepatic stellate cells. Am J Physiol Gastrointest Liver Physiol 2004;286:G722-9.

24. Tham DM, Martin-McNulty B, Wang YX, Wilson DW, Vergona R, Sullivan ME, Dole W, Rutledge JC. Angiotensin II is associated with activation of NF-kappaB-mediated genes and downregulation of PPARs. Physiol Genomics 2002;11:21-30.

25. Fritz T, Kramer DK, Karlsson HK, Galuska D, Engfeldt P, Zierath JR, Krook A. Low-intensity exercise increases skeletal muscle protein expression of PPARdelta and UCP3 in type 2 diabetic patients. Diabetes Metab Res Rev 2006;22:492-8.

26. Sandri M, Lin J, Handschin C, Yang W, Arany ZP, Lecker SH, Goldberg AL, Spiegelman BM. PGC-1alpha protects skeletal muscle from atrophy by suppressing FoxO3 action and atrophy-specific gene transcription. Proc Natl Acad Sci U S A 2006;103:16260-5.

27. Garnier A, Fortin D, Delomenie C, Momken I, Veksler V, Ventura-Clapier R. Depressed mitochondrial transcription factors and oxidative capacity in rat failing cardiac and skeletal muscles. J Physiol 2003;551:491-501.

28. Roden M. Muscle triglycerides and mitochondrial function: possible mechanisms for the development of type 2 diabetes. Int J Obes (Lond) 2005;29(Suppl 2):S111-5.

29. Carey AL, Petersen EW, Bruce CR, Southgate RJ, Pilegaard H, Hawley JA, Pedersen BK, Febbraio MA. Discordant gene expression in skeletal muscle and adipose tissue of patients with type 2 diabetes: effect of interleukin-6 infusion. Diabetologia 2006;49:1000-7.

30. Guttridge DC, Mayo MW, Madrid LV, Wang CY, Baldwin AS, Jr. NF-kappaB-induced loss of MyoD messenger RNA: possible role in muscle decay and cachexia. Science 2000;289: 2363-6.

31. Langen RC, Schols AM, Kelders MC, Wouters EF, Janssen-Heininger YM. Inflammatory cytokines inhibit myogenic differentiation through activation of nuclear factor-kappaB. Faseb J 2001;15:1169-80.

32. Langen RC, Schols AM, Kelders MC, van der Velden JL, Wouters EF, Janssen-Heininger YM. Muscle wasting and impaired muscle regeneration in a murine model of chronic pulmonary inflammation. Am J Respir Cell Mol Biol 2006;35:689-96.

33. Xiao C, Ghosh S. NF-kappaB, an evolutionarily conserved mediator of immune and inflammatory responses. Adv Exp Med Biol 2005;560:41-5.

34. Cai D, Frantz JD, Tawa NE, Jr., Melendez PA, Oh BC, Lidov HG, Hasselgren PO, Frontera WR, Lee J, Glass DJ, Shoelson SE. IKKbeta/NF-kappaB activation causes severe muscle wasting in mice. Cell 2004;119:285-98.

35. Agusti A, Morla M, Sauleda J, Saus C, Busquets X. NF-kappaB activation and iNOS upregulation in skeletal muscle of patients with COPD and low body weight. Thorax 2004;59: 483-7.

36. Rabinovich RA, Bastos R, Ardite E, Llinas L, Orozco-Levi M, Gea J, Vilaro J, Barbera JA, Rodriguez-Roisin R, Fernandez-Checa JC, Roca J. Mitochondrial dysfunction in COPD patients with low body mass index. Eur Respir J 2007;29:643-50.

37. Montes de Oca M, Torres SH, De Sanctis J, Mata A, Hernandez N, Talamo C. Skeletal muscle inflammation and nitric oxide in patients with COPD. Eur Respir J 2005;26:390-7.

38. Barreiro E, Schols AM, Polkey MI, Galdiz JB, Gosker HR, Swallow EB, Coronell C, Gea J; ENIGMA in COPD project. Cytokine profile in quadriceps muscle of patients with severe chronic obstructive pulmonary disease. Thorax 2008;63:100-7

39. Poynter ME, Daynes RA. Peroxisome proliferator-activated receptor alpha activation modulates cellular redox status, represses nuclear factor-kappaB signalling, and reduces inflammatory cytokine production in aging. J Biol Chem 1998;273:32833-41. 
40. Staels B, Koenig W, Habib A, Merval R, Lebret M, Torra IP, Delerive P, Fadel A, Chinetti G, Fruchart JC, Najib J, Maclouf J, Tedgui A. Activation of human aortic smooth-muscle cells is inhibited by PPARalpha but not by PPARgamma activators. Nature 1998;393:790-3.

41. Jiang C, Ting AT, Seed B. PPAR-gamma agonists inhibit production of monocyte inflammatory cytokines. Nature 1998;391:82-6.

42. Chawla A, Barak Y, Nagy L, Liao D, Tontonoz P, Evans RM. PPAR-gamma dependent and independent effects on macrophage-gene expression in lipid metabolism and inflammation. Nat Med 2001;7:48-52.

43. Dandona P, Aljada A. A rational approach to pathogenesis and treatment of type 2 diabetes mellitus, insulin resistance, inflammation, and atherosclerosis. Am J Cardiol 2002;90: 27G-33G.

44. Li M, Pascual G, Glass CK. Peroxisome proliferator-activated receptor gamma-dependent repression of the inducible nitric oxide synthase gene. Mol Cell Biol 2000;20:4699-707.

45. Castrillo A, Diaz-Guerra MJ, Hortelano S, Martin-Sanz P, Bosca L. Inhibition of IkappaB kinase and IkappaB phosphorylation by 15-deoxy-Delta(12,14)-prostaglandin J(2) in activated murine macrophages. Mol Cell Biol 2000;20:1692-8.

46. Woo CH, Massett MP, Shishido T, Itoh S, Ding B, McClain C, Che W, Vulapalli SR, Yan C, Abe J. ERK5 activation inhibits inflammatory responses via peroxisome proliferator-activated receptor delta (PPARdelta) stimulation. J Biol Chem 2006;281:32164-74.

47. MacNee W. Oxidants/antioxidants and COPD. Chest 2000;117:303S-17S.

48. Koechlin C, Couillard A, Cristol JP, Chanez P, Hayot M, Le Gallais D, Prefaut C. Does systemic inflammation trigger local exercise-induced oxidative stress in COPD? Eur Respir J 2004;23:538-44.

49. MacNee W. Oxidants and COPD. Curr Drug Targets Inflamm Allergy 2005;4:627-41.

50. Langen RC, Schols AM, Kelders MC, Van Der Velden JL, Wouters EF, Janssen-Heininger YM. Tumor necrosis factor-alpha inhibits myogenesis through redox-dependent and independent pathways. Am J Physiol Cell Physiol 2002;283:C714-21.

51. Buck M, Chojkier M. Muscle wasting and dedifferentiation induced by oxidative stress in a murine model of cachexia is prevented by inhibitors of nitric oxide synthesis and antioxidants. Embo J 1996;15:1753-65.

52. Stangel M, Zettl UK, Mix E, Zielasek J, Toyka KV, Hartung HP, Gold R. H2O2 and nitric oxide-mediated oxidative stress induce apoptosis in rat skeletal muscle myoblasts. J Neuropathol Exp Neurol 1996;55:36-43.

53. Barreiro E, Gea J, Corominas JM, Hussain SN. Nitric oxide synthases and protein oxidation in the quadriceps femoris of patients with chronic obstructive pulmonary disease. Am J Respir Cell Mol Biol 2003;29:771-8.

54. Jobgen WS, Fried SK, Fu WJ, Meininger CJ, Wu G. Regulatory role for the arginine-nitric oxide pathway in metabolism of energy substrates. J Nutr Biochem 2006;17:571-88.

55. Nisoli E, Clementi E, Paolucci C, Cozzi V, Tonello C, Sciorati C, Bracale R, Valerio A, Francolini M, Moncada S, Carruba MO. Mitochondrial biogenesis in mammals: the role of endogenous nitric oxide. Science 2003;299:896-9.

56. Takahashi M, Tsuboyama-Kasaoka N, Nakatani T, Ishii M, Tsutsumi S, Aburatani H, Ezaki O. Fish oil feeding alters liver gene expressions to defend against PPARalpha activation and ROS production. Am J Physiol Gastrointest Liver Physiol 2002;282:G338-48.

57. Toyama T, Nakamura H, Harano $\mathrm{Y}$, Yamauchi N, Morita A, Kirishima T, Minami M, Itoh $\mathrm{Y}$, Okanoue T. PPARalpha ligands activate antioxidant enzymes and suppress hepatic fibrosis in rats. Biochem Biophys Res Commun 2004;324:697-704.

58. Beltowski J, Wojcicka G, Mydlarczyk M, Jamroz A. The effect of peroxisome proliferatoractivated receptors alpha (PPARalpha) agonist, fenofibrate, on lipid peroxidation, total antioxidant capacity, and plasma paraoxonase 1 (PON 1) activity. J Physiol Pharmacol 2002; 53:463-75.

59. Inoue I, Noji S, Awata T, Takahashi K, Nakajima T, Sonoda M, Komoda T, Katayama S. Bezafibrate has an antioxidant effect: peroxisome proliferator-activated receptor alpha is associated with Cu2+, Zn2+-superoxide dismutase in the liver. Life Sci 1998;63:135-44. 
60. Schulz R, Ali MA. PPAR\{alpha\}: Essential component to prevent myocardial oxidative stress? Am J Physiol Heart Circ Physiol. 2007;293:H11-2

61. Tao L, Liu HR, Gao E, Teng ZP, Lopez BL, Christopher TA, Ma XL, Batinic-Haberle I, Willette $\mathrm{RN}$, Ohlstein $\mathrm{EH}$, Yue TL. Antioxidative, antinitrative, and vasculoprotective effects of a peroxisome proliferator-activated receptor-gamma agonist in hypercholesterolemia. Circulation 2003;108:2805-11.

62. Shiojiri T, Wada K, Nakajima A, Katayama K, Shibuya A, Kudo C, Kadowaki T, Mayumi T, Yura Y, Kamisaki Y. PPAR gamma ligands inhibit nitrotyrosine formation and inflammatory mediator expressions in adjuvant-induced rheumatoid arthritis mice. Eur J Pharmacol 2002; 448:231-8.

63. Girnun GD, Domann FE, Moore SA, Robbins ME. Identification of a functional peroxisome proliferator-activated receptor response element in the rat catalase promoter. Mol Endocrinol 2002;16:2793-801.

64. Delerive P, Fruchart JC, Staels B. Peroxisome proliferator-activated receptors in inflammation control. J Endocrinol 2001;169:453-9.

65. Satta A, Migliori GB, Spanevello A, Neri M, Bottinelli R, Canepari M, Pellegrino MA, Reggiani C. Fiber types in skeletal muscles of chronic obstructive pulmonary disease patients related to respiratory function and exercise tolerance. Eur Respir J 1997;10:2853-60.

66. Maltais F, LeBlanc P, Simard C, Jobin J, Berube C, Bruneau J, Carrier L, Belleau R. Skeletal muscle adaptation to endurance training in patients with chronic obstructive pulmonary disease. Am J Respir Crit Care Med 1996;154:442-7.

67. Cresci S, Wright LD, Spratt JA, Briggs FN, Kelly DP. Activation of a novel metabolic gene regulatory pathway by chronic stimulation of skeletal muscle. Am J Physiol 1996;270: C1413-20.

68. Horowitz JF, Leone TC, Feng W, Kelly DP, Klein S. Effect of endurance training on lipid metabolism in women: a potential role for PPARalpha in the metabolic response to training. Am J Physiol Endocrinol Metab 2000;279:E348-55.

69. Baldan A, Relat J, Marrero PF, Haro D. Functional interaction between peroxisome proliferator-activated receptors-alpha and Mef-2C on human carnitine palmitoyltransferase 1 beta (CPT1beta) gene activation. Nucleic Acids Res 2004;32:4742-9.

70. Leone TC, Weinheimer CJ, Kelly DP. A critical role for the peroxisome proliferator-activated receptor alpha (PPARalpha) in the cellular fasting response: the PPARalpha-null mouse as a model of fatty acid oxidation disorders. Proc Natl Acad Sci USA 1999;96:7473-8.

71. Grimaldi PA. Roles of PPARdelta in the control of muscle development and metabolism. Biochem Soc Trans 2003;31:1130-2.

72. Holst D, Luquet $S$, Nogueira V, Kristiansen $K$, Leverve X, Grimaldi PA. Nutritional regulation and role of peroxisome proliferator-activated receptor delta in fatty acid catabolism in skeletal muscle. Biochim Biophys Acta 2003;1633:43-50.

73. Tanaka T, Yamamoto J, Iwasaki S, Asaba H, Hamura H, Ikeda Y, Watanabe M, Magoori K, loka RX, Tachibana K, Watanabe Y, Uchiyama Y, Sumi K, Iguchi H, Ito S, Doi T, Hamakubo T, Naito M, Auwerx J, Yanagisawa M, Kodama T, Sakai J. Activation of peroxisome proliferator-activated receptor delta induces fatty acid beta-oxidation in skeletal muscle and attenuates metabolic syndrome. Proc Natl Acad Sci USA 2003;100:15924-9.

74. Wang YX, Lee CH, Tiep S, Yu RT, Ham J, Kang H, Evans RM. Peroxisome-proliferatoractivated receptor delta activates fat metabolism to prevent obesity. Cell 2003;113:159-70.

75. Luquet S, Lopez-Soriano J, Holst D, Fredenrich A, Melki J, Rassoulzadegan M, Grimaldi PA. Peroxisome proliferator-activated receptor delta controls muscle development and oxidative capability. Faseb J 2003;17:2299-301.

76. Lin J, Wu H, Tarr PT, Zhang CY, Wu Z, Boss O, Michael LF, Puigserver P, Isotani E, Olson EN, Lowell BB, Bassel-Duby R, Spiegelman BM. Transcriptional co-activator PGC-1 alpha drives the formation of slow-twitch muscle fibers. Nature 2002;418:797-801.

77. Doherty DE, Briggs DD, Jr. Long-term nonpharmacologic management of patients with chronic obstructive pulmonary disease. Clin Cornerstone 2004; Suppl 2:S29-34. 
Chapter 2

78. Broekhuizen R, Wouters EF, Creutzberg EC, Weling-Scheepers CA, Schols AM. Polyunsaturated fatty acids improve exercise capacity in chronic obstructive pulmonary disease. Thorax 2005;60:376-82. 


\section{Chapter 3}

\section{Regulation of mitochondrial biogenesis during myogenesis}

Remels AHV, Langen RCJ, Schrauwen P, Schaart G, Schols AMWJ, Gosker HR. Regulation of mitochondrial biogenesis during myogenesis. Mol Cell Endocrinol. Accepted 


\section{Abstract}

Pathways involved in mitochondrial biogenesis associated with myogenic differentiation are poorly defined. Therefore, $\mathrm{C} 2 \mathrm{C} 12$ myoblasts were differentiated into multi-nucleated myotubes and parameters/regulators of mitochondrial biogenesis were investigated. Mitochondrial respiration, citrate synthase- and $\beta$-hydroxyacyl-CoA dehydrogenase activity as well as protein content of complexes I, II, III and V of the mitochondrial respiratory chain increased 4-8 fold during differentiation. Additionally, an increase in the ratio of myosin heavy chain (MyHC) slow vs MyHC fast protein content was observed. PPAR transcriptional activity and transcript levels of PPAR- $\alpha$, the PPAR coactivator PGC-1 $\alpha$, mitochondrial transcription factor $A$ and nuclear respiratory factor 1 increased during differentiation while expression levels of PPAR- $y$ decreased. In conclusion, expression and activity levels of genes known for their regulatory role in skeletal muscle oxidative capabilities parallel increases in oxidative parameters during the myogenic program. In particular, PGC-1a and PPAR- $\alpha$ may be involved in the regulation of mitochondrial biogenesis during myogenesis. 


\section{Introduction}

Intrinsically, skeletal muscle is a tissue characterised by a high level of plasticity. The potential to alter muscle size, metabolic properties and/or protein isoform expression gives skeletal muscle the ability to adapt to the different challenges that may be placed upon it ${ }^{1}$. Events triggering skeletal muscle adaptive changes include endurance- and strength training, overload, aging, disuse, starvation, chronic illness and degenerative disorders ${ }^{2-4}$. Growth and repair (regeneration) of skeletal muscle tissue is inextricably linked to the action of a group of myogenic precursor cells, called satellite cells. Upon activation, these cells proliferate, differentiate and ultimately fuse with existing myofibers ${ }^{5}$. The irreversible transition from the proliferation-competent myoblast stage into fused multi-nucleated myotubes is known as myogenic differentiation and recapitulates developmental and regenerative myogenesis ${ }^{6}$.

Oxidative phenotype (OXPHEN) of a muscle depends on its oxidative capacity (determined by the activity of mitochondrial enzymes involved in oxidative substrate metabolism) and fiber type composition (e.g. ratio type I oxidative (slow-twitch) vs type IIB/X glycolytic (fast-twitch) fibers. The peroxisome proliferator-activated receptors (PPARs), especially the PPAR- $\delta$ and PPAR- $\alpha$ isoforms, and related co-activator molecules as PGC-1 $\alpha$ are highly implicated in regulation of skeletal muscle OXPHEN ${ }^{7,8}$. Accordingly, muscle-specific overexpression of PPAR- $\delta$ or PGC-1 $1 \alpha$ in mice potently up-regulated oxidative capabilities of the muscle and mediated a fiber type shift towards an increased $\mathrm{OXPHEN}^{9,10}$. Moreover, PGC-1 $\alpha$ and the PPARs govern mitochondrial biogenesis through control over other regulatory proteins including nuclear respiratory factor 1 (NRF-1) and the master mitochondrial regulator mitochondrial transcription factor $A(T f a m)^{11,12}$. An improved muscle OXPHEN may be established during the process of myogenesis (i.e. the formation, repair or hypertrophy of muscle), or through alterations within the pre-existing muscle fibers, independent of myogenic differentiation. The regulation of oxidative profile in existing muscle fibers has been described quite extensively in the literature ${ }^{9,10,13}$ whereas knowledge regarding the development of muscle oxidative profile and the involvement of key regulators herein during myogenic differentiation is rather limited.

Studying the molecular events governing regulation of mitochondrial biogenesis during myogenesis is of clinical relevance for a number of pathological conditions including chronic inflammatory myopathies and degenerative muscle conditions as e.g. Duchenne's muscular dystrophy ${ }^{14,15}$, but also in conditions characterised by loss of OXPHEN in skeletal muscle, such as COPD ${ }^{4}$. 
It has been shown that mitochondria play a mechanistic role not only in myoblast proliferation ${ }^{16,17}$, but also in myogenesis by targeting key regulators of myogenic differentiation as myogenin ${ }^{17}$ and cellular oncogens as c-myc ${ }^{18}$. Moreover, blocking mitochondrial biogenesis potently inhibits myogenic differentiation ${ }^{17,19}$. This demonstrates that mitochondria display a retrograde signalling to regulate their own biogenesis as well as cell cycle progression ${ }^{20}$, which subsequently implies that the investigation of myogenic differentiation is inevitably coupled to studying the process of mitochondrial biogenesis.

Although markers of OXPHEN (including mitochondrial biogenesis) during myogenesis have been described previously ${ }^{16,17,20-23}$, information about the expression profile of key regulators during the entire myogenic program is incomplete. Therefore, the aim of the present study was to chart the development of multiple aspects of mitochondrial biogenesis during the full length of the differentiation process of skeletal muscle cells in order to increase our understanding of the key regulatory molecules of OXPHEN during myogenesis.

\section{Materials and methods}

\section{Cell culture}

The murine skeletal muscle cell line $\mathrm{C} 2 \mathrm{C} 12$ was obtained from the American Type Culture Collection (ATCC CRL1772; Manassas, VA, USA). These cells are able to undergo differentiation into spontaneously contracting myotubes after growth factor withdrawal ${ }^{24}$. Myoblasts were cultured in growth medium (GM) composed of low-glucose Dulbecco's Modified Eagle's medium (DMEM) containing antibiotics (50 U/ml penicillin and $50 \mu \mathrm{g} / \mathrm{ml}$ streptomycin) and $9 \%$ $(\mathrm{v} / \mathrm{v})$ foetal bovine serum (FBS) (all from GIBCO, Rockville, MD, USA). Cells were plated at $10^{4}$ cells $/ \mathrm{cm}^{2}$ and cultured in GM for $24 \mathrm{~h}$. To induce differentiation, cells were washed in Hank's Balanced Salt solution (HBSS) and GM was replaced with differentiation medium (DM), which contained DMEM with $0.5 \%$ heat-inactivated FBS and antibiotics. $\mathrm{C} 2 \mathrm{C} 12$ cells were grown on Matrigel (BD Biosciences, Bedford, MA, USA) (1:50 in DMEM) (Becton Dickinson Labware, Bedford, MA, USA), which contains constituents of the natural extracellular matrix of skeletal muscle fibers including collagen IV, laminin, heparin sulfate proteoglycan and entactin. 


\section{Transfections and plasmids}

For assessment of PPAR-dependent transcriptional activity, C2C12 cells were stably transfected with a PPAR-sensitive luciferase reporter plasmid containing 3 PPAR responsive elements in tandem derived from the promoter region of the acyl CoA oxidase (ACO) gene (pSG5, Stratagene, La Jolla, CA, USA). Cells were grown to $70 \%$ confluency and transfected by Lipofectamine according to manufacturer's instructions (Invitrogen, Carlsbad, CA, USA). Transfection was performed in the presence of $3.75 \mu \mathrm{g}$ ACO luciferase plasmid DNA (pSG5, Stratagene) and $0.25 \mu \mathrm{g}$ of a plasmid containing the neomycin resistance gene (pSV2-Neo, Stratagene). For selection of positive clones, cells were cultured in GM containing $800 \mu \mathrm{g} / \mathrm{ml} \mathrm{G418} \mathrm{(Calbiochem,} \mathrm{Nottingham,}$ United Kingdom).

\section{May-Grunwald Giemsa staining}

As a morphological parameter of differentiation, the myogenic index was defined as the number of nuclei residing in cells containing three or more nuclei divided by the total number of nuclei in May-Grunwald Giemsa stained cells. Cells were grown on Matrigel-coated $60 \mathrm{~mm}$ dishes and differentiation was induced. After 0,3 or 7 days of differentiation cells were washed $2 x$ in phosphate buffered saline (PBS) (room temperature), fixed in methanol and stained in May-Grunwald Giemsa (Sigma, Saint Louis, MO, USA) according to manufacturer's instructions.

\section{Reporter assays}

The PPAR-sensitive reporter cell line was plated in $35 \mathrm{~mm}$ dishes and allowed to grow to $70 \%$ confluency. After induction of differentiation (day 0), cells were differentiated into myotubes for 3, 5 or 7 days after which cells were harvested. Cells were washed $2 x$ with cold PBS and subsequently lysed by adding (100 ul) 1x Reporter Lysis Buffer (Promega, Madison, WI, USA) and incubation on ice for $10 \mathrm{~min}$. Cell lysates were centrifuged (13 $000 \mathrm{~g}, 1 \mathrm{~min})$, and supernatants were snap-frozen and stored at $-80{ }^{\circ} \mathrm{C}$ for later analysis. Luciferase activity was measured according to manufacturer's instructions (Promega) and corrected for total protein content (Biorad, Hercules, CA, USA).

\section{Real time quantitative PCR (QPCR)}

Total RNA was extracted using the acid guanidium thiocyanate-phenolchloroform extraction method (Ambion Ltd., ljssel, The Netherlands). RNA concentration was determined using a spectrophotometer. One $\mu \mathrm{g}$ of RNA per sample was reverse transcribed into cDNA according to the manufacturer's instructions (Reverse-iT ${ }^{\mathrm{TM}}$ 1st strand synthesis, Abgene, Leusden, The 
Netherlands). cDNA was PCR amplified with SYBR Green Fluorescein Mix (Westburg, Leusden, The Netherlands) on a Biorad PCR apparatus (Biorad). Specificity of the amplification was verified by melt curve analysis and evaluation of efficiency of PCR amplification. Primers were designed to generate a PCR amplification product of 100 to $150 \mathrm{bp}$ (Table 3.1). Transcript levels for the constitutive housekeeping gene products cyclophilinA, Hypoxanthine phosphoribosyltransferase (HPRT), $\beta$-actin and Glyceraldehyde 3-phosphate dehydrogenase (GAPDH) were quantitatively measured in each sample to control for sample-to-sample differences in RNA concentration. Additionally, geNorm software was applied to calculate a normalisation factor based on the expression levels of these 4 housekeepers. geNorm calculates the gene expression stability measure $M$ for a reference gene as well as the average pairwise variation $V$ for that gene with all other tested reference genes. Stepwise exclusion of the gene with the highest $M$ value allows ranking of the tested genes according to their expression stability. The underlying principles and calculations are described in Vandesompele et al. ${ }^{25}$. Gene expression was quantified and expressed as arbitrary units (AU).

Table 3.1 Primer details.

\section{QPCR primer sequences}

\begin{tabular}{lll} 
Primer & \multicolumn{1}{c}{ Forward 5'-3' } & \multicolumn{1}{c}{ Reverse 5'-3' } \\
\hline PPAR- $\alpha$ & AGTGCCCTGAACATCGAGTGT & AAGCCCTTACAGCCTTCACATG \\
PPAR- $\delta$ & GAGCAAGTGGCCACGGGTGAC & CCACCTGAGGCCCATCACAG \\
PPAR-y & TGGGGATGTCTCACAATGCCA & TTCCTGTCAAGATCGCCCTCG \\
PGC-1a & AAACCACACCCACAGGATCAG & TCTTCGCTTTATTGCTCCATGA \\
Tfam & CGGAGTTCCCACGCTGG & CCGTCCGGTTCGTCTCAC \\
NRF-1 & CCTCCAAACCTGCATCTCAC & TCGCACCACATTCTCCAAAG \\
COXVa & TGCGAGCATGTAGACGGTTAAAT & GAGGTCCTGCTTTGTCCTTAACA \\
COXVIIC & GGCCAGAGTATCCGGAGGTT & CCACTGAAAATGGCAAATTCTTC \\
COXII & CCATCCCAGCCCGACTAA & ATTTCAGAGCATTGGCCATAGAA \\
COXIII & GGTCTCGGAAGTATTTTTCTTTGC & CAGCAGCCTCCTAGATCATGTG \\
CyclophilinA & TTCCTCCTTTCACAGAATTATTCCA & CCGCCAGTGCCATTATGG \\
GAPDH & CAACTCACTCAAGATTGTCAGCAA & TGGCAGTGATGGCATGGA \\
HPRT & TGGATATGCCCTTGACTATAATGAGTAC & AGGACTCCTCGTATTTGCAGATTC \\
$\beta$-actin & CTGAATGGCCCAGGTCTGA & CCCTCCCAGGGAGACCAA \\
\hline
\end{tabular}

Peroxisome proliferator-activated receptor: PPAR; PPAR-y co-activator 1 alpha: PGC-1a; Mitochondrial transcription factor A: Tfam; Nuclear respiratory factor 1: NRF-1; Cytochrome $c$ oxidase: COX; Glyceraldehyde 3-phosphate dehydrogenase: GAPDH; Hypoxanthine phosphoribosyltransferase: HPRT. 


\section{Western blotting}

Abundance of proteins involved in oxidative phosphorylation (OXPHOS) as well as myosin heavy chain (MyHC) protein content was evaluated by Western blotting. Cells were washed in PBS and whole cell lysates were prepared by the addition of lysis buffer $(20 \mathrm{mM}$ Tris, $150 \mathrm{mM} \mathrm{NaCl}, 1 \%(\mathrm{v} / \mathrm{v})$ Nonidet P-40, 1 $\mathrm{mM}$ DTT, $1 \mathrm{mM} \mathrm{Na} \mathrm{VO}_{4}, 1 \mathrm{mM}$ PMSF, $10 \mu \mathrm{g} / \mathrm{ml}$ leupeptin, and $1 \%(\mathrm{v} / \mathrm{v})$ aprotenin). Lysates were incubated on ice for $30 \mathrm{~min}$, followed by $30 \mathrm{~min}$ of centrifugation at $13000 \mathrm{~g}$. A fraction of the supernatant was saved for protein determination and $4 \times$ Laemmli sample buffer $(0.25 \mathrm{M}$ Tris. $\mathrm{HCl}$; $\mathrm{pH} 6.8,8 \%$ $(\mathrm{w} / \mathrm{v})$ SDS, $40 \%(\mathrm{v} / \mathrm{v})$ glycerol, $0.4 \mathrm{M} \mathrm{DTT}$, and $0.04 \%(\mathrm{w} / \mathrm{v})$ bromophenol blue) was added, followed by boiling of the samples for $5 \mathrm{~min}$ and storage at $-20^{\circ} \mathrm{C}$. Total protein was assessed using the Biorad DC protein assay kit (Biorad) according to the manufacturer's instructions. $25 \mu \mathrm{g}$ or $2 \mu \mathrm{g}$ of protein (OXPHOS and $\mathrm{MyHC}$ respectively) was loaded per lane and separated on a $10 \%$ polyacrylamide gel (Mini Protean 3 system; Biorad), followed by transfer to a $0.45 \mu \mathrm{m}$ nitrocellulose membrane (Biorad) by electro blotting. The membrane was blocked for $1 \mathrm{~h}$ at room temperature in $5 \%(\mathrm{w} / \mathrm{v})$ non-fat dry milk. Nitrocellulose blots were washed in PBS-Tween 20 (0.05\%), followed by overnight incubation $\left(4^{\circ} \mathrm{C}\right)$ with a polyclonal antibody specific for OXPHOS proteins (Cell Signaling, Beverly, MA, USA) or MyHC fast or slow (Sigma). After three wash steps of 20 min each, the blots were probed with a peroxidaseconjugated secondary antibody (Vector Laboratories, Burlingame, CA, USA) and visualised using SuperSignal West Pico chemiluminescent substrate (Pierce Biotechnology, Rockford, IL, USA) according to the manufacturer's instructions.

\section{Enzyme activity assay}

Cells were washed twice in ice-cold PBS and subsequently lysed by $10 \mathrm{~min}$ incubation with $200 \mu \mathrm{l}$ of $0.1 \%$ Triton-X100 dissolved in PBS. Cells were harvested by scraping, using rubber policemen, and transferred to an Eppendorf tube containing $45 \mu \mathrm{l} \mathrm{5 \%}$ bovine serum albumine (BSA). After vortexing for $10 \mathrm{sec}$, samples were centrifuged $\left(10 \mathrm{~min}, 13000 \mathrm{~g}, 4^{\circ} \mathrm{C}\right)$, and the supernatant was used for spectrophotometrical assessment of the following enzyme activities: HAD; EC 1.1.1.35; see Ref. ${ }^{26}$, CS; EC 2.3.3.1 ;see Ref. ${ }^{26}$ and CK; EC2.7.3.2 see Ref. ${ }^{27}$ ) (Multiskan Spectrum; Thermo Labsystems, Breda, The Netherlands). Enzyme activities were corrected for total protein content (Biorad). 


\section{Mitochondrial respiration}

C2C12 myoblasts or differentiated myotubes were harvested in trypsin, washed twice with MIRO5 respiration medium $\left(37^{\circ} \mathrm{C}\right)$ (prepared according to MiPNet protocols) (Oroboros Instruments, Innsbruck, Austria) and, after a 5 min centrifugation at $500 \mathrm{~g}$, resuspended in $2.0 \mathrm{ml}$ of MIRO5 respiration medium. Protein content was determined in dishes that were cultured in a parallel experiment. Measurement of respiration was performed by a polarographic oxygen sensor in a $2 \mathrm{ml}$ glass chamber of the respirometer Oxygraph $2 \mathrm{~K}$ (Oroboros Instruments). The amplified signal from the oxygen sensor was recorded on a computer at sampling intervals of 2 seconds using DatLab acquisition software (Oroboros Instruments). The respiration medium was equilibrated with air at $37^{\circ} \mathrm{C}$ and stirred until a stable signal was obtained for calibration at air saturation. After calibration the medium was replaced by aerated cell suspensions at a volume of $2.0 \mathrm{ml}$. After insertion, cells were permeabilised using $1 \mu \mathrm{l}$ of digitonin $(0.5 \mu \mathrm{g} / \mathrm{ml}$ final concentration) and substrates were added in chronological order (volume; final concentration): malate $(5 \mu \mathrm{l} ; 2 \mathrm{mM})$, followed by glutamate $(10 \mu \mathrm{l} ; 10 \mathrm{mM})$ or pyruvate $(5 \mu \mathrm{l}$; $5 \mathrm{mM})$ or palmitoyl-carnitine $(10 \mu \mathrm{l} ; 50 \mu \mathrm{M})$ followed by ADP $(20 \mu \mathrm{l} ; 5 \mathrm{mM})$. At the end of the substrate trace a titration with the uncoupling agent FCCP was performed (1 $\mu \mathrm{l} ; 0.5 \mu \mathrm{M}$ titration). Oxygen consumption (pmol/ml.s) was calculated as a negative time derivative of oxygen concentration $(\mathrm{nmol} / \mathrm{ml})$. Respiration rates were corrected for total protein content to correct for variability in cellular input.

\section{Mitochondrial DNA copy number}

Mitochondrial DNA (mtDNA) copy number was determined as a marker for mitochondrial density using QPCR. Total DNA was isolated from the cells according to manufacturer's instructions (Nucleospin, Machery Nagel, Ede, The Netherlands). A serial dilution standard curve was prepared from a pool of all the samples. Real-time PCR was carried out at the following parameters: 15 min denaturation step at $95^{\circ} \mathrm{C}$, followed by 40 cycles at $95^{\circ} \mathrm{C}$ for $15 \mathrm{sec}$ and $60^{\circ} \mathrm{C}$ for $45 \mathrm{sec}, 30 \mathrm{sec}$ at $95^{\circ} \mathrm{C}$ and $30 \mathrm{sec}$ at $60^{\circ} \mathrm{C}$ followed by a stepwise increase of $0.5^{\circ} \mathrm{C}$ until $95^{\circ} \mathrm{C}$ was reached (melt curve analysis). Mitochondrial DNA copy number was calculated from the ratio COXII/cyclophilinA or COXIII/cyclophilinA.

\section{Statistical analysis}

Data was analysed according to the guidelines of Altman et al. using SPSS (Statistical Package for the Social sciences, SPSS Inc., Chicago, IL, USA) ${ }^{28}$. Kruskal-Wallis tests were applied for mean comparisons as a function of time and non-parametric tests were used to detect significant differences between 
individual time-points. Data are represented as the mean \pm SD. A two-tailed probability value of less than 0.05 was considered to be significant.

\section{Results}

\section{Markers of myogenic differentiation}

In order to characterise myogenic differentiation of $\mathrm{C} 2 \mathrm{C} 12$ cells we compared biochemical and structural markers of differentiation in myoblasts vs differentiating/differentiated myotubes. Results are summarised in Table 3.2 and are illustrative of good morphological and biochemical differentiation.

Table 3.2 Parameters of myogenic differentiation.

\begin{tabular}{lccc}
\hline & Myoblasts & Myotubes (day 3) & Myotubes (day 7) \\
\hline MyHC fast (AU) & 0 & $1.7 \pm 0.4^{*}$ & $3.9 \pm 0.6^{*}$ \\
CK (U/mg protein) & $0.010 \pm 0.003$ & $0.081 \pm 0.023^{*}$ & $0.734 \pm 0.087^{*}$ \\
Myogenic index & 0 & $0.22 \pm 0.04^{*}$ & $0.51 \pm 0.08^{*}$ \\
\hline
\end{tabular}

Values are expressed as mean \pm SD from 3 independent experiments. Significance of difference compared to myoblasts: * $p<0.001$. MyHC: myosin heavy chain; CK: creatine kinase; Myogenic index: the number of nuclei residing in cells containing three or more nuclei divided by the total number of nuclei in May-Grunwald Giemsa stained cells.

\section{Mitochondrial respiration in myoblasts and myotubes}

To investigate the development of oxidative capacity during $\mathrm{C} 2 \mathrm{C} 12$ myogenesis, we measured mitochondrial $\mathrm{O}_{2}$ consumption in proliferating C2C12 myoblasts and differentiated myotubes (differentiated 7 days) in response to different substrates. As depicted in Figure 3.1, basal respiratory rate was higher in myotubes when compared to myoblasts in the presence of endogenous substrates (basal respiration) $(p=0.050)$. FCCP-induced respiration (maximal respiration), bypassing respiratory control by ATPase and thus reflecting maximal respiratory capacity, was 4 -fold higher in myotubes compared to myoblasts $(p=0.050)$. Shown in Figure 3.1 is the maximal respiratory capacity with palmitoyl-carnitine as a substrate. Differences in maximal respiratory capacity between myoblasts and myotubes were similar when other substrates were used (glutamate and pyruvate respectively, data not shown). 


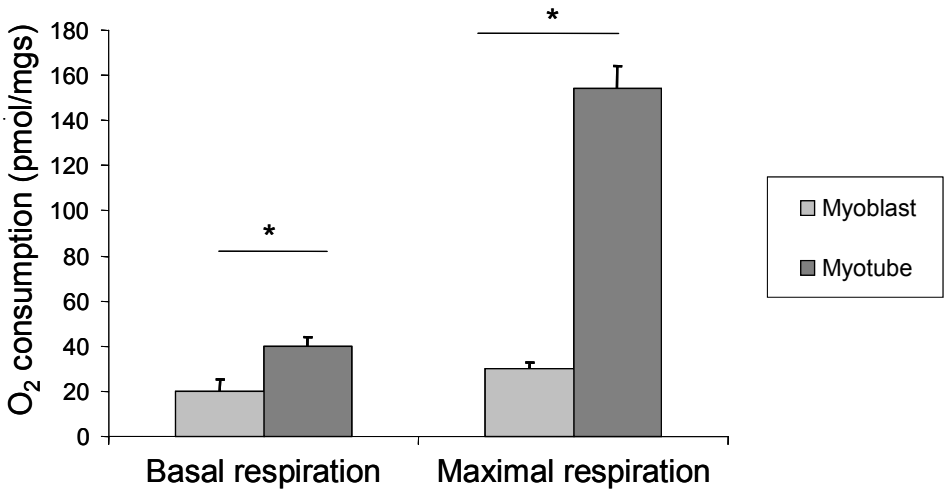

Figure 3.1 Mitochondrial respiration in $\mathrm{C2C} 12$ myoblasts vs differentiated myotubes. Mitochondrial respiration was measured in proliferating myoblasts and in myotubes which were differentiated for 7 days in DM. Cells were harvested and oxygen consumption was measured. Basal respiration (on endogenous substrates) was determined after adding the cells to the chambers. After permeabilisation with digitonin $(1 \mu \mathrm{l} ; 0.5 \mu \mathrm{g} / \mathrm{ml})$, the following substrates were added to the cells: malate $(5 \mu \mathrm{l} ; 2 \mathrm{mM})$, glutamate $(10 \mu \mathrm{l} ; 10 \mathrm{mM})$ or pyruvate $(5 \mu \mathrm{l} ; 5 \mathrm{mM})$ or palmitoylcarnitine $(10 \mu \mathrm{l} ; 50 \mu \mathrm{M})$ followed by ADP $(20 \mu \mathrm{l} ; 5 \mathrm{mM})$ and oligomycin $(1 \mu \mathrm{l} ; 1.66$ $\mu \mathrm{g} / \mathrm{ml})$. Maximal respiration was determined after titration with FCCP $(1 \mu \mathrm{l} ; 0.5 \mu \mathrm{M}$ titration). Respiration rates were corrected for total protein content. Data are represented as mean \pm SD for 3 independent experiments. Oxygen consumption is given in $\mathrm{pmol} / \mathrm{mg} \cdot \mathrm{s}$. Significance of difference: ${ }^{*} \mathrm{p} \leq 0.050$.

\section{Mitochondrial markers during myogenesis}

To gain insight in mitochondrial functioning and mitochondrial biogenesis during differentiation of $\mathrm{C} 2 \mathrm{C} 12$ cells into mature myotubes, we measured several mitochondrial markers. These included activity levels of enzymes involved in substrate oxidation, to assess functionality of the citric acid cycle and fatty acid $\beta$-oxidation pathway, structural components of the respiratory chain (OXPHOS) and mtDNA copy number as a general marker for mitochondrial content. Additionally, we also investigated mRNA transcript levels of cytochrome $c$ oxidase (COX) subunits II and III (mitochondrialencoded) and subunits $\mathrm{Va}$ and VIIc (nuclear-encoded). Activity levels of enzymes involved in oxidative metabolism, CS (Krebs cycle) and HAD ( $\beta$-oxidation), increased approximately 4-fold during myogenesis $(p=0.016)$ (Figure 3.2A). Accordingly, protein levels of all investigated complexes of the respiratory chain increased up to 8-fold $(p=0.019,0.023,0.021$ and 0.016 for complex I, II, III and $\mathrm{V}$ respectively) (Figure 3.2B) while mtDNA copy number was 4-fold higher in fully differentiated myotubes compared to myoblasts $(p=0.025)$ (Figure 3.2C). As illustrated in Figure 3.2D, transcript levels of the mitochondrial-encoded subunits $\mathrm{COX} \mathrm{II}$ and COX III as well as the nuclearencoded subunits $\mathrm{Va}$ and VIlc increased during differentiation $(p=0.023$ and 0.026 respectively). 

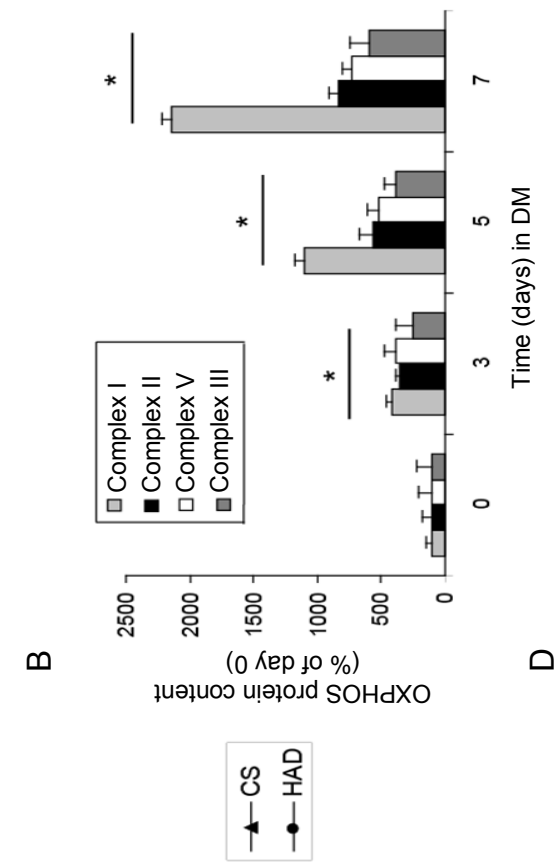

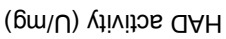

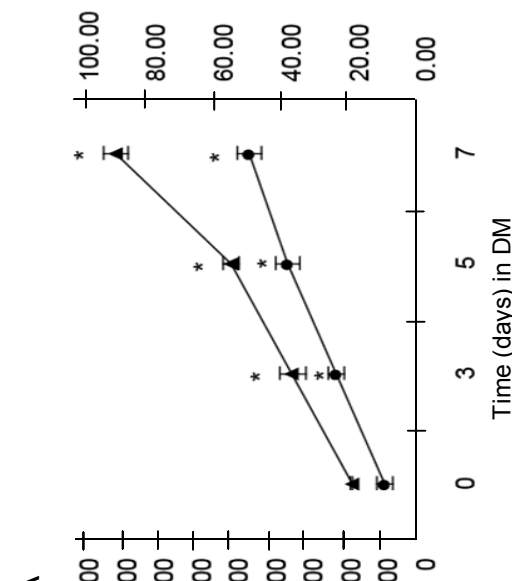

(6m/n) К१!ı!ฺJe so
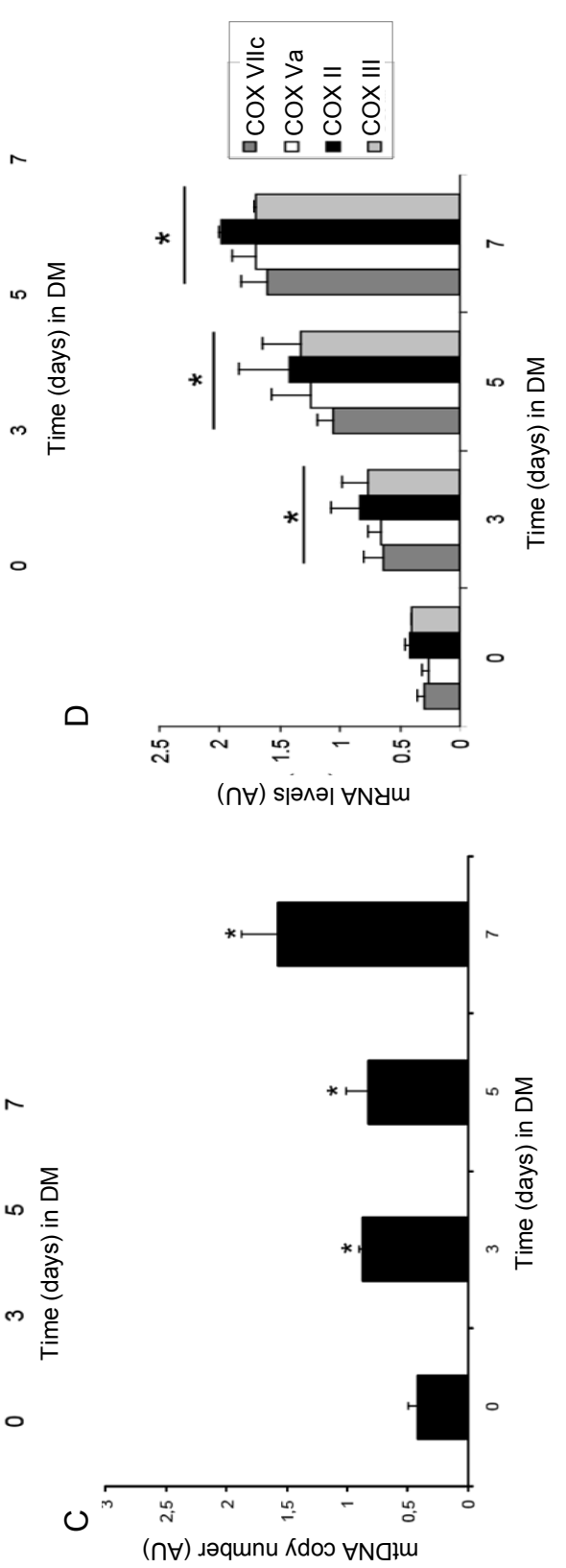

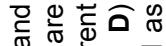

กิ

万人

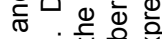

ज

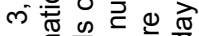

$0.5 \frac{0}{0}>\overline{0}$

ते है

능 $\frac{1}{0}$ 준

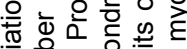

है

क

告

이워웡

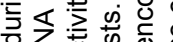

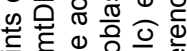

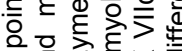

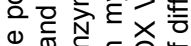

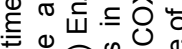

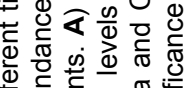

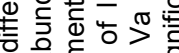

ส

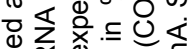

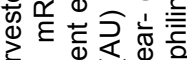

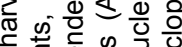

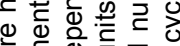

ऐ)

की

这

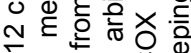

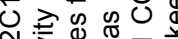

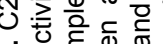

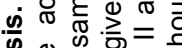

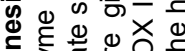

这苋 ๗

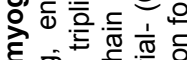

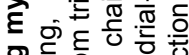

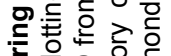

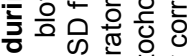

농 +1 के

Ð

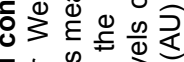

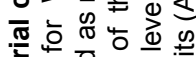

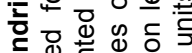

워ㅇㅝㅔ Ð

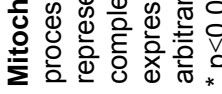

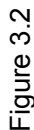




\section{Myosin heavy chain isoform protein content during myogenesis}

To assess the distribution of $\mathrm{MyHC}$ isoforms during myogenesis, we investigated protein levels of MyHC fast (type II) and MyHC slow (type I) isoforms in $\mathrm{C} 2 \mathrm{C} 12$ cells. MyHC protein levels are expressed as the ratio between the slow and fast isoform. Myoblasts expressed extremely low levels of both $\mathrm{MyHC}$ fast and slow isoforms whereas differentiated myotubes expressed significant amounts of both isoforms. During differentiation a relative higher increase in MyHC slow isoform was observed compared to MyHC fast isoform expression $(p=0.025)$ (Figure 3.3).

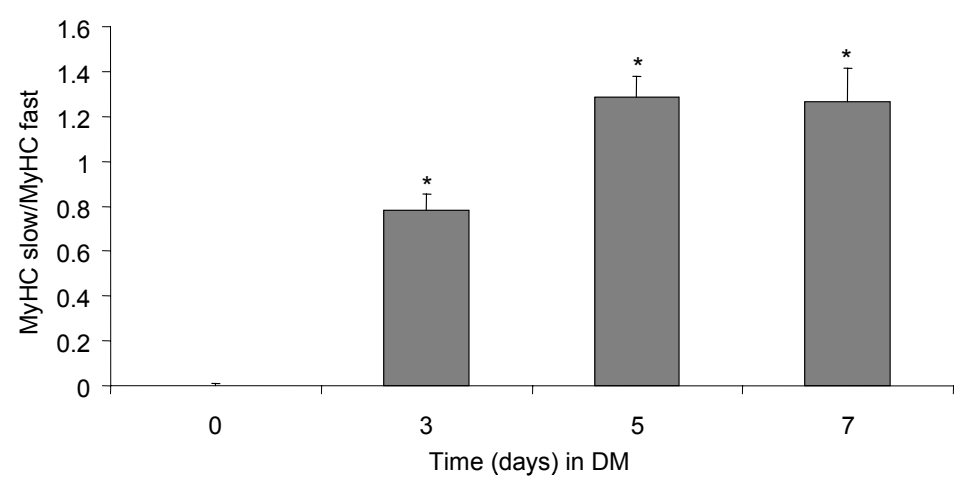

Figure 3.3 Myosin heavy chain (MyHC) distribution in $\mathrm{C2C} 12$ cells during differentiation. C2C12 cells were harvested at different time points during differentiation (day 0,3 , 5 and 7) and $\mathrm{MyHC}$ isoform protein levels were quantified by Western blot analysis. Protein levels of $\mathrm{MyHC}$ isoforms were corrected for total protein content. Data are represented as mean \pm SD from triplicate samples from 3 independent experiments. Protein levels are given as arbitrary units (AU). Quantified MyHC protein levels are expressed as the ratio between the slow and fast isoform. Significance of difference compared to myoblasts (day 0 ): * $p \leq 0.050$. 


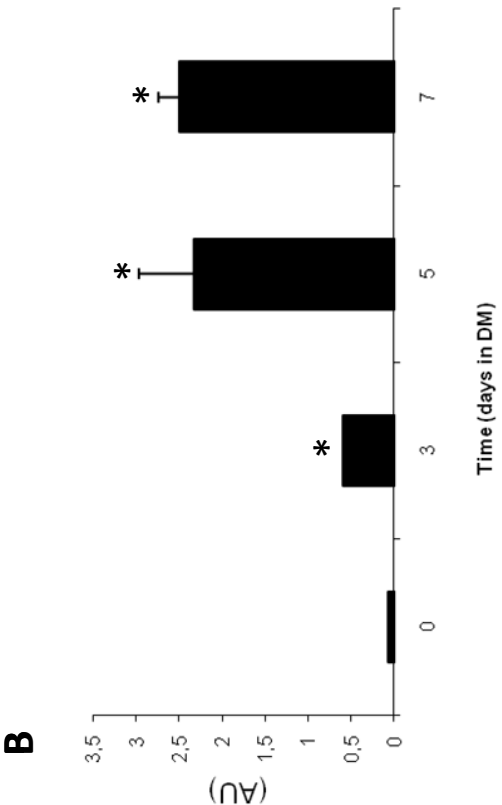

$\forall N y$ m $\mathrm{p}-\mathrm{y} \forall d d$

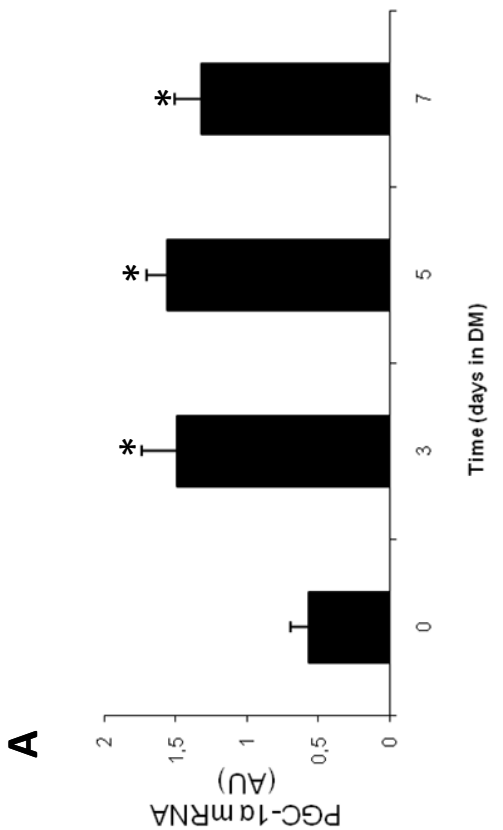

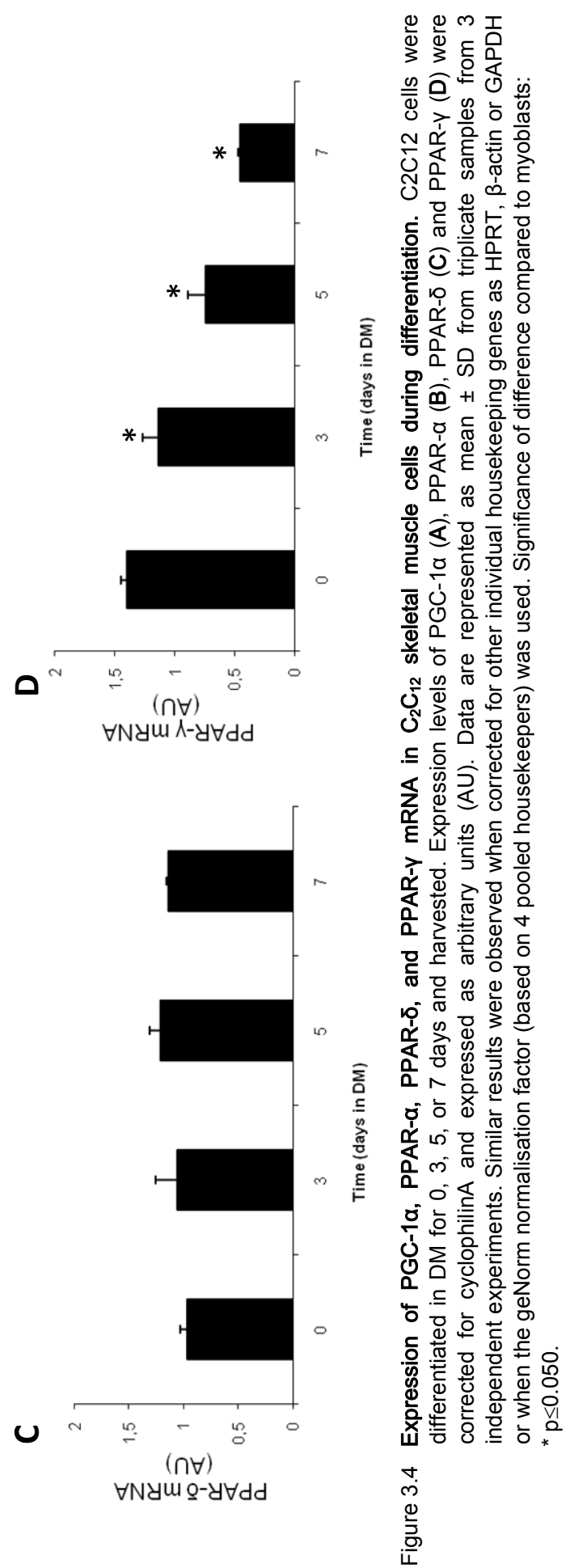




\section{PPARs and related factors during differentiation}

We determined mRNA transcript levels of PGC-1 $\alpha$ and all PPAR isotypes at different time points during the differentiation process. As illustrated in Figure 3.4, PGC-1 $\alpha$ and PPAR- $\alpha$ mRNA expression levels increased $(p=0.063$ and 0.024 respectively) while PPAR-y showed decreased mRNA expression levels during differentiation $(p=0.016)$. PPAR- $\delta$ mRNA expression levels were stable during the full myogenic program. Data was corrected for a normalisation factor derived from a geNorm analysis of 4 housekeepers (cyclophilinA, $\beta$-actin, GAPDH and HPRT). The average expression stability (M-value) for cyclophilinA, $\beta$-actin, GAPDH and HPRT was $0.473,0.987,0.688$ and 0.470 respectively. Pairwise comparison for inclusion of a fourth housekeeping gene (V3/4) was 0.244 indicating preferable use of 4 housekeeping genes. It must be mentioned that expression levels of all 4 investigated housekeeping genes decreased approximately 2 -fold during differentiation of $\mathrm{C} 2 \mathrm{C} 12$ cells (data not shown). However, similar patterns of expression of all genes of interest were observed when data was corrected for any of the 4 individual housekeepers or when correction based on the geNorm normalisation factor was applied. In addition to the PPARs and their co-activator PGC-1 $\alpha$, mRNA levels of 2 key regulators of mitochondrial biogenesis downstream of PGC-1a (NRF-1 and Tfam), were also determined during the myogenic program of $\mathrm{C} 2 \mathrm{C} 12$ cells. Tfam and NRF-1 mRNA expression levels increased from day 0 until day 3 of the differentiation process and remained increased for the duration of the differentiation process ( $p=0.096$ and 0.024 respectively) (Figure 3.5). Data corrected for the housekeeper cyclophilinA is shown as a representative housekeeper, but similar results were obtained with all other individual housekeeping genes as well as with the geNorm normalisation factor.

\section{PPAR-dependent transcriptional activity}

The PPARs as well as PGC-1 $\alpha$ are highly implicated in the regulation of skeletal muscle oxidative capacity ${ }^{9,10,13}$. Therefore, we investigated PPARdependent transcriptional activity during differentiation of $\mathrm{C} 2 \mathrm{C} 12$ cells into multi-nucleated myotubes. As depicted in Figure 3.6, PPAR-dependent transcriptional activity increased during differentiation $(p=0.022)$. 
A
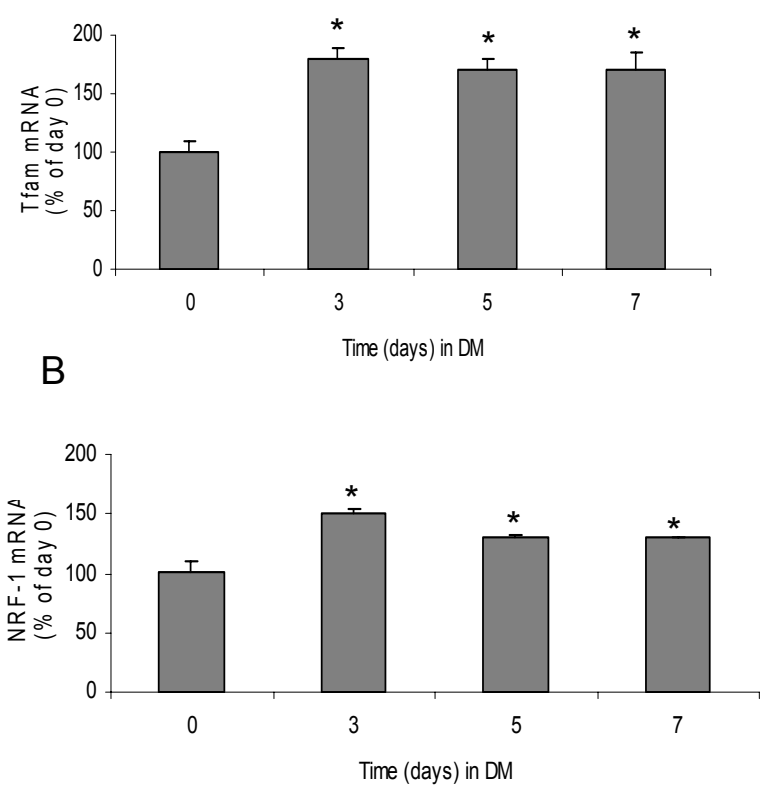

Figure 3.5 Expression of Tfam and NRF-1 mRNA in C2C12 skeletal muscle cells during differentiation. Cells were differentiated in DM for $0,3,5$, or 7 days and harvested. Expression levels of Tfam (A) and NRF-1 (B) were corrected for cyclophilinA as a representative housekeeper. Expression levels are expressed as \% of day 0 . Data are represented as mean \pm SD from triplicate samples from 3 independent experiments. Similar results were observed when corrected for individual housekeeping genes as HPRT, $\beta$-actin or GAPDH or when the geNorm normalisation factor based on 4 different housekeepers was used. Significance of difference compared to myoblasts: * $p \leq 0.050$.

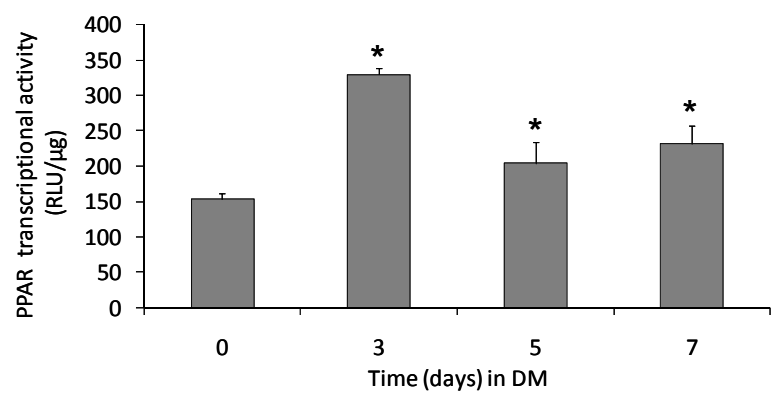

Figure 3.6 PPAR-dependent transcriptional activity in $\mathrm{C2C12}$ skeletal muscle cells during differentiation. $\mathrm{C} 2 \mathrm{C} 12$ cells stably containing a PPAR sensitive reporter construct were differentiated in DM for $0,3,5$, or 7 days and harvested. Cells were lysed; luciferase activity was determined and normalised to total protein content. Significance of difference compared to myoblasts: * $p \leq 0.050$. Error bars indicate the $\mathrm{SD}$. Shown are the mean \pm SD of 3 independent experiments. 


\section{Discussion}

In the present paper we show that multiple key determinants of OXPHEN develop during myogenic differentiation, which coincides with the initiation of mitochondrial biogenesis and increased expression and activity levels of key regulators of muscle OXPHEN.

\section{Constituents of OXPHEN}

During the process of myogenic differentiation a remarkable morphological transition from myoblasts into multi-nucleated myotubes is observed. In addition, myogenesis is accompanied by an increase in oxidative metabolism as we demonstrate in a detailed manner in the present study. We show an increased mitochondrial respiratory capacity, as well as increased protein content of the complexes of the inner mitochondrial membrane respiratory chain, which is the site of $\mathrm{O}_{2}$ consumption ${ }^{29}$. In addition, we observed increased enzyme activity levels of HAD and CS and more oxidative type 1 MyHC slow protein in myotubes as compared to myoblasts. This is in concordance with previous studies and is illustrative of development of OXPHEN during myogenesis ${ }^{22,30}$. The observed increase in the activity level of CS (established marker of mitochondrial volume) as well as increased mtDNA copy number and increases in different COX mRNA levels confirm increased mitochondrial biogenesis ${ }^{31}$. This data collectively shows that myogenic differentiation of $\mathrm{C} 2 \mathrm{C} 12$ cells is obviously associated with mitochondrial biogenesis. It can however not be excluded that, in addition to mitochondrial biogenesis, alterations in efficiency of mitochondria contribute to an increased mitochondrial capacity during myogenesis.

\section{Regulators of OXPHEN}

Coordination of the nuclear- and mitochondrial genome during mitochondrial biogenesis is regulated by a network of transcription factors including PGC-1 $\alpha$, PPARs, NRF-1 and Tfam ${ }^{32}$. In this signalling pathway, PGC-1 $\alpha$ is the master regulator coordinating PPAR activity levels as well as mitochondrial biogenesis through activation of NRF-1-mediated transcription of Tfam ${ }^{33,34}$. In the present study, PGC-1 $\alpha$ expression increased during myogenesis. The role of PGC-1 $\alpha$ in positive regulation of oxidative capacity and fiber type composition of existing muscle is well established ${ }^{9}$. Our data now also suggests a role for PGC-1 $\alpha$ in the development of OXPHEN during myogenic differentiation. In line with this notion, PGC-1 $\alpha$ mRNA levels increased during mitochondrial biogenesis in a mouse model of skeletal muscle regeneration, although these authors did not demonstrate that the induction of PGC-1a expression was associated with myogenic differentiation or took place in pre-existing muscle fibers ${ }^{22}$. 
The PPARs are known to be strongly involved in the control of genes encoding enzymes of the fatty acid oxidation pathway as e.g. $H A D^{35}$. In concordance, we observed a clear induction of PPAR transcriptional activity and HAD activity during the initiation of myogenic differentiation. To the best of our knowledge, this is the first study investigating PPAR transcriptional activity during skeletal muscle cell differentiation. Typically, PPAR- $\alpha$ and PPAR- $\delta$ are the 2 isoforms most implicated in positive regulation of fatty acid oxidative capacity of skeletal muscle, whereas PPAR- $y$ is the isoform implicated in fatty-acid uptake and storage ${ }^{36-38}$. Therefore, it is conceivable that the increase in PPAR transcriptional activity is mainly due to increased PPAR- $\alpha$ and/or PPAR- $\delta$ transcriptional activity.

In concordance with this suggestion, we found that PPAR-y mRNA levels markedly decreased during differentiation. It has been shown that constitutive high expression levels of PPAR-y in skeletal muscle cells can result in transdifferentiation into adipocytes ${ }^{39}$. On the other hand, low critical levels of PPAR-y expression are required to maintain the ability to differentiate properly ${ }^{36}$. Since $\mathrm{C} 2 \mathrm{C} 12$ cell metabolism during differentiation is directed towards a more developed OXPHEN and PPAR-y is implicated in storage of fatty acids, reduction of PPAR-y expression may be a regulatory mechanism to ensure an adequate development of the oxidative capacity of the cell. In contrast to PPAR- $\gamma$, PPAR- $\alpha$ expression levels increased dramatically in our study. PPAR- $\delta$ mRNA levels on the other hand remained constant during the entire differentiation process despite its clearly established role in regulation and development of skeletal muscle oxidative capacity ${ }^{7,40}$. Kraft et al. previously showed a 10-fold increase in PPAR- $\alpha$ expression levels in differentiating $\mathrm{C} 2 \mathrm{C} 12$ cells, although they only investigated the myogenic program up to 3 days of differentiation ${ }^{23}$. We now show that, in line with enzyme activity data, PPAR- $\alpha$ mRNA expression levels increase until day 5 of differentiation reaching a 40-fold higher level in myotubes compared to myoblasts. To date, no other studies have previously investigated PPAR- $\delta$ expression levels during skeletal muscle differentiation.

The increase in expression levels of PGC-1 $\alpha$ and PPAR- $\alpha$ during differentiation parallels the observed increase in markers of OXPHEN. In addition to their well established role as positive regulators of oxidative capacity of existing muscle fibers $^{9,10,13}$, this therefore also suggests a role for these regulators in the development of oxidative capacity during myogenesis. Although whole-body knock-out PGC-1 $\alpha$ animals only display a $20-30 \%$ reduction in mitochondrial content $^{41,42}$, muscle-specific over-expression of PGC-1a does result in an increase in basal OXPHEN ${ }^{9}$. This implies that PGC-1 $\alpha$ is a potent stimulator of mitochondrial biogenesis but may not always be required. Possibly, other co- 
factors in the PGC-1 $\alpha$ family as PRC and PGC-1 $\beta$ compensate for the loss of PGC-1 $\alpha$ in the PGC-1 $\alpha$ knock-outs ${ }^{43,44}$. It must also be noted that the PGC-1 $\alpha$ knock-out mouse is characterised by physical hyperactivity which may cause exercise-induced mitochondrial biogenesis and potentially obscures any loss of baseline mitochondrial biogenesis ${ }^{45}$. In addition to PGC-1a, our data also suggests a role for PPAR- $\alpha$ in mitochondrial biogenesis. It has been demonstrated that PPAR- $\alpha$ knock-out mice display reduced activity levels of fatty acid oxidation enzymes as HAD, however no loss of other mitochondrial enzymes was observed ${ }^{46}$. Future studies are therefore needed to address the requirement and the exact role of PPAR- $\alpha$ in skeletal muscle mitochondrial biogenesis. In contrast to PGC- $1 \alpha$ and PPAR- $\alpha$, our data suggests that differential expression levels of PPAR- $\delta$ protein are not implicated in the process of mitochondrial biogenesis during myogenic differentiation. This is in line with a recent paper from Kleiner et al. who demonstrated that PPAR- $\delta$ agonism activates fatty acid oxidation, which is confirmed in mice with skeletal muscle-specific PPAR- $\delta$ over-expression ${ }^{7}$, but fails to induce mitochondrial gene expression and function ${ }^{47}$. It can be speculated that PPAR- $\delta$ activation directs the metabolic profile of existing fibers towards a more developed OXPHEN while PGC-1 $\alpha$-mediated PPAR- $\alpha$ activation may regulate development of oxidative capacity in new muscle fibers during myogenesis. Nevertheless, as PPAR- $\delta$ remains a specific regulator of fatty acid oxidation, which is part of the mitochondrial machinery, it still contributes to muscle OXPHEN. In line with a positive role in determining skeletal muscle OXPHEN, increased PGC-1 $\alpha$ and PPAR- $\alpha$ mRNA expression levels during differentiation may mediate the observed increase in transcription of nuclear-encoded constituents of the mitochondrial respiratory chain. Next to being a co-activator for PPARs, PGC-1 $\alpha$ also functions as a co-activator for NRF-1. Subsequently, PGC-1a/NRF-1 induces the expression of Tfam which is the master regulator of mitochondrial biogenesis ${ }^{11}$. In the present study, Tfam and NRF-1 expression levels increased at the onset of differentiation, which is in line with the start of mitochondrial biogenesis in these cells at the beginning of the myogenic program. Since Tfam is a master regulator of the transcription and replication of $m \mathrm{mNA}^{11}$, its observed up-regulation likely mediated the increased mtDNA content during $\mathrm{C} 2 \mathrm{C} 12$ myogenic differentiation. Additionally, we observed increased mRNA levels of mitochondrial-encoded COX subunits which may also result from increased transcription of the mitochondrial genome by Tfam.

In conclusion, in the present paper we describe temporal profiles of a number of key constituents of OXPHEN and mitochondrial capacity during the full myogenic program of $\mathrm{C} 2 \mathrm{C} 12$ myoblasts. We show that expression and activity levels of genes known for their regulatory role in skeletal muscle oxidative 
capabilities parallel the observed increase in oxidative parameters. Based on our results we propose that increased PGC-1 $\alpha$ expression, either directly or through increased PPAR- $\alpha$ expression levels and PPAR transcriptional activity, mediates mitochondrial biogenesis and concurrent up-regulation of skeletal muscle OXPHEN during myogenic differentiation. 


\section{References}

1. Baldwin KM, Haddad F. Skeletal muscle plasticity: cellular and molecular responses to altered physical activity paradigms. Am J Phys Med Rehabil 2002;81:S40-51.

2. Fluck M. Functional, structural and molecular plasticity of mammalian skeletal muscle in response to exercise stimuli. J Exp Biol 2006;209:2239-48.

3. Narici MV, Reeves ND, Morse $\mathrm{Cl}$, Maganaris CN. Muscular adaptations to resistance exercise in the elderly. J Musculoskelet Neuronal Interact 2004;4:161-4.

4. Gosker HR, van Mameren H, van Dijk PJ, Engelen MP, van der Vusse GJ, Wouters EF, Schols AM. Skeletal muscle fibre-type shifting and metabolic profile in patients with chronic obstructive pulmonary disease. Eur Respir J 2002;19:617-25.

5. Anderson JE. The satellite cell as a companion in skeletal muscle plasticity: currency, conveyance, clue, connector and colander. J Exp Biol 2006;209:2276-92.

6. Le Grand F, Rudnicki MA. Skeletal muscle satellite cells and adult myogenesis. Curr Opin Cell Biol 2007;19:628-33.

7. Luquet S, Lopez-Soriano J, Holst D, Fredenrich A, Melki J, Rassoulzadegan M, Grimaldi PA. Peroxisome proliferator-activated receptor delta controls muscle development and oxidative capability. Faseb J 2003;17:2299-301.

8. Koves TR, Li P, An J, Akimoto T, Slentz D, Ilkayeva O, Dohm GL, Yan Z, Newgard CB, Muoio DM. Peroxisome proliferator-activated receptor-gamma co-activator 1alpha-mediated metabolic remodeling of skeletal myocytes mimics exercise training and reverses lipidinduced mitochondrial inefficiency. J Biol Chem 2005;280:33588-98.

9. Lin J, Wu H, Tarr PT, Zhang CY, Wu Z, Boss O, Michael LF, Puigserver P, Isotani E, Olson EN, Lowell BB, Bassel-Duby R, Spiegelman BM. Transcriptional co-activator PGC-1 alpha drives the formation of slow-twitch muscle fibres. Nature 2002;418:797-801.

10. Wang YX, Zhang CL, Yu RT, Cho HK, Nelson MC, Bayuga-Ocampo CR, Ham J, Kang H, Evans RM. Regulation of muscle fiber type and running endurance by PPARdelta. PLoS Biol 2004;2:e294.

11. Gleyzer N, Vercauteren K, Scarpulla RC. Control of mitochondrial transcription specificity factors (TFB1M and TFB2M) by nuclear respiratory factors (NRF-1 and NRF-2) and PGC-1 family coactivators. Mol Cell Biol 2005;25:1354-66.

12. Wu Z, Puigserver P, Andersson U, Zhang C, Adelmant G, Mootha V, Troy A, Cinti S, Lowell $B$, Scarpulla RC, Spiegelman BM. Mechanisms controlling mitochondrial biogenesis and respiration through the thermogenic coactivator PGC-1. Cell 1999;98:115-24.

13. Cantó C, Pich S, Paz JC, Sanches R, Martínez V, Orpinell M, Palacín M, Zorzano A, Gumà A. Neuregulins increase mitochondrial oxidative capacity and insulin sensitivity in skeletal muscle cells. Diabetes 2007;56:2185-93.

14. Oexle K, Kohlschutter A. Cause of progression in Duchenne muscular dystrophy: impaired differentiation more probable than replicative aging. Neuropediatrics 2001;32:123-9.

15. Wallace GQ, McNally EM. Mechanisms of muscle degeneration, regeneration, and repair in the muscular dystrophies. Annu Rev Physiol 2009;71:37-57.

16. Duguez S, Sabido O, Freyssenet $\mathrm{D}$. Mitochondrial-dependent regulation of myoblast proliferation. Exp Cell Res 2004;299:27-35.

17. Rochard P, Rodier A, Casas F, Cassar-Malek I, Marchal-Victorion S, Daury L, Wrutniak C, Cabello G. Mitochondrial activity is involved in the regulation of myoblast differentiation through myogenin expression and activity of myogenic factors. J Biol Chem 2000;275: 2733-44.

18. Seyer P, Grandemange S, Busson M, Carazo A, Gamaléri F, Pessemesse L, Casas F, Cabello G, Wrutniak-Cabello $C$. Mitochondrial activity regulates myoblast differentiation by control of c-Myc expression. J Cell Physiol 2006;207:75-86.

19. Herzberg NH, Zwart R, Wolterman RA, Ruiter JP, Wanders RJ, Bolhuis PA, van den Bogert C. Differentiation and proliferation of respiration-deficient human myoblasts. Biochim Biophys Acta 1993;1181:63-7. 
20. Jahnke VE, Sabido O, Freyssenet D. Control of mitochondrial biogenesis, ROS level, and cytosolic $\mathrm{Ca} 2+$ concentration during the cell cycle and the onset of differentiation in L6E9 myoblasts. Am J Physiol Cell Physiol 2009;296:C1185-94.

21. Moyes CD, Mathieu-Costello OA, Tsuchiya N, Filburn C, Hansford RG. Mitochondrial biogenesis during cellular differentiation. Am J Physiol 1997;272:C1345-51.

22. Duguez S, Féasson L, Denis $C$, Freyssenet $D$. Mitochondrial biogenesis during skeletal muscle regeneration. Am J Physiol Endocrinol Metab 2002;282:E802-9.

23. Kraft CS, LeMoine CM, Lyons CN, Michaud D, Mueller CR, Moyes CD. Control of mitochondrial biogenesis during myogenesis. Am J Physiol Cell Physiol 2006;290:C1119-27.

24. Yaffe D, Saxel O. Serial passaging and differentiation of myogenic cells isolated from dystrophic mouse muscle. Nature 1977;270:725-7.

25. Vandesompele J, De Preter K, Pattyn F, Poppe B, Van Roy N, De Paepe A, Speleman F. Accurate normalization of real-time quantitative RT-PCR data by geometric averaging of multiple internal control genes. Genome Biol 2002;3:RESEARCH0034.

26. Gosker HR, Schrauwen P, Broekhuizen R, Hesselink MK, Moonen-Kornips E, Ward KA, Franssen FM, Wouters EF, Schols AM. Exercise training restores uncoupling protein-3 content in limb muscles of patients with chronic obstructive pulmonary disease. Am J Physiol Endocrinol Metab 2006;290:E976-81.

27. Langen RC, Schols AM, Kelders MC, Wouters EF, Janssen-Heininger YM. Enhanced myogenic differentiation by extracellular matrix is regulated at the early stages of myogenesis. In Vitro Cell Dev Biol Anim 2003;39:163-9.

28. Altman DG, Gore SM, Gardner MJ, Pocock SJ. Statistical guidelines for contributors to medical journals. Br Med J (Clin Res Ed) 1983;286:1489-93.

29. Mathieu-Costello O, Hepple RT. Muscle structural capacity for oxygen flux from capillary to fiber mitochondria. Exerc Sport Sci Rev 2002;30:80-4.

30. Leary SC, Battersby BJ, Hansford RG, Moyes CD. Interactions between bioenergetics and mitochondrial biogenesis. Biochim Biophys Acta 1998;1365:522-30.

31. Kim K, Lecordier A, Bowman LH. Both nuclear and mitochondrial cytochrome $\mathrm{c}$ oxidase mRNA levels increase dramatically during mouse postnatal development. Biochem $\mathrm{J}$ 1995;306:353-8.

32. Butow RA, Bahassi EM. Adaptive thermogenesis: orchestrating mitochondrial biogenesis. Curr Biol 1999;9:R767-9.

33. Baar K. Involvement of PPAR gamma co-activator-1, nuclear respiratory factors 1 and 2 , and PPAR alpha in the adaptive response to endurance exercise. Proc Nutr Soc 2004;63:269-73.

34. Scarpulla RC. Transcriptional activators and coactivators in the nuclear control of mitochondrial function in mammalian cells. Gene 2002;286:81-9.

35. Wang YX, Lee CH, Tiep S, Yu RT, Ham J, Kang H, Evans RM. Peroxisome-proliferatoractivated receptor delta activates fat metabolism to prevent obesity. Cell 2003;113:159-70.

36. Singh J, Verma NK, Kansagra SM, Kate BN, Dey CS. Altered PPARgamma expression inhibits myogenic differentiation in $\mathrm{C} 2 \mathrm{C} 12$ skeletal muscle cells. Mol Cell Biochem 2007;294:163-71.

37. Fredenrich A, Grimaldi PA. Roles of peroxisome proliferator-activated receptor delta in skeletal muscle function and adaptation. Curr Opin Clin Nutr Metab Care 2004;7:377-81.

38. Lefebvre P, Chinetti G, Fruchart JC, Staels B. Sorting out the roles of PPAR alpha in energy metabolism and vascular homeostasis. J Clin Invest 2006;116:571-80.

39. Hu E, Tontonoz P, Spiegelman BM. Transdifferentiation of myoblasts by the adipogenic transcription factors PPAR gamma and C/EBP alpha. Proc Natl Acad Sci U S A 1995;92:9856-60.

40. Luquet S, Gaudel C, Holst D, Lopez-Soriano J, Jehl-Pietri C, Fredenrich A, Grimaldi PA. Roles of PPAR delta in lipid absorption and metabolism: a new target for the treatment of type 2 diabetes. Biochim Biophys Acta 2005;1740:313-7.

41. Leick L, Hellsten Y, Fentz J, Lyngby SS, Wojtaszewski JF, Hidalgo J, Pilegaard H. PGC1\{alpha\} mediates exercise-induced skeletal muscle VEGF expression in mice. Am J Physiol Endocrinol Metab 2009;297:E92-E103. 
42. Leick L, Wojtaszewski JF, Johansen ST, Kiilerich K, Comes G, Hellsten Y, Hidalgo J, Pilegaard H. PGC-1alpha is not mandatory for exercise- and training-induced adaptive gene responses in mouse skeletal muscle. Am J Physiol Endocrinol Metab 2008;294:E463-74.

43. Scarpulla RC. Nuclear control of respiratory chain expression by nuclear respiratory factors and PGC-1-related coactivator. Ann N Y Acad Sci 2008;1147:321-34.

44. Ishii KA, Fumoto $\mathrm{T}$, Iwai K, Takeshita S, Ito M, Shimohata N, Aburatani H, Taketani S, Lelliott CJ, Vidal-Puig A, Ikeda K. Coordination of PGC-1beta and iron uptake in mitochondrial biogenesis and osteoclast activation. Nat Med 2009;15:259-66.

45. Lin J, Wu PH, Tarr PT, Lindenberg KS, St-Pierre J, Zhang CY, Mootha VK, Jäger S, Vianna CR, Reznick RM, Cui L, Manieri M, Donovan MX, Wu Z, Cooper MP, Fan MC, Rohas LM, Zavacki AM, Cinti S, Shulman GI, Lowell BB, Krainc D, Spiegelman BM. Defects in adaptive energy metabolism with CNS-linked hyperactivity in PGC-1alpha null mice. Cell 2004;119: 121-35.

46. Bedu E, Desplanches D, Pequignot J, Bordier B, Desvergne B. Double gene deletion reveals the lack of cooperation between PPARalpha and PPARbeta in skeletal muscle. Biochem Biophys Res Commun 2007;357:877-81.

47. Kleiner S, Nguyen-Tran V, Baré O, Huang X, Spiegelman B, Wu Z. PPAR\{delta\} Agonism Activates Fatty Acid Oxidation via PGC-1\{alpha\} but Does Not Increase Mitochondrial Gene Expression and Function. J Biol Chem 2009;284:18624-33. 


\section{Chapter 4}

\section{Expression and content of PPARs is reduced in skeletal muscle of COPD patients}

Remels AH, Schrauwen P, Broekhuizen R, Willems J, Kersten S, Gosker HR, Schols AM. Peroxisome proliferator-activated receptor expression is reduced in skeletal muscle in COPD.

Eur Respir J 2007;30:245-52 


\section{Abstract}

COPD is a multi-organ systemic disease. Systemic features are skeletal muscle weakness and cachexia, the latter being associated with systemic inflammation. Exact mechanisms underlying skeletal muscle dysfunction in COPD remain obscure. Recent evidence suggests involvement of the peroxisome proliferator-activated receptors (PPARs) and PPAR-y co-activator (PGC-1 $\alpha$ ) in regulation of skeletal muscle morphology and metabolism while the mitochondrial transcription factor A (Tfam) has been implicated in the process of mitochondrial biogenesis. The aim of this exploratory study was therefore to compare these factors in skeletal muscle of 9 healthy control subjects and 14 COPD patients stratified by cachexia. PPAR- $\alpha$, PPAR-y, PPAR- $\delta, P G C-1 \alpha$ and Tfam were measured at the mRNA- and protein level by real time QPCR and western blotting respectively. PPAR- $\delta$ and Tfam protein content as well as PGC-1 $\alpha$ mRNA levels were decreased in skeletal muscle of COPD patients vs healthy controls. The cachectic COPD subgroup was further characterised by decreased PPAR- $\alpha$ mRNA expression and decreased Tfam protein and mRNA levels when compared to non cachectic COPD patients. In addition, PPAR- $\alpha$ mRNA levels in skeletal muscle correlated negatively with inflammatory markers in plasma. Therefore, a disturbed expression and/or content of these regulatory factors may well underlie the disturbed skeletal muscle functioning in COPD. 


\section{Introduction}

Skeletal muscle dysfunction has become a recognised hallmark of chronic obstructive pulmonary disease (COPD). Although it is obvious that impaired lung function inevitably leads to reduced exercise tolerance in this disorder, muscle dysfunction probably is an even stronger determinant of exercise capacity particularly in moderate to severe COPD ${ }^{1}$. Moreover, it has been convincingly shown that muscle wasting is a strong predictor of mortality risk in COPD, independent of the degree of airflow limitation ${ }^{2}$. Because current bronchodilating and anti-inflammatory medication primarily aimed at improving lung function is rather ineffective in reversing exercise intolerance, skeletal muscle function may be an interesting alternative target for novel therapies. Skeletal muscle dysfunction in COPD is characterised by the loss of muscle strength and endurance. The loss of muscle endurance is associated with a type $I \rightarrow|l a \rightarrow| \mid x$ fiber type shift leading to a decreased oxidative phenotype of the muscle ${ }^{3}$. The loss of muscle strength is largely explained by the loss of muscle mass due to cachexia, which is commonly observed in moderate to severe COPD patients ${ }^{4}$. Other abnormalities pointing towards intrinsic muscle abnormalities in COPD pathogenesis are a decreased content of substrates such as specific amino acids, increased oxidative stress and decreased uncoupling protein 3 (UCP-3) content, a mitochondrial protein which serves as a putative protector against lipid induced mitochondrial damage ${ }^{5-7}$. In addition, COPD is also characterised by a chronic systemic low grade inflammatory status, which has been suggested as a trigger for the loss of muscle mass and muscle weakness ${ }^{8,9}$. The exact molecular mechanisms and key mediators that are involved in the loss of muscle strength and endurance in COPD remain to be identified. The peroxisome proliferator-activated receptors (PPARs) as well as PPAR-y co-activator 1 alpha (PGC-1 $\alpha$ ), a strong co-activator of PPAR transcriptional activity, are key regulators of mitochondrial biogenesis and hence of skeletal muscle oxidative capacity ${ }^{10,11}$. Furthermore, they are potent mediators of a fiber type shift from type $\| \rightarrow I$ and have been shown to possess anti-inflammatory properties ${ }^{12,13}$. Based on these findings, we hypothesise that expression and/or content of the PPARs is reduced in skeletal muscle of COPD patients. Therefore, the aim of the current study was to determine expression of the PPARs and PGC-1 $\alpha$ on the mRNA- and protein level in skeletal muscle biopsies of COPD patients pre-stratified by cachexia and healthy control subjects. 


\section{Subjects and methods}

\section{Subjects}

The study population consisted of Dutch patients with clinically stable GOLD stage II-IV COPD $(n=14)$ and a group of healthy age-matched controls $(n=9)$. All patients suffered from chronic airflow limitation, defined as measured forced expiratory volume in 1 second $\left(\mathrm{FEV}_{1}\right)$ less than $70 \%$ of reference. Patients received standardised maintenance respiratory medication that consisted of inhaled bronchodilators, inhaled corticosteroids and, when indicated, theophyllines. Exclusion criteria were concurrent diseases such as malignancies, gastrointestinal or kidney abnormalities, metabolic or endocrine diseases, and inflammatory diseases. Written consent was obtained from all subjects and the study was approved by the ethical review board of the University Hospital Maastricht.

\section{Pulmonary function}

FEV $_{1}$ and forced vital capacity (FVC) were assessed from the flow-volume curve using a spirometer (Masterlab, Jaeger, Würzburg, Germany). Carbon monoxide diffusion factor (DLCO) was determined using the single breath method (Masterlab). Lung functional parameters were expressed as a percentage of reference values. Blood was drawn from the brachial artery to analyse arterial oxygen tension $\left(\mathrm{PaO}_{2}\right)$ and carbon dioxide tension $\left(\mathrm{PaCO}_{2}\right)$ with a blood gas analyser (Radiometer, ABL 330, Copenhagen, Denmark).

\section{Blood sampling}

Fasting blood was collected in evacuated blood collecting tubes containing EDTA (Becton Dickinson Vacutainer Systems, Plymouth, U.K.) in the early morning (08.00-10.00 h). After centrifuging twice at $1000 \mathrm{~g}$ for $10 \mathrm{~min}$ at $4^{\circ} \mathrm{C}$ within $2 \mathrm{~h}$ of collection, plasma samples were stored at $-80^{\circ} \mathrm{C}$ until analysis. Tumour necrosis factor (TNF- $\alpha$ ) was determined with the Quantikine high sensitivity ELISA (R\&D Systems, Minneapolis, U.S.A.) with a lower detection limit of $0.5 \mathrm{pg} / \mathrm{ml}$ for total TNF-a. Soluble TNF-R55 and sTNF-R75 were measured in duplicate by using the ELISA protocol as previously described by Leeuwenberg et al. ${ }^{14}$.

\section{Body composition}

Body mass index (BMI) was calculated as weight divided by height in squared metres $\left(\mathrm{kg} / \mathrm{m}^{2}\right)$. Body composition was measured using single frequency $(50 \mathrm{kHz})$ bioelectrical impedance analysis (BIA; Xitron Technologies, San Diego, CA, USA) with subjects in the supine position. FFM of patients was 
calculated using the disease-specific equation proposed by Schols et al. and described by Steiner et al. ${ }^{15}$. Fat-free mass index (FFMI) and fat mass index (FMI) were calculated as FFM or FM divided by height ${ }^{2}\left(\mathrm{~kg} / \mathrm{m}^{2}\right)$. Cachexia was defined as a BMI $\leq 21 \mathrm{~kg} / \mathrm{m}^{2}$ and FFMI $\leq 16 \mathrm{~kg} / \mathrm{m}^{2}$ for male patients and FFMI $\leq 15 \mathrm{~kg} / \mathrm{m}^{2}$ for female patients.

\section{Collection and processing of muscle tissue}

Post absorptive muscle biopsies of the lateral part of the quadriceps femoris were obtained under local anaesthesia by using the needle biopsy technique. The specimens were immediately snap frozen in liquid nitrogen and stored at $-80^{\circ} \mathrm{C}$ until use. The frozen biopsies were weighed and subsequently homogenised using a Polytron PT 1600 E (Polytron® PT 1600 E, Kinematica AG, Luzern, Swiss).

\section{Muscle fiber type composition}

A 5\% (w/v) homogenate was prepared by dispersion (Polytron® PT $1600 \mathrm{E}$, Kinematica AG, Luzern, Swiss) followed by 1 min sonication (Branson 2210, Branson Ultrasonics Corporation, Danbury, USA) of the tissue in SET buffer (250 mM sucrose, $2 \mathrm{mM}$ EDTA, $10 \mathrm{mM}$ TRIS, pH 7.4). Samples were centrifuged $\left(10 \mathrm{~min}, 10000 \mathrm{~g}, 4^{\circ} \mathrm{C}\right)$. The supernatant was used for determination of citrate synthase (CS) activity as described by Gosker et al. ${ }^{16}$. The remaining pellet was resuspended in three volumes of ice-cold extraction buffer (100 mM Na $\mathrm{O}_{7} \mathrm{P}_{2} \cdot 10 \mathrm{H}_{2} \mathrm{O}, 5 \mathrm{mM}$ EDTA, $1 \mathrm{mM} \mathrm{DTT}$, pH8.5), incubated on ice for $30 \mathrm{~min}$, and centrifuged $\left(10 \mathrm{~min}, 10000 \mathrm{~g}, 4^{\circ} \mathrm{C}\right)$. From this, the supernatant was used for Myosin heavy chain (MyHC) isoform analysis. Gels were run for $22 \mathrm{~h}$ using a Protean II Cell gel electrophoresis system (Biorad, Veenendaal, The Netherlands) at $20 \mathrm{~mA}$ with increasing voltage to a maximum of $350 \mathrm{~V}$. About $1.0 \mu \mathrm{g}$ of protein was loaded per lane. Gels were silver-stained (Silver Stain Plus Kit, Biorad), scanned and photographed with a scanning densitometer (Fluor-S ${ }^{\mathrm{TM}}$ Multilmager, Biorad), after which bands were quantified using Quantity One software (Biorad). I, IIA and IIX MyHC isoforms were expressed proportionally to each other.

\section{Real time quantitative PCR}

Total RNA was extracted using the acid guanidium thiocyanate-phenolchloroform extraction method (Ambion Ltd., United Kingdom). RNA concentration was determined using a spectrophotometer and quality was verified by agarose gel electrophoresis. Two micrograms of RNA per sample were reverse transcribed into cDNA according to the manufacturer's instructions (iScript RT kit Biorad, Hercules, CA, USA). cDNA was PCR 
amplified with Platinum Taq DNA polymerase (Invitrogen, Breda, the Netherlands) on a Biorad iCycler apparatus. Primers were designed to generate a PCR amplification product of 100 to $150 \mathrm{bp}$. Specificity of the amplification was verified by melt curve analysis and evaluation of efficiency of PCR amplification. Transcript levels for the constitutive housekeeping gene product 36B4 were quantitatively measured in each sample to control for sample-to-sample differences in RNA concentration. Gene expression was quantified and expressed as arbitrary units (AU).

\section{Western blot analysis of protein expression}

PPAR- $\delta$ and Tfam protein abundance was evaluated by Western blotting. Muscle biopsies were homogenised in PBS with PMSF $(0.4 \mathrm{mM})$ and EDTA $(1 \mathrm{mM})$ and sonicated $2 \times 10 \mathrm{sec}$ at $12 \mathrm{um}$ and $1 \times 5 \mathrm{sec}$ at $20 \mathrm{um}$. Subsequently, samples were diluted $2: 1$ in sample buffer, containing 2-mercaptoethanol and SDS, and boiled for $5 \mathrm{~min}$. Equal amounts of protein were loaded on a $10 \%$ or $12 \%$ discontinue denaturating polyacrylamide gel (PPAR- $\delta$ and Tfam respectively) and electrophoresis was performed using a Mini-PROTEAN 3 Electrophoresis Cell system (Bio-Rad Laboratories, Hercules, CA). Primary antibodies used according to the manufacturer's manual included anti-PPAR- $\delta$ diluted 1:5000 (Santa-Cruz, CA, U.S.A.) and anti-Tfam diluted 1:10 000 (Santa-Cruz, CA, U.S.A.). Secondary antibodies used (1:10 000) were Rabbit anti-Goat peroxidase (Dako Cytomation, CA, U.S.A.) and Swine anti-Rabbit peroxidase (Dako Cytomation, CA, U.S.A.) respectively. Detection was performed with Super Signal West Dura Extended Duration Substrate (Pierce Boston Technology Centre, Woburn, USA) on a CL-Xposure Film (Pierce Boston Technology Centre, Woburn, USA). Densimetric quantification was performed using Image Master VDS (Amersham Pharmacia Biotech, NJ, USA). A standard sample was included in every blot to correct for blot to blot variation. PPAR- $\delta$ and Tfam protein content were both expressed as AU.

\section{Statistical analysis}

Data was analysed according to the guidelines of Altman et al. using SPSS (Statistical Package for the Social sciences, SPSS Inc., Chicago, IL, U.S.A) with the unpaired student's t-test (corrected for unequal variances if appropriate), 1-way ANOVA (with unpaired Student's t-test as post hoc test), or the Pearson correlation test and with non-parametric tests when appropriate ${ }^{17}$. Data are represented as the mean $\pm S D$. A two tailed probability value of less than 0.05 was considered to be significant. 


\section{Results}

\section{Subject characteristics}

Characteristics of patients and control subjects are summarised in Table 4.1. No significant differences in age and pack years were observed between patients and controls, providing a correction for smoking behaviour between groups. Also, no significant differences were observed in lung function of cachectic COPD patients when compared with non cachectic patients.

Table 4.1 Subject characteristics.

\begin{tabular}{lccc}
\hline & Controls & COPD cachexia & COPD non cachexia \\
\hline $\mathrm{N}(\mathrm{M} / \mathrm{F})$ & $9(6 / 3)$ & $7(4 / 3)$ & $7(4 / 3)$ \\
Age $(\mathrm{yr})$ & $65 \pm 4$ & $58 \pm 13$ & $67 \pm 9$ \\
Height $(\mathrm{cm})$ & $166.1 \pm 7.6$ & $168 \pm 10.5$ & $167.2 \pm 7.2$ \\
Body composition & & & \\
Weight $(\mathrm{kg})$ & $74.7 \pm 10.4$ & $59.0 \pm 8.8^{2}$ & $72.5 \pm 11.7$ \\
$\mathrm{BMI}\left(\mathrm{kg} / \mathrm{m}^{2}\right)$ & $27.1 \pm 3.7$ & $20.1 \pm 1.3^{\# \#}$ & $27.0 \pm 3.4$ \\
$\mathrm{FFM}(\mathrm{kg})$ & $50.5 \pm 9.1$ & $43.2 \pm 5.9^{\#}$ & $48.8 \pm 8.05$ \\
$\mathrm{FFMl}\left(\mathrm{kg} / \mathrm{m}^{2}\right)$ & $18.0 \pm 2.3$ & $14.8 \pm 0.7^{\# \#}$ & $17.3 \pm 2.2$ \\
$\mathrm{FM}(\mathrm{kg})$ & $23.3 \pm 8.1$ & $15.8 \pm 4.1^{\#}$ & $23.7 \pm 6.4$ \\
$\mathrm{FMI}\left(\mathrm{kg} / \mathrm{m}^{2}\right)$ & $8.4 \pm 3.5$ & $5.4 \pm 1.2^{\# \#}$ & $8.9 \pm 2.2$ \\
Lung function & & & \\
$\mathrm{FVC}(\%$ pred$)$ & $100.4 \pm 20.5^{* *}$ & $74.0 \pm 15.4$ & $79.8 \pm 17.5$ \\
$\mathrm{FEV}(\% \mathrm{pred})$ & $117.2 \pm 19.8^{* *}$ & $38.8 \pm 11.6$ & $41.4 \pm 18.5$ \\
$\mathrm{DLCO}(\% \mathrm{pred})$ & $83.6 \pm 29.2^{*}$ & $43.3 \pm 18.8$ & $60.9 \pm 29.0$ \\
$\mathrm{Pack}$ years & $35 \pm 17$ & $27 \pm 14$ & $35.7 \pm 15$ \\
$\mathrm{PaO}_{2}(\mathrm{kPa})$ & $9.7 \pm 0.8$ & $9.0 \pm 1.5$ & $9.4 \pm 1.1$ \\
$\mathrm{PaCO}_{2}(\mathrm{kPa})$ & $5.2 \pm 0.4$ & $5.3 \pm 0.7$ & $5.2 \pm 0.9$ \\
\hline
\end{tabular}

Values are expressed as mean \pm SD; Significance of difference compared to patients: ${ }^{*} p<0.05$; ** $p<0.01$. Significance of difference between COPD sub-groups: $\#<0.05$; \#\#<0.01; BMI: body mass index; FFM: fat-free mass; FFMI: fat-free mass index; FM: fat mass; FMI: fat mass index; FVC: forced vital capacity; $\mathrm{FEV}_{1}$ : forced expiratory volume in one second; $\mathrm{DL}_{\mathrm{co}}$ : diffusion capacity for carbon monoxide; $\mathrm{PaO}_{2}$ : arterial oxygen pressure; $\mathrm{PaCO}_{2}$ : arterial $\mathrm{CO}_{2}$ pressure; \% pred: percentage of predicted value

\section{Muscle fiber type composition}

The proportion of MyHC type I fibers tended to be lower in COPD patients when compared to control subjects $(24.6 \pm 7.1$ vs $30.6 \pm 6.7 ; p=0.114)$. There were no significant differences in the proportion of MyHC type lla fibers between patients and healthy controls. The proportion of MyHC type Ilx fibers was higher in patients vs controls $(30.4 \pm 5.7$ vs $19.4 \pm 10.9 ; p=0.044)$ (Figure 4.1). No significant differences in fiber type composition were observed between cachectic and non cachectic patients. 


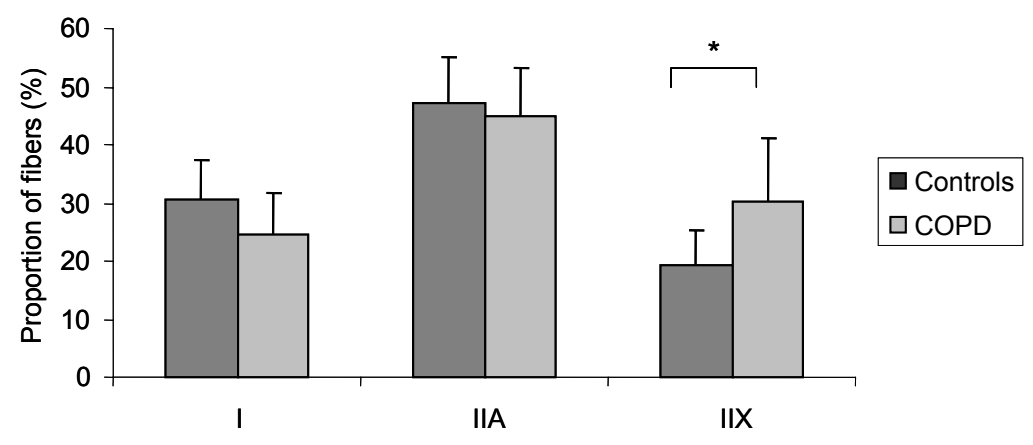

Fiber type Category

Figure 4.1 MyHC fiber type distribution in the quadriceps femoris of COPD patients $(n=13)$ and healthy control subjects $(n=6)$. Significance of difference: * $p<0.05$. Error bars indicate the SD.

\section{PPAR- $\alpha$}

There were no significant differences in PPAR- $\alpha$ mRNA expression in skeletal muscle of patients and control subjects. However, a trend of lower PPAR- $\alpha$ mRNA levels in patients compared to controls was observed $(1.39 \pm 0.75$ vs $1.87 \pm 0.46 ; p=0.09$ ) (Table 4.2). Interestingly, expression levels of PPAR- $\alpha$ mRNA were over $50 \%$ lower in cachectic COPD patients when compared to non cachectic patients $(0.87 \pm 0.47$ vs $2.14 \pm 0.69 ; p=0.008)$ and healthy controls $(1.87 \pm 0.46 ; p=0.004)$ (Figure 4.2). In addition, PPAR- $\alpha$ mRNA levels in the patient group correlated positively and significantly with BMI and FFMI $(r=0.700 ; p=0.005$ and $r=0.593 ; p=0.025$ respectively) Although we tried several commercially available PPAR- $\alpha$ antibodies, none of these were of sufficient quality and specificity to detect PPAR- $\alpha$ protein content.

Table 4.2 RNA expression levels in skeletal muscle.

\begin{tabular}{lcccc}
\hline & Healthy controls & COPD & COPD cachectic & COPD non cachectic \\
\hline PPAR- $\alpha$ & $1.87 \pm 0.46$ & $1.39 \pm 0.75$ & $0.87 \pm 0.47^{\# \#}$ & $2.14 \pm 0.69$ \\
PPAR- $\delta$ & $1.07 \pm 0.17$ & $1.12 \pm 0.34$ & $0.95 \pm 0.33$ & $1.29 \pm 0.28$ \\
PPAR- $\gamma$ & Undetectable & Undetectable & Undetectable & Undetectable \\
Tfam & $1.00 \pm 0.27$ & $1.00 \pm 0.34$ & $0.78 \pm 0.27^{\#}$ & $1.21 \pm 0.25$ \\
PGC-1 & $1.38 \pm 0.23$ & $1.00 \pm 0.49^{*}$ & $0.89 \pm 0.43$ & $1.11 \pm 0.56$ \\
\hline
\end{tabular}

Values are expressed as mean $\pm S D$; significance compared to controls: ${ }^{*} p<0.05$; significance of difference between COPD sub groups: ${ }^{\#} p<0.05 ;{ }^{\# \#} p<0.01$. 


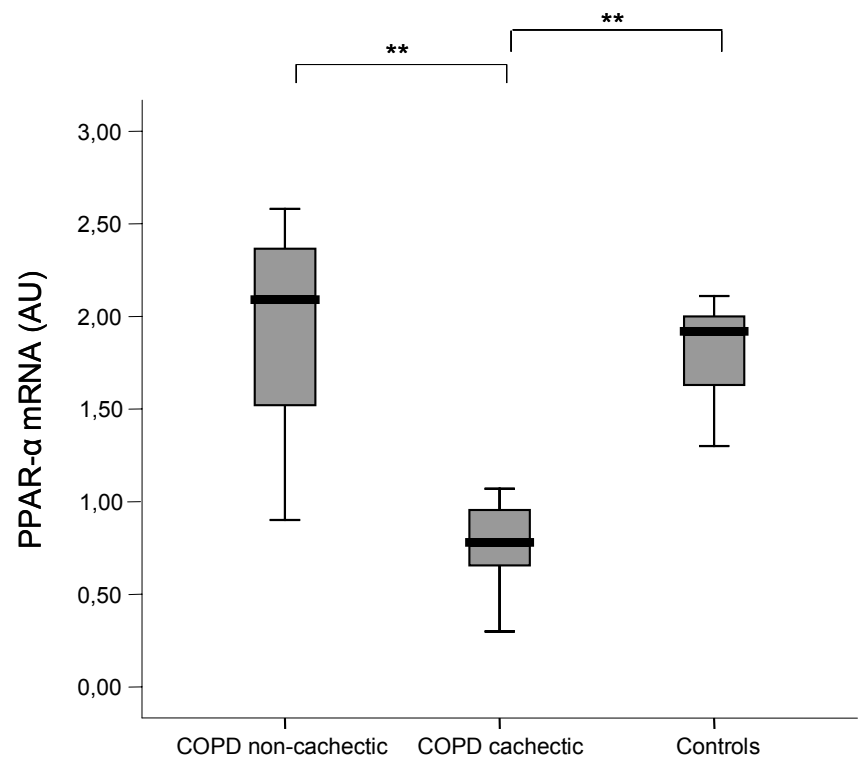

Figure 4.2 Expression of PPAR- $\alpha$ mRNA in skeletal muscle of cachectic $(n=7)$ and non cachectic COPD patients $(n=7)$ and healthy control subjects $(n=9)$ controlled for by using 36B4 as a housekeeping gene. Significance of difference: ${ }^{* *} p<0.01$. Error bars indicate the $\mathrm{SD}$. Arbitrary units $(\mathrm{AU})$ are depicted on the Y-axis.

\section{PPAR- $\delta$}

There were no significant differences in the expression levels of PPAR- $\delta$ mRNA between patients and healthy control subjects. A trend towards lower PPAR- $\delta$ mRNA levels was observed in skeletal muscle of cachectic versus non cachectic patients $(0.95 \pm 0.33$ vs $1.29 \pm 0.28 ; p=0.085)$ (Table 4.2). At the protein level, content of PPAR- $\delta$ was significantly lower in skeletal muscle of COPD patients compared to healthy control subjects ( $1.67 \pm 0.85$ vs $2.64 \pm 0.95$; $\mathrm{p}=0.037$ ) (Figure 4.3a, 4.3d). No significant differences in PPAR- $\delta$ protein content were observed between cachectic and non cachectic patients (Figure $4.3 b)$.

\section{PPAR-Y}

PPAR-y mRNA levels were too low to be detected in skeletal muscle. PPAR-y protein could be detected in human adipose tissue (as a positive control), but was below the detection limit in the muscle samples (data not shown). 
A

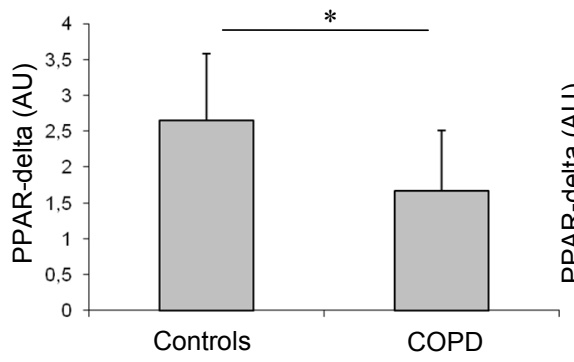

C

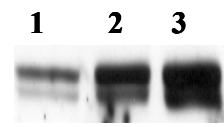

B

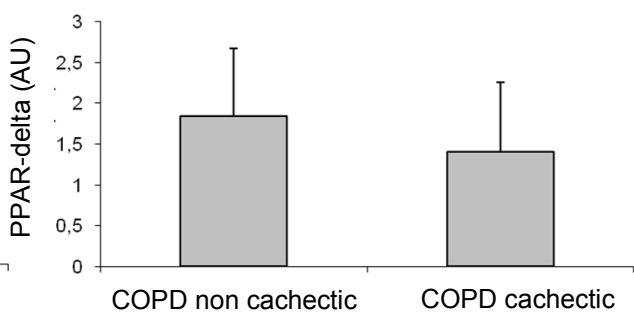

D

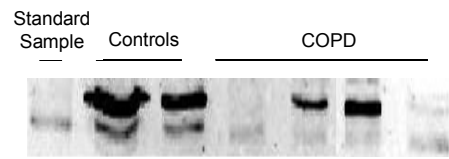

Figure 4.3 A) Expression of PPAR- $\delta$ protein in skeletal muscle of COPD patients $(n=14)$ and healthy control subjects $(n=9)$. Significance of difference compared to controls: * $p<0.05$. Error bars indicate the SD. Arbitrary units (AU) are depicted on the Y-axis. B) Expression of PPAR- $\delta$ protein in skeletal muscle of cachectic $(n=7)$ and non cachectic COPD patients $(n=7)$. Note that vertical axis is slightly different in panel A and B C) Specificity of the antibody directed against human PPAR- $\delta$ was tested by viral transfection of human PPAR- $\delta$ protein into neonatal rat cardiomyocytes. From 1-3: increasing amount of virus was added to the cell system and increasing intensity of both bands at $50 \mathrm{kDa}$ (PPAR- $\delta$ ) was observed. D) Representative sample of PPAR- $\delta$ using western blot. Equal amounts of protein were loaded in every lane. A standard sample was included in every blot to correct for blot to blot variation.

\section{Tfam}

We determined content and mRNA levels of Tfam, which is an essential factor involved in mitochondrial biogenesis. No significant differences in Tfam mRNA expression levels were found between patients and controls. However, Tfam mRNA levels were significantly lower in cachectic patients compared to non cachectic patients $(0.78 \pm 0.27$ vs $1.21 \pm 0.25 ; p=0.013)$. In addition, western blot analysis revealed a significantly lower content of Tfam protein in skeletal muscle of COPD patients compared to healthy controls $(0.80 \pm 0.36$ vs $1.20 \pm 0.13 ; p<0.001)$. Moreover, content of the Tfam protein was also significantly lower in cachectic patients when compared with non cachectic patients $(0.60 \pm 0.23$ vs $0.95 \pm 0.37 ; p=0.023)$ (Figure 4.4). 
$\mathbf{A}$

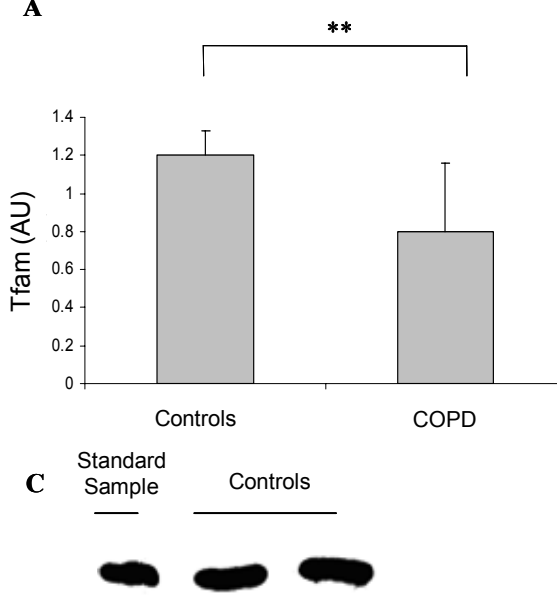

B

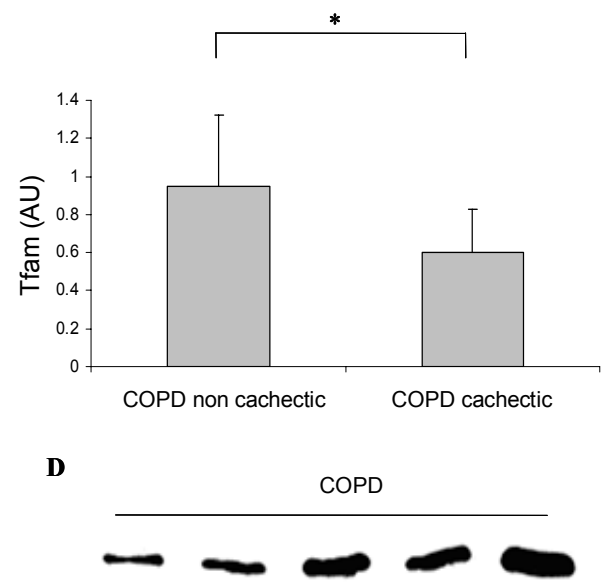

Figure 4.4 A) Tfam protein content in skeletal muscle of COPD patients $(n=14)$ and healthy control subjects $(n=9)$. Significance of difference compared to controls: ${ }^{* *} p<0.001$. Error bars indicate the SD. Arbitrary units (AU) are depicted on the Y-axis. B) Tfam protein content in skeletal muscle of cachectic $(n=7)$ and non cachectic COPD patients $(n=7)$. Significance of difference compared to controls: * $p<0.05$. C, D) Representative Sample of Tfam using western blot. Equal amounts of protein were loaded in every lane. A standard sample was included in every blot to correct for blot to blot variation. Tfam was identified as the $28 \mathrm{kDa}$ band.

\section{PGC-1a}

Expression of PGC-1a mRNA was lower in COPD patients compared to healthy controls $(1.00 \pm 0.49$ vs $1.38 \pm 0.23 ; p=0.044)$ (Figure 4.5$)$. There were no differences in PGC-1a mRNA levels between cachectic and non cachectic patients. PGC-1 $\alpha$ protein content could not be assessed due to a lack of commercially available high quality antibodies.

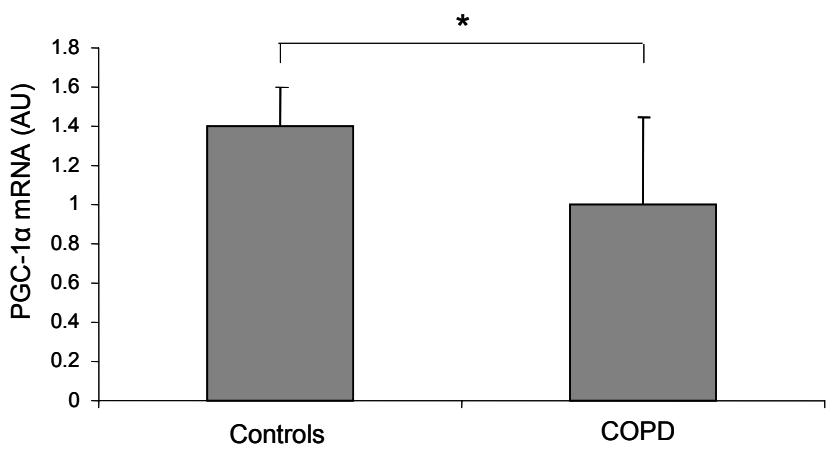

Figure 4.5 Expression of PGC-1 $\alpha$ mRNA in skeletal muscle of COPD patients $(n=14)$ and healthy control subjects $(n=9)$ controlled for by using 36B4 as a housekeeping gene. Significance of difference compared to controls: ${ }^{*} p<0.05$. Error bars indicate the SD. PGC-1 $\alpha$ expression levels are depicted as arbitrary units (AU) on the $Y$-axis. 


\section{Correlations}

Correlation analysis was performed to investigate if PPAR expression levels or protein content were associated with systemic inflammation, muscle oxidative capacity, muscle fiber type distribution or lung function. Expression levels of PPAR- $\alpha$ mRNA correlated negatively with circulating levels of TNF- $\alpha$ protein $(r=-0.576 ; p=0.031)$ (Figure 4.6). Similar results were found for the sTNF-R55 and the sTNF-R75 ( $r=-0.606 ; p=0.022$ and $r=-0.546 ; p=0.044)$. Concerning metabolic markers, PPAR- $\delta$ and PPAR- $\alpha$ mRNA levels in skeletal muscle correlated positively with the oxidative enzyme CS $(r=0.587 ; p=0.005$ and $r=0.463 ; p=0.035)$. In addition, the proportion of MyHC type I fibers (\%) correlated positively and significantly with skeletal muscle Tfam protein content $(r=0.554 ; p=0.014)$. No correlations were observed between PPAR expression levels or content and lung function parameters.

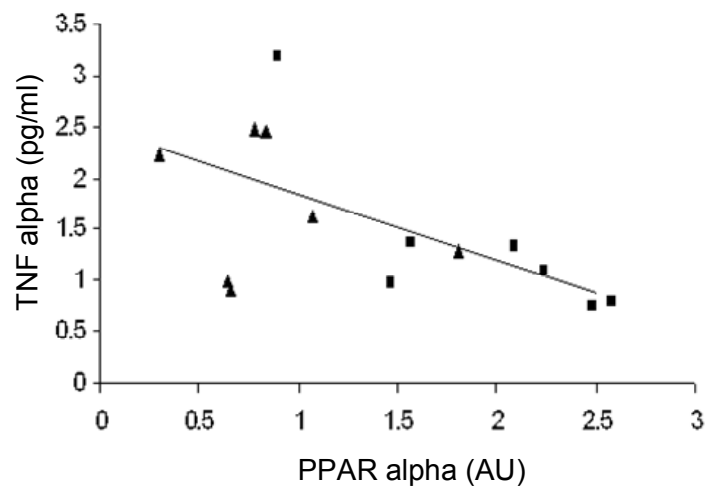

Figure 4.6 Correlation between blood circulatory levels of tumour necrosis factor alpha (TNF- $\alpha$ ) protein and expression levels of PPAR- $\alpha$ mRNA in skeletal muscle of COPD patients $(n=14)$. $\Delta$ indicates cachectic COPD patients and $\boldsymbol{\|}$ indicates non cachectic COPD patients.

\section{Discussion}

COPD is characterised by reduced skeletal muscle function. Muscle oxidative capacity is decreased which is related to a fiber type shift from type I oxidative to type IIx glycolytic fibers. In addition, oxidative capacity within intermediary type lla fibers is also reduced ${ }^{18,19}$. As the PPAR transcription factors are involved in the regulation of muscular oxidative capacity, we determined PPAR content and expression levels in skeletal muscle of COPD patients. Here we report for the first time that PPAR- $\delta$ protein content is reduced in skeletal muscle of COPD patients. Like PPAR- $\alpha$, PPAR- $\delta$ is a strong positive regulator of skeletal muscle oxidative metabolism as it is involved in the regulation of 
proteins implicated in uptake, handling and oxidation of fatty acids as well as other oxidative enzymes ${ }^{11}$. Indeed, in the present study PPAR- $\delta$ and PPAR- $\alpha$ mRNA levels correlated positively with the activity of the oxidative TCA cycle enzyme CS consistent with involvement of these 2 PPAR subtypes in skeletal muscle oxidative metabolism.

In addition to a decreased PPAR- $\delta$ protein content, mRNA levels of PGC-1 $\alpha$, a strong PPAR co-activator and key regulator of mitochondrial biogenesis, were also reduced in skeletal muscle of these patients ${ }^{20}$. It has been shown that PPAR- $\delta$ and PGC-1 $\alpha$ both have the ability to redirect fiber type distribution in skeletal muscle to a more oxidative phenotype ${ }^{11,21,22}$. Given that COPD patients are characterised by increased amount of type Ilx glycolytic fibers, it is tempting to suggest that the reduction in PPAR- $\delta$ and PGC-1 $\alpha$ is causally related to this fiber type shift. Although no significant correlations were found between PPAR, PGC-1 $\alpha$ and fiber type composition, there was a significant positive correlation between the PGC-1a-regulated Tfam protein and type I oxidative fibers. Consistent with involvement of a reduced PPAR content in the reduction of oxidative capacity in COPD is the finding that UCP-3 is reduced in COPD. Several reports show that UCP-3 is a PPAR regulated gene ${ }^{23}$. Moreover, Schrauwen et al. reported that administration of rosiglitazone, a potent PPAR- $Y$ agonist, restored muscular UCP-3 levels in diabetic patients ${ }^{24}$. These observations further strengthen the suggestion that PPARs do play a role in skeletal muscle abnormalities as observed in COPD.

Next to a regulatory role in skeletal muscle morphology, PGC-1a is also involved in the regulation of Tfam, which in turn controls the expression of mitochondrial-encoded genes involved in mitochondrial biogenesis and respiration ${ }^{25}$. Interestingly, in the present study a lower expression of PGC-1a mRNA in skeletal muscle of COPD patients was accompanied by a reduced Tfam protein content. Decreased levels of PGC-1a thus may well be involved in the loss of muscular oxidative capabilities in COPD. Intriguingly, in other disease models, as congestive heart failure (CHF) and diabetes mellitus (DM), a decreased oxidative capacity of skeletal muscle is also associated with a decreased expression of PGC-1a mRNA ${ }^{26,27}$. Due to a lack of specific antibodies, we were unable to verify whether PGC-1a protein levels were indeed reduced in skeletal muscle of COPD patients, but this remains an interesting topic for future research.

Although we did observe a lower content of PPAR- $\delta$ and Tfam protein in skeletal muscle of COPD patients, no significant differences in the expression levels of PPAR- $\delta$ or Tfam mRNA were observed in skeletal muscle between patients and control subjects. This suggests the presence of a post 
transcriptional mechanism controlling PPAR- $\delta$ and Tfam protein levels in skeletal muscle. The interaction of PPARs with specific pathways involved in protein degradation, e.g. the ubiquitin proteasome pathway, has been the subject of limited investigation. Therefore, the identity and nature of the post transcriptional mechanism involved here remains obscure. In addition, PPAR- $y$ mRNA and protein were undetectable in our samples supporting other reports that, if present at all, PPAR- $y$ content and expression in skeletal muscle is very low.

Besides a disturbed oxidative phenotype, skeletal muscle function in COPD is also severely impaired by muscle atrophy. Strikingly, a lower expression of PPAR- $\alpha$ mRNA was observed in skeletal muscle of cachectic COPD patients compared to non cachectic patients and healthy controls. Also, PPAR- $\alpha$ mRNA levels correlated negatively with levels of TNF- $\alpha$ and subunits of the TNF- $\alpha$ receptor in the current COPD population. Systemic inflammation has been recognised as an important risk factor for the loss of skeletal muscle mass ${ }^{8,9}$. Interestingly, there are also reports that describe a negative effect of TNF- $\alpha$ on the activity of PPAR- $\alpha$ in vivo ${ }^{28}$. Our results confirm a link between PPAR- $\alpha$ and inflammation-related cachexia although the exact mechanisms of the observed reduction are unclear and deserve further investigation.

The reason for the decreased content or expression of the PPARs in skeletal muscle of COPD patients may be multifaceted. As skeletal muscle is very responsive to metabolic and mechanical influences the observed reduction in PPAR- $\delta$ and Tfam protein content and the decreased expression of PGC-1 $\alpha$ and PPAR- $\alpha$ may represent an adaptation of the muscle cells due to physiological and pathological changes including inactivity, hypoxia and inflammation. Furthermore, differences in expression levels or protein levels can be more pronounced in patients suffering from the cachexia syndrome. A sedentary lifestyle which is often adopted by COPD patients due to diseaserelated exercise limitations could underlie the reduced content of PPAR- $\delta$ protein and reduced PGC-1a mRNA levels in skeletal muscle as it has been shown that PPAR- $\delta$ and PGC-1 $\alpha$ are strongly up regulated by physical exercise $^{22,29,31}$. Hypoxia and inflammation, both commonly observed in COPD, may also contribute to lower PPAR expression levels or protein content as there are several reports that suggest a negative influence of these parameters on PPAR expression levels ${ }^{32,33}$. The specific contribution of these factors remains unknown and in vitro approaches will shed more light on the involvement of hypoxia and inflammation on PPAR expression levels and content. Intriguingly, DM and $\mathrm{CHF}$, diseases characterised by systemic inflammation and increased levels of inactivity are also characterised by decreased muscular levels of PPAR and/or PGC-1 $\alpha$, suggesting a prominent 
role for inflammation and physical activity levels in controlling PPAR and PGC$1 \alpha$ levels ${ }^{26,27,34}$. As the PPARs, more specifically PPAR- $\alpha$ and PPAR- $\delta$, are highly implicated in skeletal muscle oxidative metabolism, which is obviously impaired in COPD patients, they could serve as interesting therapeutic targets in this disorder. Increasing PPAR levels by means of exercise, fatty acid supplementation and/or pharmacological modulation could serve as a potential therapeutic strategy to alleviate exercise intolerance in this disorder.

\section{Conclusions}

We found a reduced expression of PGC-1a mRNA and a lower content of PPAR- $\delta$ protein in lower limb skeletal muscle of COPD patients compared to healthy controls. In addition, these reductions were accompanied by a decreased content of Tfam protein. These findings imply a disturbed regulation of muscular oxidative capacity as PPAR- $\delta, P G C-1 \alpha$ and Tfam are highly implicated in determining skeletal muscle oxidative capacity. Therefore, a disturbed expression and/or content of these regulatory factors may well underlie the disturbed skeletal muscle functioning in COPD. In addition, we suggest that not only occurrence of the disease but also the presence of cachexia and chronic inflammation affected PPAR mRNA and protein levels. Since the explanation for a lower expression and content of PPARs and PPAR related factors in skeletal muscle of COPD patients is complex, further investigation is required to unravel the exact mechanisms behind these observations. 


\section{References}

1. Richardson RS, Leek BT, Gavin TP, Haseler LJ, Mudaliar SR, Henry R, Mathieu-Costello O, Wagner PD. Reduced mechanical efficiency in chronic obstructive pulmonary disease but normal peak VO2 with small muscle mass exercise. Am J Respir Crit Care Med 2004:169: 89-96.

2. Marquis K, Debigare R, Lacasse $Y$, LeBlanc $P$, Jobin J, Carrier G, Maltais F. Midthigh muscle cross-sectional area is a better predictor of mortality than body mass index in patients with chronic obstructive pulmonary disease. Am J Respir Crit Care Med 2002:166:809-13.

3. Mador MJ, Bozkanat E. Skeletal muscle dysfunction in chronic obstructive pulmonary disease. Respir Res 2001:2:216-24.

4. Gosker HR, van Mameren H, van Dijk PJ, Engelen MP, van der Vusse GJ, Wouters EF, Schols AM. Skeletal muscle fibre-type shifting and metabolic profile in patients with chronic obstructive pulmonary disease. Eur Respir J 2002:19:617-25.

5. Langen RC, Korn SH, Wouters EF. ROS in the local and systemic pathogenesis of COPD. Free Radic Biol Med 2003:35:226-35.

6. Gosker HR, Schrauwen P, Hesselink MK, Schaart G, van der Vusse GJ, Wouters EF, Schols AM. Uncoupling protein-3 content is decreased in peripheral skeletal muscle of patients with COPD. Eur Respir J 2003:22:88-93.

7. Engelen MP, Schols AM, Does JD, Deutz NE, Wouters EF. Altered glutamate metabolism is associated with reduced muscle glutathione levels in patients with emphysema. Am J Respir Crit Care Med 2000:161:98-103.

8. Broekhuizen R, Grimble RF, Howell WM, Shale DJ, Creutzberg EC, Wouters EF, Schols AM. Pulmonary cachexia, systemic inflammatory profile, and the interleukin 1 beta -511 single nucleotide polymorphism. Am J Clin Nutr 2005:82:1059-64.

9. Di Francia M, Barbier D, Mege JL, Orehek J. Tumor necrosis factor-alpha levels and weight loss in chronic obstructive pulmonary disease. Am J Respir Crit Care Med 1994:150:1453-5.

10. Koves TR, Li P, An J, Akimoto T, Slentz D, Ilkayeva O, Dohm GL, Yan Z, Newgard CB, Muoio DM. Peroxisome proliferator-activated receptor-gamma co-activator 1alpha-mediated metabolic remodeling of skeletal myocytes mimics exercise training and reverses lipidinduced mitochondrial inefficiency. J Biol Chem 2005:280:33588-98.

11. Luquet S, Lopez-Soriano J, Holst D, Fredenrich A, Melki J, Rassoulzadegan M, Grimaldi PA. Peroxisome proliferator-activated receptor delta controls muscle development and oxidative capability. Faseb J 2003:17:2299-301.

12. Puigserver $P$, Spiegelman BM. Peroxisome proliferator-activated receptor-gamma coactivator 1 alpha (PGC-1 alpha): transcriptional coactivator and metabolic regulator. Endocr Rev 2003: 24:78-90.

13. Daynes RA, Jones DC. Emerging roles of PPARs in inflammation and immunity. Nat Rev Immunol 2002:2:748-59.

14. Leeuwenberg JF, Jeunhomme TM, Buurman WA. Slow release of soluble TNF receptors by monocytes in vitro. J Immunol 1994:152:4036-43.

15. Steiner MC, Barton RL, Singh SJ, Morgan MD. Bedside methods versus dual energy X-ray absorptiometry for body composition measurement in COPD. Eur Respir J 2002:19:626-31.

16. Gosker HR, Schrauwen P, Broekhuizen R, Hesselink MK, Moonen-Kornips E, Ward KA, Franssen FF, Wouters EF, Schols AM. Exercise training restores uncoupling protein-3 content in limb muscles of patients with chronic obstructive pulmonary disease. Am J Physiol Endocrinol Metab 2006;290:E976-81.

17. Altman DG, Gore SM, Gardner MJ, Pocock SJ. Statistical guidelines for contributors to medical journals. Br Med J (Clin Res Ed) 1983:286:1489-93.

18. Gosker HR, Engelen MP, van Mameren H, van Dijk PJ, van der Vusse GJ, Wouters EF, Schols AM. Muscle fibre type IIX atrophy is involved in the loss of fat-free mass in chronic obstructive pulmonary disease. Am J Clin Nutr 2002:76:113-9. 
19. Gosker HR, Wouters EF, van der Vusse GJ, Schols AM. Skeletal muscle dysfunction in chronic obstructive pulmonary disease and chronic heart failure: underlying mechanisms and therapy perspectives. Am J Clin Nutr 2000:71:1033-47.

20. Baar K. Involvement of PPAR gamma co-activator-1, nuclear respiratory factors 1 and 2 , and PPAR alpha in the adaptive response to endurance exercise. Proc Nutr Soc 2004:63:269-73.

21. Lin J, Wu H, Tarr PT, Zhang CY, Wu Z, Boss O, Michael LF, Puigserver P, Isotani E, Olson EN, Lowell BB, Bassel-Duby R, Spiegelman BM. Transcriptional co-activator PGC-1 alpha drives the formation of slow-twitch muscle fibers. Nature 2002:418:797-801.

22. Wang YX, Zhang CL, Yu RT, Cho HK, Nelson MC, Bayuga-Ocampo CR, Ham J, Kang H, Evans RM. Regulation of muscle fiber type and running endurance by PPARdelta. PLoS Biol 2004:2:e294.

23. Brun S, Carmona MC, Mampel T, Vinas O, Giralt M, Iglesias R, Villarroya F. Activators of peroxisome proliferator-activated receptor-alpha induce the expression of the uncoupling protein-3 gene in skeletal muscle: a potential mechanism for the lipid intake-dependent activation of uncoupling protein-3 gene expression at birth. Diabetes 1999:48:1217-22.

24. Schrauwen P, Mensink M, Schaart G, Moonen-Kornips E, Sels JP, Blaak EE, Russell AP, Hesselink MK. Reduced skeletal muscle UCP3 protein content in pre-diabetic subjects and type 2 diabetic patients: restoration by rosiglitazone treatment. J Clin Endocrinol Metab 2006; 91:1520-5

25. Hood DA. Invited Review: contractile activity-induced mitochondrial biogenesis in skeletal muscle. J Appl Physiol 2001:90:1137-57.

26. Garnier A, Fortin D, Delomenie C, Momken I, Veksler V, Ventura-Clapier R. Depressed mitochondrial transcription factors and oxidative capacity in rat failing cardiac and skeletal muscles. J Physiol 2003:551:491-501.

27. Roden M. Muscle triglycerides and mitochondrial function: possible mechanisms for the development of type 2 diabetes. Int J Obes (Lond) 2005:29(S2):S111-5.

28. Sekiguchi K, Tian Q, Ishiyama M, Burchfield J, Gao F, Mann DL, Barger PM. Inhibition of PPAR \{alpha\} activity in mice with cardiac-restricted expression of Tumor Necrosis Factor: potential role of TGF\{beta\}/Smad3. Am J Physiol Heart Circ Physiol 2007;292:H1443-51

29. Russell AP, Feilchenfeldt J, Schreiber S, Praz M, Crettenand A, Gobelet C, Meier CA, Bell DR, Kralli A, Giacobino JP, Deriaz O. Endurance training in humans leads to fibre typespecific increases in levels of peroxisome proliferator-activated receptor-gamma coactivator-1 and peroxisome proliferator-activated receptor-alpha in skeletal muscle. Diabetes 2003:52: 2874-81.

30. Watt MJ, Southgate RJ, Holmes AG, Febbraio MA. Suppression of plasma free fatty acids upregulates peroxisome proliferator-activated receptor (PPAR) alpha and delta and PPAR coactivator 1alpha in human skeletal muscle, but not lipid regulatory genes. J Mol Endocrinol 2004:33:533-44.

31. Russell AP, Hesselink MK, Lo SK, Schrauwen P. Regulation of metabolic transcriptional coactivators and transcription factors with acute exercise. Faseb J 2005:19:986-8.

32. Narravula S, Colgan SP. Hypoxia-inducible factor 1-mediated inhibition of peroxisome proliferator-activated receptor alpha expression during hypoxia. J Immunol 2001:166:7543-8.

33. Zhang B, Berger J, Hu E, Szalkowski D, White-Carrington S, Spiegelman BM, Moller DE. Negative regulation of peroxisome proliferator-activated receptor-gamma gene expression contributes to the antiadipogenic effects of tumor necrosis factor-alpha. Mol Endocrinol 1996: 10:1457-66.

34. Nystrom T, Nygren A, Sjoholm A. Increased levels of tumour necrosis factor-alpha in type 2 diabetic patients after myocardial infarction are related to endothelial dysfunction. Clin Sci (Lond) 2006:110:673-81. 



\section{Chapter}

\section{TNF- $\alpha$ impairs regulation of muscle oxidative phenotype: Implications for cachexia in COPD?}

Remels AHV, Gosker HR, Schrauwen P, Hommelberg P, Sliwinski P, Polkey M, Galdiz J, Wouters EF, Langen RC, Schols AMWJ. TNF- $\alpha$ impairs regulation of muscle oxidative phenotype: Implications for cachexia in COPD? Submitted 


\section{Abstract}

Many patients with advanced chronic obstructive pulmonary disease (COPD) are characterised by muscle wasting, often referred to as cachexia, and loss of muscle oxidative phenotype (OXPHEN) i.e. intrinsic muscular features determining fatigue resistance and capacity for oxidative substrate metabolism. While inflammation has been implicated in cachexia, its impact on muscle OXPHEN is currently unknown. Markers and regulators of OXPHEN were investigated in vastus lateralis muscle biopsies of COPD patients and healthy smoking controls as well as in cultured muscle cells chronically stimulated with the pro-inflammatory cytokine TNF- $\alpha$. Patients with increased muscle TNF- $\alpha$ mRNA levels compared to controls were characterised by a lower body mass index $\left(23.6 \pm 3.6\right.$ vs $\left.27.2 \pm 4.8 \mathrm{~kg} / \mathrm{m}^{2}\right)$, a lower fat-free mass index $(16.7 \pm 1.5 \mathrm{vs}$ $18.2 \pm 2.4 \mathrm{~kg} / \mathrm{m}^{2}$ ) and a significant decrease in gene expression levels of markers and regulators of muscle OXPHEN. In cultured muscle cells, mitochondrial protein content and myosin heavy chain isoform I (but not II) protein and mRNA levels were reduced upon chronic TNF- $\alpha$ stimulation. In addition, TNF- $\alpha$ reduced mitochondrial respiration in a nuclear factor KB- (NF$\mathrm{KB})$ dependent manner. Importantly, TNF- $\alpha$ signalling through the NF-KB pathway also decreased promoter trans-activation of regulators of mitochondrial biogenesis and muscle OXPHEN. In conclusion, this is the first report that links impaired muscle OXPHEN to inflammatory signalling in COPD. Furthermore, these results provide strong evidence demonstrating that inflammatory stimuli such as TNF- $\alpha$ severely impair muscle OXPHEN in a NFkB-dependent manner. 


\section{Introduction}

Cachexia is a complex and disabling syndrome that occurs in the course of many chronic diseases and cancer ${ }^{1,2}$. Nevertheless, it receives limited attention in clinical practice because the accelerated muscle wasting, that distinguishes this condition from malnutrition, is being considered irreversible with current intervention strategies. More insight in the etiology of this syndrome is thus urgently needed. The prevalence of cachexia is high in chronic obstructive pulmonary disease (COPD) which is therefore an interesting clinical model for translational research on this topic. Besides cachexia, COPD, but also other chronic inflammatory diseases as congestive heart failure (CHF), are characterised by an impaired muscle oxidative phenotype (OXPHEN) ${ }^{3}$. Muscle OXPHEN encompasses oxidative fiber types I and Ila (determining fatigue resistance) and mitochondrial oxidative metabolism (essential for providing adequate energy supply for sustained physical activity $)^{4}$. Therefore, unlike muscle mass which mainly determines strength, OXPHEN determines exercise endurance capacity and fatigability of the muscle and is considered as an important factor determining exercise capacity and quality of life of patients.

Previously we demonstrated that expression levels of master regulators of muscle OXPHEN including peroxisome proliferator-activated receptors (PPARs), PPAR- $\gamma$ co-activator $1 \alpha$ (PGC-1 $\alpha$ ) and mitochondrial transcription factor A (Tfam) were reduced in lower limb muscle of COPD patients, being most pronounced in the cachectic subgroup. Intriguingly, expression levels of these markers correlated negatively with TNF- $\alpha$ levels in plasma ${ }^{5}$. A causal relationship between inflammation and muscle wasting has been firmly established in experimental models ${ }^{6}$. However, whether local inflammatory signalling negatively affects muscle OXPHEN has surprisingly not yet been addressed thus far. Nevertheless, two recent clinical trials provide indirect support for this notion, as anti-inflammatory modulation, using either nutritional or pharmacological approaches, in COPD improved exercise capacity ${ }^{7}$ and exercise endurance ${ }^{8}$ respectively. These observations sparked further investigation of the inverse relation between inflammatory signalling and determinants/regulators of muscle OXPHEN. Using a translational approach, we explored if altered regulation of skeletal muscle OXPHEN in COPD could be the resultant of local inflammation. Subsequently, we aimed to elucidate underlying mechanisms. We hypothesised that impaired regulation of OXPHEN could result directly from TNF- $\alpha$-induced activation of nuclear factor $\mathrm{KB}$ (NF-KB), a master signalling pathway relaying inflammatory signals. 


\section{Subjects and Methods}

\section{Subjects}

First we analysed mRNA expression levels of selected regulatory- and target genes implicated in skeletal muscle OXPHEN in quadriceps muscle biopsies of COPD patients stratified by muscle TNF- $\alpha$ mRNA levels and healthy agematched smoking controls. Data was extracted from the ENIGMA (European Network for Investigating the Global Mechanisms of Muscle Abnormalities in COPD - www.pul.unimaas.nl/enigma) database containing more than 100 muscle samples from patients with advanced COPD and 10 healthy agematched smoking controls. A diagnosis of COPD was established on the basis of the guidelines of the Global Initiative for Chronic Obstructive Lung Disease ${ }^{31}$. The inclusion and exclusion criteria established in this study were identical in the four participating centers (the Netherlands, Spain, United Kingdom and Poland). All individuals were Caucasian. Patients were exclusively receiving inhaled medication (long acting $\beta_{2}$ agonists, anticholinergics and low dose inhaled corticosteroids). Patients receiving oral corticosteroid treatment were not included in the study. Written consent was obtained from all subjects and the study was approved by the ethical review boards of the different European centers.

\section{Collection and processing of muscle tissue}

Post absorptive muscle biopsies of the vastus lateralis were obtained under local anesthesia. The specimens were immediately snap-frozen in liquid nitrogen and stored at $-80^{\circ} \mathrm{C}$ until use. The frozen biopsies were weighed and subsequently homogenised using a Polytron PT 1600 E (Kinematica AG, Littau/Luzern, Germany). The "high TNF- $\alpha$ " COPD subgroup was defined as having muscle TNF- $\alpha$ mRNA levels, corrected for a normalisation factor calculated on expression levels of 5 housekeeping genes, greater than the mean $+2 \times$ standard deviation of that of the control group. 17 Patients complied with this. Another 17 patients, with muscle TNF- $\alpha$ gene expression levels comparable to control subjects, were randomly selected from the remaining patients in the database.

\section{Cell culture}

The murine skeletal muscle cell line $\mathrm{C} 2 \mathrm{C} 12$ was obtained from the American Type Culture Collection (ATCC CRL1772; Manassas, VA, USA). Myoblasts were cultured as described previously ${ }^{28}$. 


\section{Transfections and plasmids}

For assessment of PPAR transcriptional activity, C2C12 cells were stably or transiently transfected with the human CPT-1 B promoter (HCBP) luciferase plasmid (pSG5, Stratagene, La Jolla, CA, USA) (PPAR reporter cell line). As a control, cells were stably or transiently transfected with equal amounts of empty vector PcDNA3.1 (Invitrogen, Rockville, MD, USA). For assessment of Tfam or NRF-1 promoter activity, cells were transiently transfected with a mtTFA$\mathrm{RC} 4 \mathrm{wt} / \mathrm{pGL} 3^{32}$ or $\mathrm{p} 4 \times \mathrm{xNRF}-1 \mathrm{Luc}^{33}$ luciferase promoter construct.

\section{Enzyme activity assay}

Activity levels of creatine kinase (CK) were measured as described previously ${ }^{1}$. Enzyme activity levels were corrected for total protein content (Biorad, Hercules, CA, USA).

\section{Mitochondrial respiration}

Respiration was measured using a respirometer (Oxygraph 2K, Oroboros Instruments, Austria). Cells were permeabilised using $1 \mu \mathrm{l}$ of digitonin $(0.5 \mu \mathrm{g} / \mathrm{ml}$ final concentration) and substrates were added in chronological order (volume; final concentration): malate $(5 \mu \mathrm{l} ; 2 \mathrm{mM})$, palmitoyl-carnitine $(10 \mu \mathrm{l} ; 50 \mu \mathrm{M})$ and ADP $(20 \mu \mathrm{l} ; 5 \mathrm{mM})$. At the end of the substrate trace a titration with the uncoupling agent FCCP was performed ( $1 \mu \mathrm{l} ; 0.5 \mu \mathrm{M}$ titration). Oxygen consumption $(\mathrm{pmol} / \mathrm{ml} \cdot \mathrm{s})$ was calculated as a negative time derivative of oxygen concentration $(\mathrm{nmol} / \mathrm{ml})$. Respiration rates were corrected for total protein content to correct for variability in cellular input. Additional details are provided in the data supplement.

\section{Western blot analysis}

Abundance of OXPHOS proteins and MyHC distribution was evaluated by Western blotting. Whole cell lysates were prepared as described previously ${ }^{35}$.

\section{Electrophoretic mobility shift assay (EMSA)}

NF-KB DNA binding activity was assessed in nuclear extracts by analysis of complexes binding to an oligonucleotide containing a $\mathrm{KB}$ consensus sequence (Santa Cruz, Santa Cruz, CA, USA). Shifted complexes were quantified by phospho-imager analysis (Biorad). Supershift reactions were performed by preincubation of the nuclear extracts with an antibody specific to the RelA subunit of NF-KB (Santa Cruz). 


\section{Statistics}

Data was analysed according to the guidelines of Altman et al. ${ }^{36}$ using SPSS (Statistical Package for the Social sciences, SPSS Inc., Chicago, IL, USA). Non-parametric tests, analysis of variance (ANOVA) or correlation analysis (Pearson) was used when appropriate. Data are represented as the mean \pm SD. A two-tailed probability value of less than 0.05 was considered to be significant.

\section{Results}

\section{Reduced muscle oxidative gene expression in COPD patients with muscle inflammation}

Patient characteristics after stratification by muscle TNF- $\alpha$ transcript levels are summarised in Table 5.1. Between patient subgroups, no differences were observed in lung function. Patients with high muscle TNF- $\alpha$ levels however revealed a lower body mass index (BMI) and fat-free mass index (FFMI) compared to control subjects indicative for (pre)cachexia. Moreover, in these patients muscle mRNA expression levels of genes involved in mitochondrial oxidative metabolism such as citrate synthase (CS), $\beta$-hydroxyacyl-CoA dehydrogenase (HAD) and cytochrome $c$ oxidase subunit 4 (COXIV) were lower $(p \leq 0.001)$ while expression of the glycolytic gene hexokinase 2 (HKII) was higher $(p=0.005)$ compared to patients with normal muscle TNF- $\alpha$ mRNA levels (Figure 5.1). Accordingly, muscle TNF- $\alpha$ transcript levels correlated negatively with transcript levels of CS and HAD and positively with transcript levels of HKII ( $r=-0.614, r=-0.514$ and $r=0.624$ respectively; $p \leq 0.001)$. Furthermore, these patients were characterised by lower muscle expression levels of several key regulators of skeletal muscle OXPHEN (PPAR- $\alpha$, PGC-1 $\alpha$ and Tfam) compared to patients with normal TNF- $\alpha$ expression levels in muscle $(p=0.001 ; p=0.003$ and $p=0.004$ respectively) (Figure 5.1). 
Table 5.1 Patient characteristics and skeletal muscle gene expression.

\begin{tabular}{lccc}
\hline & $\begin{array}{c}\text { Healthy Controls } \\
(\mathrm{n}=10)\end{array}$ & $\begin{array}{c}\text { COPD patients } \\
(\mathrm{normal} \text { TNF- } \alpha)(\mathrm{n}=17)\end{array}$ & $\begin{array}{c}\text { COPD patients } \\
(\text { high TNF- } \alpha)(\mathrm{n}=17)\end{array}$ \\
\hline Patient characteristics & & & \\
FEV1 $(\%$ predicted) & $82.8 \pm 7.6$ & $37.6 \pm 16.1 * *$ & $36.6 \pm 12.4^{* *}$ \\
Age (y) & $54.7 \pm 10.4$ & $60.5 \pm 8.3$ & $62.0 \pm 9.0$ \\
Sex (M/F) & $8 / 2$ & $16 / 2$ & $16 / 2$ \\
Weight (kg) & $77.5 \pm 17.5$ & $75.1 \pm 14.9$ & $67.2 \pm 13.3$ \\
BMl (kg/m2) & $27.2 \pm 3.7$ & $25.9 \pm 4.7$ & $23.8 \pm 3.5^{*}$ \\
FFMl (kg/m2) & $18.3 \pm 2.3$ & $17.5 \pm 2.5$ & $16.7 \pm 1.5^{*}$ \\
Muscle gene expression & & & \\
TNF- $\alpha(\mathrm{AU})$ & $0.038 \pm 0.024$ & $0.041 \pm 0.018$ & $0.147 \pm 0.065^{\# * *}$ \\
\hline
\end{tabular}

Gene expression levels for TNF- $\alpha$ were normalised by calculating a normalisation factor based on expression levels of 5 housekeeping genes (cyclophilinA, $\beta 2$-microglobuline, Glyceraldehyde-3Phosphate Dehydrogenase, hypoxanthine-guanine phosphoribosyltransferase and $\beta$-actin) using geNorm software. Gene expression was quantified and expressed as arbitrary units (AU). Values are expressed as mean $\pm S D$; significance compared to controls: * $p \leq 0.05$, ${ }^{* *} p \leq 0.001$; significance of difference between COPD sub groups: \# $p<0.001 ; F^{2} V_{1}$ : Forced expiratory volume in one second; BMI: Body mass index; FFMI: Fat-free mass index; TNF- $\alpha$ : Tumour necrosis factor alpha.
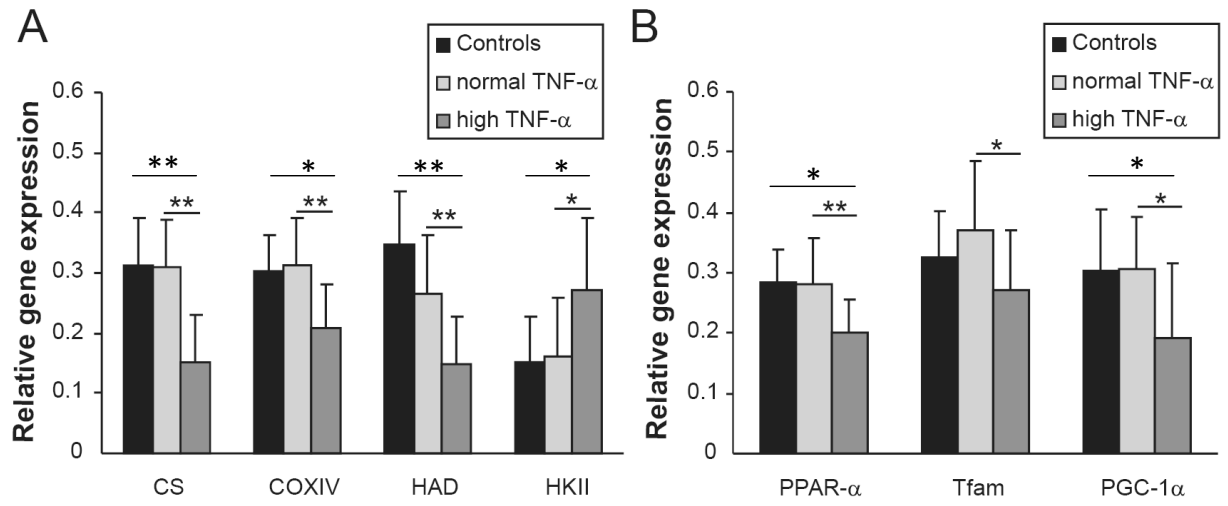

Figure 5.1 Oxidative gene expression is reduced in skeletal muscle of COPD patients with high muscle TNF- $\alpha$ mRNA expression. Transcript levels of oxidative genes and their regulators were assessed in control subjects $(n=10)$ and COPD patients characterised by high $(n=17)$ or normal $(n=17)$ muscle TNF- $\alpha$ mRNA expression. Gene expression levels were normalised by calculating a normalisation value based on five housekeeping genes (cyclophilinA, $\beta 2$-microglobuline, Glyceraldehyde-3Phosphate Dehydrogenase, hypoxanthine-guanine phosphoribosyltransferase and $\beta$-actin) using geNorm software. Significance compared to controls: * $p \leq 0.05$, ${ }^{* *} p \leq 0.001$; All data are expressed as mean \pm SD. HAD: $\beta$-hydroxyacyl-CoA dehydrogenase; CS: Citrate synthase; COXIV: Cytochrome $c$ oxidase subunit 4; HKII: Hexokinase II; PPAR- $\alpha$ : Peroxisome proliferator-activated receptor $\alpha$; PGC-1 $\alpha$ : Peroxisome proliferator-activated receptor y co-activator $1 \alpha$; Tfam: Mitochondrial transcription factor $\mathrm{A}$. 


\section{TNF-a impairs skeletal muscle OXPHEN in vitro}

To investigate if chronic elevations in local TNF- $\alpha$ levels can affect skeletal muscle OXPHEN in vitro, mitochondrial $\mathrm{O}_{2}$ consumption, oxidative phosphorylation (OXPHOS) protein content as well as myosin heavy chain $(\mathrm{MyHC})$ I and II protein and mRNA distribution were assessed in $\mathrm{C} 2 \mathrm{C} 12$ myotubes in response to chronic TNF- $\alpha$ stimulation.

As illustrated in Figure 5.2A, myotubes chronically treated with TNF- $\alpha$ displayed significantly lower basal and maximal mitochondrial $\mathrm{O}_{2}$ consumption rates compared to vehicle-treated cells (TNF- $\alpha$ stimulation 3 or 5 days following initiation of differentiation yielded similar results; Supporting Information Fig. S1). Since a decreased muscle respiratory capacity upon TNF- $\alpha$ stimulation may be caused by reduced levels of proteins involved in the mitochondrial oxidative phosphorylation chain, protein abundance of subunits of OXPHOS complexes I-V were quantified. Chronic TNF- $\alpha$ exposure resulted in decreased protein levels of subunits of OXPHOS complexes I, II, III, and V (Complex IV was not detectable) (Figure 5.2B).

A

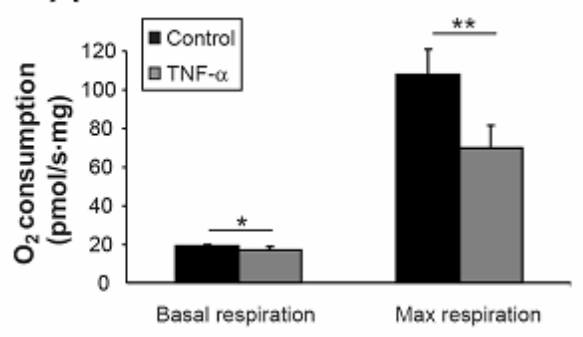

B

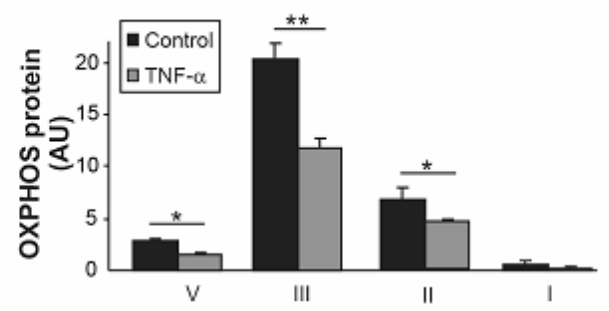

Figure 5.2 TNF- $\alpha$ impairs oxidative capacity in $\mathbf{C 2 C} 12$ cells. $\mathrm{C} 2 \mathrm{C} 12$ myoblasts were differentiated for three days in differentiation medium (DM). Myotubes were stimulated with vehicle (BSA: Control) or TNF-a $(10 \mathrm{ng} / \mathrm{ml})$ for an additional $120 \mathrm{~h}$. Cells were harvested and mitochondrial respiration rates as well as OXPHOS protein content were determined. All parameters were corrected for total protein content. A) The following substances were added to the respiration chambers in the following order and final concentration: digitonin $(1 \mu \mathrm{l} ; 0.5 \mu \mathrm{g} / \mathrm{ml})$, malate $(5 \mu \mathrm{l} ; 2 \mathrm{mM})$, palmitoylcarnitine $(10 \mu \mathrm{l} ; 50 \mu \mathrm{M})$ and ADP $(20 \mu \mathrm{l} ; 5 \mathrm{mM})$ followed by FCCP $(1 \mu \mathrm{l} ; 0.5 \mu \mathrm{M}$ titration) and oxygen consumption was measured. B) Proteins involved in the mitochondrial respiration chain were quantified by Western blot analysis. Protein levels are given as arbitrary units (AU). All data are expressed as mean \pm SD from triplicate samples (experiments $n=3$ ). Significance of difference: * $p \leq 0.05 ;{ }^{* *} p \leq 0.001$.

Next, MyHC isoform distribution in myotubes chronically treated with TNF- $\alpha$ was investigated. A selective reduction of $\mathrm{MyHC}$ slow (type I) protein abundance was observed compared to vehicle-treated cells while no significant 
effect of TNF- $\alpha$ on MyHC fast (type II) protein levels was found (Figure 5.3A, 5.3B). To further investigate the differential effect of chronic TNF- $\alpha$ stimulation on muscle MyHC isoform distribution, mRNA levels of the different MyHC isoforms were assessed. As depicted in Figure 5.3C, MyHC I mRNA levels decreased significantly whereas $\mathrm{MyHC}$ Ilb transcript abundance increased after TNF- $\alpha$ stimulation.

Since development of muscle OXPHEN parallels the process of myogenic differentiation ${ }^{9}$ and TNF- $\alpha$ is known to inhibit early differentiation ${ }^{10}$, the response of several differentiation markers upon chronic TNF- $\alpha$ stimulation was investigated. Myogenic index, which reflects the proportion of nuclei incorporated into myotubes and serves as a marker of morphological differentiation, was not significantly altered $(50.4 \% \pm 2.8$ vs $51.2 \% \pm 3.4)$ and creatine kinase activity, as a marker of biochemical differentiation, remained unchanged upon chronic TNF- $\alpha$ treatment $(0.47 \pm 0.08$ vs $0.43 \pm 0.09)$ (starting TNF- $\alpha$ stimulation after 3 or 5 days of differentiation respectively).

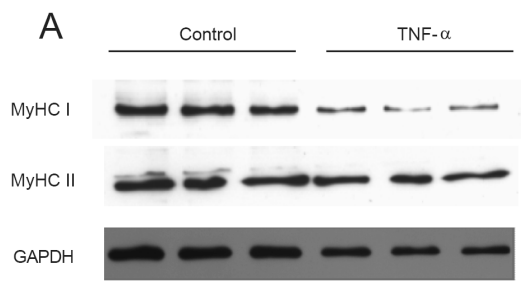

C
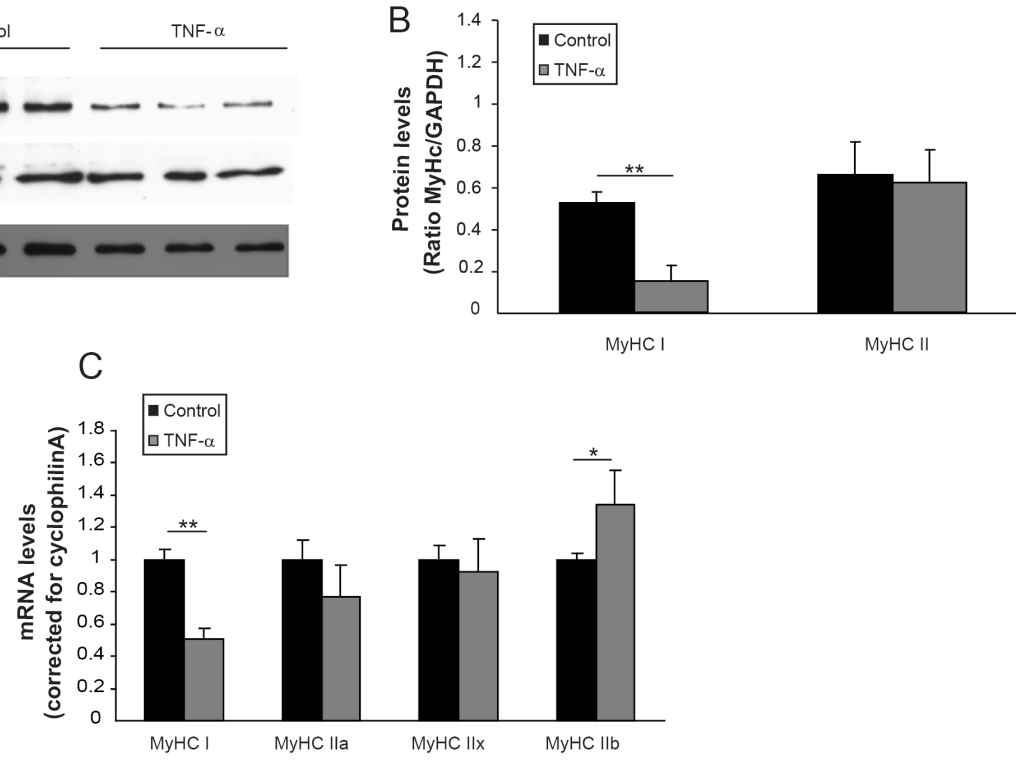

Figure 5.3 TNF- $\alpha$ alters MyHC profile in $\mathbf{C 2 C 1 2}$ cells. C2C12 myoblasts were differentiated for three days in DM. Myotubes were stimulated with vehicle (BSA: Control) or TNF- $\alpha$ $(10 \mathrm{ng} / \mathrm{ml})$ for $120 \mathrm{~h}$. Cells were harvested and MyHC profile was determined at the protein and mRNA level. A, B) MyHC protein expression was assessed and corrected for total protein content. GAPDH protein levels were used as a loading control. C) Gene expression levels were normalised for cyclophilinA as a representative housekeeping gene. Values are expressed as mean \pm SD. Significance compared to control: * $\mathrm{p} \leq 0.05,{ }^{* *} \mathrm{p} \leq 0.001$. All data are expressed as mean $\pm \mathrm{SD}$ from triplicate samples (experiments $n=3$ ). MyHC I, Ila, IIx, Ilb: Myosin Heavy Chain isoform I, Ila, Ilx or IIb; GAPDH: Glyceraldehyde-3-Phosphate Dehydrogenase. 


\section{TNF- $\alpha$ reduces expression levels of regulators of muscle OXPHEN}

We also investigated whether TNF- $\alpha$ is able to directly repress expression of regulators of skeletal muscle OXPHEN as observed in patient biopsies. As shown in Figure 5.4, chronic TNF- $\alpha$ treatment resulted in significantly decreased mRNA levels of PPAR- $\alpha$, PGC- $1 \alpha$ and Tfam, similar to observations in patients (Figure 5.4).

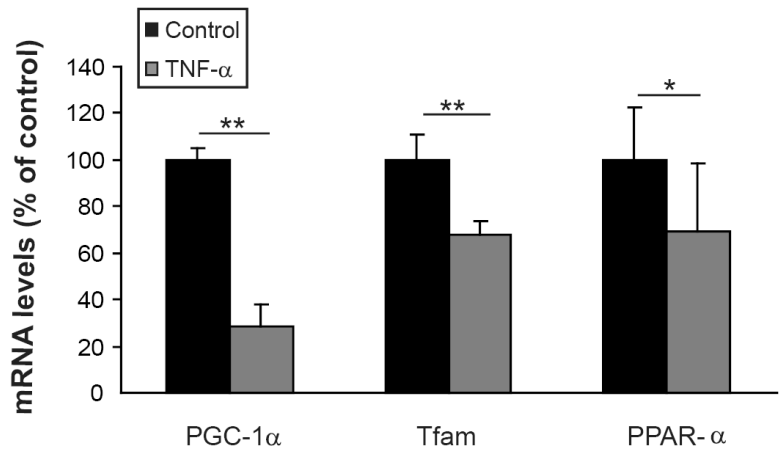

Figure 5.4 TNF- $\alpha$ reduces expression of regulators of skeletal muscle OXPHEN. C2C12 myoblasts were differentiated for three days in DM. Myotubes were stimulated with vehicle (BSA: control) or TNF- $\alpha(10 \mathrm{ng} / \mathrm{ml})$ for an additional $120 \mathrm{~h}$. Gene expression levels were normalised for cyclophilinA as a representative housekeeping gene. Gene expression was quantified and expressed as \% of control from triplicate samples (experiments $n=3$ ). Values are expressed as mean $\pm S D$. significance compared to controls: * $p \leq 0.05$, ${ }^{* *} p \leq 0.01$. PGC-1 $\alpha$ : peroxisome proliferatoractivated receptor $\mathrm{y}$ co-activator $1 \alpha$; Tfam: mitochondrial transcription factor $A$; PPAR- $\alpha$ : peroxisome proliferator-activated receptor $\alpha$.

\section{TNF- $\alpha$ reduces transcriptional activity and promoter trans- activation of major regulators of skeletal muscle OXPHEN}

Chronic TNF- $\alpha$ stimulation of myotubes resulted in reduced $(-50 \%)$ basal (Figure 5.5A) and ligand-induced PPAR transcriptional activity in myotubes (Supporting Information Figure 5.S2A). Additionally, PPAR transcriptional activity in myoblasts induced by over-expression of PPAR- $\alpha, \delta, \gamma$, or PGC-1 $\alpha$ was inhibited by TNF- $\alpha$ to the same extent (Supporting Information Figure 5.S2B). TNF- $\alpha$ also reduced nuclear respiratory factor 1 (NRF-1) as well as Tfam promoter activity levels in myoblasts by approximately $50 \%$ (Figure $5.5 \mathrm{~B}$ ). 
A

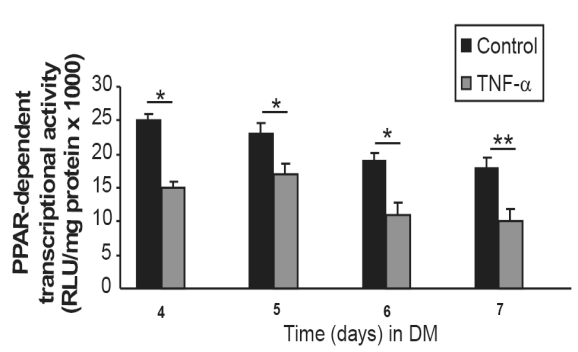

$B$

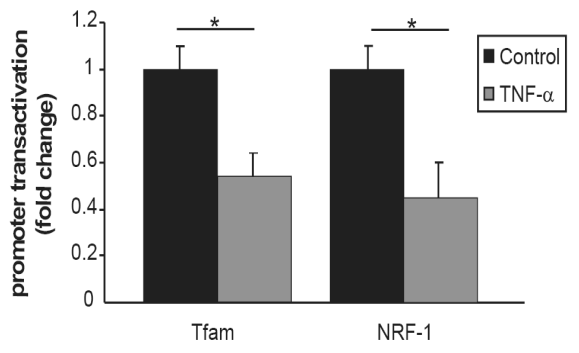

Figure 5.5 TNF- $\alpha$ reduces activity levels of major regulators of muscle OXPHEN. A) C2C12 myotubes stably transfected with a PPAR-sensitive promoter reporter construct (containing the cis-acting PPAR responsive element of the CPT-1 promoter) were differentiated for three days in DM. Myotubes were stimulated with vehicle (BSA: Control) or TNF- $\alpha(10 \mathrm{ng} / \mathrm{ml})$ and harvested every $24 \mathrm{~h}$. B) C2C12 myoblasts were transiently transfected with a Tfam or a NRF-1 promoter reporter construct and stimulated with TNF- $\alpha(10 \mathrm{ng} / \mathrm{ml})$ or vehicle (BSA: control) for $24 \mathrm{~h}$. Cells were lysed; luciferase activity was determined and normalised to $\beta$-galactosidase (transient transfection) or total protein (stable reporter cell line). Significance of difference: ${ }^{*} p \leq 0.05 ;{ }^{* *} p \leq 0.01$. Results are depicted as fold induction over control. All data are expressed as mean $\pm S D$ from triplicate samples (experiments $n=3$ ). DM: Differentiation medium; Tfam: Mitochondrial transcription factor A; NRF-1: Nuclear respiratory factor 1 .

\section{NF-kB activation is sufficient and required for impaired transcriptional regulation of muscle OXPHEN by TNF- $\alpha$}

Involvement of NF-KB signalling in the reduced activity levels of major regulators of muscle OXPHEN by TNF- $\alpha$ was investigated. Effectiveness of inflammatory cytokines and constructs encoding NF-KB subunits was confirmed using a stable NF-kB reporter cell line (Supporting Information Figure 5.S3). As illustrated in Figure 5.6A, expression of the super repressor mutant form of the inhibitory $\mathrm{KB} \alpha$ protein (IKBa-SR) fully abolished the effect of TNF- $\alpha$ on PPAR transcriptional activity, showing the requirement of intact NF-KB signalling for the effects of TNF- $\alpha$. Conversely, activation of NF-KB using constitutive active IKB kinase $\beta$ (c.a. IKK- $\beta$ ) was sufficient to inhibit PPAR transcriptional activity, which again was restored when the IKBa-SR was introduced (Figure 5.6A). Also, as illustrated in Figure 5.6B, induction of PPAR transcriptional activity by PPAR- $\alpha$ or PGC-1 $\alpha$ over-expression was attenuated when plasmids encoding the RelA NF-KB subunit were co-transfected. Since PGC-1a stimulates oxidative capacity via the transcriptional regulators of mitochondrial biogenesis NRF-1 and Tfam ${ }^{11}$, we investigated the effect of TNF- $\alpha / N F-\kappa B$ signalling on NRF-1 (Figure 5.6C) and Tfam (Figure 5.6D) promoter trans-activation. TNF-a reduced NRF-1 and Tfam promoter activity levels by $50 \%$ which was fully restored by blockade of NF-kB signalling through introduction of the IkBa-SR construct. Moreover, transfection of a c.a. IKK- $\beta$ construct also resulted in a 
$50 \%$ reduction in reporter activities which in turn was reversed when the IKBa-SR was co-introduced in the cell (Figure 5.6C, 5.6D). Introduction of the IKBa-SR construct without TNF- $\alpha$ showed increased PPAR transcriptional activity or NRF-1/Tfam promoter activity levels compared to control cells.

A

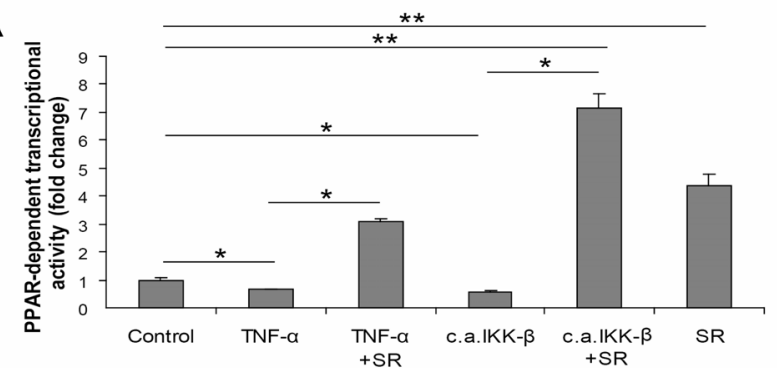

B

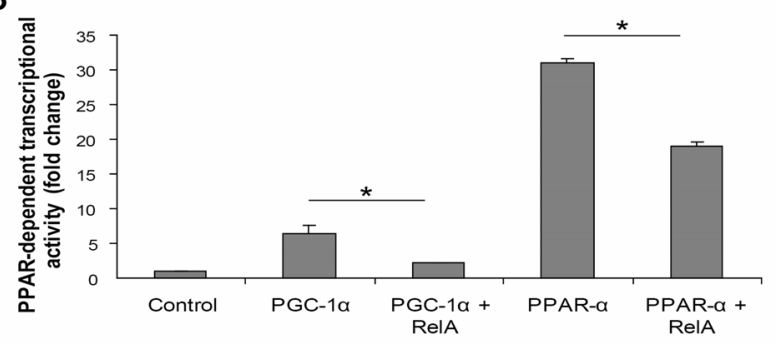

C
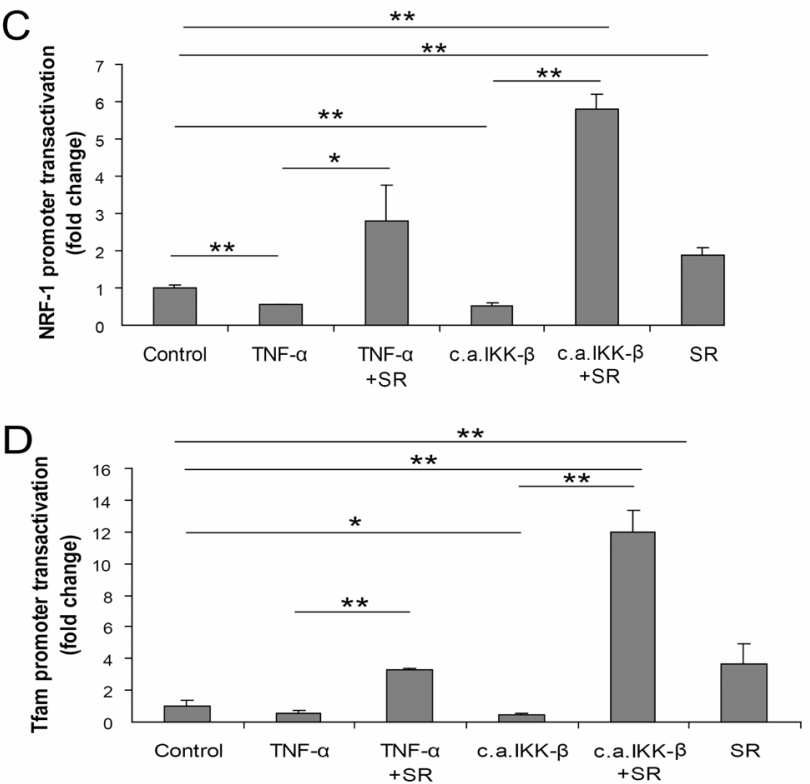
Figure 5.6 Involvement of NF-KB signaling in TNF- $\alpha$-induced deregulation of oxidative capacity. C2C12 myoblasts were co-transfected with A) a PPAR-sensitive promoter reporter construct (containing the cis-acting PPAR responsive element of the CPT-1 promoter) in combination with empty vector (e.v. pCDNA 3.1; control), an IkBa super repressor (SR) and/or a constitutive active IKB kinase $\beta$ (c.a. IKK- $\beta$ ) construct and treated with vehicle (BSA: Control) or TNF- $\alpha(10 \mathrm{ng} / \mathrm{ml})$ for $24 \mathrm{~h}$. B) a PPAR reporter (CPT-1) in combination with e.v. (pCDNA3; control) or plasmids encoding PGC-1 $\alpha$ or PPAR- $\alpha$, with/without RelA (V-Rel Avian Reticuloendotheliosis Viral Oncogene Homolog A). C2C12 myoblasts were transiently transfected with C) a NRF-1 promoter reporter construct or D) a Tfam promoter reporter construct in combination with e.v. (pCDNA3.1; control), a SR and/or constitutive active IKK- $\beta$ construct and/or stimulated with TNF- $\alpha(10 \mathrm{ng} / \mathrm{ml})$ for $24 \mathrm{~h}$. Cells were lysed; luciferase activity was determined and normalised to $\beta$-galactosidase. Data is presented as mean \pm SD (experiments $n=3$ ). Error bars indicate the SD. Significance of difference: * $p \leq 0.01$. Results are depicted as fold induction over control.

\section{NF-kB activation is required for impaired mitochondrial respiratory capacity by $\mathrm{TNF}-\alpha$}

To elucidate whether NF-KB activation is required for TNF- $\alpha$-induced impairment of mitochondrial respiration in muscle, we measured mitochondrial respiratory capacity of L6 myotubes (stably expressing a control vector or an IKBa-SR plasmid) in response to chronic TNF- $\alpha$ stimulation. Basal and TNF- $\alpha-$ induced RelA DNA-binding was assessed by gel shift and found to be abrogated in myotubes stably expressing the IKBa-SR construct (Supporting Information Figure 5.S4). As shown in Figure 5.7, impaired respiratory capacity of L6 muscle cells upon chronic TNF- $\alpha$ stimulation was fully restored by stable blockade of the NF-kB signalling pathway (Figure 5.7).

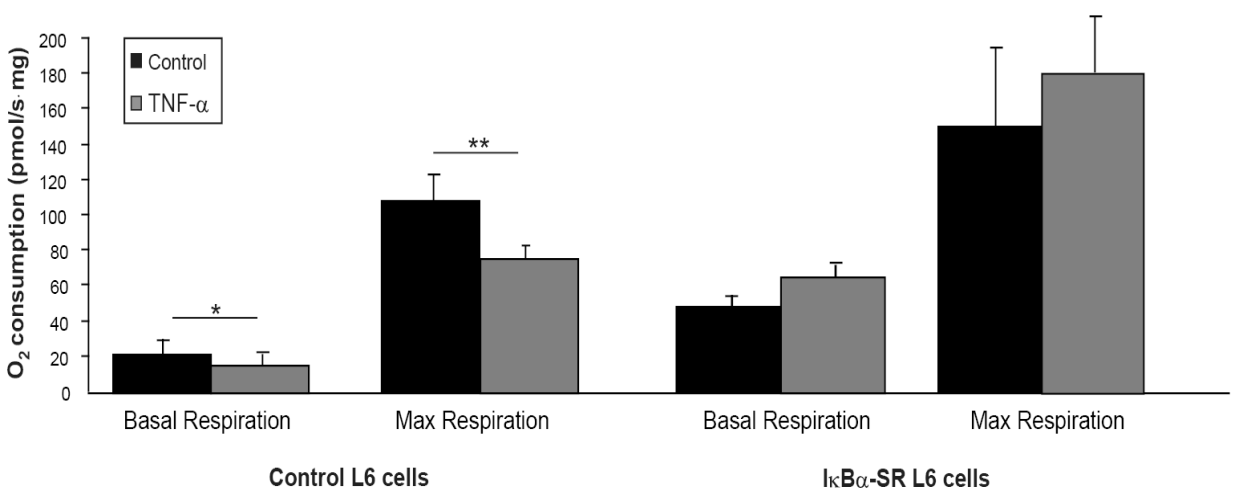

Figure 5.7 NF-KB activation is required for TNF- $\alpha$-induced impairment of skeletal muscle respiratory capacity. Control L6 muscle cells or L6 muscle cells with abrogated NF-KB signalling, through stable expression of the IKBa-SR construct, were differentiated for three days in DM. Myotubes were stimulated with vehicle (BSA: Control) or TNF- $\alpha(10 \mathrm{ng} / \mathrm{ml})$ for $120 \mathrm{~h}$. For respiration measurements, the following substances were added to the respiration chambers in the following order and final concentration: digitonin $(1 \mu \mathrm{l} ; 0.5 \mu \mathrm{g} / \mathrm{ml})$, malate $(5 \mu \mathrm{l} ; 2 \mathrm{mM})$, palmitoyl-carnitine $(10 \mu \mathrm{l} ; 50 \mu \mathrm{M})$ and FCCP $(1 \mu \mathrm{l} ; 0.5 \mu \mathrm{M}$ titration). Cells were harvested and oxygen consumption was determined. Respiration rates were corrected for total protein content. Data are expressed as mean \pm SD from triplicate samples (experiments $n=3$ ). Significance of difference: ${ }^{*} p \leq 0.05 ;{ }^{* *} p \leq 0.01$. 


\section{Discussion}

This study demonstrates that COPD patients with increased muscle TNF- $\alpha$ mRNA expression are not only characterised by cachectic features but also by decreased expression levels of markers and regulators of muscle OXPHEN. Moreover, our in vitro data reveal that TNF- $\alpha$ has a direct negative impact on muscle OXPHEN and its regulation which is dependent on NF-KB signalling. It is therefore feasible that this mechanism contributes to or mediates the loss of muscle OXPHEN in patients with advanced COPD, but possibly also in CHF.

To establish whether a disturbed regulation of muscle OXPHEN in advanced COPD patients with evidence of an increased muscle inflammatory status could be a direct effect of TNF- $\alpha$, we chronically stimulated cultured muscle cells with the pro-inflammatory cytokine TNF- $\alpha$. This resulted in an induction of TNF- $\alpha$ mRNA transcript levels in myotubes (data not shown), in line with the auto-amplificatory signalling described for this cytokine and illustrates that increased TNF- $\alpha$ mRNA levels in the biopsies may reflect autocrine or circulating cytokine actions. Similar to the data obtained in the patient group, our in vitro data showed that TNF- $\alpha$ signalling inversely relates to and actually decreases several parameters of skeletal muscle OXPHEN, including mitochondrial respiration rates and OXPHOS protein content. Interestingly, a recent study demonstrated decreased mitochondrial respiration, due to blockade of the electron transport chain, in vastus lateralis muscle of COPD patients ${ }^{12}$. Decreased mitochondrial respiration following TNF- $\alpha$ stimulation has been reported in experimental models previously ${ }^{13-15}$. However, in these particular studies only the acute effects of TNF- $\alpha$ were studied. Other studies revealed inhibition by TNF- $\alpha$ at several sites of the electron transport chain including complex II, III and $\mathrm{V}^{16,17}$. In contrast, the changes in respiration observed in our study are more likely chronic adaptations resulting from decreased expression of OXPHOS proteins after sustained incubation with TNF- $\alpha$, as the half-life of these proteins is several days ${ }^{18}$.

Loss of type I (slow, oxidative) fibers in peripheral skeletal muscle is a very consistent finding in COPD ${ }^{4,19}$ and is related to disease severity as described in a recent meta-analysis ${ }^{4}$. Unfortunately, fiber type data are not available in our COPD patient database but based on disease severity, a decreased content of type I fibers must be assumed.

The exact mechanism underlying this change in fiber type composition, which contributes significantly to exercise intolerance in patients, remains unknown. Intriguingly, chronic TNF- $\alpha$ treatment of cultured myotubes in the present study resulted in a selective reduction of oxidative (type I) MyHC isoform protein 
levels. Since it is known that inflammatory stimuli such as TNF- $\alpha$ can activate the proteolytic ubiquitin 26S-proteasome pathway ${ }^{20}$ it is possible that MyHC type I protein is selectively targeted for degradation by this pathway. However, increased gene expression levels of MuRF1 and Atrogin, the two E3 ligases that target muscle specific proteins for degradation ${ }^{21}$ were not observed after chronic TNF- $\alpha$ stimulation. As MyHC I mRNA levels were reduced while expression levels of $\mathrm{MyHC} \mathrm{llb}$ were increased after chronic TNF- $\alpha$ stimulation, the reduced protein content of MyHC type I most likely resulted from altered transcriptional control.

Previous work from our group showed that expression levels of PPARs and their co-activator PGC-1 $\alpha$ are reduced in peripheral skeletal muscle of COPD patients and correlate negatively with plasma inflammatory markers ${ }^{2}$. As the PGC-1a/PPAR signalling pathway has been shown to be a key regulatory pathway controlling muscle OXPHEN ${ }^{22}$ it is feasible that the observed detrimental effects of TNF- $\alpha$ stimulation on muscle OXPHEN are mediated through alterations in PPAR and PGC-1 $\alpha$ expression and/or activity levels. Our in vitro observations indeed demonstrate that TNF- $\alpha$ treatment of myotubes results in reduced PPAR transcriptional activity as well as PPAR mRNA expression levels. Moreover, in the present study, decreased muscle PPAR/PGC-1a mRNA expression levels were found in skeletal muscle of COPD patients with high levels of muscle TNF- $\alpha$ mRNA, establishing the pathophysiological relevance of our in vitro findings. Based on these observations, it is plausible that inflammation-associated alterations in the PPAR/PGC-1a/NRF-1/Tfam signalling axis underlie a decreased skeletal muscle OXPHEN in COPD and perhaps also in other chronic inflammatory diseases. The observation that COPD patients with elevated TNF- $\alpha$ mRNA levels in muscle were also characterised by a lower BMI and decreased muscle mass suggests that inflammatory signalling might be associated with both cachexia and impairment of muscle OXPHEN.

More mechanistic insight in the effect of TNF- $\alpha$ on skeletal muscle OXPHEN was provided by the finding that genetic blockade of the NF-KB signalling pathway inhibited TNF- $\alpha$-induced reductions in mitochondrial respiratory capacity and PPAR transcriptional activity in cultured muscle cells. Moreover, activating NF-KB signalling by over-expression of c.a. IKK- $\beta$, was sufficient to reproduce the effect of TNF- $\alpha$ on PPAR transcriptional activity. Similarly, RelA over-expression attenuated PGC-1 $\alpha$-induced PPAR transcriptional activity. Although PPARs have been shown to be able to interfere with the NF- $\mathrm{KB}$ pathway $^{23,24}$, few studies have in fact reported a negative impact of NF- $\mathrm{KB}$ signalling on the PGC-1 $\alpha / P P A R$ pathway ${ }^{25,26}$ and so far no data is available in skeletal muscle. Our findings now demonstrate that the NF-KB pathway 
mediates TNF- $\alpha$-induced inhibition of skeletal muscle mitochondrial respiratory capacity and PPAR transcriptional activity in vitro. In addition, promoter activity levels of NRF-1 and Tfam, two important regulators of mitochondrial biogenesis ${ }^{27}$, were also reduced upon TNF- $\alpha$ stimulation in a NF-KB-dependent manner. In line with these findings, a recent study showed decreased mRNA transcript levels of Tfam, NRF-1, but also PGC-1 $\alpha$, in mouse skeletal muscle satellite cells after TNF- $\alpha$ stimulation ${ }^{15}$. These observations suggest that, in addition to decreased PPAR activity, specific components implicated in regulation of mitochondrial biogenesis could also be impaired by TNF- $\alpha$ induced NF-KB activation. As Tfam mRNA levels were decreased in COPD patients with increased muscle TNF- $\alpha$ mRNA in the present study, NF-kBmediated impairment of PGC1 $\alpha / P P A R$ signalling may also be of relevance in patients.

Detrimental effects of TNF- $\alpha$ signalling are not restricted to impaired muscle OXPHEN. Loss of skeletal muscle mass ${ }^{6}$ and impaired myogenic differentiation, both mediated through the NF-KB pathway ${ }^{6,28,29}$, are well documented in skeletal muscle. Importantly, we show that the impairment of skeletal muscle OXPHEN mediated by TNF- $\alpha$ in the present study is not a consequence of impaired myogenic differentiation or decreased protein content. To the best of our knowledge this is the first report demonstrating a clear negative interaction between inflammatory mediators as TNF- $\alpha$, subsequent NF-KB signalling and skeletal muscle OXPHEN.

In light of these results and the fact that anti-inflammatory modulation in COPD improved exercise capacity ${ }^{7}$ and exercise endurance ${ }^{8}$, targeted inhibition of the NF-KB pathway could prove to be beneficial in multiple chronic inflammatory conditions characterised by disturbed muscle OXPHEN. Interestingly, our group recently demonstrated that PPAR- $y$ activation by Rosiglitazone, which is currently in use for the treatment of type 2 diabetes Mellitus (T2DM), potently inhibited cytokine-induced NF-KB activation in cultured muscle cells. Moreover, Rosiglitazone treatment of T2DM patients has been shown to increase skeletal muscle OXPHEN and restore PGC-1a/PPAR expression levels ${ }^{30}$.

In conclusion, data presented in the present manuscript collectively demonstrates that chronically elevated TNF- $\alpha$ levels potently reduce both structural and metabolic aspects that determine OXPHEN of skeletal muscle. This inflammation-associated impairment of muscle OXPHEN resulted from disturbed regulatory processes, as TNF- $\alpha$ down-regulated expression and activity levels of main regulators of muscle oxidative capacity and mitochondrial biogenesis. In addition, our in vitro data shows that deregulation of skeletal muscle OXPHEN by chronic TNF- $\alpha$ stimulation occurs in a NF-KB-dependent 
manner providing a mechanistic explanation. These results put recently published outcomes of nutritional and pharmacological anti-inflammatory therapy in COPD in a new perspective ${ }^{7,8}$ and may provide new leads for alleviation of exercise intolerance in COPD and possibly also other chronic inflammatory disorders. 


\section{References}

1. Tisdale MJ. Mechanisms of cancer cachexia. Physiol Rev 2009;89:381-410.

2. Pajak B, Orzechowska S, Pijet B, Pijet M, Pogorzelska A, Gajkowska B, Orzechowski A. (2008) Crossroads of cytokine signaling--the chase to stop muscle cachexia. J Physiol Pharmacol 2008;59(S9):251-64.

3. Gosker HR, Lencer NH, Franssen FM, van der Vusse GJ, Wouters EF, Schols AM. Striking similarities in systemic factors contributing to decreased exercise capacity in patients with severe chronic heart failure or COPD. Chest 2003;123: 1416-24.

4. Gosker H, Zeegers M, Wouters E, Schols AM. Muscle fibre type shifting in the vastus lateralis of patients with COPD is associated with disease severity: a systematic review and metaanalysis. Thorax 2007;62:944-9

5. Remels AH, Schrauwen P, Broekhuizen R, Willems J, Kersten S, Gosker HR, Schols AM. Expression and content of PPARs is reduced in skeletal muscle of COPD patients. Eur Respir J 2007;30:245-52

6. Cai D, Frantz JD, Tawa NE Jr, Melendez PA, Oh BC, Lidov HG, Hasselgren PO, Frontera WR, Lee J, Glass DJ, Shoelson SE. IKKbeta/NF-kappaB activation causes severe muscle wasting in mice. Cell 2004;119:285-98.

7. Broekhuizen R, Wouters EF, Creutzberg EC, Weling-Scheepers CA, Schols AM. Polyunsaturated fatty acids improve exercise capacity in chronic obstructive pulmonary disease. Thorax 2005;60:376-82.

8. Rennard SI, Fogarty C, Kelsen S, Long W, Ramsdell J, Allison J, Mahler D, Saadeh C, Siler T, Snell P, Korenblat P, Smith W, Kaye M, Mandel M, Andrews C, Prabhu R, Donohue JF, Watt R, Lo KH, Schlenker-Herceg R, Barnathan ES, Murray J; COPD Investigators. The safety and efficacy of infliximab in moderate to severe chronic obstructive pulmonary disease. Am J Respir Crit Care Med 2007;175:926-34.

9. Leary SC, Battersby BJ, Hansford RG, Moyes CD. Interactions between bioenergetics and mitochondrial biogenesis. Biochim Biophys Acta 1998;1365:522-30.

10. Guttridge DC, Albanese C, Reuther JY, Pestell RG, Baldwin AS Jr. NF-kappaB controls cell growth and differentiation through transcriptional regulation of cyclin D1. Mol Cell Biol 1999;19:5785-99.

11. Scarpulla RC Transcriptional activators and coactivators in the nuclear control of mitochondrial function in mammalian cells. Gene 2002;286:81-9.

12. Puente-Maestu L, Pérez-Parra J, Godoy R, Moreno N, Tejedor A, González-Aragoneses F, Bravo JL, Alvarez FV, Camaño S, Agustí A. Abnormal mitochondrial function in locomotor and respiratory muscles of COPD patients. Eur Respir J 2009;33:1045-52.

13. Lancaster JR, Jr., Laster SM, Gooding LR. Inhibition of target cell mitochondrial electron transfer by tumor necrosis factor. FEBS Lett 1989;248:169-74.

14. Schulze-Osthoff K, Bakker AC, Vanhaesebroeck B, Beyaert R, Jacob WA, Fiers W. Cytotoxic activity of tumor necrosis factor is mediated by early damage of mitochondrial functions. Evidence for the involvement of mitochondrial radical generation. $J$ Biol Chem 1992;267:5317-23.

15. Valerio A, Cardile A, Cozzi V, Bracale R, Tedesco L, Pisconti A, Palomba L, Cantoni O, Clementi E, Moncada S, Carruba MO, Nisoli E. TNF-alpha downregulates eNOS expression and mitochondrial biogenesis in fat and muscle of obese rodents. J Clin Invest 2006;116:2791-8.

16. Jia L, Kelsey SM, Grahn MF, Jiang XR, Newland AC. Increased activity and sensitivity of mitochondrial respiratory enzymes to tumor necrosis factor alpha-mediated inhibition is associated with increased cytotoxicity in drug-resistant leukemic cell lines. Blood 1996;87:2401-10.

17. Marin-Garcia J, Goldenthal MJ, Moe GW. Abnormal cardiac and skeletal muscle mitochondrial function in pacing-induced cardiac failure. Cardiovasc Res 2001;52:103-10.

18. Lyons $\mathrm{CN}$, Leary SC, Moyes CD. Bioenergetic remodeling during cellular differentiation: changes in cytochrome $\mathrm{c}$ oxidase regulation do not affect the metabolic phenotype. Biochem Cell Biol 2004;82:391-9. 
19. Gosker HR, van Mameren H, van Dijk PJ, Engelen MP, van der Vusse GJ, Wouters EF, Schols AM. Skeletal muscle fibre-type shifting and metabolic profile in patients with chronic obstructive pulmonary disease. Eur Respir J 2002;19:617-25.

20. Jackman RW, Kandarian SC. The molecular basis of skeletal muscle atrophy. Am J Physiol Cell Physiol 2004;287:C834-43.

21. Attaix D, Ventadour S, Codran A, Béchet D, Taillandier D, Combaret L. The ubiquitinproteasome system and skeletal muscle wasting. Essays Biochem 2005;41:173-86.

22. Luquet S, Lopez-Soriano J, Holst D, Fredenrich A, Melki J, Rassoulzadegan M, Grimaldi PA. Peroxisome proliferator-activated receptor delta controls muscle development and oxidative capability. Faseb J 2003;17:2299-301.

23. Pascual G, Fong AL, Ogawa S, Gamliel A, Li AC, Perissi V, Rose DW, Willson TM, Rosenfeld MG, Glass CK. A SUMOylation-dependent pathway mediates transrepression of inflammatory response genes by PPAR-gamma. Nature 2005;437:759-63.

24. Remels AH, Langen RC, Gosker HR, Russell AP, Spaapen F, Voncken JW, Schrauwen P, Schols AM. PPARgamma inhibits NF-kappaB-dependent transcriptional activation in skeletal muscle. Am J Physiol Endocrinol Metab 2009;297:E174-83.

25. Delerive P, De Bosscher K, Besnard S, Vanden Berghe W, Peters JM, Gonzalez FJ, Fruchart JC, Tedgui A, Haegeman G, Staels B. Peroxisome proliferator-activated receptor alpha negatively regulates the vascular inflammatory gene response by negative cross-talk with transcription factors NF-kappaB and AP-1. J Biol Chem 1999;274:32048-54.

26. Zhao CY, Wang JB, Deng ZJ, Liu JW, Li JM, Li L, Jiang LL. [Relationship between NF-kappa $B$ binding activity and expression of PPAR gamma-mRNA in the livers of rats with fatty liver disease]. Zhonghua Gan Zang Bing Za Zhi 2005;13:96-100.

27. Gleyzer N, Vercauteren K, Scarpulla RC. Control of mitochondrial transcription specificity factors (TFB1M and TFB2M) by nuclear respiratory factors (NRF-1 and NRF-2) and PGC-1 family coactivators. Mol Cell Biol 2005;25:1354-66.

28. Langen RC, Schols AM, Kelders MC, Wouters EF, Janssen-Heininger YM. Inflammatory cytokines inhibit myogenic differentiation through activation of nuclear factor-kappaB. Faseb J 2001;15:1169-80.

29. Guttridge DC, Mayo MW, Madrid LV, Wang CY, Baldwin AS Jr. NF-kappaB-induced loss of MyoD messenger RNA: possible role in muscle decay and cachexia. Science 2000;289:2363-6.

30. Mensink M, Hesselink MK, Russell AP, Schaart G, Sels JP, Schrauwen P. Improved skeletal muscle oxidative enzyme activity and restoration of PGC-1 alpha and PPAR beta/delta gene expression upon rosiglitazone treatment in obese patients with type 2 diabetes mellitus. Int $\mathrm{J}$ Obes (Lond) 2007;31:1302-10.

31. Fabbri L, Pauwels RA, Hurd SS. Global Strategy for the Diagnosis, Management, and Prevention of Chronic Obstructive Pulmonary Disease: GOLD Executive Summary updated 2003. Copd 2004;1:105-141; discussion 103-4.

32. Wu Z, Puigserver P, Andersson U, Zhang C, Adelmant G. Mootha V, Troy A, Cinti S, Lowell $B$, Scarpulla $R$ and Spiegelman B. Mechanisms controlling mitochondrial biogenesis and respiration through the thermogenic coactivator PGC-1. Cell 1999;98:115-24.

33. Gugneja S, Virbasius CM, Scarpulla RC. Nuclear respiratory factors 1 and 2 utilize similar glutamine-containing clusters of hydrophobic residues to activate transcription. Mol Cell Biol 1996;16:5708-16.

34. Gosker HR, Schrauwen P, Broekhuizen R, Hesselink MK, Moonen-Kornips E, Ward KA, Franssen FF, Wouters EF, Schols AM. Exercise training restores uncoupling protein-3 content in limb muscles of patients with chronic obstructive pulmonary disease. Am J Physiol Endocrinol Metab 2005;290:E976-81

35. van der Velden JL, Langen RC, Kelders MC, Willems J, Wouters EF, Janssen-Heininger YM, Schols AM. Myogenic differentiation during regrowth of atrophied skeletal muscle is associated with inactivation of GSK-3[3]. Am J Physiol Cell Physiol 2006;292:C1636-44

36. Altman DG, Gore SM, Gardner MJ, Pocock SJ. Statistical guidelines for contributors to medical journals. Br Med J (Clin Res Ed) 1983;286:1489-93. 



\section{Chapter 5}

\section{Supplementary Information}

\section{TNF- $\alpha$ impairs regulation of muscle oxidative phenotype: Implications for cachexia in COPD?}

Remels AHV, Gosker HR, Schrauwen P, Hommelberg P, Sliwinski P, Polkey M, Galdiz J, Wouters EF, Langen RC, Schols AMWJ. TNF- $\alpha$ impairs regulation of muscle oxidative phenotype: Implications for cachexia in COPD? Submitted 
Chapter 5 Supplement 


\section{TNF- $\alpha$ reduces mitochondrial respiration and alters MyHC composition in fully differentiated myotubes}

MyHC slow (type I) protein content (Figure 5.S1A, 5.S1B) and mitochondrial respiration rates (Figure 5.S1C) were significantly reduced after $120 \mathrm{~h}$ TNF- $\alpha$ treatment of fully differentiated myotubes (day 5) compared to vehicle(Control) treated cells similar to observations after chronic TNF- $\alpha$ treatment of 3 days differentiated myotubes.

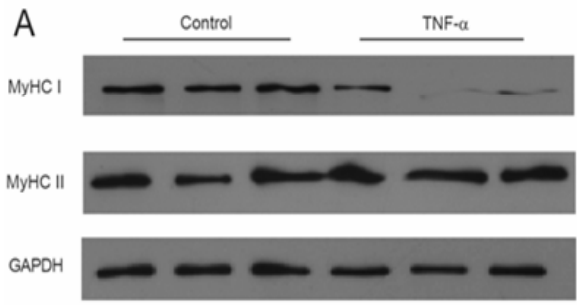

B

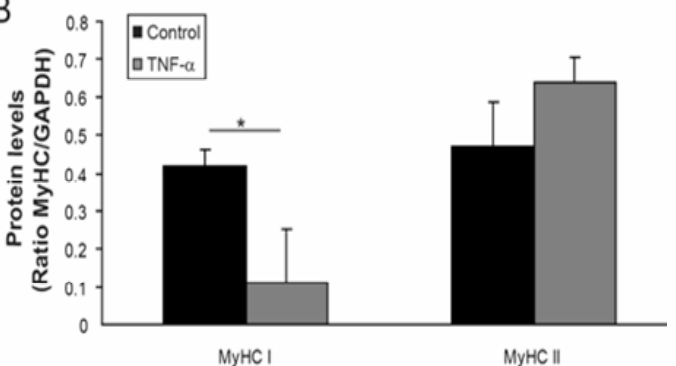

C

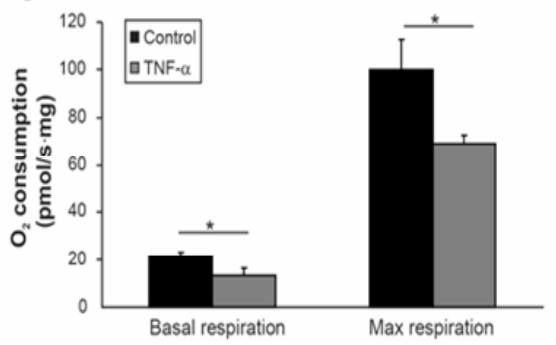

Figure 5.S1 TNF- $\alpha$ reduces mitochondrial respiration and alters MyHC profile. $\mathrm{C} 2 \mathrm{C} 12$ myoblasts were differentiated for 5 days in DM. Myotubes were stimulated with vehicle (BSA: Control) or TNF- $\alpha(10 \mathrm{ng} / \mathrm{ml})$ for $120 \mathrm{~h}$. Cells were harvested and $\mathrm{MyHC}$ profile and mitochondrial respiratory capacity were determined. All parameters were corrected for total protein content A, B) MyHC protein distribution was assessed and GAPDH (or tubulin, not shown) protein levels were used as a loading control. C) The following substances were added to the respiration chambers in the following order and final concentration: digitonin $(1 \mu \mathrm{l} ; 0.5 \mu \mathrm{g} / \mathrm{ml})$, malate $(5 \mu \mathrm{l} ; 2 \mathrm{mM})$, palmitoyl-carnitine $(10 \mu \mathrm{l} ; 50 \mu \mathrm{M})$ and ADP $(20 \mu \mathrm{l} ; 5 \mathrm{mM})$ followed by FCCP ( $1 \mu \mathrm{l} ; 0.5 \mu \mathrm{M}$ titration) and oxygen consumption was measured. Values are expressed as mean $\pm \mathrm{SD}$; Significance compared to controls: ${ }^{*} p \leq 0.05$. All from triplicate samples for 3 independent experiments. MyHC: Myosin heavy chain; TNF-a: tumour necrosis factor alpha; GAPDH: Glyceraldehyde-3-Phosphate Dehydrogenase. 


\section{TNF- $\alpha$ reduces ligand- as well as vector-induced PPAR-dependent transcriptional activity in C2C12 cells}

Chronic TNF- $\alpha$ treatment reduced ligand-induced (PPAR- $\delta$ : GW501516; PPAR- $\alpha$ : WY14643; PPAR-y: Rosiglitazone) PPAR-dependent transcriptional activity in myotubes by $50 \%$ (Figure 5.S2A). Additionally, PPAR-dependent transcriptional activity in myoblasts, induced by transient over-expression of PPAR- $\alpha, \delta$, or $\gamma$, or PGC-1 $\alpha$, was inhibited by TNF- $\alpha$ to the same extent (Figure 5.S2B).

A

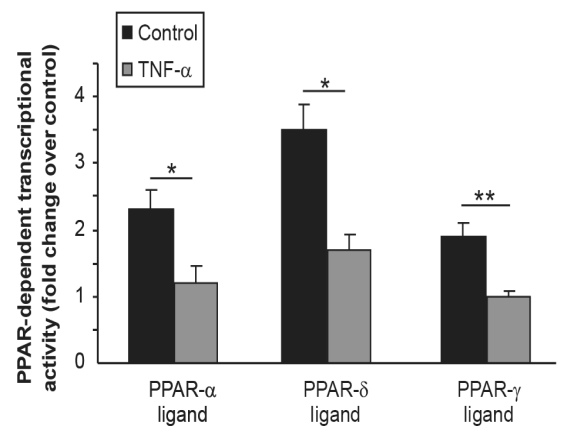

B

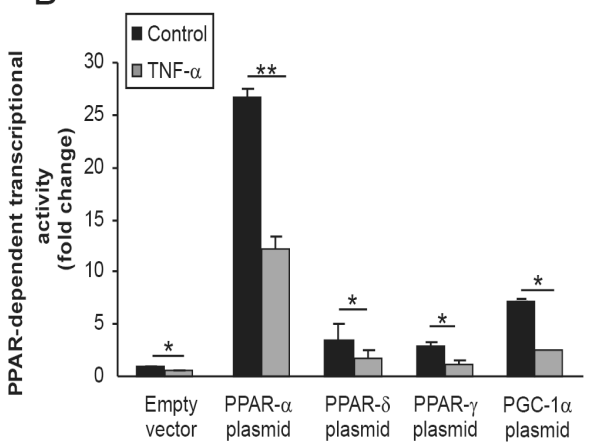

Figure 5.S2 TNF- $\alpha$ reduces PPAR-dependent transcriptional activity. A) C2C12 cells stably transfected with a PPAR-sensitive luciferase reporter construct (containing the cisacting PPRE of the CPT-1 promoter) were differentiated into myotubes for 5 days. Myotubes were stimulated with specific PPAR activators (PPAR- $\mathrm{\gamma}$ : Rosiglitazone 75 $\mu \mathrm{M}$; PPAR- $\delta$ : GW501516 $1 \mu \mathrm{M}$; PPAR- $\alpha$ : WY14643 $50 \mu \mathrm{M})$ for $24 \mathrm{~h}$ in combination with vehicle (BSA: Control) or TNF-a $(10 \mathrm{ng} / \mathrm{ml})$. B) C2C12 myoblasts were cotransfected with a PPAR reporter construct (containing the cis-acting PPRE of the CPT-1 promoter) and empty pcDNA 3.1 vector (e.v.) or plasmids encoding PPAR- $\gamma$, PPAR- $\delta$, PPAR- $\alpha$ or PGC- $1 \alpha$ and stimulated with vehicle (BSA: Control) or TNF- $\alpha$ $(10 \mathrm{ng} / \mathrm{ml})$ for $24 \mathrm{~h}$. Cells were lysed; luciferase activity was determined and normalised to total protein content (stable cell line) or $\beta$-galactosidase activity (transient transfections). PPAR-dependent transcriptional activity is expressed as fold change compared to vehicle control (no ligand, A) or BSA-treated e.v. control (B). Significance of difference: * $p \leq 0.05 ;{ }^{* *} p \leq 0.01$. Data are expressed as mean \pm $\mathrm{SD}$. Error bars indicate the SD. Shown are the representative data of 3 independent experiments.

\section{Functional verification of NF-kB modulation in C2C12 myoblasts}

Functionality of constructs encoding components of the NF-KB pathway (IKBa$\mathrm{SR}$, RelA and c.a. IKK- $\beta$ ) was verified using $\mathrm{C} 2 \mathrm{C} 12$ myoblasts transiently 
transfected with a NF-KB reporter construct, stimulated with TNF- $\alpha$ and/or cotransfected with the respective constructs. As shown in Figure 5.S3, TNF- $\alpha$ as well as c.a. IKK- $\beta$ and RelA constructs were capable of inducing NF-KB transcriptional activity in myoblasts. The IKBa-SR construct inhibited TNF- $\alpha-$ as well as c.a. IKK- $\beta$-induced NF-KB transcriptional activation.

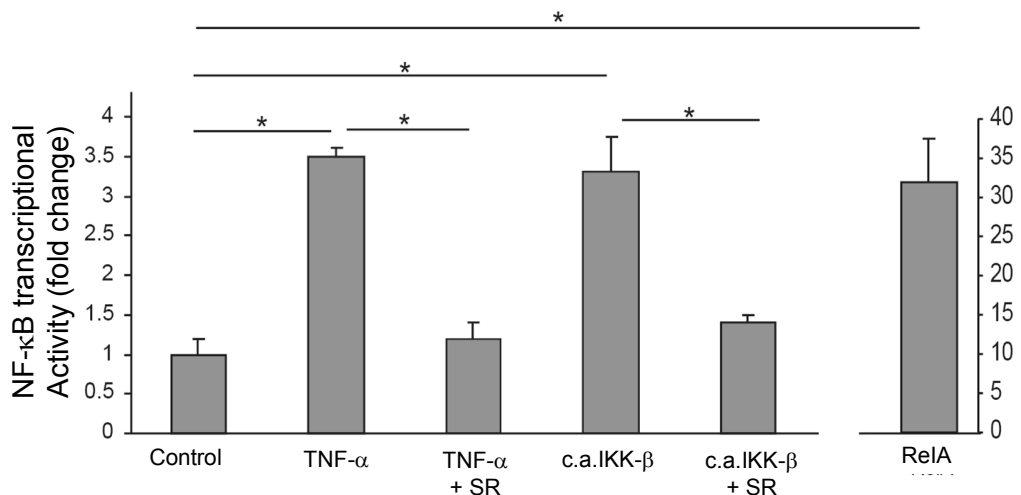

Figure 5.S3 Functionality of NF-kB-encoding constructs. $\mathrm{C} 2 \mathrm{C} 12$ myoblasts were cotransfected with a NF-KB reporter (6KB-luciferase) construct in combination with e.v. (pCDNA3.1; control), a constitutive active IKK- $\beta$ or RelA construct, alone or in combination with an IKBa super repressor (SR) construct, or treated with vehicle (BSA: Control) or TNF- $\alpha(10 \mathrm{ng} / \mathrm{ml})$ for $24 \mathrm{~h}$. Cells were lysed; luciferase activity was determined and normalised to $\beta$-galactosidase. Data is presented as mean $\pm S D$. Error bars indicate the SD. Significance of difference: * $p \leq 0.01$. Results are depicted as fold change over control. Shown are the representative data of 3 independent experiments. TNF- $\alpha$ : tumour necrosis factor alpha; SR: super repressor; c.a. IKK- $\beta$ : constitutively active IKK beta; RelA: V-Rel Avian Reticuloendotheliosis Viral Oncogene Homolog A.

\section{Functional verification of NF-KB modulation in L6 myotubes}

L6 skeletal muscle cells were stably transfected with an IKBa-SR construct or empty vector plasmid (PcDNA 3.1; control). Responsiveness of the control and the IKBa-SR cell line to TNF- $\alpha$ stimulation was verified with an electric mobility shift assay (EMSA) designed to measure RelA DNA binding capacity. As depicted in Figure 5.S4, L6 control myotubes showed increased RelA DNA binding after TNF- $\alpha$ stimulation. In contrast, IKBa-SR myotubes revealed markedly lower RelA DNA binding capacity compared to the control cells after TNF- $\alpha$ stimulation. Supershift analysis (panel B) demonstrates the presence of RelA in the main complex after TNF- $\alpha$ stimulation. 
A

Control L6 cells

I $\mathrm{B} \alpha$-SR L 6 cells

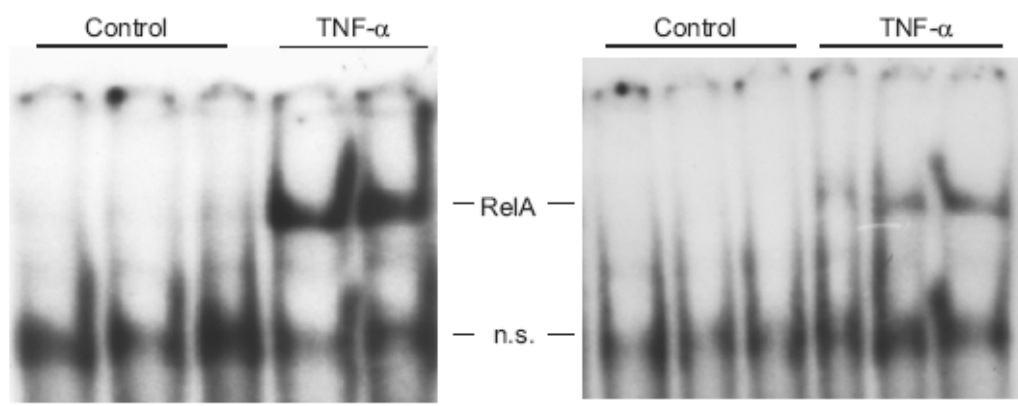

B

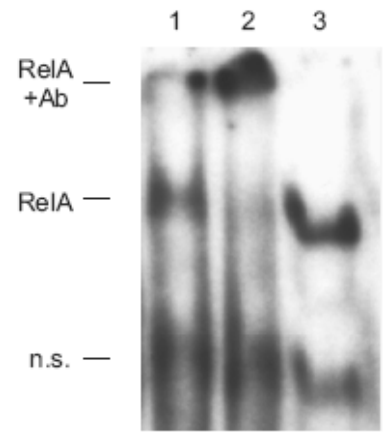

Figure 5.S4 Inhibition of TNF- $\alpha$-induced RelA translocation in IKBa-SR L6 myotubes. L6 myoblasts were stably transfected with an empty vector plasmid (PCDNA3.1) or with an IKBa-SR construct and differentiated for 5 days in differentiation medium. Myotubes were stimulated with vehicle (BSA: Control) or TNF- $\alpha(10 \mathrm{ng} / \mathrm{ml})$ for $1 \mathrm{~h}$. Cells were lysed and nuclear extracts were prepared to assess A) NF-KB DNA binding activity by electric mobility assay (EMSA). B) Supershift analysis using a RelA (V-Rel Avian Reticuloendotheliosis Viral Oncogene Homolog) A) antibody (lane 2) or an isotype control antibody (lane 3) was used to assess complex subcomposition compared to no antibody (lane 1). n.s.: Non-significant band.

\section{Subjects and Methods}

\section{Collection and processing of muscle tissue}

The specimens were immediately snap frozen in liquid nitrogen and stored at $-80^{\circ} \mathrm{C}$ until use. The frozen biopsies were weighed and subsequently homogenised using a Polytron PT 1600 E (Kinematica AG, Littau/Luzern, Germany). 


\section{Chemicals and reagents}

TNF- $\alpha$ (Calbiochem, Nottingham, United Kingdom) was dissolved in $0.1 \%$ BSA which also served as a vehicle control $(0.005 \%$ final concentration). Digitonin, malate, palmitoyl-carnitine, ADP and FCCP (all from Sigma Aldrich, Zwijndrecht, Netherlands) were dissolved according to MiPNet protocols (Oroboros Instruments, Innsbruck, Austria). Rosiglitazone-maleate (Alexis Biochemicals, Lausen, Switzerland), WY14643 (Biomol, Plymouth Meeting, PA, USA) and GW501516 (Alexis Biochemicals) were all dissolved in 100\% DMSO to a stock solution of $75 \mathrm{mM}, 25 \mathrm{mM}$ and $5 \mathrm{mM}$ respectively.

\section{Transfection and plasmids}

Cells were grown to be $50 \%$ confluent and transfected by nanofectin according to manufacturer's instructions (PAA, Pasching, Austria). For construction of the stable PPAR reporter cell line, transfection was performed in the presence of $3.75 \mu \mathrm{g}$ HCBP plasmid DNA and $0.25 \mu \mathrm{g}$ of a plasmid containing the neomycin resistance gene (pSV2-Neo, Stratagene, La Jolla, CA, USA). For selection of positive clones, cells were cultured in growth medium (GM) containing $800 \mu \mathrm{g} / \mathrm{ml} \mathrm{G418} \mathrm{(Calbiochem).} \mathrm{To} \mathrm{investigate} \mathrm{the} \mathrm{involvement} \mathrm{of} \mathrm{NF-KB}$ signalling, plasmids encoding IKBa-SR (pSFFV-NEO-IKBa-SR) (constitutively expressed under control of the SFFV-LTR); kind gift from Dr. Rosa Ten (Mayo Clinic, Rochester, MN, USA), RelA or a constitutive active form of IKK- $\beta$ (c.a. IKK- $\beta$ ); kind gifts from Dr. Michael Karin; University of California, San Diego, La Jolla, CA, USA) were transiently transfected into $\mathrm{C} 2 \mathrm{C} 12$ myoblasts according to the same protocol. For the assessment of NF-KB transcriptional activation, C2C12 cells were stably transfected with a 6KB-TK luciferase plasmid (NF-KB reporter) ${ }^{5}$. Plasmids encoding different PPAR isoforms (PPAR-ס, PPAR-y or PPAR- $\alpha$ ) or PGC-1 $\alpha$ were all kind gifts from Dr. J Auwerx (CNRS/INSERM, Lille, France), Dr. P. Grimaldi (INSERM U636, Nice, France) and Dr. D. Kelly (Washington University School of Medicine St. Louis, USA) respectively. For creation of $\mathrm{L} 6$ cells stably expressing the IKBa-SR construct, a similar approach as used for the creation of $\mathrm{C} 2 \mathrm{C} 12$ stable cell lines was applied. PcDNA3.1 empty vector again was used as a control.

\section{Reporter assays}

The PPAR reporter cell line was plated in $35 \mathrm{~mm}$ dishes and allowed to grow to $70 \%$ confluency. After induction of differentiation, cells were differentiated into myotubes for 3 or 5 days after which cells were stimulated. Stimuli were refreshed together with medium every $48 \mathrm{~h}$. After stimulation, cells were washed $2 x$ with cold PBS, and subsequently lysed by adding $(100 \mu \mathrm{l}) 1 \mathrm{x}$ Reporter Lysis Buffer (Promega, Madison, WI, USA) and incubation on ice for $10 \mathrm{~min}$. Cell lysates were centrifuged $(14000 \mathrm{rpm}, 1 \mathrm{~min})$ and supernatants 
were snap frozen and stored at $-80^{\circ} \mathrm{C}$ for later analysis. Luciferase activity was measured according to manufacturer's instructions (Promega) and corrected for total protein content (Biorad, Hercules, CA, USA). For transient transfection assays, $\mathrm{C} 2 \mathrm{C} 12$ myoblasts were plated at $60 \%$ confluency in $35 \mathrm{~mm}$ dishes and transfected according to manufacturer's instructions (PAA). $24 \mathrm{~h}$ after transfection, differentiation was induced with differentiation medium and cells were stimulated with TNF- $\alpha(10 \mathrm{ng} / \mathrm{ml})$ for 24-120 h. Luciferase (Promega) and $\beta$-galactosidase (Tropix, Bedford, MA, USA) were measured according to manufacturer's instructions.

\section{Mitochondrial respiration}

C2C12 differentiated myotubes were harvested in trypsin, washed twice with MIRO5 respiration medium $\left(37^{\circ} \mathrm{C}\right)$ and, after a 5 min centrifugation at $500 \mathrm{rpm}$, resuspended in $2.5 \mathrm{ml}$ of MIRO5 respiration medium. $2.0 \mathrm{ml}$ of cell suspension was used for the measurement of mitochondrial respiration. The remaining cell suspension was used for determination of total protein content (Biorad). The amplified signal from the oxygen sensor was recorded at $0.5 \mathrm{~Hz}$ (DatLab acquisition software, Oroboros Instruments). The respiration medium was equilibrated with air in the oxygraph chambers at $37^{\circ} \mathrm{C}$ and stirred until a stable signal was obtained for calibration at air saturation. After calibration the medium was replaced by aerated cell suspensions at a volume of $2.0 \mathrm{ml}$. After insertion, cells were permeabilised using $1 \mu \mathrm{l}$ of digitonin $(0.5 \mu \mathrm{g} / \mathrm{ml}$ final concentration) and substrates were added in chronological order (volume; final concentration): malate $(5 \mu \mathrm{l} ; 2 \mathrm{mM})$ and palmitoyl-carnitine $(10 \mu \mathrm{l} ; 50 \mu \mathrm{M})$. At the end of the substrate trace a titration with the uncoupling agent FCCP was performed (1 $\mu \mathrm{l} ; 0.5 \mu \mathrm{M}$ titration). Oxygen consumption $(\mathrm{pmol} / \mathrm{ml} \cdot \mathrm{s})$ was calculated as a negative time derivative of oxygen concentration $(\mathrm{nmol} / \mathrm{ml})$. Respiration rates were corrected for total protein content to correct for variability in cellular input.

\section{Western blot analysis}

$25 \mu \mathrm{g}$ or $10 \mu \mathrm{g}$ of protein (OXPHOS and MyHC respectively) was loaded per lane and separated on a $10 \%$ polyacrylamide gel (Mini Protean 3 system; Biorad), followed by transfer to a $0.45 \mu \mathrm{m}$ nitrocellulose membrane (Biorad Hercules) by electro-blotting. The membrane was blocked for $1 \mathrm{~h}$ at room temperature in $5 \%(\mathrm{w} / \mathrm{v})$ non-fat dry milk. Nitrocellulose blots were washed in PBS-Tween $20(0.05 \%)$, followed by overnight incubation $\left(4^{\circ} \mathrm{C}\right)$ with a polyclonal antibody specific for OXPHOS proteins (Cell Signalling, Beverly, MA, USA) or MyHC type I or II isoforms (Sigma Aldrich). The antibody used for detection of OXPHOS proteins was directed against the ND6 subunit of complex I, the $30 \mathrm{kDa}$ Ip subunit of complex II, subunit II of COXII and the 
alpha subunit of the F1F0 ATP synthase (complex V). After three wash steps of $20 \mathrm{~min}$ each, the blots were probed with a peroxidase-conjugated secondary antibody (Vector Laboratories, Burlingame, CA, USA) and visualised using SuperSignal West Pico chemiluminescent substrate (Pierce Biotechnology, Rockford, IL, USA) according to the manufacturer's instructions.

\section{Preparation of nuclear extracts}

C2C12 myotubes were harvested in ice-cold buffer A (20 mM HEPES: $\mathrm{pH} 7.8$; $20 \mathrm{mM} \mathrm{KCl} ; 4 \mathrm{mM} \mathrm{MgCl}$; $0.2 \mathrm{mM}$ EDTA: $\mathrm{pH} 8.0 ; 1 \mathrm{mM}$ DTT; $0.2 \mathrm{mM}$ NaVanadate; $0.4 \mathrm{mM}$ PMSF; $0.3 \mathrm{mg} / \mathrm{ml}$ Leupeptin; $0.2 \mathrm{mM} \mathrm{NaF}$ ) and transferred to Eppendorf tubes. Cells were kept on ice for $15 \mathrm{~min}$ followed by 45 min incubation on a rotating platform at $4^{\circ} \mathrm{C}$. Buffer B (Nonidet P40) was added, samples were mixed vigorously and centrifuged (5 min; $14000 \mathrm{rpm}$ ). Supernatant was removed (cytoplasmatic fraction), pellets were washed in buffer $A+B$, mixed and centrifuged (5 min; $14000 \mathrm{rpm}$. Supernatant was removed and nuclei were lysed in buffer $C$ (100 mM HEPES: $\mathrm{pH} 7.8 ; 100 \mathrm{mM}$ $\mathrm{KCl} ; 600 \mathrm{mM} \mathrm{NaCl} ; 0.2 \mathrm{mM}$ EDTA: pH 8.0; $20 \%$ glycerol; $1 \mathrm{mM}$ DTT; $0.2 \mathrm{mM}$ NaVanadate; $0.4 \mathrm{mM}$ PMSF; $0.2 \mathrm{mM} \mathrm{NaF}$ ) by 20 min incubation at a rotating platform at $4^{\circ} \mathrm{C}$. Samples were centrifuged (5 min; $14000 \mathrm{rpm}$ ), supernatant was transferred to a new Eppendorf tube and stored at $-80^{\circ} \mathrm{C}$.

\section{Electrophoretic mobility shift assay (EMSA)}

$2 \mu \mathrm{g}$ of nuclear protein was used per binding reaction and protein-DNA complexes were resolved on a $5 \%$ polyacrylamide gel in $0.25 \mathrm{X}$ Tris-borateEDTA buffer at $120 \mathrm{~V}$ for $2 \mathrm{~h}$. Gels were dried and exposed to film (X-Omat Blue XB-1, Kodak, Rochester, NY, USA).

\section{May-Grunwald Giemsa staining}

Cells were grown on Matrigel-coated $60 \mathrm{~mm}$ dishes and after stimulation experiments with TNF- $\alpha$, cells were washed $2 x$ in PBS (room temperature), fixed in methanol and stained in May-Grunwald Giemsa (Sigma Aldrich) according to manufacturer's instructions.

\section{Quantitative PCR (QPCR)}

Total RNA was extracted using the acid guanidium thiocyanate-phenolchloroform extraction method (Ambion Ltd., United Kingdom). RNA concentration was determined using a spectrophotometer. $0.4 \mu \mathrm{g}$ of RNA per sample was reverse transcribed into cDNA according to the manufacturer's instructions (Biorad). cDNA was PCR amplified with SYBR green mix (Westburg, Leusden, the Netherlands) on a Biorad PCR apparatus. Primers 
were designed to generate a PCR amplification product of 100 to $150 \mathrm{bp}$. Specificity of the amplification was verified by melt curve analysis and evaluation of efficiency of PCR amplification. For cDNA synthesized from human biopsies, transcript levels for the constitutive housekeeping gene products cyclophilinA, hypoxanthine phosphoribosyltransferase (HPRT), $\beta 2-$ microglobuline, $\beta$-actin and glyceraldehyde-3-phosphate dehydrogenase (GAPDH) were quantitatively measured in each sample to control for sampleto-sample differences in RNA concentration. Gene expression levels were normalised by calculating an average value of the 5 housekeeping genes using Genorm software (Primerdesign, Southampton, USA). For cDNA synthesized from $\mathrm{C} 2 \mathrm{C} 12$ myotubes, transcript levels of cyclophilinA were determined as a representative housekeeping gene in each sample to control for sample-tosample differences in RNA concentration. Gene expression was quantified and expressed as arbitrary units (AU).

\section{Primer details}

Primers used for human gene expression profiling in skeletal muscle of patients and healthy controls as well as primers used for determination of gene expression in mouse $\mathrm{C} 2 \mathrm{C} 12$ cells are summarised in Table 5.S1. 
Table 5.S1 Human/mouse primers.

\begin{tabular}{|c|c|c|}
\hline Primer & Forward 5'-3' & Reverse 5'-3' \\
\hline$\overline{C S}$ & GATGTGTCAGATGAGAAGTTACGAGACT & TGGCCATAGCCTGGAACAA \\
\hline COXIV & CGTTCGAGCCCCTGTTCA & CCATGGATGAGAAAGTCGAGT \\
\hline$H A D$ & TGGCTTCCCGCCTTGTC & TGGAGCCGGTCCACTATCTTC \\
\hline$H K I I$ & TCAAGTGGACAAAAGGCTTCAA & CCGGTGGATCGCTTCCT \\
\hline PPAR- $\alpha$ & CAGAACAAGGAGGCGGAGGTC & AGGTCCAAGTTTGCGAAGC \\
\hline$P G C-1 \alpha$ & ATGCAGTGGTCTCAGTACCCA & TCTTCGCTTTATTGCTCCATGAA \\
\hline Tfam & ATAACGTTTATGTAGCTGAAAGATTCCA & TCAGAGTCAGACAGATTTTTCCAGTTT \\
\hline MuRF1 & GCGAGGTGGCCCCATT & GATGGTCTGCACACGGTCATT \\
\hline Atrogin & GAAGAAACTCTGCCAGTACCACTTC & CCCTTTGTCTGACAGAATTAATCG \\
\hline$T N F-\alpha$ & TCAATCGGCCCGACTATCTC & CAGGGCAATTGATCCCAAAGT \\
\hline CyclophilinA & CTCGAATAAGTTTGACTTGTGTTT & CTAGGCATGGGAGGGAACA \\
\hline GAPDH & GCACCACCAACTGCTTAGCA & TGGCAGTGATGGCATGGA \\
\hline HPRT & AGAATGTCTTGATTGTGGAAGA & ACCTTGACCATCTTTGGATTA \\
\hline$\beta$-actin & AAGCCACСССАСТTСТСТСТАA & ААTGCTATCACСТССССТGTGT \\
\hline B2-microglobulin & TGACTTTGTCACAGCCCAAGATA & AATGCGGCATCTTCAAACCT \\
\hline \multicolumn{3}{|c|}{ Mouse primer details } \\
\hline & Forward 5'-3' & Reverse 5'-3' \\
\hline $\mathrm{MyHCI}$ & CCAAGGGCCTGAATGAGGAG & GCAAAGGCTCCAGGTCTGAG \\
\hline MyHC IA & CGATGATCTTGCCAGTAATG & ATAACTGAGATACCAGCG \\
\hline MyHC IIb & ACAAGCTGCGGGTGAAGAGC & CAGGACAGTGACAAAGAACG \\
\hline MyHC IIx & GACAAACTGCAATCAAAGG & TTGGTCACTTTCCTGCACTT \\
\hline PPAR- $\alpha$ & AGTGCCCTGAACATCGAGTGT & AAGCCCTTACAGCCTTCACATG \\
\hline$P G C-1 \alpha$ & AAACCACACCCACAGGATCAG & TCTTCGCTTTATTGCTCCATGA \\
\hline Tfam & CGGAGTTCCCACGCTGG & CCGTCCGGTTCGTCTCAC \\
\hline CyclophilinA & TTCСТССТTTCACAGAATTATTCCA & CCGCCAGTGCCATTATGG \\
\hline
\end{tabular}

Definition of abbreviations: CS: citrate synthase; COXIV: cytochrome $c$ oxidase subunit 4; HAD: $\beta$ hydroxyacyl CoA-dehydrogenase; HKII: Hexokinase 2; PPAR-a: Peroxisome proliferator-activated receptor alpha; PGC-1a: Peroxisome proliferator-activated receptor gamma co-activator 1 alpha; Tfam: Mitochondrial transcription factor A; MuRF1: Muscle ring finger 1; TNF- $\alpha$ : Tumour necrosis factor alpha; GAPDH: Glyceraldehyde 3-phosphate dehydrogenase; HPRT: Hypoxanthine phosphoribosyltransferase; MyHC: Myosin heavy chain. 



\section{Chapter 6}

\section{PPAR-y inhibits NF-kB-dependent transcriptional activation in skeletal muscle}

Remels AH, Langen RC, Gosker HR, Russell AP, Schrauwen P, Schols AM. PPAR-y inhibits NF-KB-dependent transcriptional activation in skeletal muscle.

Am J Physiology Endocrinol 2009;297:E174-83 


\section{Abstract}

Skeletal muscle pathology associated with a chronic inflammatory disease state (e.g. skeletal muscle atrophy and insulin resistance) is a potential consequence of chronic activation of nuclear factor kappa B (NF-kB). It has been demonstrated that peroxisome proliferator-activated receptors (PPARs) can exert anti-inflammatory effects by interfering with transcriptional regulation of inflammatory responses. The goal of the present study therefore was to evaluate if PPAR activation affects cytokine-induced NF-KB activity in skeletal muscle. Using $\mathrm{C} 2 \mathrm{C} 12$ myotubes as an in vitro model of myofibers we demonstrate that PPAR-, and specifically PPAR-y, activation potently inhibits inflammatory mediator-induced NF-KB transcriptional activity in a time- and dose-dependent manner. Furthermore, PPAR- $y$ activation by Rosiglitazone strongly suppresses cytokine-induced transcript levels of the NF-kB-dependent genes intra-cellular adhesion molecule 1 (ICAM-1) and CXCL1 (KC), the murine homologue of interleukin 8 (IL-8), in myotubes. To verify if muscular NF$\kappa B$ activity in human subjects is suppressed by PPAR- $\gamma$ activation, we examined the effect of 8 weeks Rosiglitazone treatment on muscular gene expression of ICAM-1 and IL-8 in type 2 diabetes mellitus patients. In these subjects, we observed a trend towards decreased basal expression of ICAM-1 mRNA levels. Subsequent analyses in cultured myotubes revealed that the anti-inflammatory effect of PPAR-y activation is not due to decreased RelA translocation to the nucleus or reduced RelA DNA binding. These findings demonstrate that muscle-specific inhibition of NF-KB activation may be an interesting therapeutic avenue for treatment of several inflammation-associated skeletal muscle abnormalities. 


\section{Introduction}

There is increasing evidence in the literature that chronic activation of nuclear factor kappa B (NF-KB), which is an essential signalling pathway involved in conveying inflammatory signals, is causally related to skeletal muscle pathology. Wasting of skeletal muscle mass is commonly observed in chronic inflammatory diseases and has been associated with increased morbidity and mortality ${ }^{1,2}$. Several studies have shown that systemic inflammatory cytokines, such as tumour necrosis factor alpha (TNF- $\alpha$ ) and interleukin 1 beta (IL-1 $\beta$ ), are proximal markers of cachexia ${ }^{3-5}$. More specifically, quadriceps muscle biopsies of severely cachectic patients with chronic obstructive pulmonary disease (COPD) and chronic heart failure were characterised by activation of the NF-kB signalling pathway ${ }^{6,7}$. Moreover, forced activation of NF-kB in skeletal muscle causes profound muscle wasting that resembles clinical cachexia while inhibition of NF-KB signalling has proven to be sufficient to block inflammation-induced protein degradation in cultured skeletal muscle myotubes $^{5,8}$. In type II diabetes mellitus (T2DM) skeletal muscle insulin resistance is associated with decreased protein abundance of the inhibitory protein of $\mathrm{NF}-\mathrm{KB}, \mathrm{IKBa}{ }^{9}$, and increased transcript levels of NF-KB-dependent genes, including IL-8 in skeletal muscle ${ }^{10,11}$. These observations indicate that anti-inflammatory agents, capable of inhibiting NF-KB signalling, could be useful for treatment of inflammation-associated skeletal muscle abnormalities in chronic disease states.

Interestingly, it is known that activation of peroxisome proliferator-activated receptors (PPARs) can exert anti-inflammatory effects in several cell types as smooth muscle cells, endothelial cells and macrophages ${ }^{12,13}$. PPARs are a set of nuclear receptors implicated in a multitude of physiological processes ${ }^{14}$. They display transcriptional activity and are tissue-selectively expressed ${ }^{15}$. To date, three PPAR subtypes have been identified: PPAR- $\alpha$, PPAR- $\delta$ and PPAR- $\gamma^{16}$. Anti-inflammatory properties of the PPARs include the potential to interfere with transcriptional pathways involved in inflammatory responses e.g. modulation of NF-KB signalling. Several mechanisms have been described including inhibition of $\mathrm{IKBa}$ degradation, reduction of RelA (p65) nuclear translocation and diminished binding of RelA to the DNA ${ }^{17,18}$. Data on the potential of PPARs to interfere with NF-KB signalling in skeletal muscle however is lacking. Therefore, in the present study we investigated if PPAR activation in skeletal muscle is able to modulate inflammatory mediator-induced NF-KB activity. 
Our results reveal that PPAR- $\gamma$ activation suppresses cytokine-induced NF-KB transcriptional activity and -target gene expression in skeletal muscle, independent of nuclear translocation and DNA binding

\section{Subjects and methods}

\section{Cell culture}

The murine skeletal muscle cell line $\mathrm{C} 2 \mathrm{C} 12$ was obtained from the American Type Culture Collection (ATCC\# CRL1772, Manassas, VA, USA). These cells are able to undergo differentiation into spontaneously contracting myotubes upon growth factor withdrawal ${ }^{19}$. $\mathrm{C} 2 \mathrm{C} 12$ cells were cultured as described previously ${ }^{20}$. Cells were treated with a sub-maximal dose of TNF- $\alpha(1 \mathrm{ng} / \mathrm{ml})$ or $\mathrm{IL}-1 \beta(1 \mathrm{ng} / \mathrm{ml})$ and/or PPAR agonists at day 6 of differentiation.

\section{Chemicals and reagents}

Tetradecylthioacetic acid (TTA) (Sigma Aldrich, Zwijndrecht, the Netherlands) was dissolved in $100 \%$ ethanol to a final concentration of $100 \mathrm{mM}$ and coupled to $0.4 \%$ fatty acid free bovine serum albumin (BSA) (Sigma Aldrich, Zwijndrecht, the Netherlands) in differentiation medium (DM) by 30' incubation at $37^{\circ} \mathrm{C}$ before use. Rosiglitazone-maleate (Alexis Biochemicals, Lausen, Switzerland), WY14643 (Biomol, Plymouth Meeting, PA, USA), GW501516 (Alexis Biochemicals, Lausen, Switzerland) and GW1929 (Sigma Aldrich, Zwijndrecht, the Netherlands) were all dissolved in $100 \%$ dimethyl sulfoxide (DMSO) to a stock solution of $50 \mathrm{mM}, 5 \mathrm{mM}, 25 \mathrm{mM}$ and $20 \mathrm{mM}$ respectively. TNF- $\alpha$ and IL-1 $\beta$ (both from Calbiochem, San Diego, CA, USA) were dissolved in $0.1 \%$ Bovine serum albumine (BSA).

\section{Transfections and plasmids}

For the assessment of NF-KB transcriptional activation, $\mathrm{C} 2 \mathrm{C} 12$ cells were stably transfected with the $6 \mathrm{~KB}-\mathrm{TK}$ luciferase plasmid (NF-KB reporter) as described previously ${ }^{20}$. For assessment of PPAR transcriptional activation, C2C12 cells were stably transfected with a Human CPT-1 B promoter (HCBP) luciferase reporter plasmid (pSG5, Stratagene, La Jolla, CA, USA) (PPAR reporter). Cells were grown to $70 \%$ confluency and transfected using Lipofectamine according to manufacturers' instructions (Invitrogen, Carlsbad, CA, USA). Transfection was performed in the presence of $3.75 \mu \mathrm{g} \mathrm{HCBP}$ plasmid DNA and $0.25 \mu \mathrm{g}$ of a plasmid containing the neomycin resistance gene (pSV2-Neo, Stratagene, La Jolla, CA, USA). For selection of positive clones, cells were cultured in GM containing $800 \mu \mathrm{g} / \mathrm{ml} \mathrm{G} 418$ (Calbiochem, San 
Diego, CA, USA). Transient transfections were all performed by Lipofectamine according to manufacturers' instructions (Invitrogen, Carlsbad, CA, USA).

\section{Reporter assays}

The NF-KB- or the PPAR sensitive reporter cell lines were plated in $35 \mathrm{~mm}$ dishes and allowed to grow to $70-80 \%$ confluency. Cells were differentiated for 6 days and then treated with the various stimuli. After the appropriate incubation times cells were washed $2 x$ with cold phosphate buffered saline (PBS), and subsequently lysed by adding $(100 \mu \mathrm{l})$ 1x Reporter Lysis Buffer (Promega, Madison, WI, USA) and incubation on ice for $10 \mathrm{~min}$. Cell lysates were centrifuged $(13,000 \mathrm{~g}, 1 \mathrm{~min})$, and supernatants were either snap-frozen and stored at $-80^{\circ} \mathrm{C}$ for later analysis or placed on ice for immediate analysis. Luciferase activity was measured according to manufacturers' instructions (Promega, Madison, WI, USA) and corrected for total protein content (Biorad, Hercules, CA, USA). For assessment of the inhibitory potential of PPAR activation on NF-KB transcriptional activation, cells from the NF-KB sensitive reporter cell line were incubated with PPAR activators prior to the administration of the inflammatory stimulus (TNF- $\alpha$ or IL-1 $\beta$ ).

\section{RNA isolation, cDNA synthesis and QPCR}

Total RNA from $\mathrm{C} 2 \mathrm{C} 12$ myotubes was extracted using the acid guanidium thiocyanate-phenol-chloroform extraction method (Ambion Ltd., ljssel, The Netherlands). RNA concentration was determined using a spectrophotometer. One microgram of RNA per sample was reverse-transcribed into cDNA according to the manufacturers' instructions (Reverse-IT-TM 1st strand synthesis, Abgene, Leusden, The Netherlands). Transcript levels of intracellular adhesion molecule 1 (ICAM-1) and the chemokine CXCL1 (KC: keratinocyte-derived chemokine) were determined in $\mathrm{C} 2 \mathrm{C} 12$ samples using a Biorad quantitative PCR apparatus (Biorad, Hercules, CA, USA). Transcript levels for the constitutive housekeeping gene product cyclophillineA were quantitatively measured in each sample to control for sample-to-sample differences in RNA concentration. ICAM-1 and IL-8 mRNA levels were determined in cDNA generated from skeletal muscle from diabetic subjects treated with Rosiglitazone. Gene expression was quantified and expressed as arbitrary units (AU). Total RNA was extracted from these skeletal muscle biopsies using Trizol reagent (Invitrogen, Breda, The Netherlands). One microgram of RNA was reverse-transcribed to cDNA using random hexomer primers and a stratascript enzyme (Stratagene, Amsterdam, The Netherlands). Reverse transcription and quantitative PCR (QPCR) were performed using an MX3000p thermal cycler system and Brilliant SYBER Green QPCR Master Mix (Stratagene, Amsterdam, The Netherlands). To control for any variations in the 
efficiencies of the reverse transcription and PCR, acidic ribosomal phosphoprotein PO (36B4) was used as an internal control. The number of cycles at which the best-fit line through the log linear portion of each amplified curve intersects the noise band is inversely proportional to the log copy number 11. This value is referred to as the critical threshold (CT) value. The $\triangle C T$ was calculated by subtracting the CT for 36B4 from the CT for the gene of interest. The relative expression of the gene of interest is calculated using the expression 2" $\triangle \mathrm{CT}$ and reported as arbitrary units. All PCR runs were performed in triplicate.

\section{Preparation of nuclear extracts and Western blot analysis}

Nuclear extracts were prepared as described previously ${ }^{21}$. For Western blot analysis $4 \mathrm{x}$ Laemmli sample buffer $(0.25 \mathrm{M}$ Tris $\cdot \mathrm{HCl}, \mathrm{pH} 6.8 ; 8 \%(\mathrm{w} / \mathrm{v}) \mathrm{SDS}$, $40 \%(\mathrm{v} / \mathrm{v})$ glycerol, $0.4 \mathrm{M} \mathrm{DTT}$, and $0.04 \%$ (w/v) bromophenol blue) was added to nuclear extracts followed by boiling of the samples for $5 \mathrm{~min}$ at $100^{\circ} \mathrm{C}$ and storage at $-20^{\circ} \mathrm{C}$. Total protein was assessed using the Biorad DC protein assay kit (Biorad, Hercules, CA, USA) according to the manufacturers' instructions. $15 \mu \mathrm{g}$ (RelA) or $2 \mu \mathrm{g}$ (HIS-3) of protein was loaded per lane and separated on a $10 \%$ or $12 \%$ polyacrylamide gel (Mini Protean 3 system; Biorad, Hercules, CA, USA) (RelA and HIS-3 respectively), followed by transfer to a $0.45 \mu \mathrm{m}$ nitrocellulose membrane (Biorad Hercules, CA, USA) by electro blotting. The membrane was blocked for $1 \mathrm{~h}$ at room temperature in $5 \%(\mathrm{w} / \mathrm{v})$ non-fat dry milk. Nitrocellulose blots were washed in PBS-Tween $20(0.05 \%)$, followed by overnight incubation $\left(4^{\circ} \mathrm{C}\right)$ with a polyclonal antibody specific for RelA (Santa Cruz, Santa Cruz, CA, USA) or HIS-3 (Abcam, Cambridge, UK). After three wash steps of $20 \mathrm{~min}$ each, the blots were probed with a peroxidase-conjugated secondary antibody (Vector Laboratories, Burlingame, CA, USA) and visualised using SuperSignal West Pico chemiluminescent substrate (Pierce Biotechnology, Rockford, IL, USA) according to the manufacturers' instructions.

\section{Electrophoretic Mobility Shift Analysis (EMSA)}

DNA binding activity of NF-KB was assessed in nuclear extracts by analysis of complexes binding to an oligonucleotide containing a $K B$ consensus sequence (Santa Cruz, Santa Cruz, CA, USA). $2 \mu \mathrm{g}$ of nuclear protein was used per binding reaction and protein-DNA complexes were resolved on a $5 \%$ polyacrylamide gel in $0.25 \mathrm{X}$ Tris-borate-E DTA buffer at $120 \mathrm{~V}$ for $2 \mathrm{~h}$. Gels were dried and exposed to film (X-Omat Blue XB-1, Kodak, Rochester, NY, USA). Shifted complexes were quantified by phosphor-imager analysis (Biorad, Hercules, CA, USA). To determine the sub-composition of the complexes, supershift reactions were performed by pre-incubation of the nuclear extracts 
with an antibody specific to the RelA subunit of NF-KB (Santa cruz, Santa cruz, CA, USA) or a negative IgG antibody.

\section{Chromatin Immunoprecipitation Assay (ChIP)}

After removal of the medium, 1\% Formaldehyde (Fisher Scientific,Pittsburgh, USA) was added to the cells for $10 \mathrm{~min}$ at room temperature. Cross-linking was stopped by the addition of glycine $(5 \mathrm{~min}$ ) to a final concentration of $0.125 \mathrm{M}$. Cross-linked cells were washed 2 times with PBS, scraped and resuspended in SDS buffer $(100 \mathrm{mM} \mathrm{NaCl} ; 50 \mathrm{mM}$ Tris- $\mathrm{HCl}, \mathrm{pH}$ 8.1; $5 \mathrm{mM}$ EDTA, $\mathrm{pH}$ 8.0; $0.02 \% \mathrm{NaN}_{3}$ and $0.5 \% \mathrm{SDS}$ ). Lysates were snap-frozen on dry ice. After thawing, the cells were pelleted ( $6 \mathrm{~min} ; 500 \mathrm{~g})$ at room temperature. Cells were subsequently sonicated (10 Amp; 16 cycles; $20 \mathrm{sec}$ on, $100 \mathrm{sec}$ off). Samples underwent Proteinase $\mathrm{K}$ and DNAse treatment and DNA was isolated using Phenol-chloroform isoamyl alchohol precipitation. Sonication efficiency was verified on a $2 \%$ agarose gel. The supernatant was precleared $\left(20 \mathrm{~min} ; 4^{\circ} \mathrm{C}\right.$ ) with protein $\mathrm{A}$ beads blocked with herring sperm. After removal of the beads by micro centrifugation (30 min; $14000 \mathrm{~g}$; room temperature), $4 \mu \mathrm{g}$ of RelA antibody (Abcam, Cambridge, UK) was added overnight at $4^{\circ} \mathrm{C}$ with continuous mixing. A polyclonal antibody directed against HA was used as a control antibody (Santa cruz, Santa cruz, CA, USA). Antibody-protein-DNA complexes were isolated by immunoprecipitation with blocked protein $A$ beads. Following extensive washing, bound DNA fragments were eluted and analysed by subsequent Real Time PCR. Primers were designed around the RelA binding site in the ICAM-1 promoter. Forward: 5'- GATGTCCTTTCCGGTTGCAG-3'; Reverse: 5'-CAGGGAAATTCCCGGAGTACA-3'.

\section{Human subjects}

To validate results from the in vitro setting we investigated transcript levels of NF-KB target genes in skeletal muscle of diabetic subjects who received Rosiglitazone treatment as reported previously ${ }^{22,23}$. In summary, ten middleaged obese men with type 2 diabetes mellitus participated in this study. Subjects had no major health problems beside their diabetes, and did not use any medication known to interfere with the results of the study. The Medical Ethical Review Committee of Maastricht University approved the study protocol, and all subjects gave their written informed consent before the start of the study. After baseline measurements, diabetic subjects received Rosiglitazone ( $2 \times 4 \mathrm{mg}$ per day) for 8 weeks. At the end of this 8 -week period, all measurements were repeated. Eight weeks of Rosiglitazone treatment was effective in restoring insulin sensitivity in these subjects. 


\section{Collection and processing of muscle tissue}

Post absorptive muscle biopsies of the lateral part of the quadriceps femoris were obtained under local anaesthesia by using the needle biopsy technique. The specimens were immediately snap-frozen in liquid nitrogen and stored at $-80^{\circ} \mathrm{C}$ until use. The frozen biopsies were weighed and subsequently homogenised using a Polytron PT 1600 E (Kinematica AG, Littau/Luzern, Germany) for RNA extraction.

\section{Statistical analysis}

Data was analysed according to the guidelines of Altman et al. ${ }^{24}$ using SPSS (Statistical Package for the Social sciences, SPSS Inc., Chicago, IL, U.S.A). An unpaired student's t-test was used for the in vitro data while a paired nonparametric tests was used for the gene expression analysis in skeletal muscle of Rosiglitazone treated diabetic patients. Data are represented as the mean $\pm \mathrm{SD}$ or median \pm range when appropriate for in vitro and in vivo data respectively. A two-tailed probability value of less than 0.05 was considered to be significant.

\section{Results}

\section{NF-kB activation by inflammatory cytokines}

Transcriptional activation of NF-kB was evaluated in a stable reporter cell line. In order to test responsiveness to inflammatory cytokines, C2C12 myotubes were stimulated with various concentrations of TNF- $\alpha$ for $4 \mathrm{~h}$. Stimulation with TNF- $\alpha$ resulted in a dose-dependent increase in NF-KB transcriptional activity (Figure 6.1A). In order to assess whether this cell line was also responsive to inflammatory stimuli other than TNF- $\alpha$, a similar stimulation experiment was performed using various concentrations of IL-1 $\beta$ for $4 \mathrm{~h}$ yielding similar results (Figure 6.1B). These data demonstrate that TNF- $\alpha$ and IL-1 $\beta$ potently induce $\mathrm{NF}-\kappa \mathrm{B}$ transcriptional activity in differentiated myotubes. 
A

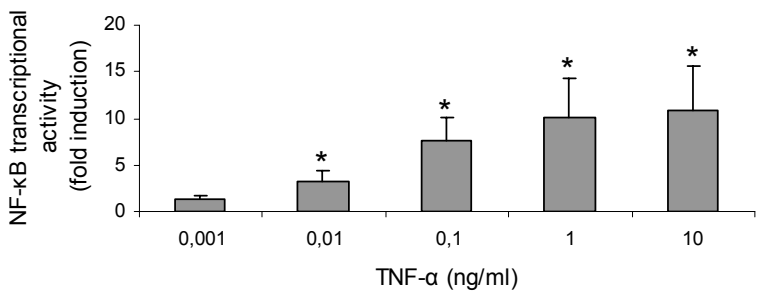

B

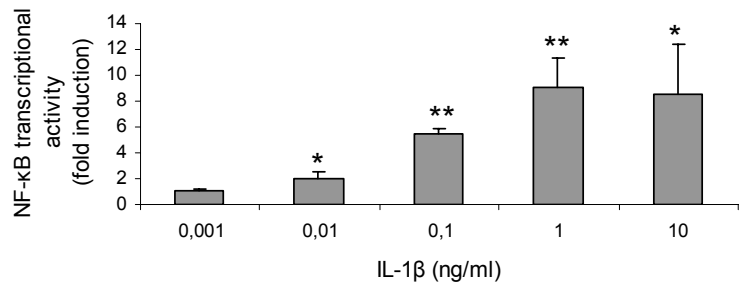

Figure 6.1 NF-kB activation by inflammatory cytokines. C2C12 myotubes from the NF-kB sensitive reporter stable cell line were stimulated with $\mathbf{A}$ ) increasing concentrations of TNF- $\alpha(0.001 ; 0.01 ; 0.1 ; 1$ or $10 \mathrm{ng} / \mathrm{ml})$ or vehicle $(0.1 \% \mathrm{BSA})$ or $\mathbf{B})$ increasing concentrations of IL-1 $\beta(0.001 ; 0.01 ; 0.1 ; 1$ or $10 \mathrm{ng} / \mathrm{ml})$ or vehicle $(0.1 \%$ BSA $)$ for $4 \mathrm{~h}$. Cells were lysed, luciferase activity was determined and normalised to total protein content. Significance of difference compared to control: * $p \leq 0.05$; ${ }^{* *} p \leq 0.01$. Each condition was performed in triplicate within an experiment. Shown are mean + SD of 3 independent experiments.

\section{Induction of PPAR transcriptional activity by specific PPAR ligands}

Responsiveness of $\mathrm{C} 2 \mathrm{C} 12$ myocytes to PPAR agonists was verified using a PPAR sensitive promoter reporter. Administration of the general PPAR agonist TTA for $24 \mathrm{~h}$ to undifferentiated $\mathrm{C} 2 \mathrm{C} 12$ myoblasts transiently transfected with a PPAR sensitive reporter luciferase plasmid resulted in a dose-dependent increase in PPAR-dependent transcriptional activity (Figure 6.2A). Treatment of

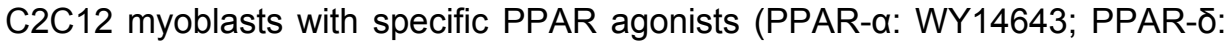
GW501516 or PPAR-y: Rosiglitazone) for $24 \mathrm{~h}$ also resulted in a dosedependent increase in PPAR transcriptional activity with a maximal induction at $50 \mu \mathrm{M}, 1 \mu \mathrm{M}$ and $75 \mu \mathrm{M}$ respectively (data not shown). This data shows that all PPAR activators used were able to induce PPAR transcriptional activity in C2C12 myoblasts. Next, a cell line containing the PPAR sensitive reporter construct stably integrated in the genome was developed to validate the ability of the agonists to activate PPAR-dependent transcriptional activity in differentiated $\mathrm{C} 2 \mathrm{C} 12$ myotubes. Stimulation of $\mathrm{C} 2 \mathrm{C} 12$ myotubes with TTA $(100 \mu \mathrm{M})$ or specific synthetic PPAR activators (WY14643: $50 \mu \mathrm{M}$; GW501516: 
$1 \mu \mathrm{M}$ or Rosiglitazone: $75 \mu \mathrm{M}$ ) resulted in an induction of PPAR transcriptional activity in a time-dependent manner with maximal inductions after $48 \mathrm{~h}$ incubation (Figure 6.2B). These data demonstrate that all PPAR activators used in this study induce PPAR-dependent transcriptional activity in $\mathrm{C} 2 \mathrm{C} 12$ myoblasts and myotubes.
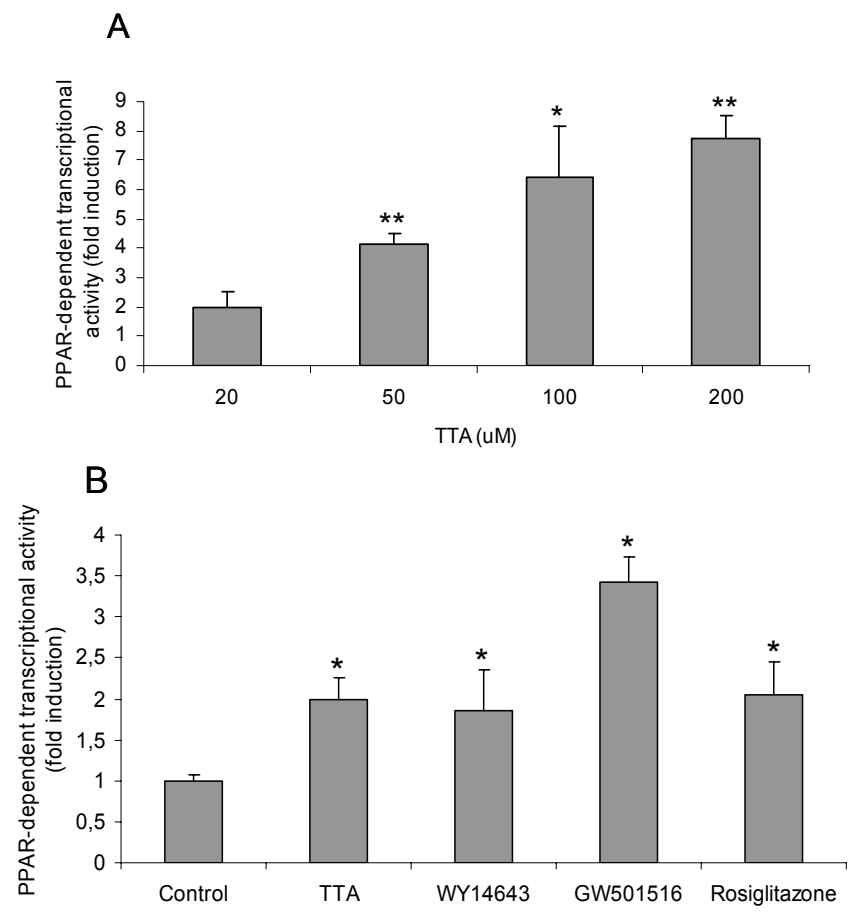

Figure 6.2 Induction of PPAR transcriptional activity by specific PPAR ligands A) C2C12 myoblasts were transiently transfected with the PPAR sensitive reporter construct and treated with increasing concentrations of TTA or vehicle (ethanol) for $24 \mathrm{~h}$. Cells were lysed and luciferase activity was determined and normalised to $\beta$-galactosidase activity to correct for differences in transfection efficiency. B) C2C12 myotubes stably transfected with the PPAR sensitive reporter construct were treated with TTA $(100 \mu \mathrm{M})$, WY14643 $(50 \mu \mathrm{M})$, GW501516 $(1 \mu \mathrm{M})$, Rosiglitazone $(75 \mu \mathrm{M})$ or vehicle (DMSO: specific agonists or ethanol: TTA) for 48 h. Cells were lysed; luciferase activity was determined and normalised to total protein content. Significance of difference compared to control: ${ }^{*} p \leq 0.05 ;{ }^{* *} p \leq 0.01$. Each condition was performed in triplicate within an experiment. Shown are mean + SD of 3 independent experiments. 


\section{PPAR-y activation inhibits NF-KB transcriptional activation}

To assess the anti-inflammatory potential of PPAR agonists in skeletal muscle, C2C12 myotubes containing the NF-KB sensitive reporter were treated with general or specific PPAR ligands prior to exposure to pro-inflammatory cytokines. Pre-treatment with TTA $(100 \mu \mathrm{M})$ resulted in a time-dependent inhibition of TNF- $\alpha$-induced NF-KB transcriptional activity with a maximal inhibitory effect at $30 \mathrm{~min}$ pre-incubation time (Figure 6.3).

To assess if the three PPAR isoforms have a differential inhibitory capacity on TNF- $\alpha$-induced NF-KB activation, pre-incubation experiments were performed with specific PPAR agonists. Pre-incubation with a PPAR- $\alpha$ (WY14643, $50 \mu \mathrm{M})$ or a PPAR- $\delta$ (GW501516, $1 \mu \mathrm{M}$ ) activator had no significant inhibitory effect on TNF- $\alpha$-induced NF-KB transcriptional activity (data not shown) while PPAR- $\gamma$ activation (Rosiglitazone, $75 \mu \mathrm{M}$ ) resulted in a time- (Figure 6.4A) and dose(Figure 6.4B) dependent inhibition of TNF-a-induced NF-KB transcriptional activity.

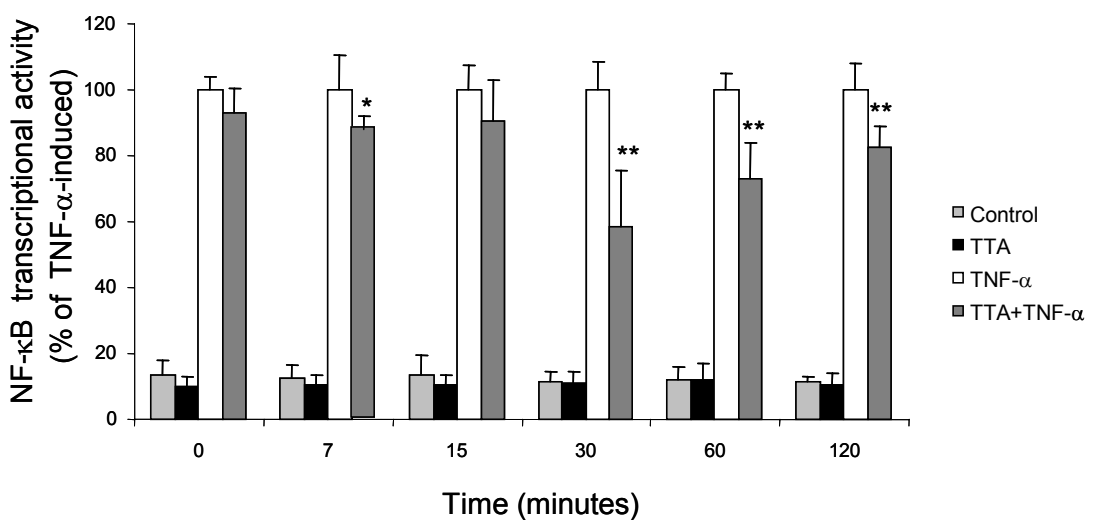

Figure 6.3 PPAR activation inhibits NF-KB transcriptional activity. C2C12 myotubes (differentiated for 6 days) from the NF-kB sensitive reporter stable cell line were pretreated (time in minutes) with TTA $(100 \mu \mathrm{M})$ or vehicle $(0.1 \%$ ethanol final concentration) prior to $4 \mathrm{~h}$ incubation with TNF- $\alpha(1 \mathrm{ng} / \mathrm{ml})$. Cells were lysed, luciferase activity was determined and normalised to total protein content. Significance of difference compared to TNF- $\alpha$-treated cells: ${ }^{*} p \leq 0.05 ;{ }^{*} p \leq 0.01$. Each condition was performed in triplicate within an experiment. Shown are mean + SD of 3 independent experiments.

In line with the observed inhibitory effect of Rosiglitazone on TNF- $\alpha$-induced NF-KB transcriptional activity, Rosiglitazone also inhibited IL-1 $\beta$-induced NF-KB transcriptional activity in a dose- and time-dependent manner. Here the optimal inhibitory effect was observed at $2 \mathrm{~h}$ pre-incubation using a concentration of 
$200 \mu \mathrm{M}$ Rosiglitazone (Figure 6.5A). To confirm that Rosiglitazone-mediated inhibition of cytokine-induced NF-KB transcriptional activity did occur through a PPAR-y-dependent mechanism, another structurally unrelated PPAR-y agonist (GW1929) was used in the same experimental set-up. Pre-incubation of $\mathrm{C} 2 \mathrm{C} 12$ myotubes from the NF-KB sensitive reporter cell line with $20 \mu \mathrm{M}$ of GW1929 resulted in a time-dependent inhibition of TNF- $\alpha$-induced NF-KB transcriptional activity with a maximal inhibitory effect (approximately $40 \%$ inhibition) at $1 \mathrm{~h}$ pre-incubation (Figure 6.5B). These data show that ligand-induced PPAR-Y activation potently inhibits pro-inflammatory cytokine-induced NF-KB transcriptional activity in skeletal muscle cells.

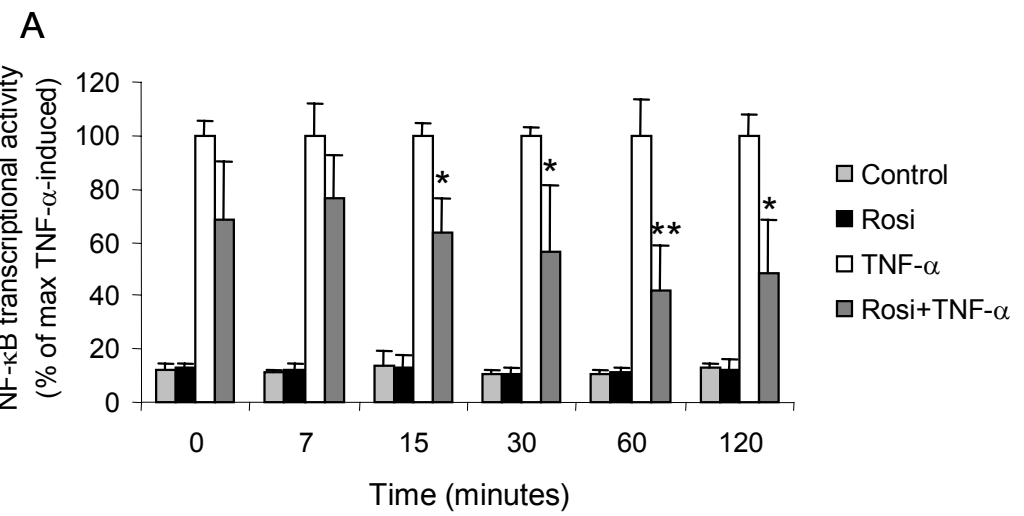

$\mathrm{B}$

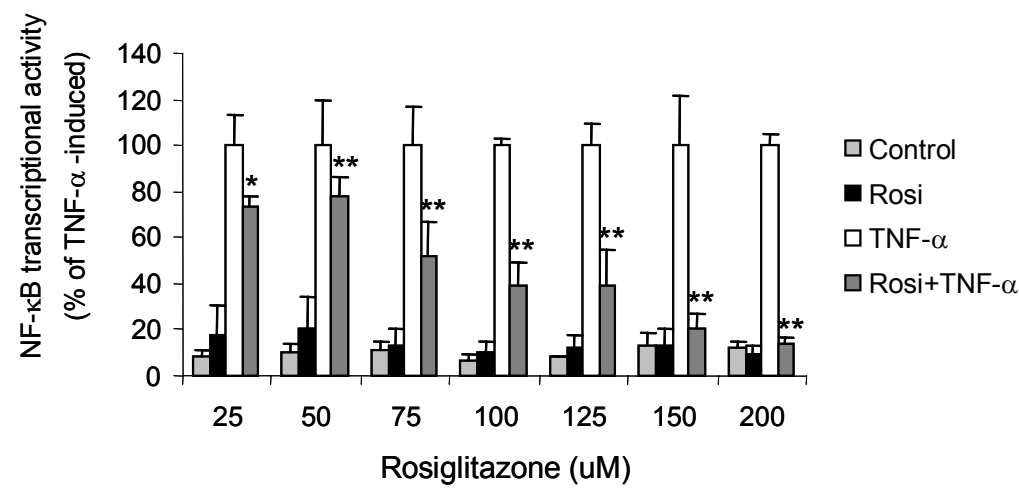

Figure 6.4 PPAR-Y activation by Rosiglitazone inhibits TNF- $\alpha$-induced NF-KB transcriptional activity. C2C12 myotubes (differentiated for 6 days) from the NF$\mathrm{KB}$ sensitive reporter stable cell line were pre-incubated (time in minutes) A) with Rosiglitazone $(75 \mu \mathrm{M})$ or vehicle (DMSO) prior to $4 \mathrm{~h}$ incubation with TNF- $\alpha$ $(1 \mathrm{ng} / \mathrm{ml})$, or $\mathbf{B})$ with an increasing dose of Rosiglitazone or vehicle (DMSO) for $1 \mathrm{~h}$ prior to $4 \mathrm{~h}$ incubation with TNF-a $(1 \mathrm{ng} / \mathrm{ml})$. Cells were lysed, luciferase activity was determined and normalised to total protein content. Significance of difference compared to TNF- $\alpha$-treated cells: ${ }^{*} p \leq 0.05 ;{ }^{* *} p \leq 0.01$. Each condition was performed in triplicate within an experiment. Shown are mean + SD of 3 independent experiments. 

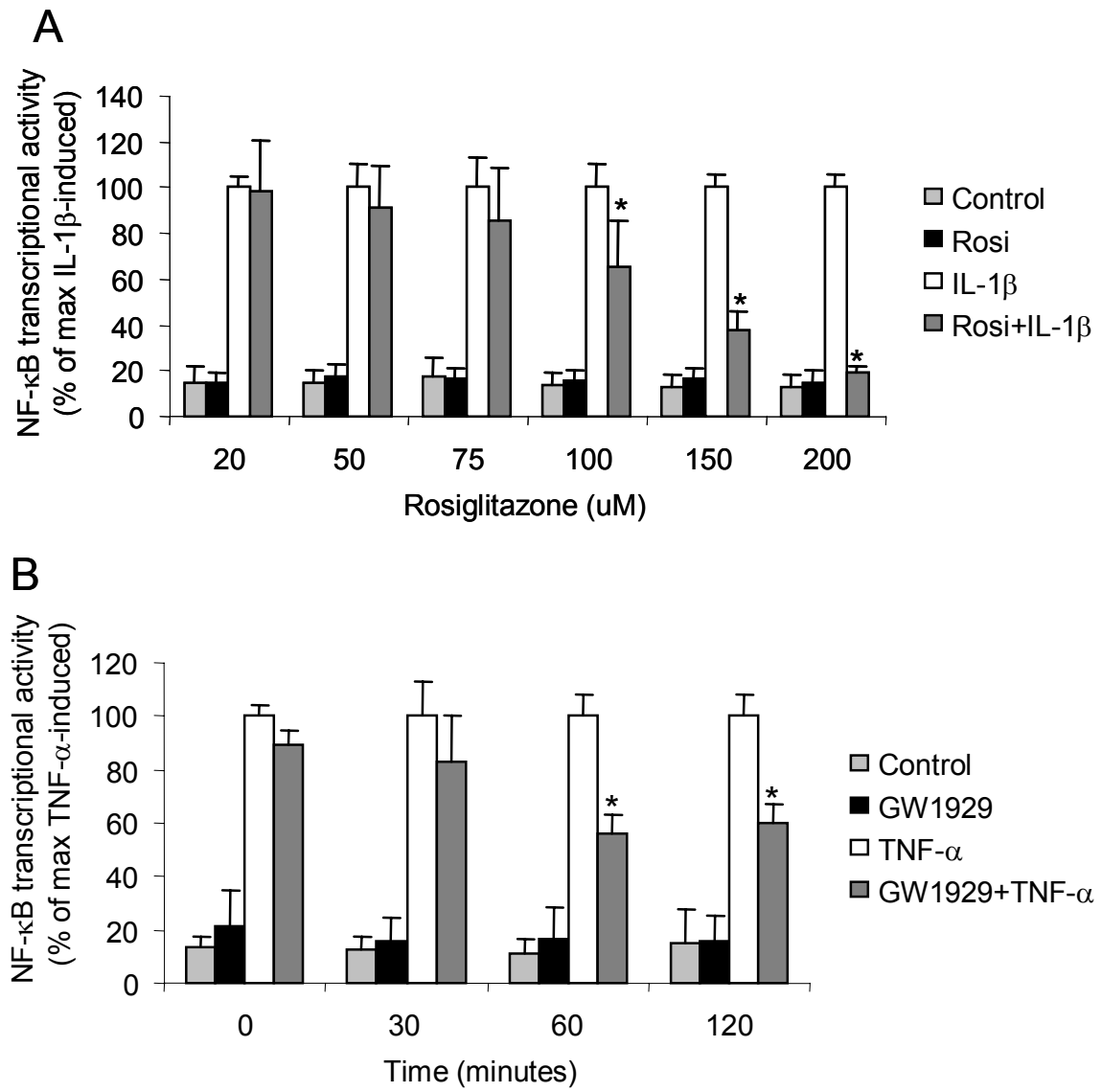

Figure 6.5 PPAR- $\gamma$ activation inhibits TNF- $\alpha-$ as well as IL-1 $\beta$-induced NF-KB transcriptional activity. $\mathrm{C} 2 \mathrm{C} 12$ myotubes (differentiated for 6 days) from the NF$\mathrm{KB}$ sensitive reporter stable cell line were pre-treated $\mathbf{A}) 1 \mathrm{~h}$ with an increasing dose of Rosiglitazone or vehicle (DMSO) prior to $4 \mathrm{~h}$ incubation with IL-1 $\beta(1 \mathrm{ng} / \mathrm{ml})$, or B) with GW1929 $(20 \mu \mathrm{M})$ or vehicle (DMSO) for an increasing amount of time prior to $4 \mathrm{~h}$ incubation with TNF- $\alpha(1 \mathrm{ng} / \mathrm{ml})$. Cells were lysed, luciferase activity was determined and normalised to total protein content. Significance of difference compared to TNF- $\alpha$-treated cells: ${ }^{*} p \leq 0.01$. Each condition was performed in triplicate within an experiment. Shown are mean + SD of 3 independent experiments.

\section{PPAR-y activation reduces TNF- $\alpha$-induced transcript levels of NF- KB target genes}

In order to investigate the functional relevance of the NF-KB reporter data, we investigated if TNF- $\alpha$-induced expression of endogenous NF-KB target genes was affected by PPAR-y activation in $\mathrm{C} 2 \mathrm{C} 12$ myotubes. Expression of ICAM-1 (intra-cellular adhesion molecule 1) and the expression of the chemokine KC 
(keratinocyt-derived chemokine, which is the mouse homologue of human IL-8) significantly increased in $\mathrm{C} 2 \mathrm{C} 12$ myotubes following stimulation with TNF- $\alpha$ for $24 \mathrm{~h}$. Pre-treatment of the cells with Rosiglitazone for $1 \mathrm{~h}$ abolished the TNF- $\alpha$ induced upregulation of KC and ICAM-1 mRNA levels (Figure 6.6). These observations show that PPAR- $\gamma$ activation can reduce NF-KB target gene transcript levels in skeletal muscle and demonstrate that data obtained in the NF-KB reporter is functionally relevant.

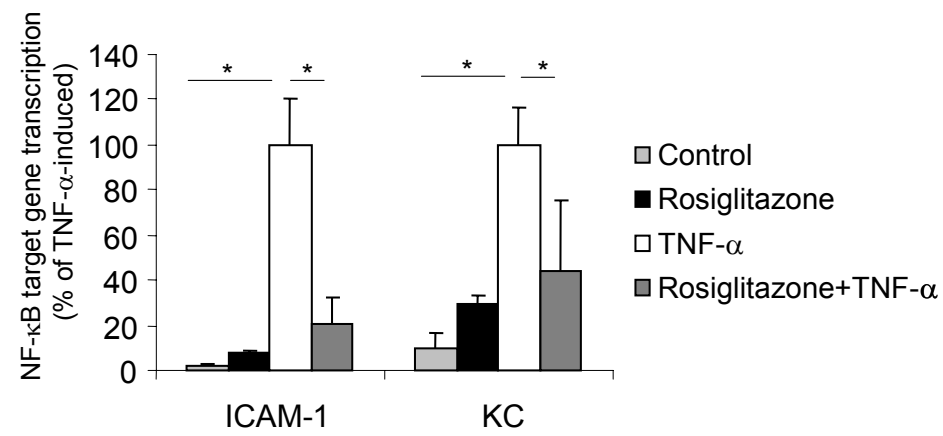

Figure 6.6 PPAR- $\gamma$ activation reduces TNF- $\alpha$-induced transcription of NF-kB target genes. $\mathrm{C} 2 \mathrm{C} 12$ myotubes (differentiated for 6 days) were pre-treated $(1 \mathrm{~h})$ with Rosiglitazone $(150 \mu \mathrm{M})$ followed by a $24 \mathrm{~h}$ incubation with TNF- $\alpha(1 \mathrm{ng} / \mathrm{ml})$. ICAM-1 and $\mathrm{KC}$ mRNA levels were assessed and corrected for the housekeeping gene cyclophilinA. Expression levels are depicted as \% of TNF- $\alpha$-induced transcript levels. Each condition was performed in triplicate within an experiment. Shown are mean + SD of 3 independent experiments. Significance of difference: ${ }^{*} p<0.001$.

\section{NF-KB target genes in skeletal muscle of Rosiglitazone-treated type II diabetic subjects}

To verify if muscular NF-kB activity in human subjects is suppressed by PPARY activation, we examined the effect of 8 weeks Rosiglitazone treatment on muscular gene expression of ICAM-1 and IL-8 in type 2 diabetes mellitus patients. Subjects characteristics before and after Rosiglitazone treatment are summarised in Table 6.1. No differences were observed in IL-8 mRNA expression levels (data not shown). A trend towards lower ICAM-1 mRNA expression levels was observed in skeletal muscle after Rosiglitazone treatment $(0.155 \pm 0.0150 \mathrm{AU}$ vs $0.137 \pm 0.006 \mathrm{AU} ; \mathrm{p}=0.074)$ (Figure 6.7). 
Table 6.1 Subject characteristics before and after Rosiglitazone treatment. Data are presented as mean $\pm \mathrm{SD}$.

\begin{tabular}{lcc}
\hline & Before & After \\
\hline Age (years) & $61.8 \pm 3.7$ & $/$ \\
Body weight $(\mathrm{kg})$ & $90.2 \pm 9.1$ & $90.8 \pm 10.0$ \\
Body mass index $\left(\mathrm{kg} / \mathrm{m}^{2}\right)$ & $30.2 \pm 3.3$ & $30.4 \pm 3.4$ \\
Glucose $(\mathrm{mmol} / \mathrm{l})$ & $9.8 \pm 2.2$ & $8.3 \pm 1.4$ \\
$\mathrm{HbA} \mathrm{Ac}_{1 \mathrm{c}}(\%)$ & $7.3 \pm 0.7$ & $7.7 \pm 1.1$ \\
$\mathrm{Si}$ & $0.012 \pm 0.0019$ & $0.032 \pm 0.019$ ** \\
$\mathrm{y}-\mathrm{GT}(\mathrm{U} / \mathrm{l})$ & $43.4 \pm 35$ & $22.8 \pm 11.2^{*}$ \\
\hline
\end{tabular}

${ }^{*} p<0.05,{ }^{* *} p<0.01$ after vs before treatment. Si: insulin sensitivity; $y$-GT: $y$-glutamyltranspeptidase; $\mathrm{HbA}_{1 \mathrm{c}}$ : Hemoglobine A1c, ${ }^{\mathrm{a}}$ After 2-week cessation of any pre-existing antidiabetic medication.

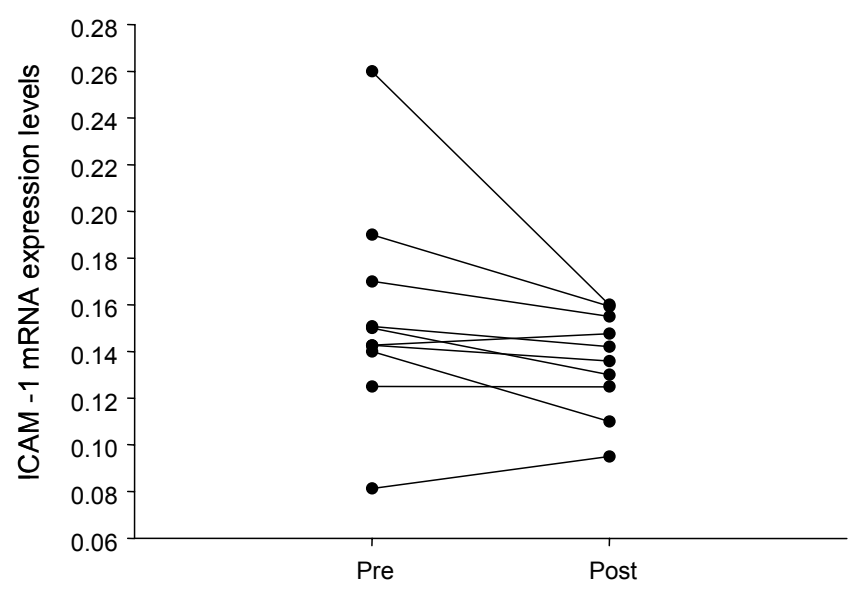

Figure 6.7 ICAM-1 expression levels are reduced in skeletal muscle of Rosiglitazonetreated type II diabetic subjects. Expression of ICAM-1 mRNA in skeletal muscle of type 2 diabetes mellitus patients $(n=10)$ before and after an 8 week Rosiglitazone treatment $(2 \times 4 \mathrm{mg} /$ day). Phosphoprotein PO (36B4) mRNA levels were used for normalisation. ICAM-1 expression levels are depicted as arbitrary units $(A U)$ on the Y-axis.

\section{PPAR-y activation does not reduce TNF- $\alpha$-induced nuclear translocation or DNA binding of NF-kB}

In order to explore potential mechanisms by which PPAR-y activation can exert its anti-inflammatory effects, we investigated TNF- $\alpha$-induced NF-KB (RelA) nuclear translocation in response to pre-incubation with Rosiglitazone. As shown in Figure 6.8, a pronounced increase in nuclear translocation of RelA was observed after $1 \mathrm{~h}$ of TNF- $\alpha$ stimulation However, no reduction in TNF- $\alpha$ induced RelA nuclear translocation was observed after pre-incubation with Rosiglitazone. 
A

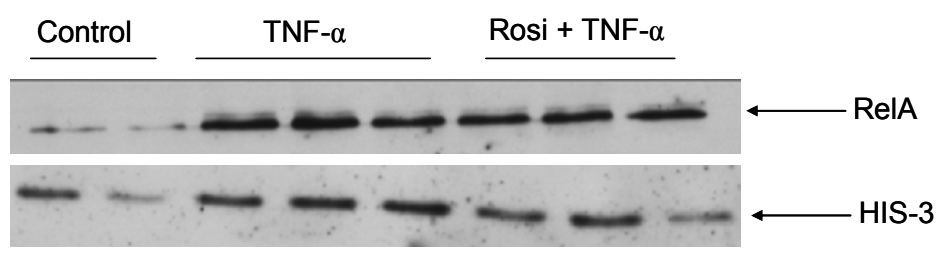

B

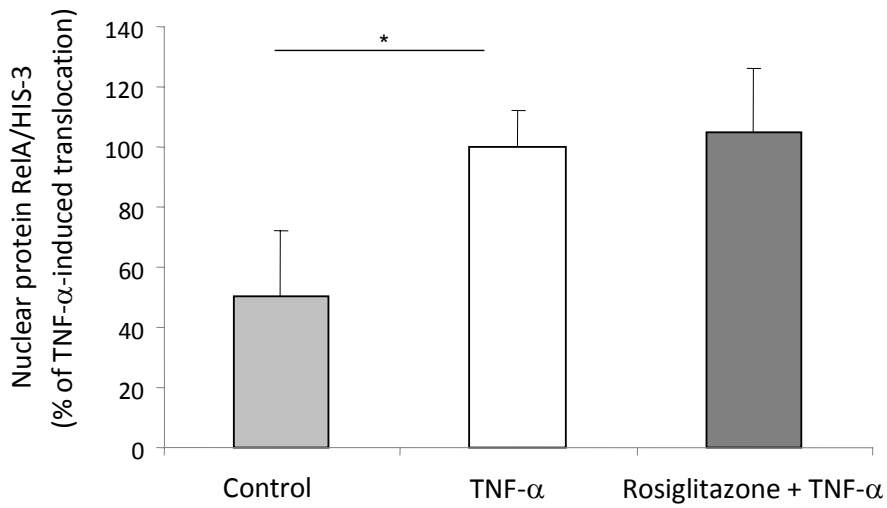

Figure 6.8 PPAR- $\gamma$ activation by Rosiglitazone does not inhibit TNF- $\alpha$-induced RelA nuclear translocation. $\mathrm{C} 2 \mathrm{C} 12$ myotubes were differentiated for 6 days and treated with vehicle (Control), TNF- $\alpha(1 \mathrm{ng} / \mathrm{ml} ; 1 \mathrm{~h})$, Rosiglitazone $(150 \mu \mathrm{M} ; 1 \mathrm{~h}$ preincubation) or Rosiglitazone + TNF- $\alpha$. Cells were lysed and nuclear extracts were prepared to assess A) nuclear protein levels of RelA and Histon-3 (loading control) by Western blotting. B) RelA and His-3 bands were quantified and expressed as a ratio. Significance of difference: * $p<0.001$. Each condition was performed in duplicate or triplicate within an experiment. Shown are mean + SD of 3 independent experiments. A representative Western blot is depicted.

In addition to nuclear translocation assays. EMSA analyses were performed. Figure 6.9A and 6.9C show that RelA DNA binding upon stimulation with TNF-a increased dramatically. Pre-treatment with Rosiglitazone did not reduce NF-kB DNA-binding in response to TNF- $\alpha$. Analysis of the sub-composition of the retarded complexes by supershift assay in Figure 6.9B revealed that the major complex induced by TNF- $\alpha$ (upper band) contained RelA. A negative control antibody was used in lane 3. ChIP assays were performed to investigate in vivo DNA binding of RelA to the ICAM-1 promoter. As indicated in Figure 6.9D, stimulation of $\mathrm{C} 2 \mathrm{C} 12$ myotubes with TNF- $\alpha$ potently induced binding of RelA to its binding site in the ICAM-1 promoter. Pre-incubation with Rosiglitazone did not reduce but rather increased TNF- $\alpha$-induced binding of RelA to its binding site in the ICAM-1 promoter. Aggrecan was included as a non-target of RelA and no differences were observed between the different experimental conditions (data not shown). These results indicate that TNF- $\alpha$-induced NF-KB 
transcriptional activity is suppressed by PPAR- $y$ activation by a mechanism downstream of RelA DNA-binding.

A

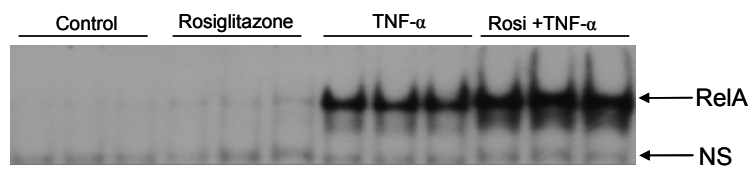

B

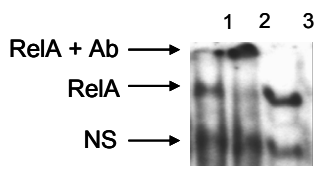

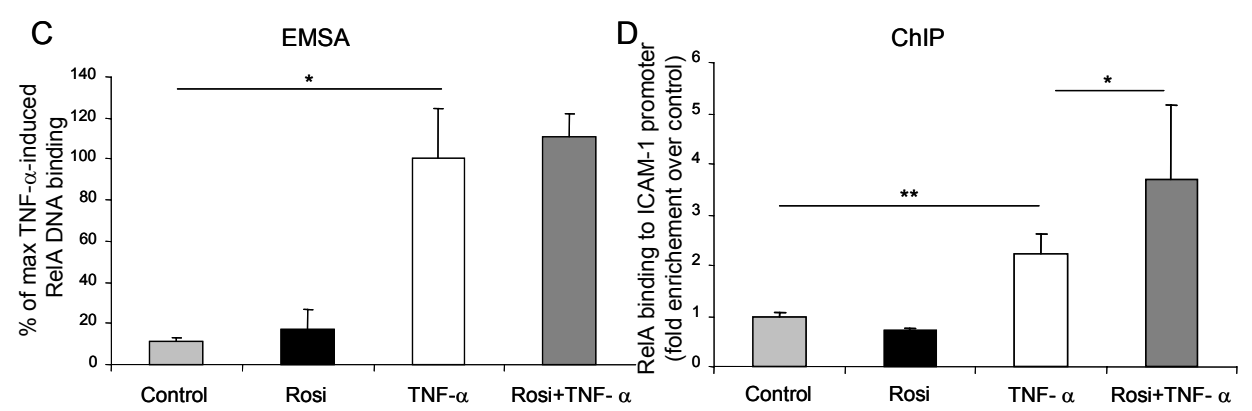

Figure 6.9 PPAR-y activation by Rosiglitazone does not inhibit TNF- $\alpha$-induced RelA DNA binding. $\mathrm{C} 2 \mathrm{C} 12$ myotubes were differentiated for 6 days and treated with vehicle (Control), TNF- $\alpha(1 \mathrm{ng} / \mathrm{ml} ; 1 \mathrm{~h})$, Rosiglitazone $(150 \mu \mathrm{M} ; 1 \mathrm{~h}$ pre-incubation) or Rosiglitazone + TNF- $\alpha$. Cells were lysed and nuclear extracts were prepared to assess A) RelA DNA binding activity by EMSA. A representative EMSA is depicted. B) Supershift analysis using no antibody (lane 1), a RelA antibody (lane 2) or a IgG control antibody (lane 3 ) to assess complex sub-composition. C) Bands containing the DNA-RelA complex were quantified. D) Cells were cross-linked, harvested and RelA binding to the ICAM-1 promoter was quantified by ChIP. All results from chip assays are corrected for non-specific precipitation using $\mathrm{HA}$ as a negative control antibody. Significance of difference: ${ }^{*} p<0.05 ;{ }^{* *} p<0.0001$. Each condition was performed in triplicate within an experiment. Shown are mean + SD of 3 independent experiments.

\section{Discussion}

The present study reveals that PPAR- $y$ activators potently inhibit TNF- $\alpha-$ and IL-1 $\beta$-induced NF-KB transcriptional activity in skeletal muscle cells. This antiinflammatory effect of PPAR- $y$ activators is not due to decreased RelA translocation to the nucleus or reduced RelA DNA binding. In addition, Rosiglitazone decreased transcript levels of known NF-KB target genes in vitro, while a trend towards decreased basal expression of ICAM-1 was observed in skeletal muscle of Rosiglitazone-treated type 2 diabetic subjects. 
We used $\mathrm{C} 2 \mathrm{C} 12$ cells as an experimental model for skeletal muscle ${ }^{19}$ as previous reports have demonstrated that insulin resistance ${ }^{25}$ and atrophy ${ }^{26}$ are induced by inflammatory stimuli in myotubes of this cell line. Moreover, it has been established that all three different PPAR proteins are present in $\mathrm{C} 2 \mathrm{C} 12$ cells $^{27}$. All synthetic agonists (Rosiglitazone, GW1929, WY14643 and GW501516) used in our study, are specific activators of PPAR-y, PPAR- $\alpha$ and PPAR- $\delta$ respectively ${ }^{28}$. We demonstrated that the PPAR activators used in this study are capable of inducing PPAR transcriptional activity in skeletal muscle myoblasts. Importantly, for all activators, this response was maintained in fully differentiated $\mathrm{C} 2 \mathrm{C} 12$ myotubes, which has only been reported for PPAR- $\alpha$ in one previous study ${ }^{29}$. In addition, other work demonstrated the potential of PPAR activators to induce DNA binding of the PPARs to their responsive elements in $\mathrm{C} 2 \mathrm{C} 12$ myotubes but did not investigate the actual transcriptional activity of these proteins in response to PPAR activators ${ }^{27}$.

All three PPAR subtypes have been implicated in the regulation of inflammatory responses ${ }^{30}$. In skeletal muscle however, reports on antiinflammatory effects of PPAR activation are rather scarce. For example, antiinflammatory properties have been ascribed to the fatty acid analogue TTA previously, but so far not in muscle ${ }^{31}$. In the present study we demonstrate antiinflammatory effects of TTA in skeletal muscle, based on its inhibitory actions on cytokine-induced NF-KB transcriptional activity. The inhibitory effect of TTA on NF-KB transcriptional activity was transient in nature, which could be due to metabolic processing of the fatty acid analogue as it can be degraded through the $\omega$-oxidation pathway ${ }^{32}$.

Although the PPAR- $\alpha$ and PPAR- $\delta$ activators we used did induce PPARdependent transcriptional activation, we did not observe any effect of PPAR- $\delta$ or PPAR- $\alpha$ activation on TNF- $\alpha$-induced NF-KB activity in skeletal muscle cells. In contrast, one recent study reported an inhibitory effect of PPAR- $\delta$ activation on NF-KB transcriptional activity in $\mathrm{C} 2 \mathrm{C} 12$ myotubes $^{33}$. These authors used a different activator of PPAR- $\delta$ (GW0742) compared to the PPAR- $\delta$ activator used in this study (GW501516), although both activators have been shown to be highly specific for PPAR- $\delta^{34}$. In addition, the duration of TNF- $\alpha$ treatment was 4-fold longer compared to our study. With respect to PPAR- $\alpha$, antiinflammatory potential has been investigated and demonstrated in spleen cells and smooth muscle cells but not previously in skeletal muscle ${ }^{35,36}$.

In contrast to PPAR- $\alpha$ and PPAR- $\delta$, PPAR-y ligands potently inhibited cytokineinduced NF-KB activity in skeletal muscle cells in the present study. Concentrations of Rosiglitazone that were applied were comparable to concentrations used in other studies culturing skeletal muscle cells ${ }^{37,38}$. 
Moreover, stimulation with Rosiglitazone in this concentration range was previously reported to potently induce PPAR- $y$ transcript levels in skeletal muscle cells ${ }^{37,38}$. Since non-specific effects of Rosiglitazone have been described $^{39}$, we used the structurally unrelated agonist GW1929 to alternatively activate PPAR-y. In line with anti-inflammatory properties of Rosiglitazone as a PPAR-y activator, GW1929 also potently inhibited pro-inflammatory cytokineinduced NF-kB activation, which suggested this effect was indeed mediated by PPAR-y. In line with our study, agonist-induced PPAR-y activation was shown to repress NF-kB activation in other cell types, e.g. macrophages and T-cells in vitro $^{40,41}$.

In order to assess the functional relevance of the NF-KB reporter data, we investigated the effect of Rosiglitazone on the transcription of known endogenous NF-KB target genes ${ }^{42}$. We observed that TNF- $\alpha$-induced $\mathrm{KC}$ and, more pronounced, ICAM-1 mRNA levels were significantly attenuated by Rosiglitazone in fully differentiated $\mathrm{C} 2 \mathrm{C} 12$ myotubes. This observation is in concordance with a recent report showing down-regulated ICAM-1 mRNA levels in lung epithelial cells in response to different PPAR-y agonists ${ }^{43}$. In addition, another study demonstrated that Rosiglitazone can attenuate NF-KBdependent ICAM-1 production in smooth muscle cells ${ }^{44}$. To verify these in vitro observations in an appropriate and relevant clinical setting, we explored IL-8 and ICAM-1 mRNA levels in skeletal muscle of diabetic subjects, who received Rosiglitazone treatment as an anti-diabetic therapy. ICAM-1 levels tended to be lower when compared to levels prior to Rosiglitazone administration, but did not reach statistical significance possibly due to a lack of statistical power. Additionally, the effective dose of Rosiglitazone that reaches the muscle in the patients unfortunately was not measured; however, it is conceivable that this dose is lower than the dose made available to the cells in our in vitro experiments. Therefore, this may explain differential results obtained in patients and in vitro cultured cells. Previously, it has been shown that Rosiglitazone treatment of patients with type 2 diabetes mellitus reduced circulating inflammatory markers such as C-reactive protein (CRP), metalloproteinase (MMP)-9/gelatinase B, and TNF- $\alpha^{45}$. Our data now shows that Rosiglitazone treatment possibly also reduces transcript levels of NF-KB target genes in skeletal muscle, although this observation should be confirmed in a larger patient population. Additionally, it must be noted that expression of PPAR-y in human skeletal muscle still is controversial. Expression levels in the musculature are low but appear of physiological importance as muscle-specific deletion of PPAR- $y$ induced insulin resistance in mice ${ }^{46}$. Therefore, future studies are necessary to clarify the exact role of PPAR-y in human skeletal muscle and its implication in the observed effects of Rosiglitazone administration on skeletal muscle gene expression of T2DM patients. 
Concentrations of Rosiglitazone that were used in the present study exceed the EC50 that has been described for this thiazolidinedione suggesting that the inhibiting effect on NF-KB activation may not depend primarily on PPAR-Y transcriptional activity. Indeed, the inflammation-modulating properties of the PPARs may not require their transcriptional activity, but could rather be mediated through the ability of PPARs to interfere with inflammatory signalling cascades, including NF-KB ${ }^{35,47}$. Interestingly, high concentrations of Rosiglitazone have been shown to induce PPAR-y mRNA expression in skeletal muscle cells ${ }^{23}$ and, in concordance with a transrepression mechanism of NF-KB modulation by PPAR-y in skeletal muscle (as has been reported previously in other cell types ${ }^{48}$ ), GW1929 did not induce PPAR transcriptional activity (data not shown) but did interfere with NF-KB signalling. These data clearly demonstrate that the PGC-1a/PPAR pathway is able to interfere with the relaying of inflammatory signals through the NF-KB pathway.

Several different transrepression mechanisms have been described to be mediated by the PPARs ${ }^{36,47,49}$. These include their ability to physically associate with various transcription factors (including NF-KB) and the ability to successfully compete for limiting amounts of co-activators. Since Rosiglitazone pre-treatment did not reduce TNF- $\alpha$-induced RelA nuclear translocation or DNA binding, the mechanism by which PPAR- $\gamma$ activation inhibits NF-KB mediated gene transcription in skeletal muscle should be located downstream of DNA binding. This may include impaired recruitment of transcriptional co-factors to the NF-kB-DNA comple ${ }^{47}$. Alternatively removal of repressor complexes of the NF-KB transcriptional machinery may be prevented by PPAR- $\gamma$ following its ligand-induced SUMOylation ${ }^{48}$.

In conclusion, we show a strong inhibitory effect of agonist-mediated PPAR- $Y$ activation on inflammatory mediator-induced NF-KB transcriptional activity in skeletal muscle, independent of RelA nuclear translocation and DNA binding. The exact mechanism by which this occurs remains obscure but warrants further investigation as muscle-specific inhibition of NF-KB activity may be an interesting therapeutic venue for treatment of several inflammation-associated skeletal muscle abnormalities. 


\section{References}

1. Jagoe RT, Engelen MP. Muscle wasting and changes in muscle protein metabolism in chronic obstructive pulmonary disease. Eur Respir J Suppl 2003;46:52s-63s.

2. Tisdale MJ. Biomedicine. Protein loss in cancer cachexia. Science 2000;289:2293-4.

3. Reid MB, Li YP. Tumor necrosis factor-alpha and muscle wasting: a cellular perspective. Respir Res 2001;2:269-72.

4. McNamara MJ, Alexander HR, Norton JA. Cytokines and their role in the pathophysiology of cancer cachexia. JPEN J Parenter Enteral Nutr 1992;16:50S-55S

5. Ladner KJ, Caligiuri MA, Guttridge DC. Tumor necrosis factor-regulated biphasic activation of NF-kappa B is required for cytokine-induced loss of skeletal muscle gene products. J Biol Chem 2003;278:2294-303.

6. Agusti A, Morla M, Sauleda J, Saus C, Busquets X. NF-kappaB activation and iNOS upregulation in skeletal muscle of patients with COPD and low body weight. Thorax 2004;59: 483-7.

7. Adams V, Spate U, Krankel N, Schulze PC, Linke A, Schuler G, Hambrecht R. Nuclear factorkappa $B$ activation in skeletal muscle of patients with chronic heart failure: correlation with the expression of inducible nitric oxide synthase. Eur J Cardiovasc Prev Rehabil 2003;10:273-7.

8. Cai D, Frantz JD, Tawa NE Jr, Melendez PA, Oh BC, Lidov HG, Hasselgren PO, Frontera WR, Lee J, Glass DJ, Shoelson SE. IKKbeta/NF-kappaB activation causes severe muscle wasting in mice. Cell 2004;119:285-98.

9. Sriwijitkamol A, Christ-Roberts C, Berria R, Eagan P, Pratipanawatr T, DeFronzo RA, Mandarino LJ, Musi N. Reduced skeletal muscle inhibitor of kappaB beta content is associated with insulin resistance in subjects with type 2 diabetes: reversal by exercise training. Diabetes 2006;55:760-7.

10. Friedman JE, Kirwan JP, Jing M, Presley L, Catalano PM. Increased skeletal muscle tumor necrosis factor-alpha and impaired insulin signaling persist in obese women with gestational diabetes mellitus 1 year postpartum. Diabetes 2008;57:606-13.

11. Lappas M, Permezel M, Rice GE. Release of proinflammatory cytokines and 8-isoprostane from placenta, adipose tissue, and skeletal muscle from normal pregnant women and women with gestational diabetes mellitus. J Clin Endocrinol Metab 2004;89:5627-33.

12. Staels B, Koenig W, Habib A, Merval R, Lebret M, Torra IP, Delerive P, Fadel A, Chinetti G, Fruchart JC, Najib J, Maclouf J, Tedgui A. Activation of human aortic smooth-muscle cells is inhibited by PPARalpha but not by PPARgamma activators. Nature 1998;393:790-3.

13. Straus DS, Glass CK. (2007) Anti-inflammatory actions of PPAR ligands: new insights on cellular and molecular mechanisms. Trends Immunol 2007;28:551-8.

14. Francis GA, Fayard E, Picard F, Auwerx J. Nuclear receptors and the control of metabolism. Annu Rev Physiol 2003;65:261-311.

15. Bragt MC, Popeijus HE. Peroxisome proliferator-activated receptors and the metabolic syndrome. Physiol Behav 2007;94:187-97.

16. Stienstra R, Duval C, Müller M, Kersten S. PPARs, Obesity, and Inflammation. PPAR Res 2007;2007:95974.

17. Verges B. Clinical interest of PPARs ligands. Diabetes Metab 2004;30:7-12.

18. Kersten S, Desvergne B, Wahli W. Roles of PPARs in health and disease. Nature 2000; 405:421-4.

19. Langen RC, Schols AM, Kelders MC, Wouters EF, Janssen-Heininger YM. Enhanced myogenic differentiation by extracellular matrix is regulated at the early stages of myogenesis. In Vitro Cell Dev Biol Anim 2003;39:163-9.

20. Langen RC, Schols AM, Kelders MC, Wouters EF, Janssen-Heininger YM. Inflammatory cytokines inhibit myogenic differentiation through activation of nuclear factor-kappaB. Faseb J 2001;15:1169-80

21. van der Velden JL, Schols AM, Willems J, Kelders MC, Langen RC. Glycogen synthase kinase 3 suppresses myogenic differentiation through negative regulation of NFATc3. J Biol Chem 2008;283:358-66. 
22. Schrauwen P, Mensink M, Schaart G, Moonen-Kornips E, Sels JP, Blaak EE, Russell AP, Hesselink MK. Reduced skeletal muscle uncoupling protein-3 content in prediabetic subjects and type 2 diabetic patients: restoration by rosiglitazone treatment. J Clin Endocrinol Metab 2006;91:1520-5.

23. Mensink M, Hesselink MK, Russell AP, Schaart G, Sels JP, Schrauwen P. Improved skeletal muscle oxidative enzyme activity and restoration of PGC-1 alpha and PPAR beta/delta gene expression upon rosiglitazone treatment in obese patients with type 2 diabetes mellitus. Int $\mathrm{J}$ Obes (Lond) 2007;31:1302-10.

24. Altman DG, Gore SM, Gardner MJ, Pocock SJ. Statistical guidelines for contributors to medical journals. Br Med J (Clin Res Ed) 1983;286:1489-93.

25. Lo YT, Tzeng TF, Liu IM. Role of tumor suppressor PTEN in tumor necrosis factor alphainduced inhibition of insulin signaling in murine skeletal muscle $\mathrm{C} 2 \mathrm{C} 12$ cells. Horm Metab Res 2007;39:173-8.

26. Guttridge DC, Mayo MW, Madrid LV, Wang CY, Baldwin AS Jr. NF-kappaB-induced loss of MyoD messenger RNA: possible role in muscle decay and cachexia. Science 2000;289: 2363-6.

27. Bendinelli $\mathrm{P}$, Piccoletti $\mathrm{R}$, Maroni $\mathrm{P}$. Leptin rapidly activates PPARs in $\mathrm{C} 2 \mathrm{C} 12$ muscle cells. Biochem Biophys Res Commun 2005;332:719-25.

28. Sparatore A, Godio C, Perrino E, Romeo S, Staels B, Fruchart JC, Crestani M. [4-(2H-1,2,3benzotriazol-2-yl)phenoxy]alkanoic acids as agonists of peroxisome proliferator-activated receptors (PPARs). Chem Biodivers 2006;3:385-95.

29. Yoon MJ, Lee GY, Chung JJ, Ahn YH, Hong SH, Kim JB. Adiponectin increases fatty acid oxidation in skeletal muscle cells by sequential activation of AMP-activated protein kinase, p38 mitogen-activated protein kinase, and peroxisome proliferator-activated receptor alpha. Diabetes 2006;55:2562-70.

30. Daynes RA, Jones DC. Emerging roles of PPARs in inflammation and immunity. Nat Rev Immunol 2002;2:748-59.

31. Dyroy E, Yndestad A, Ueland T, Halvorsen B, Damas JK, Aukrust P, Berge RK. Antiinflammatory effects of tetradecylthioacetic acid involve both peroxisome proliferatoractivated receptor alpha-dependent and -independent pathways. Arterioscler Thromb Vasc Biol 2005;25:1364-9.

32. Bjorndal B, Helleland C, Boe SO, Gudbrandsen OA, Kalland KH, Bohov P, Berge RK, Lillehaug JR. Nuclear import of factors involved in signaling is inhibited in C3H/10T1/2 cells treated with tetradecylthioacetic acid. J Lipid Res 2002;43:1630-40.

33. Woo CH, Massett MP, Shishido T, Itoh S, Ding B, McClain C, Che W, Vulapalli SR, Yan C, Abe J. ERK5 activation inhibits inflammatory responses via peroxisome proliferator-activated receptor delta (PPARdelta) stimulation. J Biol Chem 2006;281:32164-74.

34. Sznaidman ML, Haffner CD, Maloney PR, Fivush A, Chao E, Goreham D, Sierra ML, LeGrumelec C, Xu HE, Montana VG, Lambert MH, Willson TM, Oliver WR Jr, Sternbach DD. Novel selective small molecule agonists for peroxisome proliferator-activated receptor delta (PPARdelta)--synthesis and biological activity. Bioorg Med Chem Lett 2003;13:1517-21.

35. Poynter ME, Daynes RA. Peroxisome proliferator-activated receptor alpha activation modulates cellular redox status, represses nuclear factor-kappaB signaling, and reduces inflammatory cytokine production in aging. J Biol Chem 1998;273:32833-41.

36. Delerive P, De Bosscher K, Besnard S, Vanden Berghe W, Peters JM, Gonzalez FJ, Fruchart JC, Tedgui A, Haegeman G, Staels B. Peroxisome proliferator-activated receptor alpha negatively regulates the vascular inflammatory gene response by negative cross-talk with transcription factors NF-kappaB and AP-1. J Biol Chem 1999;274:32048-54.

37. Anandharajan R, Jaiganesh S, Shankernarayanan NP, Viswakarma RA, Balakrishnan A. In vitro glucose uptake activity of Aegles marmelos and Syzygium cumini by activation of Glut-4, PI3 kinase and PPARgamma in L6 myotubes. Phytomedicine 2006;13:434-41.

38. Kumar N, Dey CS. Development of insulin resistance and reversal by thiazolidinediones in C2C12 skeletal muscle cells. Biochem Pharmacol 2003;65:249-57. 
39. Chawla A, Barak Y, Nagy L, Liao D, Tontonoz P, Evans RM. PPAR-gamma dependent and independent effects on macrophage-gene expression in lipid metabolism and inflammation. Nat Med 2001;7:48-52.

40. Castrillo A, Diaz-Guerra MJ, Hortelano S, Martin-Sanz P, Bosca L. Inhibition of IkappaB kinase and IkappaB phosphorylation by 15-deoxy-Delta(12,14)-prostaglandin $\mathrm{J}(2)$ in activated murine macrophages. Mol Cell Biol 2000;20:1692-8.

41. Rossi A, Kapahi P, Natoli G, Takahashi T, Chen Y, Karin M, Santoro MG. Anti-inflammatory cyclopentenone prostaglandins are direct inhibitors of IkappaB kinase. Nature 2000;403: 103-8

42. Pahl HL. Activators and target genes of Rel/NF-kappaB transcription factors. Oncogene 1999;18:6853-66.

43. Arnold R, Neumann M, Konig W. Peroxisome proliferator-activated receptor-gamma agonists inhibit respiratory syncytial virus-induced expression of intercellular adhesion molecule-1 in human lung epithelial cells. Immunology 2007;121:71-81.

44. Bai YP, Liu YH, Chen J, Song T, You Y, Tang ZY, Li YJ, Zhang GG. Rosiglitazone attenuates NF-kappaB-dependent ICAM-1 and TNF-alpha production caused by homocysteine via inhibiting ERK1/2/p38MAPK activation. Biochem Biophys Res Commun 2007;360:20-6.

45. Haffner SM, Greenberg AS, Weston WM, Chen H, Williams K, Freed MI. Effect of rosiglitazone treatment on nontraditional markers of cardiovascular disease in patients with type 2 diabetes mellitus. Circulation 2002;106:679-84.

46. Hevener AL, He W, Barak Y, Le J, Bandyopadhyay G, Olson P, Wilkes J, Evans RM, Olefsky J. Muscle-specific Pparg deletion causes insulin resistance. Nat Med 2003;9:1491-7.

47. Li M, Pascual G, Glass CK. Peroxisome proliferator-activated receptor gamma-dependent repression of the inducible nitric oxide synthase gene. Mol Cell Biol 2000;20:4699-707.

48. Pascual G, Fong AL, Ogawa S, Gamliel A, Li AC, Perissi V, Rose DW, Willson TM, Rosenfeld MG, Glass CK. A SUMOylation-dependent pathway mediates transrepression of inflammatory response genes by PPAR-gamma. Nature 2005;437:759-63.

49. Kim EK, Kwon KB, Koo BS, Han MJ, Song MY, Song EK, Han MK, Park JW, Ryu DG, Park $\mathrm{BH}$. Activation of peroxisome proliferator-activated receptor-gamma protects pancreatic betacells from cytokine-induced cytotoxicity via NF kappaB pathway. Int J Biochem Cell Biol 2007;39:1260-75. 

Chapter 7

General discussion and future directions 
Chapter 7

126 


\section{Prologue}

According to definitions of the World Health Organization (WHO), chronic diseases are not only characterised by their respective primary organ impairment, but also by disability and handicap ${ }^{1}$. In COPD, progressive exercise intolerance is a common symptom leading to disability. It is yet well established that, in addition to respiratory impairment, skeletal muscle dysfunction is an important determinant of decreased exercise capacity in this disorder. Skeletal muscle function in COPD is impaired due to muscle wasting and loss of muscle oxidative phenotype (OXPHEN i.e. lower slow twitch fiber expression, mitochondrial content and oxidative enzyme activity). Besides ageing and inactivity, low grade inflammation has been identified as a determinant of exercise intolerance in COPD. Experimental models clearly show a causal relation between inflammation and wasting of muscle mass ${ }^{2}$, although clinical validation of this relationship in COPD patients is currently limited. Surprisingly however, the role of inflammatory signals in loss of skeletal muscle OXPHEN remains largely unexplored.

The overall aim of this thesis therefore was to explore the molecular basis of loss of skeletal muscle OXPHEN using a translational approach with COPD as clinical model. Analyses in patient muscle biopsies yielded leads for the underlying pathobiology of COPD-associated loss of OXPHEN, e.g. the interaction between inflammation and regulators of skeletal muscle OXPHEN. Subsequent in vitro studies using cultured skeletal muscle cells revealed causality between inflammatory signalling and loss of muscle OXPHEN and the molecular basis of this relationship was partly resolved. Moreover, in vitro experiments yielded a tempting therapeutic angle to suppress inflammatory signalling in muscle by either nutritional or pharmacological modulation.

\section{PPARs and COPD}

As outlined in chapter 2, the PGC-1a/PPAR signalling cascade has emerged as a key regulatory pathway involved in positive regulation of OXPHEN of muscle fibers. In addition, chapter 3 demonstrates that PGC-1 $\alpha$, PPARs and its downstream targets, e.g. mitochondrial transcription factor $A(T f a m)$ and nuclear respiratory factor 1 (NRF-1), are associated with the development of skeletal muscle OXPHEN during the process of myogenic differentiation in cultured muscle cells. Therefore, in chapter 4, expression levels and protein content of these mediators were investigated in skeletal muscle biopsies of COPD patients. It was observed that protein content of PPAR- $\delta$ and Tfam as well as mRNA transcript levels of PGC-1 $\alpha$ and PPAR- $\alpha$ were lower in skeletal 
muscle of COPD patients compared to healthy controls. In light of the key role of the PGC-1a/PPAR pathway in regulation of skeletal muscle OXPHEN, the observed disturbances in this pathway in the musculature of COPD patients may well underlie the loss of muscle OXPHEN in these patients. As the loss of lower limb OXPHEN is considered to be an important underlying aspect of impaired muscle endurance and mechanical efficiency in COPD, it is tempting to speculate that lower levels of PGC-1 $\alpha$ and the PPARs in skeletal muscle of COPD patients contribute to functional impairment in this disorder.

As COPD is to be considered a multi-component systemic disease, the cause of the decreased content or expression levels of constituents of the PGC$1 \alpha / P P A R$ pathway in skeletal muscle of COPD patients may be multifaceted. Medication, malnutrition, oxidative stress, hypoxia, inactivity, and inflammation must all be considered. Maintenance medication in many COPD patients consists of inhaled corticosteroids and long acting $\beta 2$-agonists. The inhaled steroid fluticasone has been shown to decrease PPAR expression levels in nasal polyposis ${ }^{3}$. Also, fluticasone as well as the $\beta 2$-agonist salmeterol, have been shown to increase binding of PPARs to other nuclear receptors, thereby possibly inhibiting their respective primary functions ${ }^{4}$. Reports on muscle PPAR levels upon treatment protocols for COPD patients involving corticosteroids or B2-agonists however are lacking and any effects of these drugs on PPAR levels in the musculature of patients therefore remain highly speculative. Malnutrition due to decreased appetite or (unbalanced) increased energy requirements is commonly observed in COPD patients ${ }^{5}$. Poly-unsaturated fatty acids (PUFAs), found e.g. in fatty fish, are known activators of the PGC1a/PPAR pathway ${ }^{6}$. An increased dietary PUFA intake to balance malnutritioninduced changes therefore might positively influence the PGC-1 $\alpha / P P A R$ pathway in muscle of COPD patients. Presence of oxidative stress in skeletal muscle of COPD patients has been demonstrated ${ }^{7}$. Oxidative stress can impair PPAR signalling ${ }^{8}$ and thus might also contribute to an impaired content of the PGC-1a/PPAR pathway in lower limb muscles of COPD patients. Hypoxia, feasibly via activation of hypoxia inducible factor 1 alpha (HIF-1 $\alpha$ ), has been shown to down-regulate PPAR- $\alpha$ levels ${ }^{9,10}$, but reports on the role of HIF-1 $\alpha$ in PPAR regulation in muscle are lacking. Since the PGC-1a/PPAR pathway is activated by physical activity ${ }^{11-13}$ and COPD patients are characterised by a low physical activity level $1^{14,15}$, it is conceivable that inactivity will contribute to decreased levels of these mediators in skeletal muscle of COPD patients. Unfortunately, objective assessment of physical activity level was not performed in chapter 4 limiting any conclusions about the involvement of this determinant. Instead, inflammatory markers in plasma of these patients however were investigated. Intriguingly, it was found that PPAR expression levels in muscle were inversely related to circulating levels of TNF- $\alpha$ and its 
receptors in plasma which suggest that patients' systemic inflammatory status may influence regulation of muscle OXPHEN. It must be recognised that this observation is purely associative but is however in line with studies demonstrating that levels of inflammatory mediators are inversely related to exercise capacity, which is determined, in part, by muscle OXPHEN. A limitation of chapter $\mathbf{4}$ concerned the fact that muscle inflammatory status was not investigated, which precluded any interpretations regarding a potential contribution of muscle inflammatory signalling in relation to decreased muscle OXPHEN. To adequately resolve this issue, constituents and regulators of skeletal muscle OXPHEN were investigated after stratification of biopsies of COPD patients for normal and high muscular inflammatory signalling based on differential TNF- $\alpha$ expression in chapter 5.

\section{Battle between PPARs and NF-KB}

Chapter 5 demonstrates that COPD patients with high muscle TNF- $\alpha$ mRNA levels display decreased transcript levels of constituents of the PGC-1 $\alpha / P P A R$ pathway in their skeletal muscle. This suggests that inflammation, and in particular TNF- $\alpha$, can interfere with regulation of skeletal muscle OXPHEN. This however obviously is purely associative. A possible venue to address causality between TNF- $\alpha$ and impaired regulation of skeletal muscle OXPHEN in humans might be administration of an agent capable of removing TNF- $\alpha$. Recently a phase II trial has been performed with the chimeric mouse/human monoclonal anti-TNF- $\alpha$ antibody Infliximab in patients with mild-to-moderate $\mathrm{COPD}^{17}$. The intention-to-treat analysis failed to demonstrate any short term beneficial effects on lung function and lung inflammation and even revealed undesirable side effects as pulmonary malignancies ${ }^{18}$. Post-hoc analysis however did reveal a significant positive effect of the intervention on exercise capacity in the sub-group of cachectic patients.

One important consideration regarding (de)regulation of muscle OXPHEN in COPD and in particular the role of inflammation herein is how the presence of a systemic inflammatory process correlates with inflammatory status of the muscle. In addition, since the PGC-1a/PPAR pathway is considered to be one of the main molecular mediators of physical activity-induced muscle remodeling, a role for physical inactivity, next to a possible role for inflammation, in altering muscular levels of PGC-1 $\alpha$ and the PPARs should also be considered. Indeed, as described above, COPD patients are characterised by disuse of the musculature by physical inactivity ${ }^{19}$. Since PGC1a/PPAR expression ${ }^{11,20}$ and signalling relies in part on physical activityinduced $\mathrm{Ca}^{2+}$ signalling ${ }^{21}$, physical inactivity (sedentary lifestyle) feasibly also 
contributes to the loss of muscle OXPHEN in COPD via decreased PPAR signalling $^{22}$. The present thesis however focused on the effect of inflammatory events in the regulation of skeletal muscle OXPHEN. To address causality of the association between high TNF- $\alpha$ and decreased muscle expression levels of oxidative genes and their regulators found in patients, an in vitro approach in which cultured skeletal muscle cells were chronically stimulated with TNF- $\alpha$ was applied in chapter 5 . These experiments demonstrated that chronic TNF- $\alpha$ treatment of skeletal muscle cells impaired total cellular respiration rates and shifted myosin heavy chain composition towards a more glycolytic distribution resulting in a decreased skeletal muscle OXPHEN. This revealed a direct link between increased TNF- $\alpha$ signalling and impairment of OXPHEN of muscle cells. Interestingly, decreased intrinsic mitochondrial respiratory rates in COPD patients with a low body mass have been described recently ${ }^{23,24}$. Another study, using COPD patients without active muscle wasting, demonstrated that impaired respiratory capacity in COPD was not due to intrinsic mitochondrial abnormalities but is probably explained by lower amounts of mitochondria ${ }^{25}$. These studies suggest that both lower amounts of mitochondria as well as impaired intrinsic mitochondrial function might be of relevance for impaired skeletal muscle respiratory capacity in COPD. Respiration rates in chapter 5 were not corrected for mitochondrial content of the muscle cells and therefore no conclusions regarding intrinsic mitochondrial (dys)function in response to chronic TNF- $\alpha$ exposure can be drawn. However, protein content of the complexes of the mitochondrial respiratory chain was decreased suggesting a decreased mitochondrial content upon TNF- $\alpha$ stimulation. Interestingly, PuenteMaestu et al. investigated intrinsic mitochondrial respiratory capacity in peripheral- as well as respiratory muscles and found similar impairments in mitochondrial function between the muscles. This is suggestive of a systemicrather than a local factor in the etiology of impaired mitochondrial function in COPD. Since the patients included in their study were matched for physical activity levels with healthy controls, these authors suggested a role for a systemic factor e.g. systemic inflammation or (intermittent) hypoxia in impairment of mitochondrial function in COPD patients ${ }^{24}$.

The exact molecular mechanism by which TNF- $\alpha$ impairs skeletal muscle OXPHEN is unclear. To address this, the proximal part of the TNF- $\alpha$ signalling pathway was investigated in chapter $\mathbf{5}$. Upon binding to its receptor, TNF- $\alpha$ initiates an intra-cellular signalling cascade, i.e. the classical NF-KB pathway, resulting in degradation of the inhibitor $1 \mathrm{KBa}$ leading to transduction of the inflammatory signal to the nucleus of the cell. These events result in nuclear translocation of RelA (the main subunit of the classical NF-KB pathway involved in inflammatory signalling) and subsequent transcription of its target genes. This leads to the notion that inflammatory events, as elevated levels of pro- 
inflammatory cytokines, for example TNF- $\alpha$ but possibly also other inflammatory cytokines as IL-1 $\beta$, impair skeletal muscle OXPHEN through activation of the NF-KB signalling pathway. To address this, mechanistic experiments were performed in chapter 5. These demonstrated that the impairing effect of chronic TNF- $\alpha$ stimulation on skeletal muscle OXPHEN was indeed mediated through and depended on activation of the classical NF-KB signalling route, as the effect of TNF- $\alpha$ depended on IKBa degradation. Moreover, these experiments convincingly showed that the classical NF-KB pathway can interfere with the PGC-1 //PPAR pathway. Activation of the NF-KB pathway has been shown to decrease PGC-1 $1 \alpha$ expression in muscle ${ }^{26}$ and PPAR- $\delta$ activity in heart muscle ${ }^{27}$. Together with results from chapter $\mathbf{5}$, this shows that the inflammatory classical NF-KB pathway can interfere with pathways regulating OXPHEN in muscle (PGC-1a/PPAR), thereby feasibly contributing to an impaired skeletal muscle OXPHEN. In this context it would be very interesting to investigate skeletal muscle OXPHEN in mice with altered levels of components of the classical NF-KB signalling pathway specifically in skeletal muscle tissue. These transgenic mouse models have been developed but have thus far only been applied in research concerning skeletal muscle mass regulation ${ }^{2}$.

Interaction between NF-KB and the PGC-1a/PPAR pathway has been described in several tissues. The main mechanism described in literature involves a physical interaction between RelA and the different PPAR subtypes. Firstly, physical interaction with RelA has been shown to inhibit PPAR-a transcriptional activity through diminished DNA binding capacity ${ }^{28,29}$. Secondly, RelA has also been shown to physically interact with PPAR- $\delta$, resulting in impaired DNA binding and diminished transcriptional activity ${ }^{30}$ (in muscle cells) leading to a loss of oxidative capacity ${ }^{27}$. Thirdly, PPAR-y DNA binding and transactivation is disturbed by RelA ${ }^{31,32}$. In contrast to RelA, the p50 subunit of $N F-K B$ is unable to physically interact with the PPAR proteins ${ }^{30}$. In addition, NF$K B$ activation has been shown to be causally related to decreased PGC-1a mRNA transcript levels in response to palmitate stimulation of cultured skeletal muscle cells ${ }^{26}$. Thus, activation of classical NF-kB signalling resulting in the nuclear presence of RelA appears to repress PPAR-mediated transactivation via a direct physical interaction between RelA and PPARs. The exact mechanism operating in muscle upon chronic exposure to elevated TNF- $\alpha$ levels however merits further investigation.

In addition to data described in chapter 5, a significant body of evidence supports the presence of an interaction between the NF-KB and PGC-1 $1 \alpha / P P A R$ signalling pathways. The exact mechanisms operating in skeletal muscle however remain unknown. Interestingly, interplay between the classical NF-kB 
and the PGC-1 1 /PPAR signalling axes has been suggested to be bi-directional. Since NF-KB activation is elevated in skeletal muscle of COPD patients ${ }^{33}$ and activation of this pathway has been shown to have several detrimental effects on muscle tissue including skeletal muscle atrophy ${ }^{2}$, impaired myogenic differentiation ${ }^{34}$ and a disturbed OXPHEN (chapter 5), we investigated the potential of the PPARs to interfere with inflammatory signalling through the classical NF-KB pathway in skeletal muscle cells in chapter 6 . This led to the observation that pharmacological activation of PPAR- $\gamma$ potently inhibited inflammatory cytokine-induced classical NF-KB activation in cultured skeletal muscle cells. These findings were translated into a clinically relevant setting, by including type 2 diabetes mellitus (T2DM) patients treated with Rosiglitazone as an anti-diabetic therapy. Although group size was limited, a trend towards decreased expression of NF-KB target genes was illustrative of the pathophysiological relevance of the in vitro findings. Anti-inflammatory potential of PPAR-y activation has been shown in other tissues and several mechanisms have been proposed ranging from inhibition of IKBa degradation ${ }^{35}$, reduction in RelA translocation to the nucleus ${ }^{36}$ and diminished DNA binding of key components of the NF-KB pathway ${ }^{37}$. The anti-inflammatory effects mediated by PPAR-y activation in skeletal muscle described in chapter 6 however appeared to be independent of RelA nuclear translocation or DNA binding suggestive of a transrepression mechanism.

Several different transrepression mechanisms have been described to be mediated by the PPARs ${ }^{28,38,39}$. These include their ability to physically associate with various transcription factors (including NF-KB) and the ability to successfully compete for limiting amounts of co-activators. Since Rosiglitazone pre-treatment did not reduce TNF- $\alpha$-induced RelA nuclear translocation and DNA binding, the mechanism by which PPAR-y activators inhibit NF-KB activity in skeletal muscle should be located downstream of DNA binding. This may include impaired recruitment of transcriptional co-factors to the NF-kB-DNA complex $^{38}$. Alternatively, removal of repressor complexes of the NF-KB transcriptional machinery may be prevented by PPAR-y following its ligandinduced SUMOylation ${ }^{40}$. In the latter case, ligand-dependent SUMOylation of the PPAR-y ligand-binding domain targets PPAR- $y$ to nuclear receptor corepressor (NCoR)-histone deacetylase-3 (HDAC3) complexes on inflammatory gene promoters. As a result, NCoR complexes are not cleared from the promoter and target genes are maintained in a repressed state. This mechanism provides an explanation for how an agonist-bound nuclear receptor like PPAR-y can be converted from an activator of transcription to a promoterspecific repressor of the NF-KB signalling pathway ${ }^{40}$. Which of the proposed transrepression mechanisms is activated in skeletal muscle tissue upon PPARY activation remains to be established. Clarification of the exact mechanism 
might be therapeutically relevant since it may identify specific targets for pharmacological intervention.

In addition, causality between PPAR-y activation and anti-inflammatory effects of Rosiglitazone administration to skeletal muscle cells was not fully elucidated as only pharmacological modulation (and not genetic manipulation) of PPAR- $y$ was applied, However, two different, structurally unrelated, pharmacological PPAR- $\gamma$ activators both potently inhibited NF-KB activation suggesting that the observed effects are indeed PPAR- $\gamma$-mediated. Still we cannot fully exclude that anti-inflammatory actions of the PPAR- $y$ activators that we used in the present study were PPAR- $y$-independent and therefore caution needs to be exercised in ascribing a role for PPAR-y in these effects on the basis of the action of its ligands.

Extrapolation of the results described in chapter 6 to the in vivo clinical setting of COPD patients also warrants caution. Indeed, in chapter 4 , it was shown that PPAR- $\gamma$ protein in skeletal muscle of COPD patients (and healthy controls) was undetectable, suggesting that, if present at all, PPAR-y protein content of human skeletal muscle is probably very low $^{41}$. Other reports in literature however do suggest the presence of PPAR- $\gamma$ protein in human skeletal muscle $^{42}$. Since, PPAR-y is mainly implicated in storage of fatty acids and adipocyte cell differentiation it is highly expressed in adipose tissue ${ }^{43}$. Therefore, the possibility emerges that PPAR-y measured in skeletal muscle tissue might originate from intramuscular fat tissue. On the other hand, skeletal muscle-specific knock-out of PPAR- $y$ resulted in diminished insulin sensitivity in mice ${ }^{44}$ and impaired skeletal muscle differentiation in cultured muscle cells ${ }^{45}$. Furthermore, treatment of mice with muscle-specific ablation of PPAR-y with the insulin sensitizing thiazolidinediones (TZD), which are potent PPAR- $y$ activators, failed to improve insulin sensitivity in contrast to what is observed in wild type mice ${ }^{44}$. This reveals a crucial role for muscle PPAR-y in maintaining insulin sensitivity. Feasibly, PPAR-y protein content in human skeletal muscle is very low but still remains physiologically relevant.

The identification of a bi-directional interplay between the classical NF-KB pathway and the PGC-1a/PPAR signalling cascade in skeletal muscle offers important novel insights and is illustrative of the complex nature of intracellular signalling pathways. Indeed, simplified representations of these pathways are inherently incomplete as interactions between these pathways, especially in disease related states, may significantly influence functional (disease-related) outcome measures. This is illustrated by e.g. the dual role of the classical NF$\mathrm{KB}$ pathway in regulation of skeletal muscle abnormalities in chronic inflammatory diseases. In addition to the detrimental role of classical NF-KB 
signalling on the regulation of skeletal muscle OXPHEN, described in the present thesis, this pathway has also been implicated in the process of skeletal muscle wasting. Wasting of skeletal muscle mass is observed in several chronic inflammatory disorders and has been linked to increased morbidity, disability and morbidity. Increased activation of classical NF-KB signalling has been shown in COPD patients suffering from severe muscle wasting ${ }^{33}$. In addition, transgenic mouse models have demonstrated a clear causal link between activation of classical NF-KB signalling and the process of skeletal muscle atrophy ${ }^{2}$. This dual role of the classical NF-kB pathway has broad implications for its conceived role in skeletal muscle dysfunction in chronic disease states. Indeed, based on data observed in literature and data presented in this thesis the notion unfolds that patients who suffer from a chronic inflammatory disorder as e.g. COPD, T2DM and cancer who display increased activation of the classical NF-KB pathway in their muscle are not only at risk for active loss of muscle mass but also for deregulation of OXPHEN of the remaining muscle. This severely compromises function of the peripheral musculature and hence mobility and quality of life of patients. This positions the classical NF-KB pathway as a central molecular mechanism underlying skeletal muscle abnormalities in COPD and possibly also in other chronic inflammatory diseases.

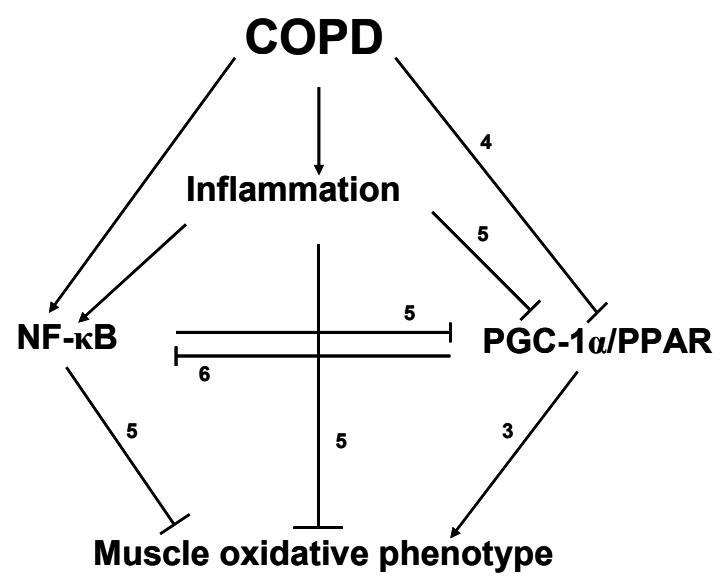

Figure 7.1 Schematic representation of findings in chapter 3, 4, 5 and 6 . Numbers represent the respective chapters. 


\section{Therapeutic perspectives}

Impaired skeletal muscle OXPHEN and a reduced exercise capacity is observed in COPD, chronic heart failure (CHF) and T2DM ${ }^{46,47}$ and severely compromises mobility and quality of life of patients. Interestingly, these disorders are all characterised by lower PGC-1 $\alpha$ and/or PPAR expression levels in peripheral skeletal muscle ${ }^{48,49}$. Therefore, it is tempting to speculate that a decreased muscular content of the PGC-1a/PPAR pathway underlies disturbed muscle function and reduced mechanical efficiency in these disorders. The PGC-1 $\alpha$ /PPAR pathway therefore may represent an interesting therapeutic target as experimental models show that its activation increases skeletal muscle OXPHEN, ${ }^{51}$ and restores mitochondrial dysfunction ${ }^{52,53}$. Although studies in humans are scarce, findings indirectly point toward beneficial effects of modulation of the PGC-1a/PPAR pathway on exercise capacity of human subjects. Direct activation of the PGC-1a/PPAR pathway can be achieved by pharmacological- as well as nutritional intervention and/or physical exercise. Since genetic polymorphisms in the PPAR- $\delta$ gene have been associated with maximal exercise capacity in human subjects ${ }^{54}$ and administration of the PPAR- $\delta$ agonist GW501516 to obese human subjects increased skeletal muscle oxidative capacity ${ }^{55}$, studies describing the effects of oral administration of a synthetic PPAR- $\delta$ agonist e.g. GW501516, on skeletal muscle exercise capacity or endurance of COPD patients could give valuable information regarding the therapeutic potential of PPAR modulation in COPD. An important consideration in use of pharmacological PPAR activators however is safety. Indeed, several adverse effects of PPAR- $\delta$ activation have been described including potential carcinogenicity in rodents, signs of myopathy and rhabdomyolysis, weight gain, fluid retention, peripheral oedema and potential increased risk of cardiac failure ${ }^{56}$. Future in depth investigations are required to evaluate safety and efficacy of synthetic PPAR activators in improving exercise capacity in human subjects. Alternatively, nutritional components can be used to activate the PGC-1alPPAR pathway in skeletal muscle. Obviously, concerning safety, nutritional intervention is preferred compared to the use of synthetic substances. Interestingly, a randomised clinical trial from our group demonstrated that nutritional supplementation with poly unsaturated fatty acids (PUFAs), as adjunct to exercise training, in COPD patients markedly enhanced their exercise capacity compared to the placebo treated group ${ }^{57}$. As PUFAs are known PPAR activators ${ }^{58,59}$, the positive effect of PUFA nutritional supplementation on skeletal muscle exercise capacity in COPD might well be mediated through the PGC-1a/PPAR pathway. This however remains speculative. Measurements of PPAR levels and/or activity before and after PUFA supplementation in this study would have been helpful in elucidating the molecular mechanisms underlying the observed beneficial effects on muscle 
exercise capacity. Studies suggest that the magnitude of pharmacological activation of PPAR activity far exceeds that of PPAR activation by nutritional components. In this context, pharmacological modulation of the PGC-1a/PPAR pathway is exceedingly interesting compared to nutritional modulation. However, we explored the potential for several fatty acids, including PUFAs, to activate PPAR transcriptional activity in cultured adult skeletal muscle cells and compared it with the potency of a well known pharmacologic PPAR- $\delta$ activator. These experiments showed that PUFAs, as eicosapentaenoic acid (EPA) and docosahexaenoic acid (DHA), were capable of inducing PPAR transcriptional activity with efficiency comparable to that of the synthetic PPAR- $\delta$ agonist GW501516 (Figure 7.2).
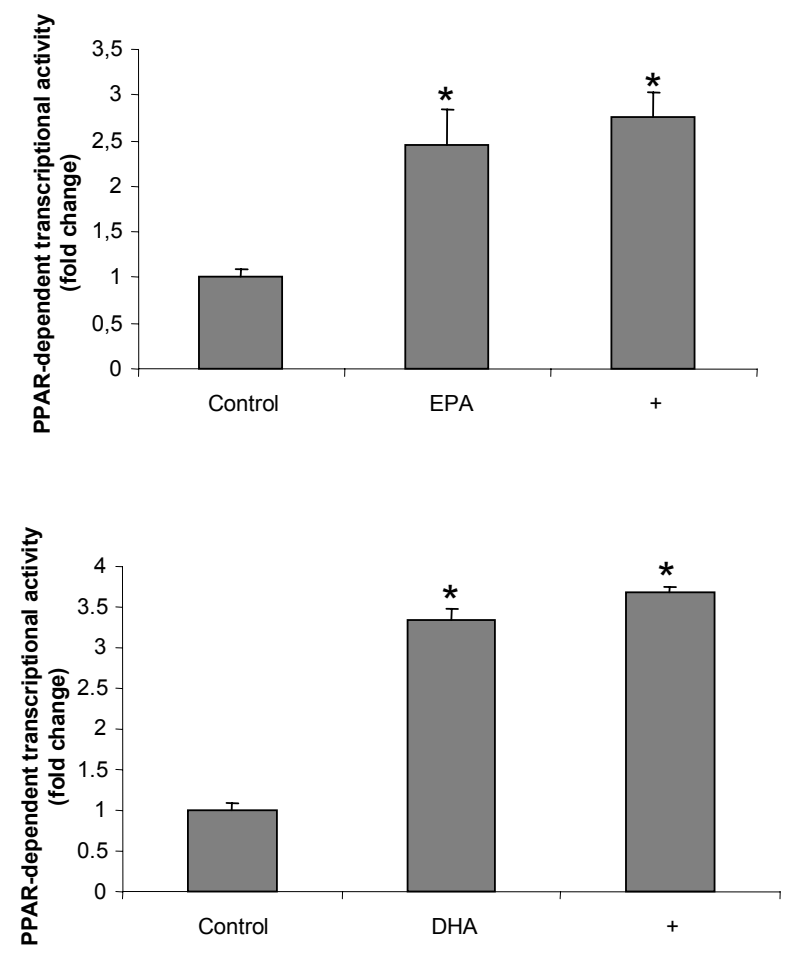

Figure 7.2 PUFAs induce PPAR transcriptional activity in $\mathrm{C2C} 12$ myotubes. $\mathrm{C} 2 \mathrm{C} 12$ myoblasts were differentiated for 3 days in DM. Myotubes were stimulated with vehicle (ethanol: Control), poly-unsaturated fatty acids (EPA: $100 \mu \mathrm{M}$ or DHA: $250 \mu \mathrm{M}$ ) or a synthetic PPAR- $\delta$ activator (GW501516; positive control +) for $48 \mathrm{~h}$. Cells were lysed; luciferase activity was determined and normalised to total protein. Error bars indicate the SD. * $p \leq 0.001$. 
Moreover, incubation with the PUFA DHA resulted in an increase in the activity levels of enzymes involved in substrate oxidation, including citrate synthase (CS) (Krebs cycle) and $\beta$-hydroxyacyl CoA-dehydrogenase (HAD) (fatty acid $\beta$ oxidation) demonstrating functional relevance (Figure 7.3).

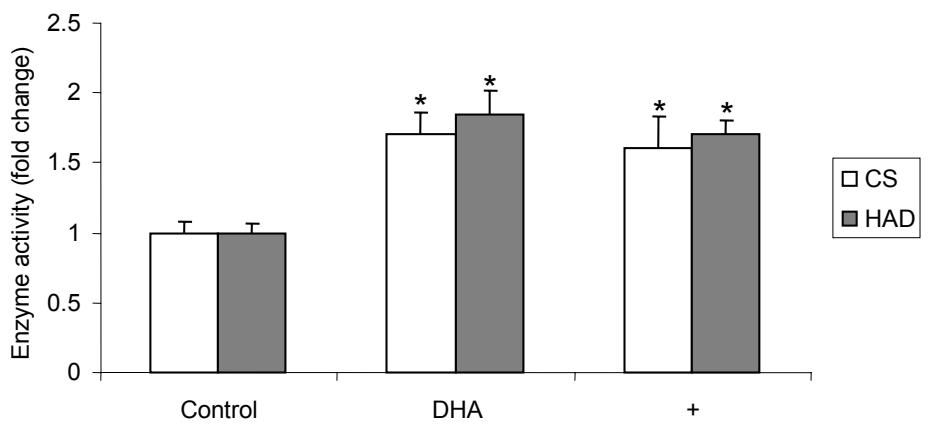

Figure 7.3 PUFAs induce oxidative enzyme activity in C2C12 myotubes. C2C12 myoblasts over-expressing PPAR- $\delta$ were differentiated for 3 days in DM. Myotubes were stimulated with vehicle (ethanol: Control), poly-unsaturated fatty acids (EPA: $100 \mu \mathrm{M}$ or DHA: $250 \mu \mathrm{M}$ ) or a synthetic PPAR-ठ activator (GW501516; positive control +) for $48 \mathrm{~h}$. Cells were lysed; oxidative enzyme activity was determined and normalised to total protein. Error bars indicate the SD. ${ }^{*} \mathrm{p} \leq 0.05$.

However, there are some considerations for translation of these findings to human subjects. First of all, before binding to transcription factors, PUFAs must be absorbed in the intestine and delivered to cells. Subsequently, they must enter the cell and the nucleus. PUFA concentrations within the cell determine their potency to act as transcription modulators and depend on many different factors. Since dietary components interact first with the gastrointestinal tract, the mechanisms which regulate the bioavailability at the site of physiological activity of a nutritional molecule are fundamental to understand its bioactive role. Concentrations of specific fatty acids delivered directly to cultured muscle cells in our in vitro system may be relatively high (100-250 $\mu \mathrm{M})$ compared to expected concentrations of specific fatty acids ultimately reaching skeletal muscle cells after nutritional modulation in the in vivo situation. Therefore, future studies addressing the potential of fatty acid nutritional modulation to improve exercise capacity in chronic inflammatory disorders should also focus on investigation of molecular mechanisms (PGC-1a/PPAR signalling) and measuring intracellular fatty acid levels in myocytes.

In addition to pharmacological or nutritional intervention, physical exercise is an evidence-based, practical and financially attractive approach to improve skeletal muscle OXPHEN, function and hence quality of life of patients. Most 
COPD patients indeed improve their exercise capacity upon training. However, a subgroup of COPD patients fails to improve exercise capacity upon pulmonary rehabilitation ${ }^{60,61}$. Strikingly, this discrepancy is not explained by differences in lung function ${ }^{61}$. It can be speculated that, since a subset of COPD patients is characterised by increased levels of muscle TNF- ${ }^{62}$ (chapter 5), an increased inflammatory status of the muscle over rides the ability of the muscle to adapt favorably to exercise.

For example, chapter 3 suggests a role for the PGC-1a/PPAR pathway in the development of skeletal muscle OXPHEN during skeletal muscle differentiation, as would be observed upon muscle regeneration after muscle loss following acute exacerbations in COPD or after damage induced by e.g. exercise training. Chapter 3 suggests a role for PGC-1 $\alpha$ in development of muscle OXPHEN in myogenesis. Interestingly, MyoD, a pivotal regulator of myogenesis, binds to the promoter of the PGC-1a gene and activates it illustrating that PGC-1 $\alpha$ is indeed recruited to build up OXPHEN during myogenic differentiation ${ }^{63}$. Chapter 5 demonstrates that TNF- $\alpha$ can inhibit PGC-1 $\alpha$ expression in muscle. Also, TNF- $\alpha$-induced NF-KB activation has been shown to negatively regulate myogenic differentiation by inducing loss of MyoD $\mathrm{mRNA}^{34}$ and reducing MyoD protein stability ${ }^{64}$. Since the PGC-1 1 /PPAR pathway is up-regulated by physical exercise ${ }^{11,20,65}$, it is feasible that attenuated activation of this pathway upon physical activity under inflammatory conditions may contribute to non-responsiveness to exercise stimuli in a subgroup of COPD patients. Future studies are required to shed light on the involvement of inflammatory processes in exercise-induced muscle remodelling in chronic inflammatory disorders as COPD. In this context, anti-inflammatory properties of PPAR-y activation in skeletal muscle (chapter 6) may have therapeutic potential. However, the molecular mechanism and the causality of PPAR- $y$ in the observed anti-inflammatory effects of PPAR- $y$ activators were not fully elucidated in chapter 6 . Concerning the molecular mechanism involved it is of importance to establish the IC50 of PPAR-y activators since the concentrations used in this study are relatively high. In addition, PUFAs as EPA possess potent anti-inflammatory properties ${ }^{66,67}$, have been shown to activate PPAR$\mathrm{Y}^{58,68}$ and can reverse inflammation-induced muscle abnormalities ${ }^{69,71}$. Therefore, it is tempting to speculate that, in addition to direct PPAR- $\alpha$ or PPAR- $\delta$ activation by PUFA supplementation and physical exercise, antiinflammatory effects of PUFA supplementation, possibly mediated through PPAR- $y$, indirectly contributed to the observed beneficial effects on exercise capacity of COPD patients ${ }^{57}$. It must be noted however that activation of the PPAR-y isotype by oral thiazolidinediones (TZD) administration in T2DM subjects has been shown to be ineffective in restoring in vivo mitochondrial function ${ }^{72,73}$. Nevertheless, it can be suggested that direct activation of the 
PGC-1a/PPAR pathway in combination with indirect activation (alleviation of inflammatory status) may prove to be beneficial in restoring muscle function in chronic inflammatory disorders.

\section{Future directions}

Although valuable new insights have emerged from this work, a number of issues remain unresolved and new questions arise. For example, chapter $\mathbf{5}$ suggests a role for the classical NF-KB pathway in deregulation of skeletal muscle OXPHEN in chronic inflammatory disorders. However, the exact implication of this pathway and the precise mechanisms by which it interferes with the regulation of skeletal muscle OXPHEN remain unclear. Moreover, it appears that the impact of NF-KB signalling on skeletal muscle structure or function is not solely confined to detrimental effects. A recent report from Guttridge et al. yielded new and exciting results which opened novel insights in the involvement of the NF-KB pathway in regulation of muscle OXPHEN. They showed that the alternative NF-KB signalling pathway, which can be distinguished from the classical NF-KB pathway by different signalling proteins and activators, is positively involved in the development of cellular oxidative capacity during myogenesis ${ }^{74}$. This is in contrast with the detrimental role of the classical NF-KB pathway on muscle mass ${ }^{34}$ and muscle OXPHEN (chapter 5). As chapter 3 shows that the PGC-1a/PPAR pathway is also associated with myogenesis, interplay between the alternative NF-KB pathway and the PGC$1 \alpha / P P A R$ pathway in this context is feasible. Since PGC-1a/PPAR expression ${ }^{11,20}$ and signalling ${ }^{21}$ relies in part on physical activity-induced $\mathrm{Ca}^{2+}$ signalling ${ }^{21}$, and physical inactivity results in decreased $\mathrm{Ca}^{2+}$ signalling ${ }^{75,76}$, physical inactivity (sedentary lifestyle) feasibly also contributes to the loss of muscle OXPHEN in COPD via decreased PPAR signalling ${ }^{22}$. Intriguingly, physical inactivity also results in activation of the alternative NF-KB pathway ${ }^{77}$. However, the exact role of the classical- and alternative NF-KB pathways in loss of muscle OXPHEN in response to disuse or chronic inflammation and the link with PGC-1a/PPAR signalling remain to be determined. More specifically, it remains to be firmly established whether activation of classical NF-KB signalling is sufficient or required for the effects of TNF- $\alpha$ on skeletal muscle OXPHEN. Secondly, it is unclear whether activation of the alternative NF-KB pathway will lead to an up-regulation of the PGC-1a/PPAR signalling pathway and consequently will attenuate inflammation-induced loss of skeletal muscle OXPHEN. Finally, whether and how classical- and alternative NF-KB signalling control muscle OXPHEN through (de)regulation of the PGC-1 1 /PPAR pathway remains to be explored. Investigation of parameters of skeletal muscle $\mathrm{OXPHEN}$ and constituents of classical- as well as alternative NF-KB signalling 
and PGC-1a/PPAR pathway in several experimental mouse models can increase insights in this matter. These models include inflammatory models, such as muscle-specific IKK- $\beta$ (classical NF-KB pathway) over-expressing mice $^{2}, \mathrm{Sp}-\mathrm{C} / \mathrm{TNF}-\alpha$ (muscle pathology induced by pulmonary inflammation) ${ }^{78}$ and inactivity models (hind limb suspension), as well as the combination of these models. In human subjects, investigation of muscle inflammatory status and physical activity patterns combined with investigation of basal- as well as exercise-induced muscle OXPHEN and investigation of classical- as well as alternative NF-KB signalling and the PGC-1a/PPAR pathway can aid in unravelling the details about the involvement of these pathways in regulation of muscle OXPHEN and the role of inflammation and disuse herein.

Another question that deserves attention is whether inflammatory markers in the circulation are linked to local inflammatory signalling in muscle of COPD patients. This can be addressed by assessing both plasma and muscle inflammatory status of a large group of COPD patients by measuring a multitude of inflammatory cytokines and investigating any possible correlations. If the presence of inflammatory mediators in plasma proves to be a determinant of skeletal muscle inflammatory status it can be used as a risk marker that could be measured relatively easily (blood sampling and determination of plasma inflammatory profile) and used to potentially tailor the treatment according to the need for anti-inflammatory interventions. Additionally, it remains to be determined whether classical NF-KB signalling is indeed elevated in skeletal muscle of COPD patients and related to impaired OXPHEN.

As PPAR- $\gamma$ activation in muscle blocks activation of the classical NF-KB pathway (chapter 6), which is implicated in deregulation of muscle OXPHEN (chapter 5), it remains to be determined whether PPAR-y modulation can alleviate skeletal muscle dysfunction associated with an increased inflammatory status. By elucidation of the mechanism of the anti-inflammatory effect of PPAR-y activation (transrepression) in skeletal muscle, future studies may identify the precise molecular mediators involved and subsequently identify new therapeutic targets to alleviate skeletal muscle inflammatory status.

It also remains unresolved whether patients with increased muscle inflammatory status are characterised by decreased physical activity levels as a result of reduced muscle endurance. One can speculate that an impaired regulation of skeletal muscle OXPHEN, possibly mediated by inflammation (see chapter 5), increases lactate and $\mathrm{CO}_{2}$ production which can lead to more dyspnoea and increased fatigability and subsequent disuse of the musculature. Future studies investigating physical activity levels of COPD patients should 
therefore include measurements of muscle inflammatory status (e.g. TNF- $\alpha$ levels and markers of activation of the classical NF-kB pathway) and investigate associations with physical activity levels of patients.

In conclusion, data presented in the present thesis postulates the classical NF$\mathrm{KB}$ signalling pathway as an important pathway involved in impaired regulation of skeletal muscle OXPHEN under inflammatory conditions. Moreover, inflammation-induced disturbances of the PGC-1a/PPAR signalling pathway (mediated through the classical NF-kB pathway) may lie at the molecular basis of reduced exercise capacity of skeletal muscle in chronic inflammatory disorders as COPD but possibly also other inflammatory disorders as CHF and T2DM. 


\section{References}

1. Wood $\mathrm{PH}$. Appreciating the consequences of disease: the international classification of impairments, disabilities, and handicaps. WHO Chron 1980:34:376-80.

2. Cai D, Frantz JD, Tawa NE, Jr., Melendez PA, Oh BC, Lidov HG, Hasselgren PO, Frontera WR, Lee J, Glass DJ, Shoelson SE. IKKbeta/NF-kappaB activation causes severe muscle wasting in mice. Cell 2004;119:285-98.

3. Cardell LO, Hagge M, Uddman R, Adner M. Downregulation of peroxisome proliferatoractivated receptors (PPARs) in nasal polyposis. Respir Res 2005;6:132.

4. Nie M, Corbett L, Knox AJ, Pang L. Differential regulation of chemokine expression by peroxisome proliferator-activated receptor gamma agonists: interactions with 5) glucocorticoids and beta2-agonists. J Biol Chem 2005;280:2550-61.

5. Schwartz DB. Malnutrition in chronic obstructive pulmonary disease. Respir Care Clin N Am 2006;12:521-31.

6. Sampath $\mathrm{H}, \mathrm{Ntambi} \mathrm{JM}$. Polyunsaturated fatty acid regulation of gene expression. Nutr Rev 2004;62:333-9.

7. MacNee W. Oxidants, COPD. Curr Drug Targets Inflamm Allergy 2005;4:627-41.

8. Yu BC, Chang CK, Ou HY, Cheng KC and Cheng JT. Decrease of peroxisome proliferatoractivated receptor delta expression in cardiomyopathy of streptozotocin-induced diabetic rats. Cardiovasc Res 2008;80:78-87.

9. Huss JM, Levy FH, Kelly DP. Hypoxia inhibits the peroxisome proliferator-activated receptor alpha/retinoid $\mathrm{X}$ receptor gene regulatory pathway in cardiac myocytes: a mechanism for O2dependent modulation of mitochondrial fatty acid oxidation. J Biol Chem 2001;276:27605-12.

10. Belanger AJ, Luo Z, Vincent KA, Akita GY, Cheng SH, Gregory RJ, Jiang C. Hypoxiainducible factor 1 mediates hypoxia-induced cardiomyocyte lipid accumulation by reducing the DNA binding activity of peroxisome proliferator-activated receptor alpha/retinoid $\mathrm{X}$ receptor. Biochem Biophys Res Commun 2007;364:567-72.

11. Baar K. Involvement of PPAR gamma co-activator-1, nuclear respiratory factors 1 and 2 , and PPAR alpha in the adaptive response to endurance exercise. Proc Nutr Soc 2004;63:269-73.

12. Horowitz JF, Leone TC, Feng W, Kelly DP, Klein S. Effect of endurance training on lipid metabolism in women: a potential role for PPARalpha in the metabolic response to training. Am J Physiol Endocrinol Metab 2000;279:E348-55.

13. Lunde IG, Ekmark M, Rana ZA, Buonanno A, Gundersen K. PPARdelta expression is influenced by muscle activity and induces slow muscle properties in adult rat muscles after somatic gene transfer. J Physiol 2007;582:1277-87.

14. Pitta F, Troosters T, Spruit MA, Probst VS, Decramer M, Gosselink R. Characteristics of physical activities in daily life in chronic obstructive pulmonary disease. Am J Respir Crit Care Med 2005;171:972-7.

15. Walker PP, Burnett A, Flavahan PW, Calverley PM. Lower limb activity and its determinants in COPD. Thorax 2008;63:683-9.

16. Broekhuizen R, Wouters EF, Creutzberg EC, Schols AM. Raised CRP levels mark metabolic and functional impairment in advanced COPD. Thorax 2006;61:17-22.

17. van der Vaart $\mathrm{H}$, Koeter GH, Postma DS, Kauffman HF, ten Hacken NH. First study of infliximab treatment in patients with chronic obstructive pulmonary disease. Am J Respir Crit Care Med 2005;172:465-9.

18. Dentener MA, Creutzberg EC, Pennings HJ, Rijkers GT, Mercken E, Wouters EF. Effect of infliximab on local and systemic inflammation in chronic obstructive pulmonary disease: a pilot study. Respiration 2008;76:275-82.

19. Cooper CB. Airflow obstruction and exercise. Respir Med 2008;103:325-34.

20. Tunstall RJ, Mehan KA, Wadley GD, Collier GR, Bonen A, Hargreaves M, Cameron-Smith D. Exercise training increases lipid metabolism gene expression in human skeletal muscle. Am J Physiol Endocrinol Metab 2002;283:E66-72. 
21. Wu H, Kanatous SB, Thurmond FA, Gallardo T, Isotani E, Bassel-Duby R, Williams RS. Regulation of mitochondrial biogenesis in skeletal muscle by CaMK. Science 2002;296: 349-52.

22. Rimbert V, Boirie Y, Bedu M, Hocquette JF, Ritz P, Morio B. Muscle fat oxidative capacity is not impaired by age but by physical inactivity: association with insulin sensitivity. Faseb $\mathrm{J}$ 2004;18:737-9.

23. Rabinovich RA, Bastos R, Ardite E, Llinas L, Orozco-Levi M, Gea J, Vilaro J, Barbera JA Rodriguez-Roisin R, Fernandez-Checa JC, Roca J. Mitochondrial dysfunction in COPD patients with low body mass index. Eur Respir J 2007;29:643-50.

24. Puente-Maestu L, Perez-Parra J, Godoy R, Moreno N, Tejedor A, Gonzalez-Aragoneses F, Bravo JL, Villar F, Camano S, Agusti A. Abnormal mitochondrial function in locomotor and respiratory muscles of COPD patients. Eur Respir J 2009;33:1045-52

25. Picard M, Godin R, Sinnreich M, Baril J, Bourbeau J, Perrault H, Taivassalo T, Burelle Y. The mitochondrial phenotype of peripheral muscle in chronic obstructive pulmonary disease: disuse or dysfunction? Am J Respir Crit Care Med 2008;178:1040-7.

26. Coll T, Jove M, Rodriguez-Calvo R, Eyre E, Palomer X, Sanchez RM, Merlos M, Laguna JC, Vazquez-Carrera M. Palmitate-mediated downregulation of peroxisome proliferator-activated receptor-gamma coactivator 1alpha in skeletal muscle cells involves MEK1/2 and nuclear factor-kappaB activation. Diabetes 2006;55:2779-87.

27. Planavila A, Laguna JC, Vazquez-Carrera M. Nuclear factor-kappaB activation leads to down-regulation of fatty acid oxidation during cardiac hypertrophy. J Biol Chem 2005;280: 17464-71.

28. Delerive P, De Bosscher K, Besnard S, Vanden Berghe W, Peters JM, Gonzalez FJ, Fruchart JC, Tedgui A, Haegeman G, Staels B. Peroxisome proliferator-activated receptor alpha negatively regulates the vascular inflammatory gene response by negative cross-talk with transcription factors NF-kappaB and AP-1. J Biol Chem 1999;274:32048-54.

29. Rodriguez-Calvo R, Serrano L, Barroso E, Coll T, Palomer X, Camins A, Sanchez RM, Alegret M, Merlos M, Pallas M, Laguna JC, Vazquez-Carrera M. Peroxisome proliferatoractivated receptor alpha down-regulation is associated with enhanced ceramide levels in ageassociated cardiac hypertrophy. J Gerontol A Biol Sci Med Sci 2007;62:1326-36.

30. Westergaard M, Henningsen J, Johansen C, Rasmussen S, Svendsen ML, Jensen UB, Schroder HD, Staels B, Iversen L, Bolund L, Kragballe K, Kristiansen K. Expression and localization of peroxisome proliferator-activated receptors and nuclear factor kappaB in normal and lesional psoriatic skin. J Invest Dermatol 2003;121:1104-17.

31. Suzawa M, Takada I, Yanagisawa J, Ohtake F, Ogawa S, Yamauchi T, Kadowaki T, Takeuchi $\mathrm{Y}$, Shibuya H, Gotoh Y, Matsumoto K, Kato S. Cytokines suppress adipogenesis and PPAR-gamma function through the TAK1/TAB1/NIK cascade. Nat Cell Biol 2003;5: 224-30.

32. Ruan H, Pownall HJ, Lodish HF. Troglitazone antagonizes tumor necrosis factor-alphainduced reprogramming of adipocyte gene expression by inhibiting the transcriptional regulatory functions of NF-kappaB. J Biol Chem 2003;278:28181-92.

33. Agusti A, Morla M, Sauleda J, Saus C, Busquets X. NF-kappaB activation and iNOS upregulation in skeletal muscle of patients with COPD and low body weight. Thorax 2004;59: 483-7.

34. Guttridge DC, Mayo MW, Madrid LV, Wang CY, Baldwin AS Jr. NF-kappaB-induced loss of MyoD messenger RNA: possible role in muscle decay and cachexia. Science 2000;289: 2363-6.

35. Rossi A, Kapahi P, Natoli G, Takahashi T, Chen Y, Karin M, Santoro MG. Anti-inflammatory cyclopentenone prostaglandins are direct inhibitors of IkappaB kinase. Nature 2000;403: 103-8.

36. Zand H, Rahimipour A, Salimi S, Shafiee SM. Docosahexaenoic acid sensitizes Ramos cells to Gamma-irradiation-induced apoptosis through involvement of PPAR-gamma activation and NF-kappaB suppression. Mol Cell Biochem 2008;317:113-20. 
37. Straus DS, Pascual G, Li M, Welch JS, Ricote M, Hsiang CH, Sengchanthalangsy LL, Ghosh G, Glass CK. 15-deoxy-delta 12,14-prostaglandin J2 inhibits multiple steps in the NF-kappa B signaling pathway. Proc Natl Acad Sci U S A 2000;97:4844-9.

38. Li M, Pascual G, Glass CK. Peroxisome proliferator-activated receptor gamma-dependent repression of the inducible nitric oxide synthase gene. Mol Cell Biol 2000;20:4699-707.

39. Kim EK, Kwon KB, Koo BS, Han MJ, Song MY, Song EK, Han MK, Park JW, Ryu DG, Park $\mathrm{BH}$. Activation of peroxisome proliferator-activated receptor-gamma protects pancreatic betacells from cytokine-induced cytotoxicity via NF kappaB pathway. Int J Biochem Cell Biol 2007; 39:1260-75.

40. Pascual G, Fong AL, Ogawa S, Gamliel A, Li AC, Perissi V, Rose DW, Willson TM, Rosenfeld MG, Glass CK. A SUMOylation-dependent pathway mediates transrepression of inflammatory response genes by PPAR-gamma. Nature 2005;437:759-63.

41. Remels AH, Schrauwen P, Broekhuizen R, Willems J, Kersten S, Gosker HR, Schols AM. Expression and content of PPARs is reduced in skeletal muscle of COPD patients. Eur Respir J 2007;30:245-52.

42. Loviscach M, Rehman N, Carter L, Mudaliar S, Mohadeen P, Ciaraldi TP, Veerkamp JH, Henry RR. Distribution of peroxisome proliferator-activated receptors (PPARs) in human skeletal muscle and adipose tissue: relation to insulin action. Diabetologia 2000;43:304-11.

43. Schoonjans K, Staels B, Auwerx J. The peroxisome proliferator activated receptors (PPARS) and their effects on lipid metabolism and adipocyte differentiation. Biochim Biophys Acta 1996;1302:93-109.

44. Hevener AL, He W, Barak Y, Le J, Bandyopadhyay G, Olson P, Wilkes J, Evans RM, Olefsky J. Muscle-specific Pparg deletion causes insulin resistance. Nat Med 2003;9:1491-7.

45. Singh J, Verma NK, Kansagra SM, Kate BN, Dey CS. Altered PPARgamma expression inhibits myogenic differentiation in C2C12 skeletal muscle cells. Mol Cell Biochem 2007;294: 163-71.

46. Gosker HR, Wouters EF, van der Vusse GJ, Schols AM. Skeletal muscle dysfunction in chronic obstructive pulmonary disease and chronic heart failure: underlying mechanisms and therapy perspectives. Am J Clin Nutr 2000;71:1033-47.

47. Phielix E, Mensink M. Type 2 diabetes mellitus and skeletal muscle metabolic function. Physiol Behav 2008;94:252-8.

48. Vescovo G, Ravara B, Gobbo V, Angelini A, Dalla Libera L. Skeletal muscle fibres synthesis in heart failure: role of PGC-1alpha, calcineurin and GH. Int J Cardiol 2005;104:298-306.

49. Mensink M, Hesselink MK, Russell AP, Schaart G, Sels JP, Schrauwen P. Improved skeletal muscle oxidative enzyme activity and restoration of PGC-1 alpha and PPAR beta/delta gene expression upon rosiglitazone treatment in obese patients with type 2 diabetes mellitus. Int $\mathrm{J}$ Obes (Lond) 2007;31:1302-10.

50. Lin J, Wu H, Tarr PT, Zhang CY, Wu Z, Boss O, Michael LF, Puigserver P, Isotani E, Olson EN, Lowell BB, Bassel-Duby R, Spiegelman BM. Transcriptional co-activator PGC-1 alpha drives the formation of slow-twitch muscle fibres. Nature 2002;418:797-801.

51. Wang YX, Zhang CL, Yu RT, Cho HK, Nelson MC, Bayuga-Ocampo CR, Ham J, Kang H, Evans RM. Regulation of muscle fiber type and running endurance by PPARdelta. PLoS Biol 2004;10:e294.

52. Wenz T, Diaz F, Spiegelman BM, Moraes CT. Activation of the PPAR/PGC-1alpha pathway prevents a bioenergetic deficit and effectively improves a mitochondrial myopathy phenotype. Cell Metab 2008;8:249-56.

53. Chen X, Matthews J, Zhou L, Pelton P, Liang Y, Xu J, Yang M, Cryan E, Rybczynski P, Demarest K. Improvement of dyslipidemia, insulin sensitivity, and energy balance by a peroxisome proliferator-activated receptor alpha agonist. Metabolism 2008;57:1516-25.

54. Hautala AJ, Leon AS, Skinner JS, Rao DC, Bouchard C, Rankinen T. Peroxisome proliferator-activated receptor-delta polymorphisms are associated with physical performance and plasma lipids: the HERITAGE Family Study. Am J Physiol Heart Circ Physiol 2007;292: H2498-505. 
55. Riserus U, Sprecher D, Johnson T, Olson E, Hirschberg S, Liu A, Fang Z, Hegde P, Richards D, Sarov-Blat L, Strum JC, Basu S, Cheeseman J, Fielding BA, Humphreys SM, Danoff T, Moore NR, Murgatroyd P, O'Rahilly S, Sutton P, Willson T, Hassall D, Frayn KN, Karpe F. Activation of peroxisome proliferator-activated receptor (PPAR)delta promotes reversal of multiple metabolic abnormalities, reduces oxidative stress, and increases fatty acid oxidation in moderately obese men. Diabetes 2008;57:332-9.

56. Rubenstrunk A, Hanf R, Hum DW, Fruchart JC, Staels B. Safety issues and prospects for future generations of PPAR modulators. Biochim Biophys Acta 2007;1771:1065-81.

57. Broekhuizen R, Wouters EF, Creutzberg EC, Weling-Scheepers CA, Schols AM. Polyunsaturated fatty acids improve exercise capacity in chronic obstructive pulmonary disease. Thorax 200560:376-82.

58. Bordoni A, Di Nunzio M, Danesi F, Biagi PL. Polyunsaturated fatty acids: From diet to binding to ppars and other nuclear receptors. Genes Nutr 2006;1:95-106.

59. Jump DB, Clarke SD, Thelen A, Liimatta M, Ren B, Badin MV. Dietary fat, genes, and human health. Adv Exp Med Biol 1997;422:167-76.

60. Gosker HR, Schrauwen P, Broekhuizen R, Hesselink MK, Moonen-Kornips E, Ward KA, Franssen FF, Wouters EF, Schols AM. Exercise training restores uncoupling protein-3 content in limb muscles of patients with chronic obstructive pulmonary disease. Am J Physiol Endocrinol Metab 2005;290:E976-81.

61. Creutzberg EC, Schols AM, Weling-Scheepers CA, Buurman WA, Wouters EF. Characterization of nonresponse to high caloric oral nutritional therapy in depleted patients with chronic obstructive pulmonary disease. Am J Respir Crit Care Med 2000;161:745-52.

62. Montes de Oca M, Torres SH, De Sanctis J, Mata A, Hernandez N, Talamo C. Skeletal muscle inflammation and nitric oxide in patients with COPD. Eur Respir J 2005;26:390-7.

63. Chang JH, Lin KH, Shih $\mathrm{CH}$, Chang YJ, Chi HC, Chen SL. Myogenic basic helix-loop-helix proteins regulate the expression of peroxisomal proliferator activated receptor-gamma coactivator-1alpha. Endocrinology 2006;147:3093-106.

64. Langen RC, Van Der Velden JL, Schols AM, Kelders MC, Wouters EF, Janssen-Heininger YM. Tumor necrosis factor-alpha inhibits myogenic differentiation through MyoD protein destabilization. Faseb J 2004;18:227-37.

65. Fritz T, Kramer DK, Karlsson HK, Galuska D, Engfeldt P, Zierath JR, Krook A. Low-intensity exercise increases skeletal muscle protein expression of PPARdelta and UCP3 in type 2 diabetic patients. Diabetes Metab Res Rev 2006;22:492-8.

66. Komatsu W, Ishihara K, Murata M, Saito H, Shinohara K. Docosahexaenoic acid suppresses nitric oxide production and inducible nitric oxide synthase expression in interferon-gamma plus lipopolysaccharide-stimulated murine macrophages by inhibiting the oxidative stress. Free Radic Biol Med 2003;34:1006-16.

67. Simopoulos AP. Omega-3 fatty acids in inflammation and autoimmune diseases. J Am Coll Nutr 2002;21:495-505.

68. Sampath $\mathrm{H}$, Ntambi JM. Polyunsaturated fatty acid regulation of genes of lipid metabolism. Annu Rev Nutr 2005;25:317-40.

69). Magee P, Pearson S, Allen J. The omega-3 fatty acid, eicosapentaenoic acid (EPA), prevents the damaging effects of tumour necrosis factor (TNF)-alpha during murine skeletal muscle cell differentiation. Lipids Health Dis 2008;7:24.

70. Banga A, Unal R, Tripathi P, Pokrovskaya I, Owens RJ, Kern PA, Ranganathan G. Adiponectin translation is increased by the PPAR \{gamma\} agonists pioglitazone and \{omega\}-3 fatty acids. Am J Physiol Endocrinol Metab 2008;296:E480-9.

71. Kawashima A, Harada T, Imada K, Yano T, Mizuguchi K. Eicosapentaenoic acid inhibits interleukin-6 production in interleukin-1beta-stimulated C6 glioma cells through peroxisome proliferator-activated receptor-gamma. Prostaglandins Leukot Essent Fatty Acids 2008;79: 59-65.

72. Schrauwen-Hinderling VB, Mensink M, Hesselink MK, Sels JP, Kooi ME, Schrauwen P. The insulin-sensitizing effect of rosiglitazone in type 2 diabetes mellitus patients does not require improved in vivo muscle mitochondrial function. J Clin Endocrinol Metab 2008;93:2917-21. 
73. Pagel-Langenickel I, Schwartz DR, Arena RA, Minerbi DC, Johnson DT, Waclawiw MA, Cannon RO, 3rd, Balaban RS, Tripodi DJ, Sack MN. A discordance in rosiglitazone mediated insulin sensitization and skeletal muscle mitochondrial content/activity in Type 2 diabetes mellitus. Am J Physiol Heart Circ Physiol 2007;293:H2659-66.

74. Bakkar N, Wang J, Ladner KJ, Wang H, Dahlman JM, Carathers M, Acharyya S, Rudnicki MA, Hollenbach AD, Guttridge DC. IKK/NF-kappaB regulates skeletal myogenesis via a signaling switch to inhibit differentiation and promote mitochondrial biogenesis. J Cell Biol 2008;180:787-802.

75. Tothova J, Blaauw B, Pallafacchina G, Rudolf R, Argentini C, Reggiani C, Schiaffino S. NFATc1 nucleocytoplasmic shuttling is controlled by nerve activity in skeletal muscle. J Cell Sci 2006;119:1604-11.

76. Oishi Y, Ogata T, Yamamoto KI, Terada M, Ohira T, Ohira Y, Taniguchi K, Roy RR. Cellular adaptations in soleus muscle during recovery after hindlimb unloading. Acta Physiol (Oxf) 2008;192:381-95.

77. Hunter RB, Stevenson E, Koncarevic A, Mitchell-Felton H, Essig DA, Kandarian SC. Activation of an alternative NF-kappaB pathway in skeletal muscle during disuse atrophy. Faseb J 2002;16:529-38.

78. Langen RC, Schols AM, Kelders MC, van der Velden JL, Wouters EF and Janssen-Heininger YM. Muscle wasting and impaired muscle regeneration in a murine model of chronic pulmonary inflammation. Am J Respir Cell Mol Biol 2006;35:689-96. 
Summary 


\section{Summary}

Loss of exercise capacity is observed in several chronic inflammatory disorders as e.g. chronic obstructive pulmonary disease (COPD) and chronic heart failure (CHF). Exercise intolerance in these disorders contributes significantly to clinical outcome of these diseases as it impairs patients in their daily activities, diminishes quality of life and increases morbidity of the disease, independent of the primary organ dysfunction. Impaired exercise capacity in COPD might be caused by loss of muscle oxidative phenotype (OXPHEN) which includes a fiber type shift towards a more glycolytic distribution, diminished activity levels of enzymes involved in oxidative metabolism and a reduced mitochondrial content. The exact mechanisms underlying the loss of muscle OXPHEN in chronic inflammatory diseases as COPD to date remain unresolved. The aim of this thesis therefore was to investigate molecular mechanisms underlying loss of skeletal muscle OXPHEN in chronic inflammatory disorders using COPD as a model. Basic molecular mechanisms were investigated in vitro using cultured skeletal muscle cells and gathered knowledge was subsequently translated to human subjects by analysis of blood samples and muscle biopsies of patients.

\section{The PGC-1a/PPAR pathway and muscle OXPHEN in COPD}

In the last decade, the PGC-1a/PPAR pathway has emerged as a key regulatory pathway involved in determination of muscle OXPHEN. In addition, this signal transduction cascade has an array of other physiological implications including modulation of inflammatory responses. Since COPD is characterised by inflammation and clinically significant muscle pathology, chapter 2 discusses the potential therapeutic implications of the PGC-1a/PPAR pathway in combating COPD systemic pathology based on an extensive review of existing literature.

The role of the PGC-1 $\alpha /$ PPAR pathway in the regulation of OXPHEN in existing muscle fibres is widely established. The implication of this pathway in the development of OXPHEN during the process of myogenic differentiation however is largely unexplored. In chapter $\mathbf{3}$ we investigated multiple aspects of OXPHEN as well as temporal expression profiles of components of the PGC-1a/PPAR pathway in cultured $\mathrm{C} 2 \mathrm{C} 12$ skeletal muscle cells during myogenesis. PPAR transcriptional activity as well as PGC-1a, Tfam, NRF-1 and PPAR- $\alpha$ mRNA expression levels increased during myogenic differentiation paralleling the development of OXPHEN. PPAR- $\delta$ mRNA levels on the other hand remained constant during the entire differentiation process. This suggests that PGC-1 $\alpha$ and PPAR- $\alpha$ might be implicated in the development of OXPHEN during myogenic differentiation, while the role of 
PPAR- $\delta$ in regulation of skeletal muscle OXPHEN is possibly confined to preexisting muscle fibers.

Activation or over-expression of the PGC-1a/PPAR pathway in skeletal muscle of mice results in increased proportions of oxidative fibers, higher activity levels of mitochondrial enzymes and a higher mitochondrial content. Notably, these changes are the opposite of what is observed in muscle tissue of COPD patients. Therefore, in chapter 4 we investigated muscular content and expression levels of key constituents of the PGC-1a/PPAR pathway in skeletal muscle of CODP patients and compared these to levels in skeletal muscle of healthy control subjects. This demonstrated that protein content of Tfam, which is the master regulator of mitochondrial biogenesis, and PPAR- $\delta$ as well as mRNA transcript levels of PGC-1 $\alpha$ and PPAR- $\alpha$ were decreased in skeletal muscle of COPD patients compared to healthy controls which was most pronounced in the cachectic patients. Moreover, PPAR mRNA expression levels in muscle were inversely related to levels of inflammatory markers in plasma. This implies that a disturbed expression and/or content of these regulatory factors may well underlie the impaired muscle OXPHEN in COPD. Furthermore, it suggests that cachexia and impaired muscle OXPHEN may be intertwined processes, possibly with inflammation as a common denominator. Activation of the PGC-1a/PPAR pathway therefore may represent an interesting approach to alleviate exercise intolerance in COPD.

\section{Battle between PGC-1a/PPAR and NF-KB}

Chapter 4 demonstrated that PPAR expression levels in muscle of COPD patients were inversely correlated with circulating levels of TNF- $\alpha$ and its receptors. This suggests that systemic inflammatory status may influence regulation of muscle OXPHEN in COPD patients. To address this in more detail, the link between inflammation and regulation of skeletal muscle OXPHEN was investigated in chapter 5 .

Chapter 5 showed that COPD patients with increased muscle TNF- $\alpha$ expression had higher glycolytic gene expression while expression levels of oxidative genes and their major regulators (PGC-1 $\alpha$, PPAR- $\alpha$ and Tfam) were significantly lower compared to COPD patients with normal muscle TNF- $\alpha$ mRNA transcript levels. The 'high TNF- $\alpha$ ' group was also characterised by a lower body mass index and fat-free mass index compared to healthy controls, indicative of (pre)cachexia. These findings lead to the notion that a subpopulation of COPD patients with increased muscle inflammatory status may be at risk, not only for wasting of muscle mass, but also for impairment of OXPHEN of the remaining muscle. To address causality of the association between TNF- $\alpha$ and decreased muscle oxidative gene expression found in 
patients, an in vitro approach in which cultured skeletal muscle cells were chronically stimulated with TNF- $\alpha$ was applied. These experiments demonstrated that chronic TNF- $\alpha$ treatment of skeletal muscle cells impaired cellular respiration rates and shifted myosin heavy chain composition towards a more glycolytic distribution resulting in a decreased skeletal muscle OXPHEN. TNF- $\alpha$ also potently inhibited activity and expression levels of the PGC-1a/PPAR pathway. Importantly, we demonstrate that the effects of TNF- $\alpha$ on muscle OXPHEN depended on activation of one of the most important cellular cascades mediating inflammatory signals, the classical NF-kB pathway. This implicates the classical NF-KB pathway not only in skeletal muscle atrophy, as shown previously, but also in the loss of OXPHEN under chronic inflammatory conditions, which is an important novelty in understanding the etiology of muscle abnormalities in COPD.

Interplay between the NF-KB pathway and the PGC-1a/PPAR signalling axis has been shown in several tissues. Chapter 6 was aimed at investigating a potential bi-directional nature of this interaction in skeletal muscle. While NF-kB activation inhibited PGC-1 $\alpha$ /PPAR signalling in chapter 5, experiments in chapter $\mathbf{6}$ showed that pharmacological activation of PPAR- - , but not PPAR- $\delta$ or PPAR- $\alpha$, potently inhibited pro-inflammatory cytokine-induced NF-kB activation in cultured skeletal muscle cells. This was verified in T2DM patients receiving the PPAR-y activator Rosiglitazone as anti-diabetic treatment. In line with in vitro findings of chapter $\mathbf{6}$, patients receiving Rosiglitazone tended to have decreased muscular transcript levels of a NF-KB target gene. Interestingly, anti-inflammatory effects mediated by Rosiglitazone-mediated PPAR-y activation in skeletal muscle in vitro described in chapter 6 appeared to be independent of RelA nuclear translocation or DNA binding suggestive of a transrepression mechanism.

In conclusion, the studies described in this thesis suggest that the PGC$1 \alpha / P P A R$ pathway is impaired in skeletal muscle of COPD patients and that an increased muscle inflammatory status and subsequent inflammatory signalling through the NF-KB pathway impairs skeletal muscle OXPHEN. Collectively, this implies that inflammation-induced impairment of the PGC-1a/PPAR pathway might underlie impaired exercise capacity observed in COPD. Finally, activation of PPAR-y blocks inflammatory signalling in skeletal muscle and therefore may represent an interesting therapeutic target to alleviate skeletal muscle dysfunction in chronic inflammatory disorders. 

Samenvatting 



\section{Samenvatting}

Chronisch inflammatoire aandoeningen zoals chronisch obstructieve longziekte (COPD) en chronisch hartfalen worden vaak gekenmerkt door een verlies van inspanningscapaciteit. Vermits dit resulteert in een verminderde bewegingsvrijheid en een beperking van het dagelijks functioneren van patiënten draagt dit verlies aan inspanningscapaciteit sterk bij aan een verminderde kwaliteit van leven en verhoogde morbiditeit in deze aandoeningen, onafhankelijk van de primaire aandoening. De verminderde inspanningscapaciteit van patiënten met COPD kan mogelijk toegeschreven worden aan een veranderd oxidatief fenotype van de skeletspieren in de onderste ledematen. Deze veranderingen omvatten onder andere een vezelverschuiving naar een meer glycolytische verdeling, verlaagde activiteit van enzymen betrokken in oxidatief substraatmetabolisme en een verminderde mitochondriële inhoud. De precieze mechanismen die leiden tot een verminderd oxidatief fenotype van de spier in COPD patiënten blijven tot op heden echter onopgehelderd. Het doel van dit proefschrift was dan ook om de moleculaire mechanismen te onderzoeken die aan de basis liggen van het veranderde spier oxidatief fenotype in chronisch inflammatoire aandoeningen zoals COPD. Basale moleculaire mechanismen werden in vitro bestudeerd door gebruik te maken van gekweekte spiercellen. Kennis hieruit verkregen werd vervolgens vertaald naar de humane setting door het verzamelen en analyseren van bloed- en spiermonsters van COPD patiënten.

\section{De PGC-1a/PPAR cascade en spier oxidatief fenotype in COPD}

Recent onderzoek heeft aangetoond dat de PGC-1a/PPAR cascade een belangrijke regulator is van spier oxidatief fenotype. Daarnaast is gebleken dat deze signaalcascade betrokken is in verschillende andere fysiologische processen zoals bijvoorbeeld modulatie van inflammatoire signaaltransductie. Vermits COPD gekenmerkt wordt ontstekingsprocessen alsook een verstoord spiermetabolisme handelt hoofdstuk 2 over de mogelijke therapeutische rol van de PGC-1 $\alpha$ /PPAR cascade in de behandeling van systemische afwijkingen geassocieerd met COPD. Dit overzicht is gebaseerd op een uitgebreide literatuurstudie.

De rol van de PGC-1a/PPAR cascade in de regulatie van oxidatief fenotype van bestaande spiervezels is overtuigend aangetoond. De rol van deze signaaltransductieweg in de ontwikkeling van oxidatief fenotype gedurende differentiatie van spiercellen naar spiervezels is echter onbekend. In hoofdstuk 3 werden verschillende parameters alsook belangrijke regulatoren van spier oxidatief fenotype onderzocht in gekweekte C2C12 spiercellen die gedifferentieerd werden naar spiervezels. De transcriptionele activiteit van de 
PPARs alsook mRNA expressie niveaus van PPAR- $\alpha$, PGC-1 $\alpha$, Tfam en NRF1 , die allen beschouwd worden als belangrijke regulatoren van spier oxidatief fenotype, stegen in parallel met de ontwikkeling van het oxidatief fenotype in deze cellen tijdens differentiatie. In tegenstelling, mRNA expressie niveaus van PPAR- $\delta$ bleven constant tijdens differentiatie ondanks een duidelijk beschreven rol van PPAR- $\delta$ in de regulatie van spier oxidatief fenotype. Dit suggereert dat PGC-1 $\alpha$ en PPAR- $\alpha$ betrokken zijn in de ontwikkeling van spier oxidatief fenotype gedurende differentiatie terwijl de rol van PPAR- $\delta$ in de regulatie van spier oxidatief fenotype mogelijk beperkt is tot bestaande spiervezels.

Het is overtuigend aangetoond dat activatie of over expressie van componenten van de PGC-1a/PPAR cascade, in de skeletspier van muizen, resulteert in een verhoogd spier oxidatief fenotype gekenmerkt door een toename in het aantal oxidatieve vezels en hogere activiteit van mitochondriële enzymen. Het is opmerkelijk dat deze veranderingen precies het omgekeerde zijn van de afwijkingen die vastgesteld zijn in de spieren van COPD patiënten. Daarom werd in hoofdstuk 4 onderzocht of skeletspieren van COPD patiënten gekenmerkt worden door veranderde expressie niveaus of eiwitinhoud van componenten van de PGC-1a/PPAR cascade vergeleken met gezonde controle personen. Deze experimenten toonden aan dat eiwitinhoud alsook mRNA expressieniveaus van bestanddelen van de PGC-1a/PPAR cascade, waaronder Tfam, PGC-1 $\alpha$ en PPAR- $\alpha$, verlaagd waren in de spieren van COPD patiënten vergeleken met gezonde controles. Een hoogst interessante bevinding was dat deze verlaging het meest uitgesproken was in de cachectische patiënten en omgekeerd evenredig was met de hoeveelheid ontstekingsmediatoren in plasma. Deze bevindingen geven aan dat veranderingen in de hoeveelheid van expressie niveaus en eiwitinhoud van bestanddelen van de PGC-1a/PPAR cascade mogelijk aan de basis liggen van het verminderde spier oxidatief fenotype geobserveerd in COPD patiënten. Aanvullend geven deze data aan dat cachexia en verstoord spier oxidatief fenotype mogelijk met elkaar verbonden zijn, met inflammatoire processen als mogelijk gemeenschappelijke basis. De therapeutische implicatie van deze bevindingen is dat activatie van de PGC-1a/PPAR cascade in de spieren van COPD patiënten een eventuele strategie kan zijn om inspanningsintolerantie in deze ziekte te behandelen.

\section{Strijd tussen PGC-1a/PPAR en NF-kB}

Hoofdstuk 4 van dit proefschrift toont aan dat PPAR expressie niveaus in de skeletspier van COPD patiënten omgekeerd gerelateerd zijn aan de hoeveelheid TNF- $\alpha$ en zijn receptoren in de circulatie. Dit geeft aan dat inflammatoire status van patiënten mogelijk de regulatie van spier oxidatief fenotype beïnvloedt. De relatie tussen inflammatoire processen en spier 
oxidatief fenotype werd daarom in meer detail onderzocht in hoofdstuk $\mathbf{5}$. Experimenten uit hoofdstuk $\mathbf{5}$ toonden aan dat COPD patiënten met een verhoogde expressie van TNF- $\alpha$ in de spier gekenmerkt werden door verlaagde expressie niveaus van oxidatieve genen en hun regulatoren (PGC$1 \alpha / P P A R)$ alsook door een verlaagde body mass index en vet-vrije massa (spier). Dit suggereert dat COPD patiënten met een verhoogde spier inflammatoire status het risico lopen niet alleen spiermassa maar ook spier oxidatief fenotype te verliezen. De relatie tussen inflammatie en verlaagde oxidatieve genexpressie werd bevestigd door de bevinding dat chronische TNF- $\alpha$ behandeling van gekweekte $\mathrm{C} 2 \mathrm{C} 12$ cellen resulteerde in een verminderde celrespiratie, een verlaagde mitochondriële inhoud en een verschuiving naar een meer glycolytische vezelverdeling. TNF- $\alpha$ stimulatie van spiercellen in kweek had ook een verlaging van de activiteit en expressie niveaus van de PGC-1a/PPAR cascade tot gevolg. Een belangrijke observatie in hoofdstuk 5 was dat de effecten van TNF- $\alpha$ op spieroxidatief fenotype gemedieerd werden door 1 van de belangrijkste signaaltrans-ductiewegen betrokken in de transmissie van inflammatoire signalen namelijk de klassieke $\mathrm{NF}-\mathrm{kB}$ signaalcascade. Dit impliceert de klassieke NF-kB signaalcascade niet alleen in het verlies van spiermassa, wat in het verleden overtuigend is aangetoond, maar ook in verlies van spier oxidatief fenotype, wat een belangrijk nieuw inzicht is in de ontwikkeling van spierafwijkingen in COPD.

Het is bekend dat de NF-KB cascade en de PGC-1a/PPAR signaaltransductieweg met elkaar kunnen interfereren. In hoofdstuk 6 werd onderzocht of activatie van de PGC-1a/PPAR cascade kan interfereren met inflammatoire cytokine-gemedieerde activatie van de NF-KB cascade in spiercellen. In hoofdstuk 5 is beschreven dat activatie van NF-KB de PGC1a/PPAR signaalweg kan remmen. In hoofdstuk 6 tonen we aan dat farmacologische activatie van PPAR- $ү$ (Rosiglitazone), maar niet van PPAR- $\delta$ of PPAR- $\alpha$, resulteert in een sterke inhibitie van NF-KB signalering in gekweekte spiercellen. Dit werd bevestigd in patiënten met type 2 diabetes mellitus die Rosiglitazone kregen als behandeling voor hun ziekte. De ontstekingsremmende effecten van Rosiglitazone behandeling in cellen bleken echter onafhankelijk van RelA translocatie naar de nucleus of binding aan het DNA, wijzend op een transrepressie mechanisme.

Samengevat beschrijven de studies in deze thesis dat CODP patiënten gekenmerkt worden door verlaagde niveaus van componenten van de PGC$1 \alpha / P P A R$ cascade in de spieren van hun onderste ledematen. Aanvullend geven de studies van deze thesis aan dat ontstekings-gemedieerde signaaltransductie de regulatie van spier oxidatief fenotype kan remmen. Dit suggereert dat ontstekings-gemedieerde remming van de PGC-1a/PPAR 
cascade mogelijk aan de basis ligt van de verminderde inspanningscapaciteit van COPD patiënten. Ter afsluiting tonen we aan dat farmacologische activatie van PPAR- $\gamma$ resulteert in een inhibitie van inflammatoire signalering wat mogelijk interessante therapeutische implicaties heeft gezien de, in deze thesis aangetoonde, negatieve effecten van inflammatoire signalering op spier oxidatief fenotype. 
Dankwoord 



\section{Dankwoord}

Waar is de tijd dat ik zenuwachtig in mijn pak zat te wachten voor het sollicitatiegesprek op het secretariaat Longziekten in Maastricht. Hier zit ik dan in het verre Ohio, zondagavond, schrijflampje aan, na te denken over hoe snel de tijd gaat en hoeveel mensen mij hebben bijgestaan in het tot stand komen van dit proefschrift... Hier is de plaats waar ik jullie allemaal op de gepaste manier kan bedanken. We have come a long way...

Hoewel $u$ niet rechtstreeks betrokken was in mijn project wil ik $u$ bedanken Prof. Wouters voor de mogelijkheid om te promoveren op de afdeling Longziekten, ik moet eerlijk toegeven dat ik stiekem trots ben op een landgenoot als hoofd van de afdeling. Mijn promotieteam ben ik veel verschuldigd. Annemie, Ramon, Harry en Patrick, zonder jullie zou ik nu niet staan waar ik sta in mijn persoonlijke ontwikkeling en carrière en ik wil jullie daar dan ook op een gepaste manier voor bedanken. Annemie: het is ongelooflijk hoe je met schijnbaar gemak de spierlijn uit de grond gestampt hebt. Je staat altijd klaar met goede ideeën en raad. Onze gesprekken, al dan niet over werkgerelateerde onderwerpen, hebben me veel geleerd en ik hoop deze in de toekomst in dezelfde leuke sfeer verder te kunnen zetten. Harry en Ramon: ja mannen het is zover, dit is jullie plaats in het dankwoord. Jullie waren degene die me dagelijks begeleid hebben en sterk hebben bijgedragen aan een succesvolle en plezante promotieperiode. Woorden schieten me te kort om uit te drukken hoezeer ik genoten en hoeveel ik geleerd heb van onze samenwerking. Bij deze toch een bescheiden poging. Ramon: Je verbaast me steeds opnieuw met je kennis en inzichten. Je bent wat mij betreft de perfecte mentor: geduldig, stimulerend en altijd klaar om te helpen, hoewel je het steeds drukker en drukker krijgt de laatste jaren. Het was een waar genoegen met je te mogen samenwerken en laten we het succesvol afronden van deze eerste periode maar eens goed vieren met een biertje en een danspasje op mijn promotiefeest, want geef toe net zoals mij hou je daar toch ook van. Het kan niet altijd en alleen wetenschap zijn! Harry: voor jou zullen het dan alleen biertjes worden, maar ik wacht nog steeds op de dag dat ik je een danspasje zie wagen. Alle gekheid op een stokje...Harry: we hebben onze ups en downs gehad, maar ik ben zeer trots met jou in mijn promotieteam. Je stond altijd klaar om te helpen met wat dan ook. Ik heb veel geleerd van je nauwkeurigheid en soms eigenzinnige inzichten die zeker significant (T-test of nonparametrisch) hebben bijgedragen aan deze thesis. Bedankt voor alles Harry: ik weet niet zeker of je wel weet hoezeer je geholpen hebt in mijn wetenschappelijke en persoonlijke ontwikkeling de afgelopen jaren, maar laat ik je dit zeggen, zonder jou was het niet hetzelfde geweest en zeker niet zo leuk! Tot slot mannen: het was altijd zalig jullie kamer binnen te lopen, waar het 
naast werk toch ook vaak lachen geblazen was. Bedankt voor alles! Patrick, jij was er ook vanaf het prille begin bij en ook jou ben ik veel verschuldigd. Bedankt voor al je waardevolle input bij besprekingen, jouw visie op dingen heeft me veel bijgebracht. Van jou heb ik geleerd opportunistisch te zijn en straight forward te denken. Ik hoop dat we onze samenwerking kunnen verderzetten in de toekomst en ik wens je alle succes met je eigen onderzoek, want wat dat betreft ben je zeker 1 van mijn grote voorbeelden!

Mijn collega's van de afdeling Longziekten mogen natuurlijk niet ontbreken. Het is een komen en gaan geweest van vele leuke, interessante mensen gedurende de jaren, laat ik beginnen bij het begin...

Jos, ja makker ik ben je zeker nog niet vergeten hoewel je nu ver weg woont in het mooie Vermont. Jij bent degene die me vele labtechnieken heeft geleerd in het begin en we kwamen er snel achter dat we naast het werk veel gemeenschappelijk hadden. Ik moet nog steeds lachen als ik denk aan onze stapavondjes op congres. Jij was mijn labmaatje toen je nog in Maastricht was en ik ben blij je ondertussen een vriend te noemen. Ik wens je alle succes en geluk samen met Kim en ik hoop dat we elkaar nog vaak kunnen zien ondanks de vele kilometers die we van elkaar verwijderd zijn. Ik ben er zeker van dat, hoelang het ook geleden zal zijn dat we elkaar zagen, het weer vanouds gezellig en vertrouwd zal zijn als we elkaar weer terugzien. Kim: keep an eye on this guy, he is one in a million! Jouw beurt Evi: we hebben altijd goed met elkaar kunnen opschieten. Als medebelg en goedlachse collega was jij altijd een frisse wind op de afdeling. Het is jammer dat we elkaar veel minder gaan zien nu ook jij de stap naar de Verenigde Staten hebt gezet. Je ambitie en gedrevenheid hebben me verbaasd en ik hoop dat je het goed doet en een fantastische tijd hebt in Baltimore, maar daar twijfel ik geen moment aan! Ook de feestjes samen met jou zal ik niet snel vergeten (-). Pascal: je bent ondertussen verhuisd naar Groningen en als het goed is ook druk aan het schrijven aan je eigen proefschrift. Het was altijd lachen met jou, ik wens je alle succes toe met promoveren en breng ons nog eens een bezoekje in Maastricht, maar dan wel als ik weer terug ben.

Het rijtje is lang dus laat ik snel verdergaan. Collega's van het eerste moment Roelinka en Erica: het was leuk jullie te leren kennen en met jullie samen te werken. Hoewel jullie niet meer bij Longziekten in Maastricht werken wens ik jullie het allerbeste toe op alle vlakken! Dan de post-docs: Niki, Astrid (jaja je bent al post-doc nu, het gaat snel), Juanita en Mieke, jullie wil ik ook bedanken voor de leuke tijd samen. Jullie doen het allemaal heel goed en ik ben blij dat ik jullie vanaf volgend jaar mag vergezellen in het post-doc team van Longziekten, het gaat vast een leuke verderzetting worden van onze samenwerking! 
Marco: Ik wil jou ook graag bedanken voor alle hulp die ik de afgelopen jaren van jou heb gekregen. Je bent ondertussen hoofdanalist en dat is wat mij betreft volledig terecht! Jodil, jij mag natuurlijk ook niet ontbreken. Bedankt voor alle hulp met Western blots en andere labtechnieken in het begin van mijn promotieperiode. Het doet me deugd je gelukkig te zien met je wederhelft en als je toch ooit nog eens naar Canada verhuist vergeet ons in het verre Maastricht dan niet, het ga je goed! Chiel, Claudia, Anon, Frank, Gonda maar ook Johanna en Nadja, ik wil jullie ook bedanken voor de leuke samenwerking en hulp met labtechnieken. Dan onze nieuwe garde, hoewel jullie natuurlijk ook alweer een tijdje bezig zijn (de tijd gaat inderdaad snel). Céline, Ine, Nicky, Koen, Bram en Valéry, jullie maken van onze afdeling een leuke, jonge levendige groep. Ik geniet steeds opnieuw weer van onze leuke uitstapjes naar de stad om weer eens goed te gaan uit eten of een paar pintjes te gaan pakken. Laten we dit vooral blijven doen! Jullie weten ondertussen dat promoveren niet altijd van een leien dakje loopt maar ik zie en ervaar dat jullie stuk voor stuk harde en gemotiveerde werkers zijn, dus ik heb er alle vertrouwen in. Amanda, it was very nice to have the privilige of having you as a roommate. I hope you enjoyed Maastricht and I wish you all the best now you are back in London, we will definitely try to come and visit you soon.

Esther, bedankt voor alle hulp met oxygraaf metingen en veel succes met afronden van je promotie. Melissa, Sabine en Kris, oud mede-studenten op de universiteit in Diepenbeek en allemaal in Maastricht terecht gekomen, ook jullie wil ik bedanken voor leuke tijden samen zowel in Diepenbeek als Maastricht! Nejla, jou wil ik bedanken voor vele dingen. Voor de jaartjes dat we samen zijn geweest en de mooie momenten die we hebben gedeeld. Het heeft niet mogen zijn tussen ons maar ik wens je alle geluk, liefde en succes toe in alles wat je doet!

Jelle, the maestro, Achten. Uiteindelijk ook gestrand in Maastricht en geef toe het is fijn vertoeven hier! Sinds onze tijd in Diepenbeek is er veel gebeurd en veranderd voor ons allebei. Ik ben blij dat we nog steeds bevriend zijn en vereerd dat jij straks achter me staat als paranimf. They say: a true friend is hard to find, I say: zo moeilijk was het nu ook weer niet $:$;

I would also like to thank the people from the Department of Cancer Genetics at Ohio State University, Ohio, USA. Denis, I would like to thank you for the opportunity to work in your lab for 7 months. I enjoyed every moment of it and learned a lot! Nadine, Jay, Jen, Jingxin, Bill, Wei, Jon, Eric and Kate thank you for all your help with lab stuff and for the good time I had while I was in Ohio! 
If you work hard, play hard is what they say, en er is natuurlijk geen plezier en ontspanning zonder je vrienden. Hier komen ze dan: Wally, Ken, Ollie en Wendy, Ronald, Lea en Joke, Stephen en Tanja, Joris en Elie, De Ost, Wimpie en Elke, Barto, Vanhees en Joke, Domien en Isabella, Greetje en Sara, al de mannen van de wijk, AC en geert, Tompie, Beuk en Briers and last but not least mister Phillicious. Bedankt voor de supertijd de afgelopen jaren! Het is altijd een feestje als we samen zijn en laten we dat zo houden voor as long as possible. Het gaat me deugd doen jullie allemaal weer terug te zien als ik weer terug in België ben!

En tot slot natuurlijk de belangrijkste personen. Mama, papa en Anneleen, jullie wil ik speciaal bedanken voor alle jaren van liefde en steun. Ik hoop dat ik jullie trots heb gemaakt, dat zal ik altijd proberen te blijven doen! Younes, je bent nu ook een deel van de familie, zorg goed voor mijn zusje!

Als laatste de belangrijkste persoon: Bettine, lieve schat, jou beschouw ik als het grootste succes van mijn promotieperiode. Wie had gedacht dat dingen zo gingen lopen, nu zijn we ondertussen al bijna 2 jaar samen en het voelt nog steeds iedere dag beter en beter. Helaas was promoveren niet jouw ding, maar ik ben blij dat je nu je draai hebt gevonden als longarts in opleiding, ik ben trots op je!! Ik zal er altijd voor je zijn om je te steunen en van je te houden en ik kan niet wachten om samen met jou een toekomst uit te bouwen die ongetwijfeld vol liefde en geluk zal zijn. 


\section{List of publications}





\section{List of publications}

1. Remels AH, Gosker HR, van der Velden J, Langen RC, Schols AM. Systemic inflammation and skeletal muscle dysfunction in chronic obstructive pulmonary disease: state of the art and novel insights in regulation of muscle plasticity. Clin Chest Med 2007;28:537-52 (Impact factor 2.0).

2. Remels AH, Schrauwen P, Broekhuizen R, Willems J, Kersten S, Gosker $\mathrm{HR}$, Schols AM. Peroxisome proliferator-activated receptor expression is reduced in skeletal muscle in COPD. Eur Respir J 2007;30:245-52 (Impact factor 5.545).

3. Remels AH, Gosker HR, Schrauwen P, Langen RC, Schols AM. Peroxisome proliferator-activated receptors: a therapeutic target in COPD? Eur Respir J 2008;31:502-8. (Impact factor 5.545).

4. Remels AH, Langen RC, Gosker HR, Russell AP, Schrauwen P, Schols AM. PPAR- $\gamma$ inhibits NF-kB-dependent transcriptional activation in skeletal muscle. Am J Physiology Endocrinol 2009;297:E174-83 (Impact factor 3.855).

5. Remels AH, Langen RC, Schrauwen, P, Schaart G, Schols AM, Gosker HR. Regulation of mitochondrial biogenesis during myogenesis. Mol Cell Endo. Accepted (Impact factor 3.611).

6. Remels AH, Gosker HR, Schrauwen P, Hommelberg P, Sliwinski P, Polkey M, Galdiz J, Wouters EFM, Langen RC, Schols AM. TNF- $\alpha$ impairs regulation of muscle oxidative phenotype: Implications for cachexia in COPD? Submitted. 

Curriculum Vitae

169 



\section{Curriculum Vitae}

Alexander Remels was born on the $13^{\text {th }}$ of February 1982 in Herk-De-Stad, Belgium. After he finished high school in 2000 at the Humaniora Kindsheid Jesu in Hasselt, he started his studies in Biomedical Sciences at the University of Hasselt. As a part of his Masters degree he attended Maastricht University Medical Centre for 1 year. He did his internship at the Department of Immunology at Hasselt University where he investigated the role of cytokines in the development of Multiple Sclerosis. He graduated from Hasselt University in September 2004. In October 2004 he started his $\mathrm{PhD}$ training at the Department of Respiratory Medicine, Maastricht University, the Netherlands. $\mathrm{He}$ worked on the role of specific proteins regulating skeletal muscle oxidative phenotype in chronic obstructive pulmonary disease (COPD). From May 2009 until December 2009 he joined the research group of Cancer Genetics and Molecular Virology at the Ohio State University, USA. Currently, he is working as a post-doctoral fellow at the Department of Respiratory Medicine at Maastricht University studying the role of inflammation and (in)activity in the development of skeletal muscle abnormalities in COPD. 
